MIRLÉIA APARECIDA DE CARVALHO

\title{
SISTEMA DE SUPORTE A DECISÃO PARA ALOCAÇÃO DE ÁGUA EM PROJETOS DE IRRIGAÇÃO
}

Tese apresentada à Escola Politécnica da Universidade de São Paulo para obtenção do título de Doutor em Engenharia. 


\section{SISTEMA DE SUPORTE A DECISÃO PARA ALOCAÇÃO DE ÁGUA EM PROJETOS DE IRRIGAÇÃO}

Tese apresentada à Escola Politécnica da Universidade de São Paulo para obtenção do título de Doutor em Engenharia.

Área de concentração: Eng. Hidráulica e Sanitária.

Orientador:

Rubem La Laina Porto 
“ Se eu pudesse deixar algum presente à você, deixaria o acesso ao sentimento de amor à vida dos seres humanos. A consciência de aprender tudo o que nos foi ensinado pelo tempo afora, lembraria dos erros que foram cometidos, com os sinais para que não mais se repetissem.

A capacidade de escolher novos rumos, deixaria para você se pudesse, o respeito à aquilo que é indispensável: além do pão, o trabalho, a ação. E quando tudo mais faltasse para você, eu deixaria, se pudesse, um segredo: o de buscar no interior de si mesmo o respeito e a força interior para encontrar a saída. ” 
A Deus que renova todas a coisas.

Aos meus pais, Francisco (in memorian) e Lazarina. 


\section{AGRADECIMENTOS}

Aos meus amados irmãos, cunhados e sobrinhos, pelo apoio incondicional.

Ao Prof. Dr. Rubem La Laina Porto pela amizade, compreensão e orientação fornecida durante a elaboração deste trabalho.

À Prof.a. Mônica do Amaral Porto pelos gestos de incentivo.

À Dejanyne Paiva Zamprogno pela presença em todos os momentos.

À D. Marli Penido e à Maria Gorete Modesto pelas orações e amizade incondicional.

Ao André Schardong pela elaboração do programa computacional e pela troca de idéias sempre positiva.

Aos amigos do LabSid, Alexandre, Arisvaldo, Celimar, Cristiano, Honório, Roberto Amorim, Roberto Oliveira, Satie e Silvana, pela convivência e colaboração.

Ao Conselho Nacional de Desenvolvimento Científico e Tecnológico (CNPq) pela bolsa de estudo concedida.

À Iara, ao Ricardo e ao Odorico pela atenção e colaboração.

Aos colegas, professores e funcionários do Departamento de Engenharia Hidráulica e Sanitária da EPUSP/USP. 


\section{SUMÁRIO}

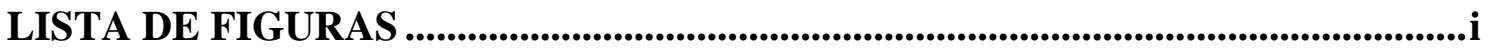

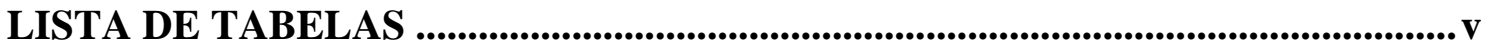

LISTA DE ABREVIATURAS ..........................................................................

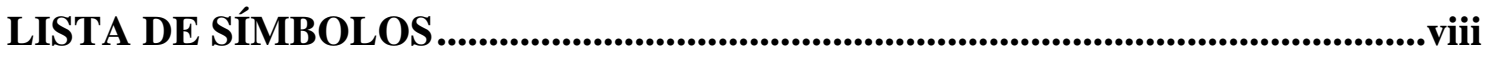

RESUMO

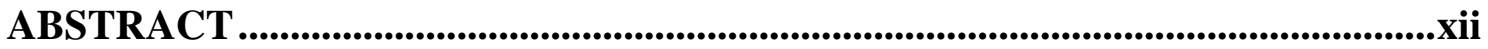

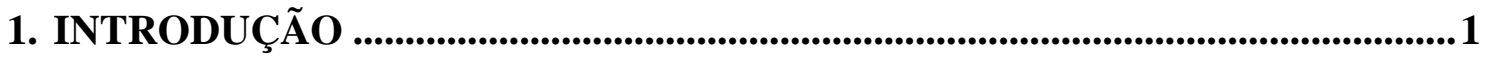

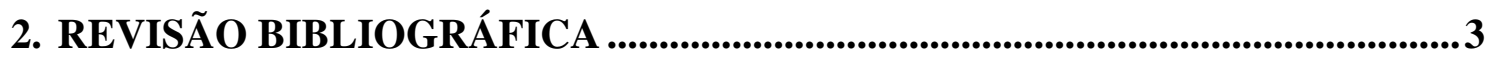

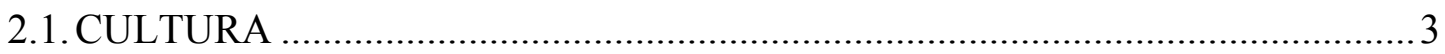

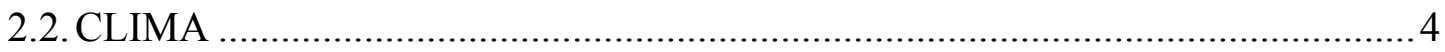

2.2.1. Evapotranspiração de Referência ........................................................ 6

2.2.2. Evapotranspiração Máxima ou Potencial ................................................. 8

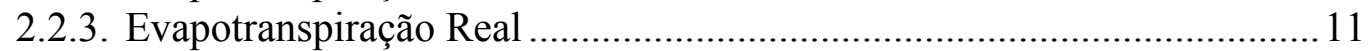

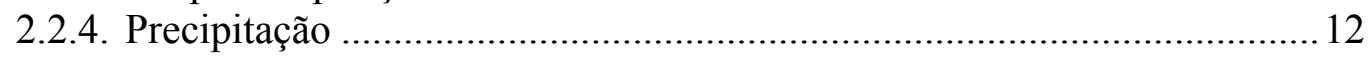

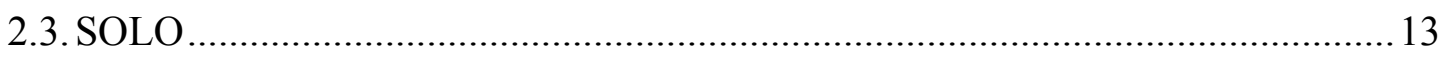

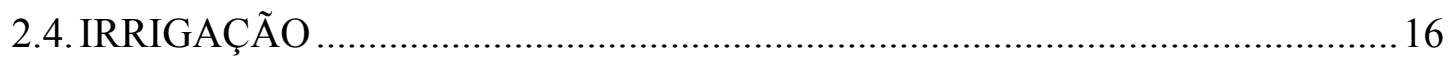

2.5. MODELOS DE SIMULAÇÃO ..................................................................... 19

2.6. SISTEMA DE SUPORTE A DECISÕES …...................................................23

2.6.1. Sistema de Suporte a Decisões para a Agricultura ..................................25

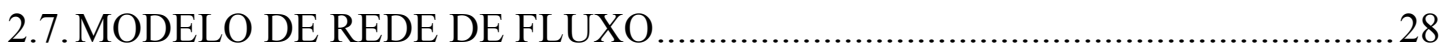

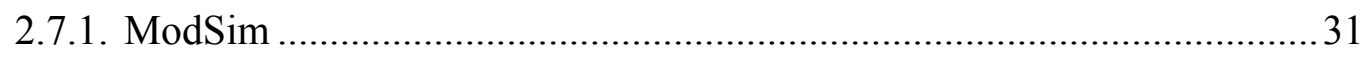

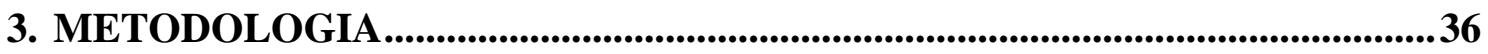

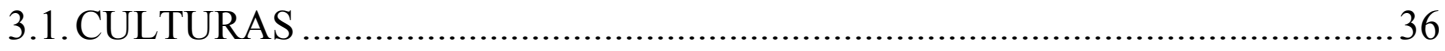

3.1.1. Profundidade Efetiva do Sistema Radicular .......................................... 37

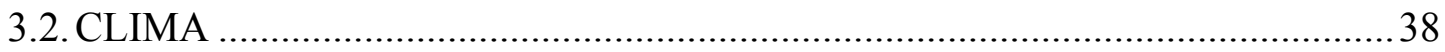

3.2.1. Evapotranspiração de Referência ........................................................... 38 


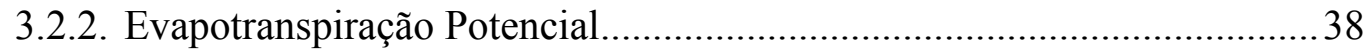

3.2.3. Evapotranspiração Real ................................................................... 40

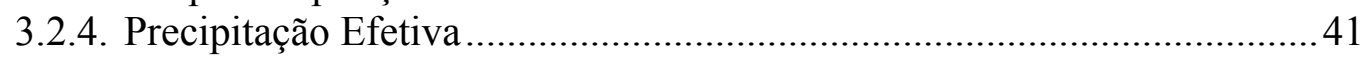

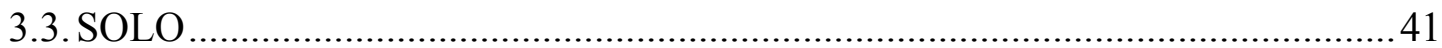

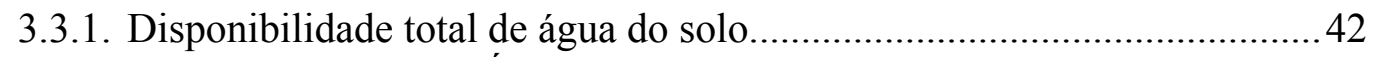

3.3.2. Capacidade Total de Água no Solo ....................................................... 44

3.3.3. Capacidade Real de Água do Solo ........................................................ 45

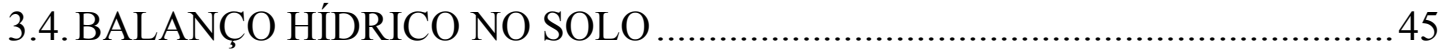

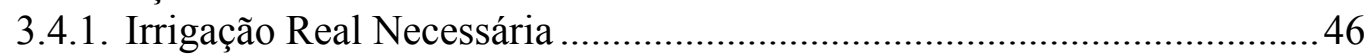

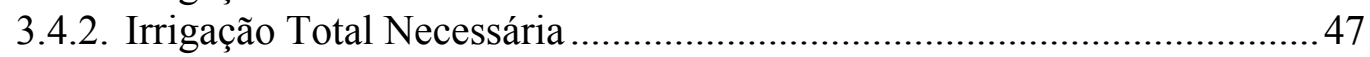

3.4.3. Determinação do Calendário de Irrigação ................................................ 48

3.4.4. Resposta da Cultura ao Suprimento Hídrico ............................................ 51

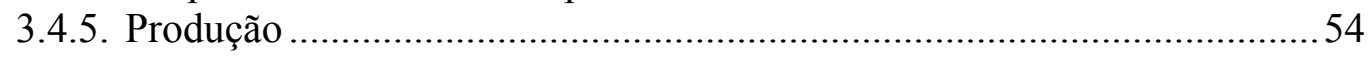

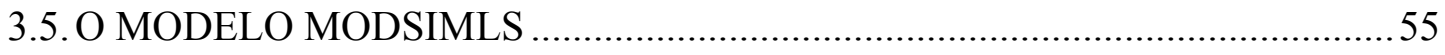

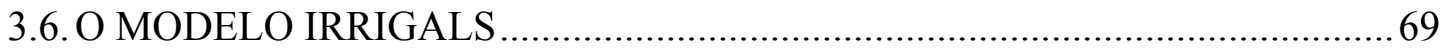

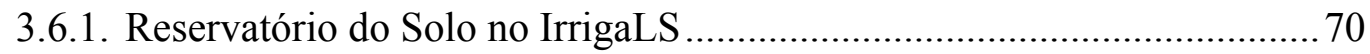

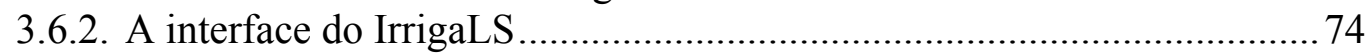

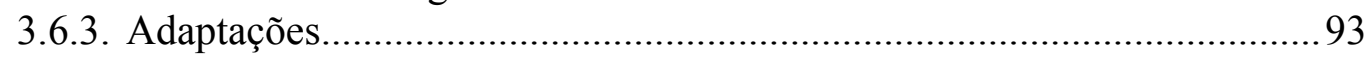

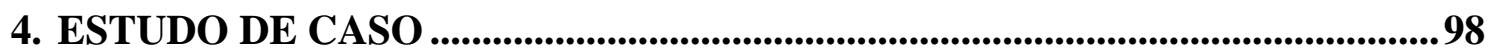

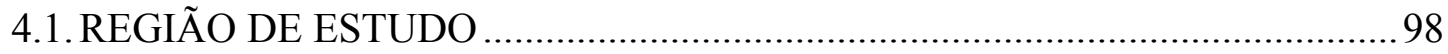

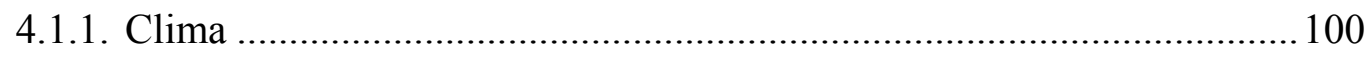

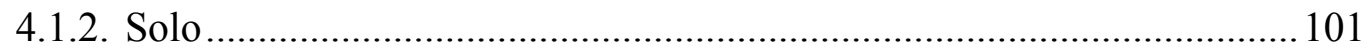

4.2. TOPOLOGIA DO SISTEMA DA BACIA DO ITAPICURU …........................ 102

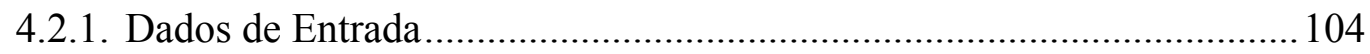

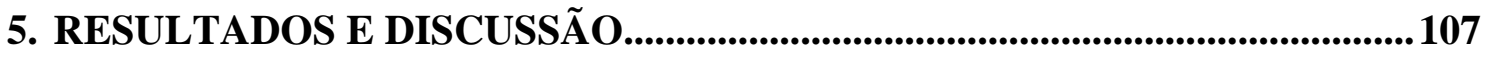

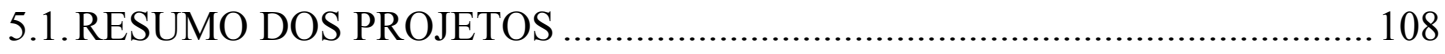

5.2. AJUSTE DOS VALORES DAS TABELAS ............................................... 110

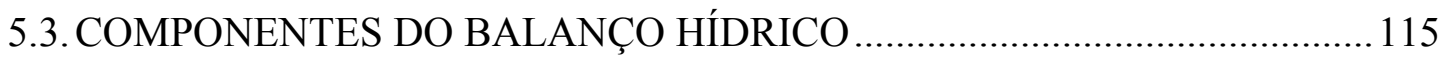

5.4. IRRIGALS E MÉTODO DO BALANÇO HÍDRICO ...................................... 117

5.4.1. Coeficiente de Umidade do Solo Constante e Volume Meta no Solo Igual ao Volume na Capacidade de Campo ................................... 123

5.4.2. Coeficiente de Umidade do Solo Logarítmico e Volume Meta do Solo Abaixo da Capacidade de Campo ................................................ 129

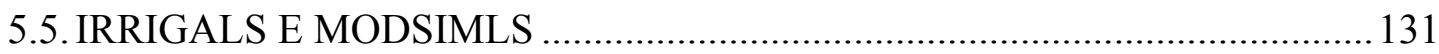

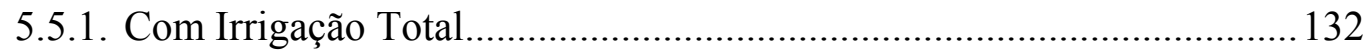

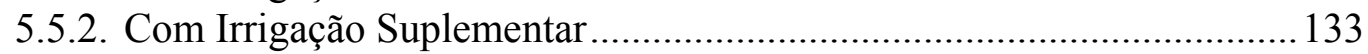


5.5.3. Economia Total de Água

5.6. SUPRIMENTO DE ÁGUA E RENDIMENTO DAS CULTURAS ...................136

5.7. ANÁLISE DO SISTEMA DA BACIA DO ITAPICURU …............................. 138

5.7.1. Relação entre o Reservatório do Solo e o Reservatório Superficial....... 142

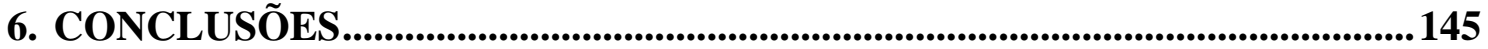

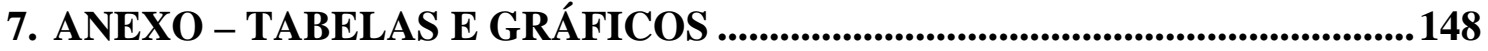

8. REFERÊNCIAS BIBLIOGRÁFICAS ................................................................. 165

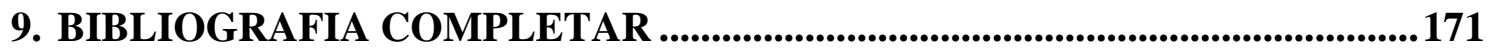




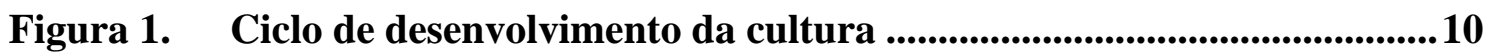

Figura 2. Representação esquemática de um modelo de simulação ....................22

Figura 3. Características de um sistema de suporte a decisão ............................... 25

Figura 4. Representação de um sistema como uma rede de fluxo ......................29

Figura 5. Arcos e nós artificiais de vazões não reguladas.....................................58

Figura 6. Arcos e nós artificiais de vazões não reguladas com adição do volume inicial ..............................................................................59

Figura 7. Arcos e nós artificias de volume ...........................................................59

Figura 8. Demandas terminais .................................................................65

Figura 9. Demandas de passagem ....................................................................................66

Figura 10. Iterações para se determinar as perdas por infiltração nos

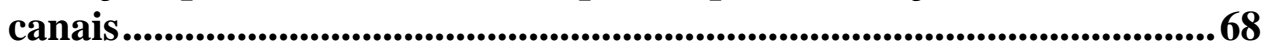

Figura 11. Representação esquemática das relações existentes entre os reservatórios superficial e do solo ................................................ 73

Figura 12. Botões de traçado ..................................................................................77

Figura 13. Vários links entre dois nós ............................................................................77

Figura 14. Exemplo de traçado .............................................................................. 78

Figura 15. Tela de definições gerais ................................................................................... 79

Figura 16. Planilha de entrada/edição de dados quando se utiliza o solo como reservatório - Características gerais .................................80

Figura 17. Planilha do link com coeficiente de perda preenchido automaticamente de acordo com a eficiência do sistema.

Figura 18. Planilha de entrada de dados quando se utiliza o solo como reservatório - Água (Perda e Contribuições) ...................82 
Figura 19. Planilha de entrada de dados quando se utiliza o solo como reservatório - Volume Meta no Solo

Figura 20. Tela para escolha dos elementos cujos dados serão fornecidos/editados

Figura 21. Tela de escolha dos resultados 86

Figura 22. Tela de resultados mostrando volumes e vazões no mesmo gráfico 86

Figura 23. Resumo dos resultados em formato gráfico 87

Figura 24. Menu irrigação com as opções de comparação entre os métodos: simulação do IrrigaLS e cálculos diretos (tradicional)

Figura 25. Planilha de comparação das variáveis de irrigação obtidas através da simulação no IrrigaLS e através de cálculos diretos pelo método do balanço hídrico. 89

Figura 26. Resultado em forma de gráfico comparando a capacidade de campo, o ponto de murcha permanente e a lâmina atual de água no solo obtidos pelo método do balanço hídrico de cálculo da irrigação

Figura 27. Resultados em forma de planilha comparando a capacidade de campo, 0 ponto de murcha permanente e a lâmina atual de água no solo obtidos pelo método do balanço hídrico de cálculo da irrigação

Figura 28. Comparação entre os resultados obtidos pelo métodos ModSim e do balanço hídrico

Figura 29. Análise do rendimento relativo e da produção relativa obtidos através da simulação no ModSim e através de cálculos diretos pelo método do balanço hídrico

Figura 30. Tela para dimensionar os elementos .92

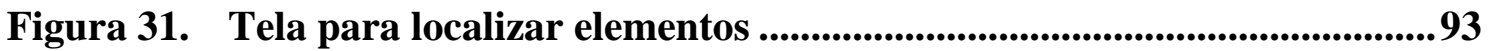

Figura 32. Exemplo de elemento localizado ....................................................93

Figura 33. Localização da bacia do Rio Itapicuru ......................................................99

Figura 34. Área de drenagem da bacia do Rio Itapicuru 100 
Figura 35. Topologia usada na simulação do sistema da Bacia do Itapicuru, não considerando-se o solo como um reservatório.

Figura 36. Topologia usada na simulação do sistema da Bacia do Itapicuru, considerando-se o solo como um reservatório

Figura 37. Curvas de ajuste da precipitação efetiva $\left(\mathbf{P P}_{\mathrm{e}}\right)$ quando a capacidade total de água no solo (CTA) for de $75 \mathrm{~mm} / \mathrm{mês}$

Figura 38. Curva de ajuste da correção da precipitação efetiva $\left(\mathrm{PP}_{\mathrm{e}}\right)$ quando a capacidade total de água no solo (CTA) for diferente de $75 \mathrm{~mm}$

Figura 39. Curvas de ajuste da fração de esgotamento de água no solo

(f) para diferentes grupos de cultura

Figura 40. Curvas de ajuste da produção relativa $\left(\mathbf{P}_{\mathrm{a}} / \mathbf{P}_{\mathrm{p}}\right)$, em função do coeficiente $K_{\mathbf{y}}$ e da evapotranspiração relativa $\left(\mathrm{ET}_{\mathbf{a}} / \mathbf{E T}_{\mathbf{p}}\right)$

Figura 41. Variação dos componentes do balanço hídrico para a banana

Figura 42. Variação dos componentes do balanço hídrico para a cana-de-açúcar

Figura 43. Variação dos componentes do balanço hídrico para as cítricas

Figura 44. Variação dos componentes do balanço hídrico para o feijão

Figura 45. Variação dos componentes do balanço hídrico para a melancia

Figura 46. Variação dos componentes do balanço hídrico para o milho.

Figura 47. Gráfico da variação da evapotranspiração de referência $\left(E T_{0}\right)$, da evapotranspiração potencial $\left(E_{p}\right)$ e da evapotranspiração atual da cultura $\left(\mathrm{ET}_{\mathrm{a}}\right)$, fornecido pelo IrrigaLS, considerando a umidade do solo variável (a) e constante (b)

Figura 48. Gráfico da variação do coeficiente de cultura $\left(K_{c}\right)$ e do fator de variação da umidade do solo $\left(K_{s}\right)$, fornecido pelo IrrigaLS, considerando a umidade do solo variável (a) e constante (b) 
Figura 49. Gráfico da variação da capacidade de campo (CC), do ponto de murcha permanente (PM) e da capacidade atual de água no solo (CAA), fornecido pelo IrrigaLS

Figura 50. Gráfico da variação da precipitação efetiva $\left(P P_{e}\right)$ e da água no solo antes da primeira irrigação (AS), fornecido pelo IrrigaLS

Figura 51. Gráfico que relaciona a capacidade total de água no solo e a variação das lâminas irrigadas (atual, máxima e real), fornecido pelo IrrigaLS.

Figura 52. Evapotranspiração atual média mensal $\left(E T_{a}\right)$ para as culturas permanentes (a) e temporárias (b), para coeficiente de umidade do solo constante $\left(K_{s}=1\right)$ e volume meta no solo igual ao volume na capacidade de campo $\quad($ Vmeta $=1)$

Figura 53. Demandas de irrigação obtidas por simulação no IrrigaLS e no ModSimLS, considerando-se a precipitação igual a zero $\left(\mathrm{PP}_{\mathrm{e}}=\mathbf{0}\right)$ e solo na capacidade de campo(CC)

Figura 54. Demandas de irrigação obtidas por simulação no IrrigaLS

$(P P \neq 0)$ e no ModSimLS (PP = 0), considerando-se

o solo na capacidade de campo

Figura 55. Relação entre a diminuição de rendimento relativo

(1 - $\left.\mathbf{Y}_{\mathbf{a}} / \mathbf{Y}_{\mathbf{p}}\right)$ e o déficit de evapotranspiração relativa

(1 - $\mathbf{E T}_{\mathrm{a}} / \mathrm{ET}_{\mathrm{p}}$ ) para as culturas da banana, cana-de-açúcar, cítricas, feijão, melancia e milho 137

Figura 56. Relação entre a diminuição de rendimento relativo $\left(1-Y_{a} / Y_{p}\right)$ e o déficit de evapotranspiração relativa (1 - $\mathbf{E T}_{\mathrm{a}} / \mathrm{ET}_{\mathrm{p}}$ ) para as culturas da banana, cana-de-açúcar, cítricas, feijão, melancia e milho, obtida no método adaptado

Figura 57. Relação entre a diminuição da produção relativa $\left(1-P_{a} / P_{p}\right)$ e o déficit de evapotranspiração relativa (1 - $-\mathrm{ET}_{\mathrm{a}} / \mathrm{ET}_{\mathrm{p}}$ ) para as culturas da banana, cana-de-açúcar, cítricas, feijão, melancia e milho 138

Figura 58. Relação entre a diminuição da produção relativa $\left(1-P_{a} / P_{p}\right)$ e o déficit de evapotranspiração relativa (1 - $\mathbf{E T}_{\mathbf{a}} / \mathbf{E T}_{\mathrm{p}}$ ) para as culturas da banana, cana-de-açúcar, cítricas, feijão, melancia e milho, obtida no método adaptado 
Tabela 1. Demonstração da montagem da Tabela

Cota-Area-volume no IrrigaLS

Tabela 2. Valores característicos do solo da região de estudo .............................105

Tabela 3. Culturas consideradas no estudo e suas respectivas áreas................. 106

Tabela 4. Resumo dos projetos considerados no estudo da eficiência do IrrigaLS e na validação das adaptações

Tabela 5. Equações da precipitação efetiva $\left(\mathrm{PP}_{\mathrm{e}}\right)$ quando a capacidade total de água no solo (CTA) for de $75 \mathrm{~mm}$

Tabela 6. Equação que representa o Fator de correção da precipitação efetiva $\left(\mathrm{PP}_{\mathrm{e}}\right)$ quando a capacidade total de água no solo (CTA) for diferente de $75 \mathrm{~mm}$

Tabela 7. Equações que representam a fração de esgotamento de água no solo (f) para diferentes grupos de cultura

Tabela 8. Equações que representam a produção relativa $\left(P_{a} / P_{p}\right)$, em função do coeficiente $K_{y}$ e da evapotranspiração relativa $\left(\mathrm{ET}_{\mathbf{a}} / \mathbf{E T}_{\mathbf{p}}\right)$

Tabela 9. Variáveis envolvidas no cálculo do método do balanço hídrico, fornecidas pelo IrrigaLS

Tabela 10. Valores mensais do número de irrigação $\left(\mathrm{N}_{\mathrm{i}}\right)$, das irrigações real e total (IRN e ITN), e da evapotranspiração atual da cultura $\left(\mathrm{ET}_{\mathrm{a}}\right)$, fornecidos pelo IrrigaLS

Tabela 11. Lâminas irrigadas real e total (IRN e ITN) e a evapotranspiração atual $\left(\mathrm{ET}_{\mathrm{a}}\right)$ obtidos pelo IrrigaLS e pelo método do balanço hídrico

Tabela 12. Lâminas irrigadas real e total (IRN e ITN) e a evapotranspiração atual (ET $\left.\mathrm{T}_{\mathrm{a}}\right)$, obtidos pelo IrrigaLS e pelo método do balanço hídrico, para diferentes áreas irrigadas $\left(\mathbf{A}_{\mathbf{i}}\right)$ 
Tabela 13. Lâminas irrigadas real e total (IRN e ITN) e a evapotranspiração atual (ET $\left.{ }_{a}\right)$ obtidos pelo IrrigaLS e pelo método do balanço hídrico

Tabela 14. Lâminas obtidas pelo método do balanço hídrico e pelo IrrigaLS com redução do volume meta (Vmeta)

Tabela 15. Economia conseguida, no IrrigaLS, na lâmina total irrigada (ITN) com a redução do volume meta (Vmeta)

Tabela 16. Demandas de irrigação no IrrigaLS e no ModSimLS

Tabela 17. Economia de água obtida pela inclusão da precipitação no IrrigaLS

Tabela 18. Econômica de água obtida pelo IrrigaLS em comparação com o ModSimLS

Tabela 19. Cenário atual da situação das demandas de irrigação, jusante e urbana no sistema da bacia do Itapicuru para o IrrigaLS e ModSimLS.

Tabela 20. Cenário atual da situação dos reservatórios de Aipim, Pindobaçu e Ponto Novo no sistema da bacia do Itapicuru para o IrrigaLS e ModSimLS.

Tabela 21. Cenário futuro da situação das demandas de irrigação, jusante e urbana no sistema da bacia do Itapicuru para o IrrigaLS e ModSimLS

Tabela 22. Cenário futuro da situação dos reservatórios de Aipim, Pindobaçu e Ponto Novo no sistema da bacia do Itapicuru para o IrrigaLS e ModSimLS

Tabela 23. Volume no reservatório do solo de acordo com a área irrigada $\left(A_{i}\right)$ e a profundidade do sistema radicular $\left(Z_{r}\right)$

Tabela 24. Relação entre a evapotranspiração real média mensal das culturas $\left(\mathrm{ET}_{\mathrm{a}}\right)$ e a evaporação real média mensal $\left(E_{a}\right)$ do reservatório de Ponto Novo 


\section{LISTA DE ABREVIATURAS}

FAO Organização da Agricultura e Alimentação das Nações Unidas

ICID Comitê Internacional de Irrigação e Drenagem

IIC Centro Internacional de Irrigação

MMA Ministério do Meio Ambiente

MRF Modelos de Rede de Fluxo

SCS Soil Conservation Service

SRH Superintendência de Recursos Hídricos

SISDA Sistema de Suporte a decisão Agrícola

SSD Sistema de Suporte a Decisão

UFV Universidade Federal de Viçosa 


\section{LISTA DE SÍMBOLOS}

$\varepsilon \quad$ Eficiência dos métodos de irrigação

$\tau \quad$ Margem de tolerância

A Área média da superfície do reservatório superficial

$\mathrm{A}_{\mathrm{i}} \quad$ Área irrigada

C Custos

CC Capacidade de campo

$c_{\mathrm{ij}} \quad$ Custo (prioridade) da unidade de vazão que transita entre os nós $\mathrm{ij}$

CAA Capacidade atual de água no solo

$\mathrm{C}_{\max } \quad$ Capacidade máxima do reservatório superficial

$\mathrm{C}_{\min } \quad$ Capacidade mínima do reservatório superficial

$\mathrm{C}_{\min }^{*} \quad$ Capacidade mínima admissível no reservatório superficial

CRA Capacidade real de água do solo

CTA Capacidade total de água disponível do solo

$\mathrm{D}_{\mathrm{a}} \quad$ Massa específica do solo

$\mathrm{DEMR}_{\mathrm{i}} \quad$ Prioridade da demanda

DTA Disponibilidade total de água do solo

$\mathrm{e}_{\mathrm{i}} \quad$ Taxa de evaporação no arco

$\mathrm{E}_{\mathrm{i}} \quad$ Evaporação no reservatório

$\mathrm{E}_{\text {imeta }} \quad$ Evaporação meta no reservatório

$\mathrm{E}_{\mathrm{i} \min } \quad$ Evaporação mínima no reservatório

$\mathrm{E}_{\mathrm{i} \max } \quad$ Evaporação máxima no reservatório 


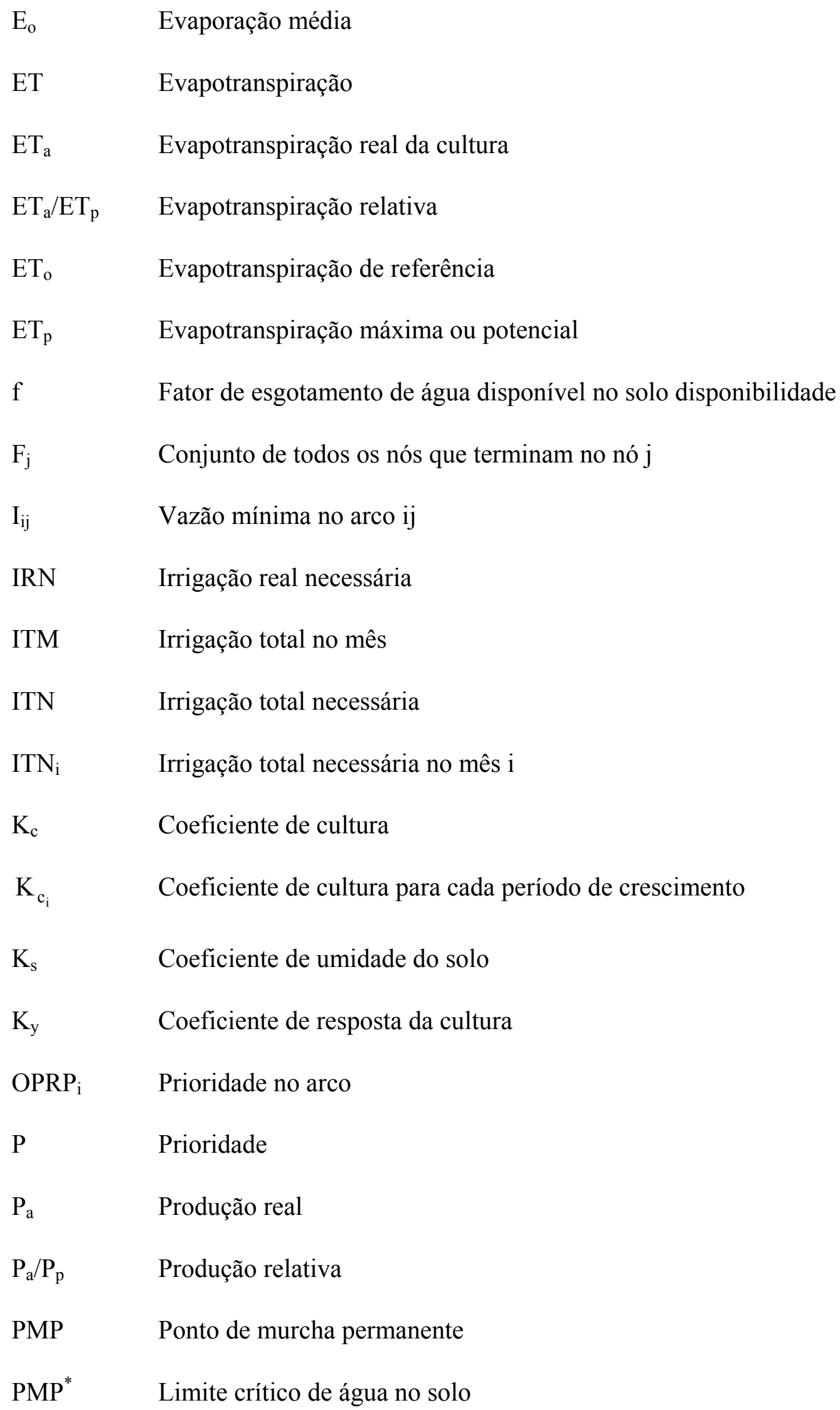




\begin{tabular}{|c|c|}
\hline$P_{p}$ & Produção potencial \\
\hline $\mathrm{PP}$ & Precipitação \\
\hline $\mathrm{PP}_{\mathrm{e}}$ & Precipitação efetiva \\
\hline $\mathrm{PP}_{\mathrm{i}}$ & Precipitação na estação i \\
\hline $\mathrm{q}_{\mathrm{ij}}$ & Vazão que transita do nó j ao i \\
\hline $\mathrm{q}_{\mathrm{i} \text { total }}$ & Vazão total no arco \\
\hline $\mathrm{q}_{\text {is (meta) }}$ & Vazão ótima no arco \\
\hline $\mathrm{q}_{\text {is (final) }}$ & Vazão final no arco \\
\hline $\mathrm{S}_{\mathrm{ij}}$ & Limite superior da vazão no arco ij \\
\hline $\mathrm{S}_{\mathrm{i} \max }$ & Volume máximo no arco \\
\hline $\mathrm{S}_{\mathrm{i} \min }$ & Volume mínimo ou volume morto no arco \\
\hline $\mathrm{T}_{\mathrm{i}}$ & Volume meta no período atual \\
\hline UA & Umidade atual de água no solo \\
\hline $\mathrm{U}_{\mathrm{ij}}$ & Vazão máxima no arco ij \\
\hline VDA & Volume disponível de água no solo \\
\hline $\mathrm{V}_{\text {meta }}$ & Volume meta do solo \\
\hline $\mathrm{V}_{\text {morto }}$ & Volume morto no reservatório \\
\hline $\mathrm{V}_{\text {total }}$ & Volume total no reservatório \\
\hline $\mathrm{V}_{\text {util }}$ & Volume útil no reservatório \\
\hline $\mathrm{Y}_{\mathrm{a}}$ & Rendimento real da cultura \\
\hline $\mathrm{Y}_{\mathrm{a}} / \mathrm{Y}_{\mathrm{p}}$ & Rendimento relativo da cultura \\
\hline $\mathrm{Y}_{\mathrm{p}}$ & Rendimento máximo ou potencial da cultura \\
\hline $\mathrm{Z}$ & Profundidade do reservatório superficial \\
\hline $\mathrm{Z}_{\mathrm{r}}$ & Profundidade efetiva do sistema radicular \\
\hline
\end{tabular}


No presente trabalho, fez-se a adaptação do reservatório superficial do ModSimLS para trabalhar como reservatório do solo. O modelo denomina-se IrrigaLS.

Por comparação com o método do balanço hídrico, verificou-se que o IrrigaLS é apto para determinar demandas de irrigação suplementares e/ou totais. Com a adaptação, o modelo considera a produção agrícola como o resultado da interação dos fatores água-clima-planta-solo.

A capacidade de simular sistemas complexos de recursos hídricos foi testada por comparação dos resultados do IrrigaLS com um modelo de simulação similar (ModSimLS). No ModSimLS, as demandas foram calculadas usando método tradicional de balanço hídrico. Verificou-se que o modelo é apto para simular sistemas complexos de recursos hídricos e apresenta algumas vantagens sobre o ModSimLS, quais sejam: determina a necessidade hídrica real da cultura; garante em períodos de seca um suprimento mínimo de água para a planta; garante uma economia de água pela inclusão da precipitação e possibilidade de variação do volume meta; diferencia as culturas com relação a sensibilidade ao déficit hídrico e calcula o balanço hídrico diário do solo. 
In this work, an adaptation in the ModSimLS surface reservoir has been made in order to make it work as a soil reservoir. The model is called IrrigaLS.

When compared to the water balance method, it was ascertained that IrrigaLS is suitable for determining supplementary and/or total irrigation demands. The model adaptation considers agricultural production as a result from water-weather-plant-soil factors interaction.

The model capability to simulate complex water resources systems has been tested has been tested by comparing the results of IrrigaLS with a similar simulation model (ModSimLS) where the irrigation demands were computed using traditional water balance methods. It was ascertained that the model is suitable for simulating complex water resources systems and it has some advantages over ModSimLS, that are: it determines the real water needs of the culture; it guarantees a minimum water supply to the crop during dry periods, it guarantees water saving by the inclusion of rainfall and by the possibility to choose the soil moisture target; it distinguishes the crops in relation to the water deficit sensibility and it calculates the soil daily water balance. 


\section{INTRODUÇÃO}

O crescimento da demanda mundial por água de boa qualidade, à uma taxa superior à da renovação do ciclo hidrológico é, consensualmente, previsto nos meios técnicos e científicos. A eficiência do uso da água, tanto qualitativa quanto quantitativa, é tema de grande preocupação entre órgãos competentes de todo país.

Numa visão mais ampla, entende-se que a espécie humana deva utilizar os recursos naturais de forma a não alterar as atuais condições do equilíbrio planetário, o qual depende fundamentalmente do equilíbrio climático atual e da biodiversidade existente. Nos chamados sistemas produtivos, especialmente aqueles relacionados com a produção agrícola e florestal, a análise da sustentabilidade poderá ser feita tomando por base o balanço hídrico das bacias hidrográficas.

A agricultura irrigada é reconhecidamente em todo o mundo, uma das atividades econômicas que apresentam as maiores demandas de água para a produção. A necessidade de usar maior quantidade possível de solo agricultáveis vem impulsionando o uso da irrigação não só para complementar as necessidades hídricas das regiões úmidas, como para tornar produtiva as regiões áridas e semi-áridas do globo.

Com o crescimento populacional a demanda de água para irrigação tende a se tornar cada vez maior. Futuras irrigações, mesmo nas regiões com suficiente disponibilidade de água, poderão sofrer limitações devido à competição com a expansão populacional e o aumento de instalações industriais.

Em casos de escassez e baseados em dados de previsão futura, deve-se considerar com mais cautela o planejamento e gestão de recursos hídricos. Percebe-se que a solução de tais questões, requer a utilização de técnicas e instrumentos capazes de auxiliar profissionais na análise, operação, planejamento e tomada de decisões.

A solução para os conflitos pela água é uma gestão integrada e compartilhada de seu uso, controle e conservação. Não mais pode existir o conceito de gestão de recursos hídricos baseada exclusivamente na análise da irrigação, geração hidrelétrica ou saneamento básico. Um bom conhecimento das necessidades de seus diversos usuários e da capacidade de oferta e renovação de suas fontes naturais, são fundamentais para a 
definição dos marcos regulatórios principais e da capacidade de suporte de cada bacia hidrográfica, evitando assim o desperdício de água.

Enfocando-se a tendência futura de aumento da demanda agrícola e o fato desta demanda ser o principal concorrente pelo uso da água, o objetivo desse trabalho é desenvolver uma ferramenta que facilite a análise de estratégias de manejo de irrigação em um contexto integrado e compartilhado com os outros usos da água.

Para o proposto optou-se por adaptar um sistema de suporte a decisão (ModSimLS) para trabalhar com o reservatório do solo, considerando que a produção agrícola é o resultado da interação dos fatores água, clima, planta e solo. Esta adaptação permite simular a variação da água armazenada no solo e a alocação da água em projetos de irrigação ao longo do período de cultivo, em sistemas complexos de recursos hídricos. 


\section{REVISÃO BIBLIOGRÁFICA}

\subsection{CULTURA}

Quando o suprimento de água não atende as necessidades hídricas da cultura desenvolve-se um estresse hídrico na planta, o qual afetará seu crescimento e seu rendimento. Porém, o efeito da água sobre o rendimento não pode ser considerado independente de outros fatores agronômicos, tais como os fertilizantes, a densidade de plantas e a proteção da cultura, porque esses fatores também determinam o quanto o rendimento real $\left(\mathrm{Y}_{\mathrm{a}}\right)$ aproxima-se do rendimento máximo ou potencial $\left(\mathrm{Y}_{\mathrm{p}}\right)$, (Doorenbos e Kassam, 1979).

O nível de $\mathrm{Y}_{\mathrm{p}}$ de uma cultura é determinado principalmente, por suas características genéticas e grau de adaptação ao ambiente predominante. Os métodos de determinação de $Y_{p}$ permitem a quantificação do potencial produtivo de diferentes áreas, possibilitando a identificação das mais apropriadas para a produção de determinada cultura. Entre esses métodos os autores citam: (1) o de "Wageningen"; e (2) o da zona agroecológica, (Doorenbos e Kassam, 1979).

Os efeitos do déficit hídrico sobre o rendimento de diferentes culturas são da maior importância para o planejamento da produção. Doorenbos e Kassam (1979) quantificam o efeito do estresse hídrico na planta através do coeficiente de resposta da cultura $\left(\mathrm{K}_{\mathrm{y}}\right)$.

Reichardt (1990) divide os estádios de desenvolvimento em quatro. No caso das hortaliças: Estádio -I: da emergência até $10 \%$ do desenvolvimento vegetativo (DV); Estádio -II: de 10 até $80 \%$ do DV; Estádio -III: de 80 à 100\% do DV (ou enchimento 
dos grãos) e Estádio -IV: maturação. Para hortaliças com frutos: Estádio -I: semeadura e germinação; Estádio -II: ramificação; Estádio -III: frutificação e Estádio -IV: maturação.

Geralmente, as culturas são mais sensíveis ao déficit hídrico durante a emergência, a floração e na fase inicial de formação da colheita do que durante o período vegetativo, após o estabelecimento, e maturação. Isto implica que a programação do momento de aplicação de água é tão importante quanto o nível de suprimento de água durante o período total de crescimento. Portanto, o planejamento do suprimento estacional deve considerar o fornecimento ótimo de água à cultura durante as fases de ciclo fenológico, (Frizzone, 1998).

\subsection{CLIMA}

Os fatores climáticos têm influência direta nos requerimentos de água pelas culturas, sendo um dos principais fatores que determinam as necessidades hídricas de uma cultura para crescimento e rendimentos ótimos (Doorenbos e Kassam, 1979).

Dentre as vantagens de se conhecer o clima encontram-se: (1) previsão de fatores adversos às culturas, tais como geadas e estiagens; (2) planejamento da irrigação; (3) estabelecimento de calendários de plantio e colheita; (4) seleção de variedades aptas à região; (5) controle e prevenção de algumas doenças e pragas; e (6) dimensionamento de estruturas de controle e dissipação de excedentes hídricos (Doorenbos e Kassam, 1979).

O consumo de água do conjunto solo-planta, conhecido também como necessidade hídrica da cultura, corresponde a quantidade de água que passa à atmosfera 
em forma de vapor (transpiração e evaporação). Em uma cultura bem estabelecida e desenvolvida, a taxa de transpiração é bem superior à taxa de evaporação, do ponto de vista agronômico, porém, as duas taxas são de importância, pois representam a perda total para a atmosfera. À união dessas duas taxas dá-se o nome de taxa de evapotranspiração (ET). A necessidade hídrica da cultura é normalmente expressa mediante a ET (Doorenbos e Kassam, 1979).

Dois sistema físicos básicos regulam o clima nas vizinhanças das plantas: o balanço de energia (radiação solar, temperatura e comprimento do dia) e a transferência aerodinâmica (velocidade do vento ou distância por ele percorrida e umidade relativa do ar). Muitos destes fatores são inter-relacionados e é difícil de se especificar o efeito de cada um na ET, (Goldberg e Teixeira, 1976)

Reichardt (1985, 1990), denomina ET como sendo a transferência de água na forma de vapor, do sistema solo-planta para a atmosfera. Essa transferência dá-se na superfície do solo (evaporação) e na superfície da planta (transpiração).

As condições de solo, pragas, a própria cultura e suas características de crescimento, além de práticas agrícolas, também influenciam a transferência de água para a atmosfera, mas segundo Klar (1991) o clima é o fator que mais afeta a perda de água de uma cultura.

Para Valadão (1995), os estudos de ET propiciam informações do uso da água pela planta, fornecendo parâmetros para o manejo da água e para o dimensionamento de sistemas de irrigação.

Fernandes et al. (1999), em estudos feitos com soja, relatam que a quantidade de água que sai de um volume de solo, desprezando-se os movimentos laterais e verticais, compreende a perda por evaporação e transpiração da cultura, portanto, o conhecimento 
da ET permite o planejamento das irrigações de tal forma a dotar o solo de uma condição de umidade que forneça sempre conforto hídrico às culturas e não ocorram perdas.

\subsubsection{Evapotranspiração de Referência}

Tem-se demonstrado que o nível de evapotranspiração (ET) está relacionado com a demanda evaporativa do ar. Essa demanda pode ser expressa como evapotranspiração de referência $\left(\mathrm{ET}_{\mathrm{o}}\right)$ que, quando calculada, prediz o efeito do clima sobre o nível de ET da cultura (Doorenbos e Kassam, 1979).

Define-se $\mathrm{ET}_{\mathrm{o}}$ como sendo a quantidade de água evapotranspirada na unidade de tempo e de área, por uma cultura de baixo porte (de 8 a $15 \mathrm{~cm}$ de altura), de altura uniforme, verde, em ativo crescimento e sem deficiência de água, cobrindo totalmente o solo. Para esta superfície, as condições climáticas comandam o processo evapotranspirativo.

$\mathrm{A} \mathrm{ET}_{\mathrm{o}}$ é um fator básico na determinação do total de água necessário durante o ciclo de uma cultura, quando se deseja um manejo correto da água nos trabalhos de irrigação e drenagem (Sediyama, 1987).

Existem vários métodos para estimar a $\mathrm{ET}_{\mathrm{o}}$, de acordo com Jensen (1973) a escolha do método depende do clima local e dos dados disponíveis.

Segundo Doorenbos e Pruitt (1977) são utilizados métodos indiretos de estimativa da quantidade de água requerida pelas culturas devido a dificuldade de se conseguir medidas de campo com precisão.

Os métodos para a avaliação de $\mathrm{ET}_{\mathrm{o}}$, segundo Bernardo (1995), podem ser divididos em: (1) Diretos: lisímetros, parcelas experimentais de campo, controle de 
umidade, método de entrada e saída em grandes áreas, e; (2) Indiretos: evaporímetros e equações.

De acordo com Doorenbos e Kassam (1974) a Organização da Agricultura e Alimentação das Nações Unidas (FAO), por intermédio de seu Grupo de Exigência de Água pelas Culturas, através da publicação n⿳o 24 da coleção Irrigação e Drenagem, recomenda quatro métodos indiretos para estimativa da $\mathrm{ET}_{\mathrm{o}}$ : (1) Penman modificado; (2) Radiação; (3) Tanque evaporimétrico; e (4) Blaney-Criddle. Para os autores, os métodos relacionados permitem a predição da $\mathrm{ET}_{\mathrm{o}}$ com 10 a $20 \%$ de erro, desde que os dados meteorológicos sejam confiáveis e obtidos num ambiente agrícola representativo, contanto que se conheçam o período total de crescimento e a duração dos diferentes estádios de desenvolvimento.

Devido às dificuldades de determinação da $\mathrm{ET}_{\mathrm{o}}$ através de medições diretas e exatas em condições reais, os métodos indiretos têm sido largamente utilizados, possibilitando resultados satisfatórios, (Marouelli, 1986).

Os métodos para determinar $\mathrm{ET}_{\mathrm{o}}$, segundo Mota (1989), podem agrupar-se em cinco categorias: (1) medidas diretas com lisímetros; (2) fórmulas empíricas que usam um ou mais elementos climáticos comuns; (3) método aerodinâmico; (4) método do balanço de energia; e (5) evaporímetros.

O emprego de métodos mais precisos, na maioria das vezes, é limitado pela indisponibilidade de parâmetros específicos o que favorece a utilização de métodos mais simples para estimativa da evapotranspiração, nem sempre propiciando resultados satisfatórios. 
O Comitê Internacional de Irrigação e Drenagem (ICID) e a FAO consideram o uso do método de Penman-Monteith como "Standard" para estimativa da $\mathrm{ET}_{\mathrm{o}}$, Hargreaves (1994).

Augusto et al. (1996) estudando os efeitos da variação temporal da $\mathrm{ET}_{\mathrm{o}} \mathrm{em}$ projetos de irrigação, concluíram que, para efeito de projetos de irrigação, deve-se utilizar valores médios de $\mathrm{ET}_{\mathrm{o}}$ para a série de dados de maior duração possível.

\subsubsection{Evapotranspiração Máxima ou Potencial}

A evapotranspiração potencial $\left(\mathrm{ET}_{\mathrm{p}}\right)$ refere-se às condições em que a água é suficiente para um crescimento e desenvolvimento sem restrição e representa a taxa de evapotranspiração máxima de uma cultura sadia que cresce em grandes áreas sob condições ótimas de manejo agronômico e de irrigação (Marouelli, 1986).

Klar (1991) define $\mathrm{ET}_{\mathrm{p}}$ ou demanda evaporativa ideal como a perda de água por uma cultura qualquer sem nenhuma restrição de água em qualquer estádio de desenvolvimento. Pode ser estimada através de métodos diretos, ou, indiretamente a partir de $\mathrm{ET}_{\mathrm{o}}$.

Serruto (1992) propôs uma fórmula para estimar $\mathrm{ET}_{\mathrm{p}}$, em base mensal, utilizando a temperatura média e a radiação solar extraterrestre. A equação é aplicada pelo autor para as condições do lago Titicaca (Peru-Bolívia) e do vale do Paraíba no Estado de São Paulo.

Quando a umidade do solo está próxima da capacidade de campo (CC), a evapotranspiração de uma cultura é mantida na sua potencialidade e determinada pelo tipo de cultura e principalmente pelas condições climáticas predominante, (Doorenbos e Kassam, 1974). 
Segundo Telles (1996), a maneira mais indicada para se determinar os requerimentos de água, de uma cultura, é através da estimativa $\mathrm{ET}_{\mathrm{p}}$, que depende basicamente do clima e do tipo de cultura e seu estádio de desenvolvimento.

\subsubsection{Coeficientes de cultura}

A $\mathrm{ET}_{\mathrm{p}}$ está relacionada com a $\mathrm{ET}_{\mathrm{o}}$ através de um coeficiente adimensional que é determinado empiricamente, denominado coeficiente de cultura $\left(\mathrm{K}_{\mathrm{c}}\right)$. O valor de $\mathrm{K}_{\mathrm{c}} \mathrm{e}$ função das diferenças de interface cultura-atmosfera entre a cultura de referência (grama batatais) e outros cultivos, também em diferentes estádios de desenvolvimento. Para a maioria das culturas, o valor de $\mathrm{K}_{\mathrm{c}}$ aumenta a partir de um pequeno valor no momento da emergência até um máximo durante o período em que é alcançado seu pleno desenvolvimento e diminui à medida em que amadurece (Doorenbos e Kassam, 1979).

$\mathrm{O} \mathrm{K}_{\mathrm{c}}$ para cada tipo de cultura assume valores distintos segundo a fase de crescimento da cultura, conforme apresentado na Tabela 2 no ANEXO.

Doorenbos e Pruitt (1977) propõem uma série de procedimentos para a determinação do $\mathrm{K}_{\mathrm{c}}$. Classificam as culturas em dezesseis grupos e apresentam duas figuras e nove tabelas, nas quais os valores de $\mathrm{K}_{\mathrm{c}}$ variam com o estádio vegetativo da cultura e com as condições climáticas. Os mesmos autores reconhecem a existência de períodos críticos durante o ciclo de desenvolvimento das plantas, nos quais o déficit hídrico acarreta maiores perdas na produtividade. Quanto maior for a demanda evapotranspirométrica local e, ou, quanto mais sensível for a planta ao déficit de água no solo, maior deverá ser o $\mathrm{K}_{\mathrm{c}}$. 


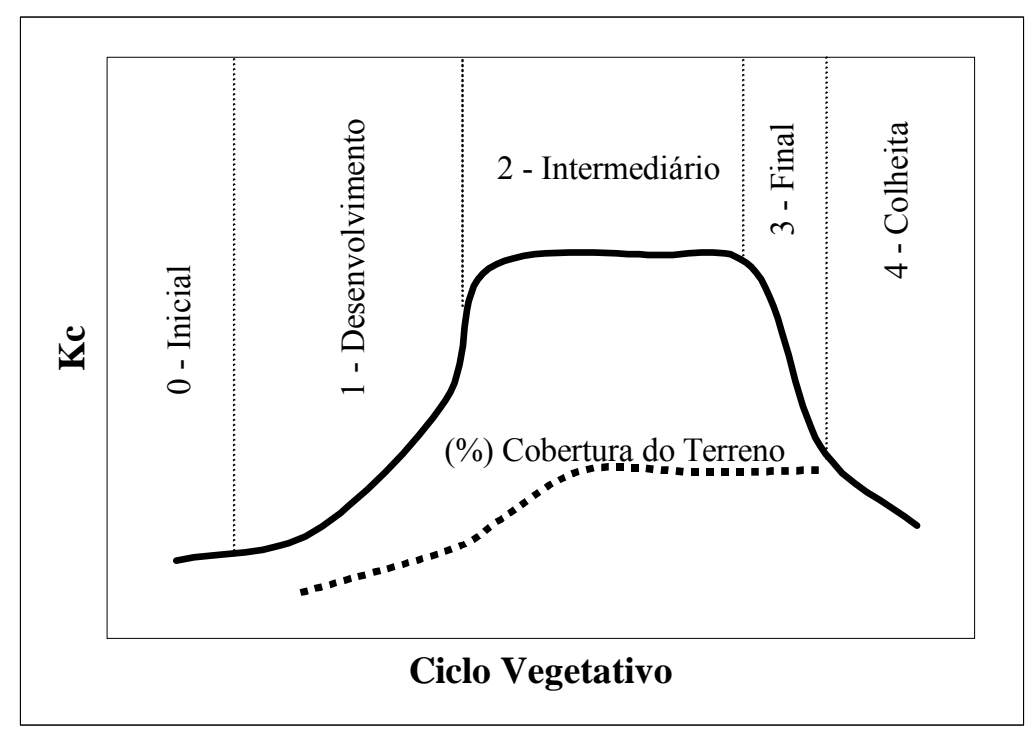

Fonte: Bernardo (1995)

Figura 1. Ciclo de desenvolvimento da cultura

$\mathrm{O}$ valor de $\mathrm{K}_{\mathrm{c}}$ para o estádio inicial está relacionado principalmente com a evaporação do solo. Sendo assim, ele depende da demanda evapotranspirométrica e da umidade do solo local (Doorenbos e Pruitt, 1977).

Doorenbos e Kassam (1979) fornecem uma tabela completa de $\mathrm{K}_{\mathrm{c}}$, para inúmeras culturas, em cada um dos seus estádios, em função do vento e da umidade do ar. Bernardo (1998) sugere que para as condições do Brasil, onde na maioria do território a irrigação deve ser suplementar, podem-se, de uma maneira mais simplificada, usar tais tabelas.

De acordo com Klar (1991), dispondo-se de valores de $\mathrm{K}_{\mathrm{c}}$, determinados experimentalmente para a região, estes deverão ser utilizados. 


\subsubsection{Evapotranspiração Real}

Vila Nova e Reichardt (1989) referem-se a evapotranspiração real (ET $\left.{ }_{\mathrm{a}}\right)$ como a perda de água por evapotranspiração de uma superfície em quaisquer condições de vegetação e suprimento de água.

Klar (1991) define $\mathrm{ET}_{\mathrm{a}}$ como sendo a taxa de perda de água da superfície vegetada, nas condições prevalecentes de solo, clima e planta.

A demanda de água da cultura deve ser atendida pela água do solo, através do sistema radicular. A taxa real de absorção de água do solo pela cultura, em relação a sua $\mathrm{ET}_{\mathrm{p}}$ é determinada quer pelo fato de que a água disponível no solo seja suficiente, ou que a cultura venha a sofrer estresse resultante de déficit hídrico (Bernardo, 1995).

Dados confiáveis de $\mathrm{ET}_{\mathrm{a}}$ são exigidos para o planejamento, a construção e operação de reservatórios e de sistemas de irrigação de drenagem, (Sediyama, 1987). O autor relata, baseado em dados obtidos em lisímetros de pesagem, que a $\mathrm{ET}_{\mathrm{a}}$ mantém-se acima de $90 \%$ da $\mathrm{ET}_{\mathrm{o}}$ enquanto a umidade nos primeiros 75 a $90 \mathrm{~cm}$ de solo estiver acima de aproximadamente um terço de água disponível. Depois ela cai mais rapidamente, até um valor abaixo de $50 \%$ da $\mathrm{ET}_{\mathrm{o}}$, para umidade do solo no ponto de murchamento (Bernardo, 1995).

Existem várias proposições para o cálculo de $\mathrm{ET}_{\mathrm{a}}$, das quais as baseadas na disponibilidade de umidade do solo parecem mais simples e mais realísticas. $\mathrm{A} \mathrm{ET}_{\mathrm{a}}$ será igual a $\mathrm{ET}_{\mathrm{p}}$ quando a água disponível no solo para a cultura for suficiente, ou seja, $\mathrm{ET}_{\mathrm{a}}$ $=\mathrm{ET}_{\mathrm{p}}$. Entretanto, $\mathrm{ET}_{\mathrm{a}}<\mathrm{ET}_{\mathrm{p}}$ quando a água disponível no solo for limitada, (Doorenbos e Kassam, 1974).

Bernardo (1995), tomando como base os resultados de Pierce, cita que a $E_{a}$ é igual a $\mathrm{ET}_{\mathrm{p}}$ durante algum tempo, decrescendo rapidamente a partir de determinado 
valor de umidade do solo, podendo ser quantificada para períodos entre irrigações ou chuvas intensas e para períodos mensais. $\mathrm{O}$ autor cita também que determinação da $\mathrm{ET}_{\mathrm{a}}$ é fator de fundamental importância para o correto manejo dos sistemas de irrigação.

Para Valadão (1995) a necessidade de se conhecer o consumo ideal de água de uma cultura permite, entre outros, a obtenção de resultados econômicos e o melhor aproveitamento pela planta da água aplicada através da irrigação.

\subsubsection{Precipitação}

Do total de precipitação (PP) que incide em uma área, parte é retida pela cobertura vegetal, parte escoa sobre a superfície do solo e parte infiltra no solo. Da quantidade que infiltra no solo, uma parte é retida na zona radicular e outra parte percola para as partes mais profundas. Segundo Bernardo (1995) a distribuição da precipitação entre estas quatro partes depende, principalmente: (1) do total precipitado; (2) da intensidade e da freqüência da precipitação; (3) da cobertura vegetal; (4) da topografia local; (5) do tipo de solo; e (6) do teor de umidade no solo antes da chuva.

Quanto à irrigação, interessa principalmente (Bernardo, 1998): (1) a parte precipitada que será utilizada diretamente pela cultura (precipitação efetiva); (2) a freqüência e a magnitude de precipitação, que se podem esperar na área de projeto (precipitação provável); e (3) a quantidade de água que abastecerá os rios e as represas a fim de ser usada na irrigação. 


\subsubsection{Precipitação Efetiva}

Segundo Bernardo (1995), precipitação efetiva $\left(\mathrm{PP}_{\mathrm{e}}\right)$, sob o ponto de vista da irrigação, corre ponde a parte da PP que é utilizada pela cultura para atender a sua demanda evapotranspirométrica. Ou seja, é a precipitação total menos a parte que escoa sobre a superfície do solo e a parte que percola abaixo do sistema radicular da cultura. $\mathrm{O}$ autor cita que dentre os métodos de determinação da $\mathrm{PP}_{\mathrm{e}}$ encontram-se: (1) Método de Balanço de Umidade do Solo; (2) Método do Lisímetro; (3) Método do US Bureau of Reclamation; (4) Método de Conservação de Solo dos EUA; e (5) várias equações.

Cardoso et al. (1997) consideram que quando a precipitação ocorrida for menor que $25 \mathrm{~mm}$, toda a precipitação é considerada efetiva.

Zahed e Porto em apostila da disciplina de hidrologia cita uma adaptação, para as condições do Estado de São Paulo, do método do Serviço de Conservação do Solo do Departamento de Agricultura dos Estados Unidos. Tal método acha-se descrito em detalhes no Boletim Técnico do DAEE v 2, nº 2, Maio/Ago 1979, pág. 82.

\subsection{SOLO}

O solo pode ser definido como um sistema poroso constituído por partículas sólidas e volume de vazios, que podem ser ocupados pelo ar e pela água, sendo, portanto, utilizado pela plantas como suporte e fonte nutrientes e água, (Klar, 1984).

Depois de exposto ao ar por tempo relativamente longo, um solo permanece a uma umidade praticamente constante, variável de solo para solo, (Reichardt, 1990). 
Segundo o mesmo autor, enquanto houver água disponível no solo há o movimento de água da planta para a atmosfera, não havendo água disponível, o movimento cessa.

Qualquer tentativa de quantificar a água disponível no solo, baseando-se apenas em parâmetros do solo, não pode dar resultados satisfatórios. Por outro lado, existe a necessidade da definição da água disponível para a possibilidade de um manejo agrícola racional. Definiu-se, então, uma quantidade de água disponível baseada em parâmetros do solo, de grande utilidade desde que se reconheçam suas limitações, são elas a capacidade de campo (CC) e ponto de murcha permanente (PMP), (Reichardt, 1990).

A disponibilidade total de água no solo (DTA), segundo Doorenbos e Kassam (1974), é a lâmina de água armazenada por profundidade de solo, entre os teores de umidade na CC e no PMP.

Para Doorenbos e Kassam (1974) CC é considerada como o limite superior da quantidade de água no solo disponível para a alimentação das plantas e o PMP corresponde ao ponto no qual as plantas não conseguem mais extrair água do solo e se murcham de maneira irreversível. A umidade na $\mathrm{CC}$ corresponde a um estado aparentemente de equilíbrio, alcançado depois da drenagem da água gravitacional proveniente de um solo saturado e no PMP corresponde a um estado de umidade mínimo do solo.

Andrade et al. (1998) relatam que muitas tentativas têm sido feitas para associar o limite superior de água disponível com o conteúdo de umidade do solo em equilíbrio com 1/3 atm (-30 kPa). Essa definição desconsidera o fato de o equilíbrio da água no solo depender das propriedades de transição do meio poroso como um todo e do gradiente de potencial total, e não somente do estado de energia da água em um ponto particular do perfil. Além do mais, devido ao formato da curva de retenção naquela 
faixa de potencial, grandes erros podem ser cometidos na obtenção do valor da umidade do solo na CC associado com determinado valor de potencial matricial.

O conteúdo de água no potencial matricial de 15 atm $(-1500 \mathrm{kPa})$ é geralmente adequado para caracterizar o PMP. Nestas condições as plantas não podem utilizar a água do solo, e murcham de tal maneira que mesmo chovendo ou irrigando elas já não se recuperam mais. Ao contrário do que ocorre com o limite superior de água disponível, os erros cometidos na determinação do ponto de murcha permanente representam pequenas variações em termos de conteúdo de umidade do solo e, de fato, podem ser desprezíveis, (Andrade et al., 1998).

Existe uma relação funcional entre a umidade (com base em peso ou em volume) com o potencial matricial que é chamada curva de retenção de água. Como para cada tipo de solo existe um valor característico de umidade correspondente a um determinado valor de potencial matricial, essa relação funcional é também chamada de curva característica de umidade, (Andrade et al., 1998).

O balanço hídrico do solo corresponde a somatória das quantidades de água que entram e saem de um elemento de volume do solo, num intervalo de tempo, apresentando como resultado a quantidade líquida de água que permanece disponível às plantas. Os componentes do balanço são a PP, a irrigação, o deflúvio superficial, a percolação profunda ou ascensão capilar, a variação de armazenamento no solo e a ET, Reichardat (1985).

Fernandes et al. (1999) comentam que de grande importância para a análise do comportamento de uma cultura são as variações de umidade do solo e, conseqüentemente, do armazenamento de água. Estas variações são um reflexo das taxas de ET, PP, irrigação e movimentos de água no perfil de solo. 
Segundo Mendonça (2001) o balanço entre a entrada por PP e a saída por ET, recarga subterrânea e escoamento superficial pode ser estimado para um perfil de solo. Esse balanço permite a computação da ET, recarga do aqüífero e vazão a partir de umas poucas observações do solo, da vegetação e de informações hidrometeorológicas.

O balanço hídrico em perfis de solo tem sido usado para calcular demandas de irrigação, umidade do solo para plantações e vegetação natural, predição de vazões e de níveis de lençol, fluxo de água, variações de nível e salinidade em lagos. Tendo e vista que são utilizados dados meteorológicos disponíveis, longo período de dados de umidade do solo, água subterrânea e vazões podem ser gerados e sujeitos a análise probabilística para estudos de viabilidade econômica e ecológica de alternativas de uso de solo e de recursos hídricos. Apesar de ser um método aproximado, serve para prever chances de sucessos, modos de operação e impactos ambientais de alternativas analisadas, (Mendonça, 2001).

O balanço hídrico do solo também pode ser calculado indiretamente, com o uso da $\mathrm{ET}_{\mathrm{p}}$. O potencial de perda acumulada de água pode ser calculado em função da capacidade de água disponível e da quantidade de água retida no solo. A capacidade de água disponível na zona das raízes é função do tipo e textura de solo e da profundidade do sistema radicular das raízes, (Mendonça, 2001).

\subsection{IRRIGAÇÃO}

A irrigação é uma prática agrícola de fornecimento de água às culturas, onde e quando as dotações pluviométricas, ou qualquer outra forma natural de abastecimento não são suficientes para suprir as necessidades hídricas das plantas, (Gomes, 1999). 
A irrigação tem grande impacto na produção, principalmente de pequenos produtores, mesmo quando é usada em pequenos lotes, permite diversificar a produção e reduz os riscos de incertezas quanto ao produto final (Gomes, 1999).

Com o crescimento populacional, a humanidade se vê compelida a usar maior quantidade possível de solos agricultáveis, o que vem impulsionando o uso da irrigação, não só para complementar as necessidades hídricas das regiões úmidas, como para tornar produtiva as regiões áridas e semi-áridas do globo, que constituem cerca de $55 \%$ das áreas continentais, Leme (1991).

Gartuno (1994) cita que mais de $80 \%$ da água consumida em todo o mundo vai para a agricultura, embora a eficiência média seja apenas 37\%.

A produtividade agrícola a sustentabilidade da produção e o futuro da agricultura irrigada estão condicionados por riscos de saturação dos solos, salinização nas áreas áridas e semi-áridas e competição pelo uso da água com outros usos (humano, pecuário e industrial), (Lima et al., 1999).

Leme (1991) cita que o mais importante recurso disponível para se racionalizar a aplicação de água é a programação da irrigação que requer certos procedimentos que permitem a determinação de turno e da quantidade de água da próxima irrigação.

O estádio tecnológico atual mostra que a viabilidade econômica da irrigação está relacionada com a aplicação de água na quantidade certa e em estádios da cultura que apresentem maior potencial de resposta e não com a aplicação de lâmina de água máxima durante todo o ciclo. Portanto a tendência atual é a otimização da irrigação das culturas, visando a obtenção da produtividade real ótima, com a maximização de lucros e não com a maximização da produtividade, (Leme, 1991). 
A agricultura irrigada é reconhecidamente em todo o mundo, uma das atividades econômicas que apresentam as maiores demandas de água para a produção, (Arruda, 1994).

Bastos (1994), recomendam que se deve estimular um manejo racional da irrigação e a otimização dos equipamentos elétricos utilizados, com a finalidade de tornar a utilização da água e da energia elétrica mais eficientes. O estabelecimento do consumo de água das culturas deve ser feito criteriosamente a fim de propiciar um correto dimensionamento de sistemas de irrigação.

Para Cirino (1994) o pleno conhecimento dos parâmetros necessários para a elaboração de um projeto de irrigação racional, tais como: facilidade com que a água movimenta-se no solo, disponibilidade de água no solo para as plantas, aeração e porosidade efetiva no solo, é indispensável no processo de planejamento e dimensionamento da irrigação e drenagem de terras destinadas à agricultura. Existem critérios ou métodos empíricos que permitem estimar estes parâmetros sem precisar ir ao campo ou laboratório.

Para se fazer irrigações corretas, deve-se, (Bernardo, 1995): (1) analisar os fatores de solo, clima, planta e suprimento de água; (2) considerar os fatores de solo, água e de engenharia na determinação da aplicação de água; (3) avaliar a inter-relação entre irrigação e outros fatores culturais, tais como: variedade, densidade de plantio, fertilizante, ervas daninhas, colheitas etc.; e (4) visar sempre à obtenção da melhor função econômica.

A aplicação da água na lavoura é feita por métodos de irrigação, que podem ser classificados em: irrigação superficial (sulcos de irrigação, taças de inundação, corrugação, etc), irrigação sub-superficial (tubos porosos, tubos perfurados, elevação do 
lençol freático), irrigação por aspersão (convencional, autopropelido, pivô central, montagem direta, etc) e irrigação localizada (gotejamento, jato-pulsante, microaspersão, etc), (Telles, 1996).

Na 26ํㅡㄹ Conferência Regional da FAO foi discutido que nos últimos anos uma das inovações da ciência e arte de irrigar tem sido a introdução dos sistemas de irrigação localizada usando técnicas que relacionam alta-freqüência e baixo-volume de aplicação de água (e nutrientes), respeitando o ciclo de desenvolvimento da cultura. Outra modernidade corresponde ao desenvolvimento de modelos digitais, métodos e técnicas de simulação matemática e otimização dos sistemas de irrigação, o que possibilita aumenta a eficiência dos sistema de irrigação e minimiza os custos da água requerida pela cultura.

\subsection{MODELOS DE SIMULAÇÃO}

A simulação é uma técnica de modelagem utilizada para aproximar o comportamento de um sistema no computador, representando da melhor maneira possível as características desse sistema através do emprego de descrições algébricas ou matemáticas, (Yeh, 1985; Porto e Azevedo, 1997). O primeiro modelo de simulação utilizado em um sistema de reservatórios citado em literatura parece ser o estudo desenvolvido pelo U. S. Army Corps of Engineers em 1953, para a análise operacional de seis reservatórios no rio Missouri, EUA, (Yeh, 1985).

Os modelos descritivos ou de simulação são particularmente atrativos para fornecer as respostas e a performance do sistema de recursos hídricos diante de diversas estratégias operacionais, (Labadie, 1998). Além disso, fornecem a resposta do sistema para diversos dados de entrada fornecidos, incluindo regras de decisão, e permitem ao 
decisor examinar as conseqüências de vários cenários de um sistema existente ou de um novo sistema a ser implementado, (Yeh, 1985).

A simulação é diferente das técnicas de programação matemática, que encontram uma decisão ótima para a operação do sistema respeitando restrições enquanto maximizam ou minimizam algum objetivo. Um modelo de programação matemática normalmente necessita de hipóteses na estrutura do modelo e nas restrições do sistema para aplicações práticas, enquanto um modelo de simulação é mais flexível e versátil para simular as respostas do sistema. Por outro lado, a otimização implicitamente analisa todas as alternativas de decisão, enquanto a simulação está limitada a um número finito de alternativas de entrada, (Yeh, 1985).

A maioria dos modelos de simulação adotam alguma série particular de vazões afluentes como representativa de toda a série histórica. Períodos hidrológicos críticos tem sido utilizados com sucesso em projetos e estudos de simulação de reservatórios. O uso de séries geradas sinteticamente é recomendado porque, se diversas seqüências de vazões são utilizadas e cada uma delas tem a mesma probabilidade de ocorrência no período de interesse, é provável que toda a faixa de cenários futuros tenha sido explorada, (Yeh, 1985).

Um modelo de simulação de sistemas de reservatórios reproduz a performance hidrológica e, em alguns casos, a performance econômica do sistema para regras operacionais e vazões afluentes fornecidas. Os modelos são baseados no balanço de massa para reproduzir o caminhamento de água através do sistema de reservatórios, (Wurbs, 1993).

Várias estratégias podem ser adotadas na aplicação de modelos de simulação. Diversas rodadas são feitas para comparar a performance do sistema diante de configurações alternativas de reservatórios, armazenamentos, regras de operação, níveis 
de demanda e séries de vazões afluentes. A performance do sistema pode ser avaliada com a simples observação dos níveis de armazenamento, vazões efluentes, energia hidroelétrica gerada, abastecimento de água para demandas e lazer e valores dos parâmetros de qualidade da água, (Wurbs, 1993).

Diversos tipos de análises de armazenamento e descarga podem ser realizados. Os modelos de simulação devem também ter a capacidade de analisar a operação de sistemas de reservatórios utilizando medidas hidrológicas e de performance econômica, como, por exemplo, vazões firmes, confiabilidade, rendimento da geração hidroelétrica, danos causados por enchentes e benefícios econômicos associados a diversas finalidades, (Wurbs, 1993).

Com o surgimento e o rápido desenvolvimento dos computadores, as dificuldades de cálculo que existiam na aplicação de modelos de simulação em recursos hídricos vem sendo superadas. Os modelos de simulação atuais são extremamente flexíveis, detalhados e representam os sistemas em estudo com alto grau de fidelidade, (Roberto e Porto, 1999).

As incertezas associadas ao comportamento das variáveis de entrada e às demandas podem ser levadas em conta de forma implícita com o auxílio da hidrologia estocástica ou técnicas de Monte Carlo de forma geral. Esses modelos podem calcular o valor de uma função objetivo ou índices de performance solicitados pelo usuário e a não linearidade, seja da função objetivo, seja dos processos simulados geralmente não constitui grande problema (Roberto e Porto, 1999). Na Figura 2 é apresentada uma representação esquemática de um modelo de simulação. 


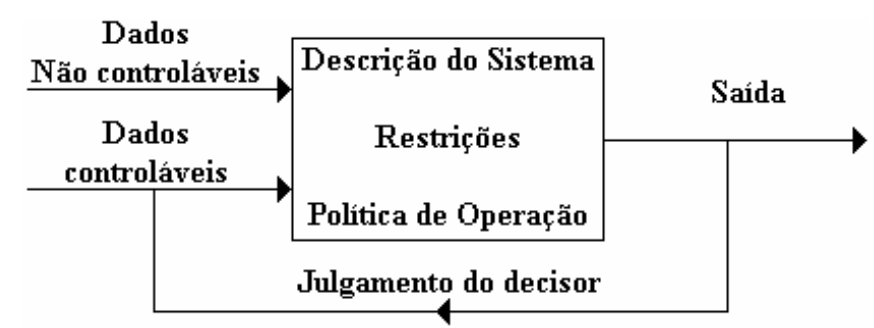

Fonte: Porto e Azevedo (1997)

\section{Figura 2. Representação esquemática de um modelo de simulação}

Os modelos de simulação são fáceis de entender e, por esta razão, são amplamente aceitos por altos níveis gerenciais, geralmente constituídos por não especialistas e até mesmo por leigos. Por estas razões esta classe de modelos é, com certeza, a mais amplamente utilizada na análise de sistemas de recursos hídricos, (Roberto e Porto, 1999). Entretanto, os modelos de simulação são incapazes de encontrar os valores das variáveis de decisão que otimizem os critérios formulados pelo usuário, o que constitui o ponto fraco da técnica. O usuário que desejar encontrar valores ótimos para as variáveis de decisão utilizando um modelo de simulação é obrigado a recorrer aos chamados métodos de força bruta (processos de tentativa e erro), que se baseiam no processamento repetitivo do modelo, de tal forma a exaurir a faixa de valores possíveis das variáveis de decisão. Mesmo assim não se pode garantir que os valores ótimos tenham sido encontrados, (Roberto e Porto, 1999).

Nos últimos anos a tendência tem sido a de incorporar esquemas de otimização aos modelos de simulação e tem se tornado comum ter algumas rotinas de otimização nos modelos de simulação. Como resultado, a distinção frequentemente feita entre simulação e otimização tende a desaparecer. Sob esse ponto de vista, a simulação é uma ótima ferramenta no estudo da operação de sistemas de recursos hídricos complexos incorporando a experiência e o julgamento do decisor no modelo. É desejável que o modelo de simulação tenha alguma capacidade de otimização para reduzir a quantidade 
de cálculos realizada até a obtenção do ótimo ou alguma resposta próxima do ótimo para o sistema de reservatórios.

\subsection{SISTEMA DE SUPORTE A DECISÕES}

À medida que as demandas de água crescem, aumentam-se os conflitos e disputas pelo recurso e os sistemas de recursos hídricos tendem a se tornar maiores e mais complexos, havendo a necessidade de planejamentos estratégicos que conciliem eficiência econômica, sustentabilidade, flexibilidade e equidade.

Em ambientes onde há escassez de recurso hídrico, o problema de alocação da água torna-se extremamente complexo e para ajudar a resolvê-lo tem sido apresentado o Sistema de Suporte a Decisões (SSD).

SSD é uma metodologia de auxílio à tomada de decisões baseada na intensa utilização de bases de dados e modelos matemáticos e também na facilidade com que propicia o diálogo entre o usuário e o computador. Esta metodologia vem sendo aplicada, com sucesso, a diversos campos da atividade humana em que o problema da decisão é muito complexo, como é o caso de gerenciamento e do planejamento de recursos hídricos.

Para Porto e Azevedo (1997) "qualquer coisa" que ajude (apoie) uma tomada de decisão pode ser considerado um SSD. Adotando uma definição mais restrita, sistemas de suporte a decisões são sistemas computacionais que tem por objetivo ajudar indivíduos que tomam decisões na solução de problemas não estruturados (ou parcialmente estruturados).

O melhor SSD não é obrigatoriamente aquele que utiliza as melhores técnicas mas o que é capaz de induzir às melhores decisões. Não tem usualmente o objetivo de 
encontrar a solução ótima, mas sim auxiliar o decisor a escolher uma alternativa satisfatória, (Porto e Azevedo, 1997).

O SSD não é construído para tomar decisões, mas, para apoiar ou assistir um indivíduo ou grupo de indivíduos na execução desta tarefa. É preciso definir quais os princípios que orientarão a escolha, seja para se chegar a uma solução "ótima" ou a uma solução "satisfatória", disposto a assumir riscos ou não. Deve-se procurar expressar as alternativas em termos monetários ou em termos de outro indicador de desempenho (por exemplo, atendimento a uma vazão de demanda com determinada garantia), (Porto e Azevedo, 1997).

De maneira geral, os atributos de um sistema de suporte a decisão estão apresentados na Figura 3.

Em um SSD deve haver uma interação entre o homem e a máquina (computador). O homem soluciona problemas a partir de dois elementos essenciais: (1) Informações: permitem conhecer uma determinada situação que requer sua atuação; e (2) Concepção intelectual do problema (modelo): quais são suas variáveis, como elas interagem etc., (Porto Azevedo, 1997). O computador, por sua vez, deve auxiliar o homem na utilização de informações e modelos.

O procedimento para se efetuar uma análise de simulação da operação de um sistema de reservatórios pode ser resumido nas seguintes etapas: (1) identificação do sistema; (2) determinação dos objetivos do estudo e definição de critérios de avaliação; (3) coleta e análise de dados do sistema; (4) formulação do modelo de simulação; (5) calibração e validação do modelo; (6) organização e execução das simulações; e (7) análise e avaliação dos resultados, (Azevedo e Porto, 2002). 


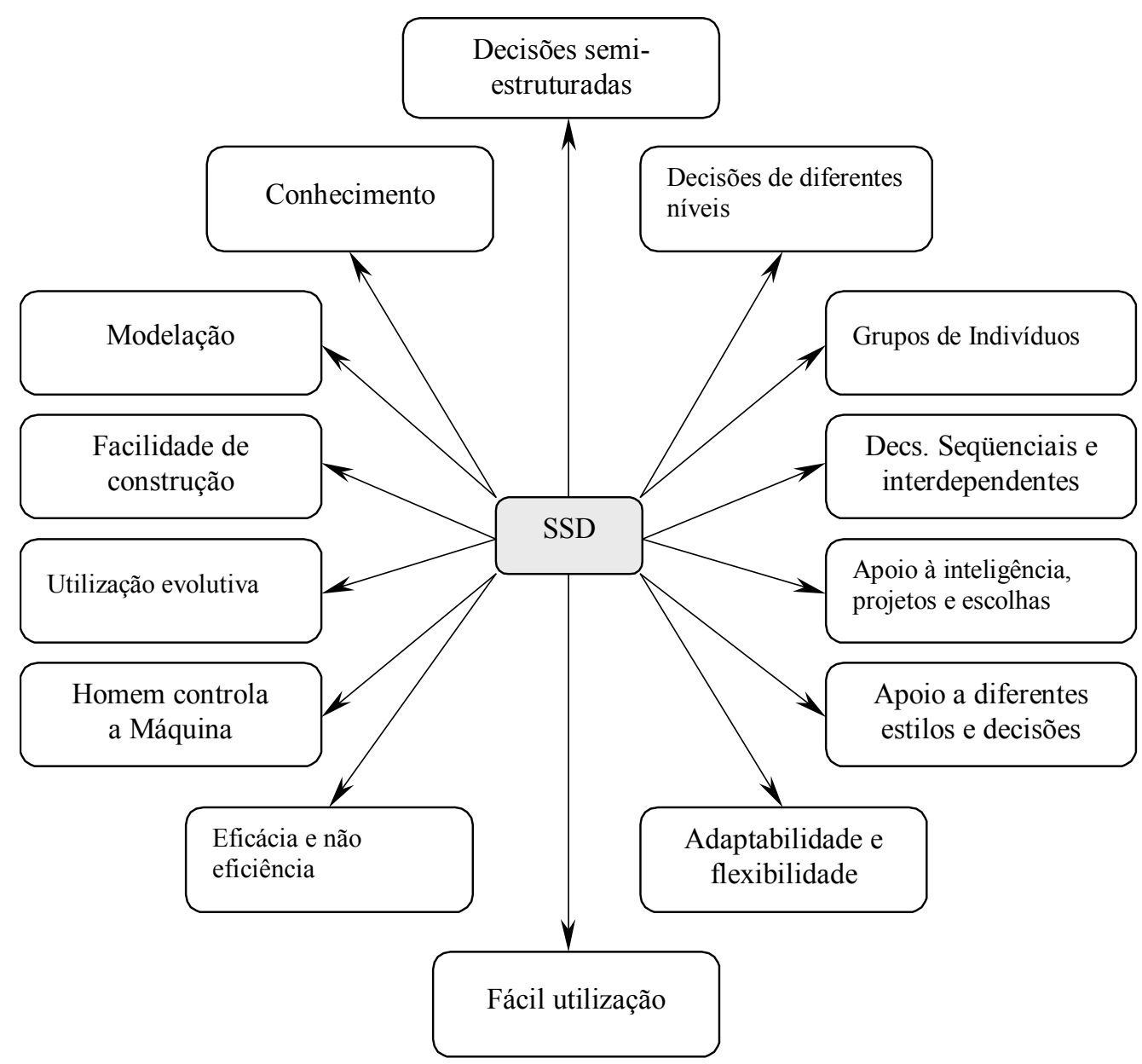

Fonte: Turban (1993) apud Porto e Azevedo (1997)

\section{Figura 3. Características de um sistema de suporte a decisão}

A tomada de decisões a respeito de sistemas de recursos hídricos deve considerar obrigatoriamente aspectos hidrológicos, ambientais, econômicos, políticos e sociais, mutáveis no tempo e associados a incertezas de difícil quantificação (Azevedo e Porto, 2002).

\subsubsection{Sistema de Suporte a Decisões para a Agricultura}

Visando a necessidade de uma utilização mais eficiente da água, em uma ação conjunta, a Secretaria de Recursos Hídricos (SRH) do Ministério do Meio Ambiente, 
dos Recursos Hídricos e da Amazônia Legal (MMA), e a Universidade Federal de Viçosa (UFV), desenvolveram um sistema informatizado especialista o Sistema de Suporte à Decisão Agrícola (SISDA), (Cardoso et al., 1997).

O SISDA é voltado ao monitoramento de áreas irrigadas visando dar sustentabilidade a irrigação em áreas agrícolas, possibilitando um uso mais eficiente dos recursos hídricos e racionalizando o uso da água em lavouras. A concepção do sistema considera três aspectos fundamentais: (1) rigor científico sem perder de vista a praticidade na utilização; (2) sistema de fácil comunicação e interação com o usuário, tanto do ponto de vista de manusear o programa quanto das informações, resultados e serviços prestados; e (3) sistema que considera o gerenciamento integrado dos recursos hídricos, com visão ampla dos aspectos água, solo, clima, planta (fitotecnia e fitopatologia), e sistema de irrigação. O SISDA foi desenvolvido com base em dois objetivos: (1) manejo; e (2) simulação, (Cardoso et al., 1997).

Antes de utilizar o sistema de manejo e simulação de irrigação o usuário deve fornecer informações básicas, compondo um cadastro do seu sistema de produção agrícola. O SISDA disponibiliza ao usuário, caso necessário, a maioria das informações externas (clima, coeficientes da planta e do solo) e exigindo dele apenas as informações inerentes a sua propriedade e à atividade a ser desenvolvida, (Cardoso et al., 1997).

A consolidação dos resultados alcançados associado a novas perspectivas criadas implicaram na incorporação de novas propostas como o desenvolvimento do SISDACafeicultura e do SISDA-Fruticultura para atender as demandas peculiares destes grupos de culturas, (Cardoso et al., 1997).

O Land and Water Development Division of FAO desenvolveu um programa de computador para o planejamento e gerenciamento da irrigação denominado 
CROPWAT. O CROPWAT é um sistema de suporte a decisão disponível na internet, cujas principais funções são: (1) calcular a evapotranspiração da cultura de referência, a exigência hídrica da cultura e a necessidade de irrigação da cultura; (2) desenvolver calendários de irrigação sob várias condições de gerenciamento e esquemas de suprimento de água; e (3) avaliar os efeitos da seca e da chuva na produção e eficiência de práticas da irrigação. O CROPWAT é uma ferramenta prática que auxilia na determinação da evapotranspiração da cultura, uso racional da água e mais especificamente nos projetos e manejos da irrigação, (Clark, 1998).

O programa consta de uma base de entrada de dados, quais sejam: (1) dados da cultura; (2) dados climatológicos da região. A base de dados climatológicos corresponde ao CLIMWAT. A programação da irrigação é feita por um balanço hídrico diário, (Clark, 1998). Os métodos de cálculos são baseados nas metodologias apresentadas nos Manuais de Irrigação e Drenagem da FAO, nº 24 (Doorenbos e Pruitt, 1977) e $\mathrm{n}^{\mathrm{o}} 33$ (Doorenbos e Kassam, 1979).

O SSD, resultado da integração do LabSid e da Superintendência de Recursos Hídricos (SRH) do Estado da Bahia, integra pela sua interface gráfica, os módulos de cálculo de demandas hídricas. A interface desenvolvida em Visual Basic utiliza componentes do software GeoMedia Professional da Intergraph Corporation, (Lisboa Neto e Porto, 2001). $\mathrm{O} \mathrm{K}_{\mathrm{c}}$, a $\mathrm{Z}_{\mathrm{r}}$, a área irrigada $\left(\mathrm{A}_{\mathrm{i}}\right)$ e a eficiência do sistema de irrigação $(\varepsilon)$ devem ser fornecidas pelo usuário numa tela de entrada de dados. Como os valores dos postos climatológicos da região estão armazenados em um banco de dados, fornecendo-se as coordenadas geográficas do local (latitude, longitude), a $\mathrm{ET}_{\mathrm{o}}$ é determinada automaticamente por interpolação. 


\subsection{MODELO DE REDE DE FLUXO}

Os modelos de rede de fluxo (MRF) misturam características dos modelos de simulação e otimização e podem incorporar as características estocásticas das vazões de entrada, (Porto e Azevedo, 1997).

Os MRF representam sistemas de recursos hídricos por uma rede formada de "nós" e "arcos". Os nós representam reservatórios, demandas, reversões, confluências, e outros pontos importantes de um sistema. Os arcos são os elos de ligação entre os nós e representam trechos de rios, adutoras, canais e outras estruturas semelhantes, (Porto e Azevedo, 1997).

Cada arco é caracterizado por três parâmetros, ou seja, os limites superior e inferior do fluxo que passa pelo arco (ex.: capacidade máxima e mínima de um canal) e um "custo" por unidade de fluxo que transita pelo arco. Os custos podem ser positivos ou negativos, ou seja, podem representar uma penalidade (no caso de custo positivo), ou um prêmio (custo negativo), influindo na quantidade de fluxo que irá passar pelo arco e fornecendo um mecanismo para expressar as prioridades relativas utilizadas na definição das regras operacionais, (Wurbs, 1993). Este custo não significa, obrigatoriamente, um valor monetário, podendo representar preferências estabelecidas pelo usuário. As capacidades máxima e mínima de cada arco podem ser fixas para todo o período de simulação ou podem variar ao longo do tempo, (Roberto e Porto, 1999). Na Figura 4 é apresentada uma representação de um sistema como uma rede de fluxo. 


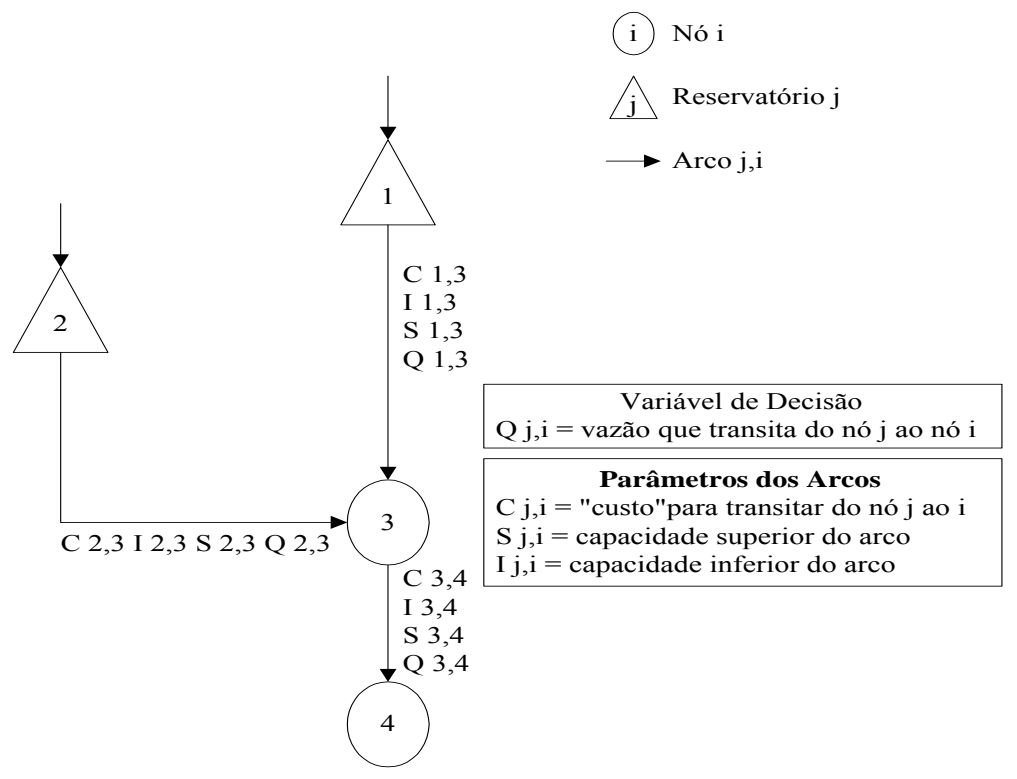

Fonte: Porto e Azevedo (1997)

\section{Figura 4. Representação de um sistema como uma rede de fluxo}

Em um modelo de rede de fluxo, cada um dos elementos (nós e arcos) deve conter as características da estrutura que o mesmo está representando. Algumas dessas características, especificadas por tipo de elemento, são: (1) reservatórios: volumes máximos e mínimos, curva cota-área-volume, níveis de armazenamento desejados, série de vazões afluentes, taxa de evaporação; (2) demandas: valor e distribuição temporal da demanda, prioridade de atendimento, retornos; e (3) arcos: capacidades máximas e mínimas, custo, perdas por infiltração, (Roberto e Porto, 1999).

Quando um modelo de rede de fluxo é aplicado na análise de sistemas de recursos hídricos, o algoritmo do modelo busca minimizar o custo total da rede que representa o problema em estudo, (Roberto e Porto, 1999).

Cada nó deve conter as características da estrutura que representa. Por exemplo se o nó “ $i$ ” estiver representando um reservatório, o analista deve fornecer a relação cota-área-volume, os volumes máximos e mínimos de armazenamento, os níveis de 
armazenamento que se deseja atingir, o percentual de perdas por infiltração, a taxa de evaporação, etc, (Roberto e Porto, 1999).

Entre as características que tornam atrativa a utilização dessa classe de modelos para análise de sistemas de recursos hídricos, destacam-se as seguintes, (Porto e Azevedo 1997): (1) na grande maioria dos casos, pode-se representar um sistema de recursos hídricos de forma adequada, realista, flexível e bastante clara como uma rede composta de nós e arcos; (2) esses modelos possuem a flexibilidade típica dos modelos de simulação, ou seja, podem representar o comportamento de um sistema de recursos hídricos de forma bastante completa; e (3) MRF incluem também algoritmos de otimização que minimizam o custo total da rede, ou seja, determinam os fluxos em todos os arcos de tal forma que a somatória de todos os custos seja mínima.

Os MRF podem modelar também as interações entre águas superficiais e subterrâneas como, por exemplo, a diminuição das vazões dos rios devido ao bombeamento de aqǘ́feros ou o retorno de vazões aos cursos de água através do subsolo, (Roberto e Porto, 1999).

Os algoritmos de otimização de redes de fluxo costumam ser altamente eficientes (ordens de magnitude mais rápido que o Simplex) o que significa que sistemas extremamente grandes e complexos podem ser tratados em microcomputadores comuns.

Embora modelos de rede sejam extremamente vantajosos, eles apresentam limitações. Os algoritmos de rede de fluxo otimizam apenas sistemas lineares, uma vez que aplicação de técnicas não lineares ainda não constitui tecnologia madura. A função objetivo é pré-definida e portanto não pode ser livremente especificada pelo usuário. 
Estes algoritmos admitem também apenas os dois tipos de restrições acima citados. Como os sistemas de recursos hídricos costumam ser altamente condicionados, em alguns casos pode haver necessidade de adoção de artifícios para que seja obtida representação adequada, (Roberto e Porto, 1999).

Geralmente a otimização dos MRF é executada a cada intervalo de tempo, de forma seqüencial. O intervalo mensal é usualmente o mais utilizado para os problemas de planejamento e gerenciamento de recursos hídricos, embora a técnica seja aplicável a intervalos mais curtos. Deve ser enfatizado, entretanto, que na maioria dos MRF a otimização efetuada não é dinâmica, ou seja, não se garante o ótimo global para um período de “ $n$ ” intervalos de tempo à frente, (Roberto e Porto, 1999).

As perdas de condução em canais e evaporação em reservatórios representam um desvio da condicionante que impõe o balanço de massas. Tal fato não representa entretanto grande problema uma vez que estas perdas podem ser calculadas por processos iterativos sem grande perda de eficiência, (Roberto e Porto, 1999).

Em resumo, os modelos de rede de fluxo reúnem características das técnicas de simulação e otimização. As características de flexibilidade e adaptabilidade dos modelos de simulação são quase que integralmente preservadas nos MRF, ao mesmo tempo que o algoritmo de otimização, apesar das limitações citadas, libera o usuário dos trabalhosos e demorados processos de tentativa e erro, (Roberto e Porto, 1999).

\subsubsection{ModSim}

O ModSim é um modelo de rede de fluxo de caráter geral e adaptável a diversos tipos de problemas. Assim, a maior parte das configurações e estruturas operacionais 
das bacias hidrográficas pode ser representada por meio da especificação de dados de entrada apropriados.

Uma das principais características do ModSim é o fato de que o modelo incorpora automaticamente uma série de funções que são comuns na simulação de bacias hidrográficas sem que o usuário tenha que se preocupar em programá-las. Entre elas as mais importantes são, (Roberto e Porto, 1999): (1) os usuários podem colocar quantos nós de demanda forem necessários para levar em conta as demandas na bacia (consuntivas ou não). O modelo atenderá a estas demandas de acordo com um valor de prioridade atribuída pelo usuário, que pode variar de 1 a 99, sendo o valor 1 a maior prioridade. $\mathrm{Na}$ realidade as prioridades $(\mathrm{P})$ e os custos $(\mathrm{C})$ estão relacionados de forma biunívoca $(\mathrm{C}=10 \mathrm{P}-1000)$, o que significa que os valores de $\mathrm{C}$ que representam prioridades são sempre negativos. Portanto, ao atender uma prioridade o modelo estará diminuindo os custos da rede de um valor C por unidade de vazão fornecida; (2) a operação dos reservatórios é feita utilizando-se o conceito de volume meta ou nível meta, ao qual se atribui uma prioridade. Desta forma, sempre que o volume armazenado for menor que o volume meta, o reservatório guardará água desde que as outras prioridades da rede sejam menores. O volume armazenado acima do nível meta tem custo zero, ou seja, é livre para atender a quaisquer demandas por menores que sejam suas prioridades; (3) as perdas por evaporação dos reservatórios são levadas em conta por meio de processo iterativo; (4) o modelo calcula a produção de energia elétrica desde que sejam fornecidas as características da usina; (5) o modelo faz o balanço água superficial - água subterrânea, desde que sejam fornecidas as características do aqüífero.

O ModSim realiza uma otimização em rede para atender metas operacionais realizada de modo seqüencial em cada intervalo de tempo, em vez da forma plenamente 
dinâmica. O modelo executa a otimização seqüencial sem previsão e pode ser tratado como um modelo de simulação mediante o qual centenas ou milhares de anos de dados históricos ou sintéticos de vazões podem ser utilizados, (Azevedo e Porto, 2002).

Os atributos mais importantes do ModSim são: (1) faz uma simulação de rede de fluxo de volume armazenados em reservatórios e da distribuição de vazões em um sistema complexo de recursos hídricos em uma bacia hidrográfica; (2) inclui a capacidade de otimizar a operação de sistemas mediante a utilização de um algoritmo de rede de fluxo, o "out-of-kilter" (mais detalhes em Azevedo e Porto, 2002); e (3) o modelo pode ser usado para formulação de diretrizes operacionais de curto prazo (semanal) ou a longo prazo (sazonal ou plurianual).

Além de ser um instrumento de gerenciamento, o ModSim também pode ser usado para o planejamento, para a análise do impacto de propostas alternativas para a implantação de projetos de aproveitamento de recursos hídricos. O modelo também pode servir no processo de seleção inicial de alternativas com base na análise econômica, em um nível simplificado, por meio da inclusão direta de dados de custos e benefícios em lugar da especificação relativa de prioridades.

Deve-se notar que, internamente, os cálculos do ModSim envolvem números inteiros, o que favorece muito a velocidade de processamento do modelo. Além disso, o algoritmo Out-of-Kilter tem a vantagem de não necessitar de uma solução inicial viável, embora o balanço de massas deva ser satisfeito em toda a rede. Isto é conseguido facilmente, começando com fluxos iguais a zero em cada arco, no procedimento de solução, (Azevedo e Porto, 2002). 
Foi desenvolvido no Laboratório de Sistemas de Suporte a Decisões em Engenharia de Recursos Hídricos e Ambiental (Labsid) uma nova versão do ModSim chamada ModSimLS, (Roberto e Porto, 2001).

\subsubsection{Interfaces Gráficas do ModSim}

O Labsid da Escola Politécnica da USP, desenvolveu interfaces gráficas para facilitar a aplicação do ModSim. As interfaces foram desenvolvidas no formato típico de um sistema de suporte a decisões, ou seja, estão presentes em sua estrutura um módulo de diálogo, uma base de dados e uma base de modelos.

Acompanhando a primeira versão (ModSim Fortran) vem a chamada de ModSimP32 (Roberto e Porto, 1999) e Roberto (2002). Acompanhando a versão do ModSimLS tem-se a interface ModSimLS (Roberto e Porto, 2001). Na aparência, a versão ModSimLS é bastante semelhante ao modelo ModSimP32 (Roberto e Porto, 1999). Entretanto, as duas versões são completamente diferentes quando se considera o funcionamento e o armazenamento/leitura de dados e resultados. O ModSimP32 funciona com arquivos próprios e é completamente responsável pela criação e atualização desses arquivos. Já o ModSimLS aproveita a estrutura e a funcionalidade possibilitada pela utilização de arquivos em formato de Banco de Dados.

Desenvolvido a partir do sistema ModSimLS, o AcquaNet é um sistema que permite a utilização integrada de diversos tipos de cálculos, usuais na área de Recursos Hídricos. Inicialmente o AcquaNet está operando com um único modelo, destinado a cálculos de alocação de água, o AlocaLS. Estão em implementação modelos para 
integração quantidade-qualidade produção de energia elétrica e outorgas, (Roberto, 2002). 


\section{METODOLOGIA}

Os aspectos agronômicos básicos necessários para a elaboração de um projeto de irrigação se resumem em questões como a determinação da quantidade de água útil armazenada pelo solo, e a determinação das necessidades hídricas das plantas necessárias para o pleno desenvolvimento da cultura. A quantidade de água armazenada pelo solo depende basicamente das características físicas e hídricas do solo, como também do tipo de cultura a implantar. Por sua vez, as necessidades hídricas das plantas dependem da cultura e das condições climáticas da região. O conhecimento dessas duas questões permite a determinação da freqüência de aplicação das sucessivas dotações ou lâminas de irrigação ao terreno.

O solo armazena uma quantidade limitada de água, sendo somente parte desta, disponível para as plantas. Assim, para que o manejo da irrigação se proceda dentro de um critério racional, é necessário o controle da umidade do solo durante todo o ciclo da cultura para, deste modo, determinar o momento da irrigação e a quantidade de água a ser aplicada. Com este propósito é necessário o conhecimento prévio de uma série de parâmetros relacionados ao solo, à planta, à água e ao clima.

\subsection{CULTURAS}

Sendo o enfoque desse trabalho a irrigação e o objetivo a que ela se propõe, que é o de abastecer as plantas de água, à medida que elas necessitam, visando a quantidade e qualidade da produção, partiu-se do princípio que as culturas selecionadas e assentadas na região são as mais apropriadas para o clima e o solo a que se referem. 
Depois de identificadas as principais culturas, foram levantados os seguintes dados:

- necessidades hídricas da cultura;

- suprimento de água e rendimento da cultura;

- capacidade de retirada de água pela cultura;

- calendário de irrigação.

\subsubsection{Profundidade Efetiva do Sistema Radicular}

Para cada tipo de cultura, a densidade do sistema radicular, em geral, aumenta conforme avança a fase de crescimento vegetativo da planta, até alcançar uma profundidade máxima no solo. No entanto, as raízes se distribuem de forma não uniforme no solo e se concentram na sua grande maioria na metade superior do solo. A $\mathrm{Z}_{\mathrm{r}}$ representa portanto a profundidade do sistema radicular no solo, onde se concentra em torno de $80 \%$ das raízes da cultura. Esta profundidade efetiva determina a espessura da camada de solo, que é utilizada no cálculo da lâmina de água nos projetos dos sistemas de irrigação.

A $Z_{r}$ depende fundamentalmente do tipo de cultura e das condições do solo, tais valores encontram-se tabelados. Neste estudo utilizou-se os valores que constam na Tabela 1 no ANEXO. 


\subsection{CLIMA}

\subsubsection{Evapotranspiração de Referência}

Caso os dados da $\mathrm{ET}_{\mathrm{o}}$ não estejam disponíveis, pode-se recorrer aos métodos indiretos de determinação de $\mathrm{ET}_{0}$. $\mathrm{O}$ método de cálculo selecionado vai depender dos dados meteorológicos existentes.

Os métodos mais utilizados e recomendados pela FAO, por intermédio de seu Grupo de Exigência de Água pelas Culturas, podem ser encontrados em Doorenbos e Kassam (1974) e Telles (1996).

\subsubsection{Evapotranspiração Potencial}

Os dados meteorológicos utilizados para o cálculo da $\mathrm{ET}_{\mathrm{p}}$ devem ser coletados, preferencialmente, em estações situadas dentro de da área agrícola (irrigada) que se deseja analisar. Quando se coletam os dados em estações situadas em áreas secas, desnudas, os valores calculados da $\mathrm{ET}_{\mathrm{p}}$ devem ser corrigidos, visto que os dados não representam os diferentes micro-climas que se encontram dentro dos projetos de irrigação. Nas zonas áridas e semi-áridas com ventos moderados, $\mathrm{ET}_{\mathrm{p}}$ pode necessitar de um ajuste negativo de aproximadamente 20 a 25\% (Bernardo, 1995). 


\subsubsection{Coeficiente de Cultura}

Quando o suprimento de água atende plenamente as necessidades hídricas da cultura $\mathrm{ET}_{\mathrm{p}}$ é relacionada com $\mathrm{ET}_{\mathrm{o}}$ através dos $\mathrm{K}_{\mathrm{c}}$, sendo determinada, para um período de 30 dias, de acordo com a equação:

$$
\mathrm{ET}_{\mathrm{p}}=\mathrm{K}_{\mathrm{c}} \cdot \mathrm{ET}_{\mathrm{o}}
$$

em que:

- $\mathrm{ET}_{\mathrm{p}}=$ evapotranspiração potencial $[\mathrm{mm} / \mathrm{mês}] ;$

- $\mathrm{K}_{\mathrm{c}}=$ coeficiente de cultura (Tabela 2 no ANEXO);

- $\mathrm{ET}_{\mathrm{o}}=$ evapotranspiração de referência $[\mathrm{mm} / \mathrm{mês}]$;

Pelo fato do ModSimLS trabalhar em base mensal, para os períodos de duração dos estádios de desenvolvimento do cultivo menores que 30 dias, utilizou-se o valor médio de $\mathrm{K}_{\mathrm{c}}$, ou seja:

$$
\mathrm{K}_{\mathrm{c}}=\frac{\left(\sum_{\mathrm{i}=1}^{\mathrm{n}} \mathrm{K}_{\mathrm{ci}}\right)}{\mathrm{n}}
$$

em que:

- $\mathrm{K}_{\mathrm{ci}}=$ coeficiente de cultura para cada período de crescimento (Tabela 2 no ANEXO);

- i = período de crescimento específico;

- $\mathrm{n}=$ período de crescimento total. 


\subsubsection{Evapotranspiração Real}

À medida que o solo perde a umidade a $\mathrm{ET}_{\mathrm{a}}$ apresenta valores abaixo da $\mathrm{ET}_{\mathrm{p}}$, a partir de determinado teor de umidade do solo. Se houver água disponível no solo e o fluxo de água do solo para a planta atender à demanda atmosférica, $\mathrm{ET}_{\mathrm{a}}=\mathrm{ET}_{\mathrm{p}}$, se houver restrição de água no solo e a demanda atmosférica não for atendida, $\mathrm{ET}_{\mathrm{a}}<\mathrm{ET}_{\mathrm{p}}$. Partindo dessa afirmação, optou-se por determinar $\mathrm{ET}_{\mathrm{a}}$ em função da umidade do solo. $\mathrm{A} \mathrm{ET}_{\mathrm{a}}$ e $\mathrm{ET}_{\mathrm{p}}$ foram relacionadas a partir do coeficiente relativo à umidade do solo $\left(\mathrm{K}_{\mathrm{s}}\right)$, de acordo com a equação.

$$
\mathrm{ET}_{\mathrm{a}}=\mathrm{K}_{\mathrm{s}} \cdot \mathrm{ET}_{\mathrm{p}}
$$

em que:

- $\mathrm{ET}_{\mathrm{a}}=$ evapotranspiração real da cultura $[\mathrm{mm} / \mathrm{mês}]$;

- $\mathrm{ET}_{\mathrm{p}}=$ evapotranspiração potencial da cultura [mm/mês], Equação 1;

- $\mathrm{K}_{\mathrm{s}}=$ coeficiente relativo a umidade do solo [adimensional].

$\mathrm{K}_{\mathrm{s}}$ pode ser determinado pela equação em que a umidade do solo decresce exponencialmente, ou seja (Bernardo, 1995):

$$
\mathrm{K}_{\mathrm{s}}=\frac{\ln (\mathrm{UA}-\mathrm{PMP}+1)}{\ln (\mathrm{CC}-\mathrm{PMP}+1)}=\frac{\ln (\mathrm{CAA}+1)}{\ln (\mathrm{CTA}+1)}
$$

em que:

- UA = umidade atual de água no solo [mm];

- PMP = ponto de murcha permanente $[\mathrm{mm}]$;

- $\mathrm{CC}=$ capacidade de campo $[\mathrm{mm}]$ 
- $\mathrm{CAA}=$ capacidade atual de água no solo [mm], item 3.4.3;

- CTA = capacidade total de água no solo [mm], Equação 7.

Para o caso em que se deseja manter o solo com umidade máxima, ou seja, UA $=\mathrm{CC}, \mathrm{a} \mathrm{CAA}=\mathrm{CTA}$ e $\mathrm{K}_{\mathrm{s}}=1$.

\subsubsection{Precipitação Efetiva}

$\mathrm{O}$ método utilizado neste trabalho, na determinação da $\mathrm{PP}_{\mathrm{e}}$, foi o Método do Serviço de Conservação do Solo dos EUA. Este método estima a $\mathrm{PP}_{\mathrm{e}}$ média mensal em função dos valores regionais da PP média mensal e da $\mathrm{ET}_{\mathrm{p}}$, para as condições em que a CTA seja igual a $75 \mathrm{~mm}$ (Tabela 3 no ANEXO). Para valores da CTA diferentes de 75 mm a PPe é multiplicada por um fator de correção (Tabela 4 no ANEXO).

Deve ser observado que a quantidade de PP realmente efetiva dependerá do teor de umidade do solo imediatamente anterior à precipitação. Quando a chuva ocorrer após uma irrigação, praticamente não haverá efetividade; quando ocorrer poucos dias após a irrigação, a quantidade realmente efetiva será a lâmina que o solo poderá reter até que o seu teor de umidade chegue à CC e não a quantidade dada pela Tabela 3 no ANEXO.

Apesar de ser recomendado que o período em que os dados de $\mathrm{PP}_{\mathrm{e}}$ são agrupados sejam, para regiões tropicais e subtropicais, de 5, 10 ou 15 dias, neste trabalho, considerou-se o intervalo mensal pelo fato do ModSimLS trabalhar em base mensal.

\subsection{SOLO}


A freqüência de irrigação requerida para a cultura, sob determinado clima, depende principalmente da quantidade de água que pode ser "armazenada" no solo após uma irrigação.

Para o bom desenvolvimento da planta é necessário que o solo não alcance um limite crítico que é superior ao conteúdo de água equivalente ao PMP. Entre este limite, no qual as plantas começam a ressentir o déficit hídrico, e o PMP, as raízes ainda conseguem extrair água do solo, porém o crescimento vegetativo é sensivelmente prejudicado, pois a facilidade com que as raízes das plantas absorvem água também diminui com o conteúdo de água.

A relação entre o conteúdo de umidade do solo nesse limite crítico e sua DTA denomina-se déficit hídrico tolerável. O déficit hídrico tolerável depende do tipo de cultura, do tipo de solo e da ET.

Quando o solo dispõe de água em abundância, a ET é mantida numa taxa potencial, determinada pelas condições meteorológicas. À medida que a umidade do solo começa a diminuir, a taxa de evapotranspiração se torna mais baixa que a potencial, prevalecendo ainda as condições meteorológicas com participação das forças de retenção de água no solo. Prosseguindo o secamento do solo, começa a haver predominância das características de retenção de umidade do solo.

\subsubsection{Disponibilidade total de água do solo}


Determinou-se a água disponível do solo a partir do conhecimento dos teores de umidade correspondente à $\mathrm{CC}$ e ao $\mathrm{PMP}$, as propriedades físicas do solo e a profundidade do solo (igual a $Z_{r}$ ). A Tabela 2 no ANEXO apresenta os valores de $Z_{r}$.

O cálculo da DTA depende da qualidade dos dados de solo disponíveis, ou seja, se os valores da CC e do PMP são fornecidos em percentagem em peso do solo (\%peso) ou percentagem em volume do solo (\%volume).

\section{a) Percentagem em Peso do Solo}

Quando os dados de solo estavam disponíveis em \%peso, a DTA foi calculada pela equação:

$$
\mathrm{DTA}=\frac{1}{10}(\mathrm{CC}-\mathrm{PM}) \mathrm{D}_{\mathrm{a}}
$$

em que:

- DTA = disponibilidade total de água no solo $[\mathrm{mm} / \mathrm{cm}]$;

- CC = conteúdo da umidade á capacidade de campo [\%peso];

- PMP = conteúdo da umidade correspondente ao ponto de murcha [\%peso];

- $\mathrm{D}_{\mathrm{a}}=$ massa específica aparente do solo, relativa à densidade da água [adimensional].

\section{b) Percentagem em Volume do Solo}


Quando os dados de solo estavam disponíveis em \%volume, DTA foi calculada pela equação:

$$
\mathrm{DTA}=\frac{1}{10}(\mathrm{CC}-\mathrm{PM})
$$

em que:

- DTA = disponibilidade total de água no solo $[\mathrm{mm} / \mathrm{cm}]$;

- $\mathrm{CC}=$ conteúdo da umidade á capacidade de campo [\%volume];

- PMP = conteúdo da umidade correspondente ao ponto de murcha [\%volume].

As características associadas à retenção e a disponibilidade de água $(\mathrm{CC}-0,33$ atm e PMP - 15 atm) das classes de solo devem estar de acordo com as características das áreas irrigáveis da bacia em estudo. Caso os dados não estejam disponíveis pode-se recorrer a uma extrapolação.

\subsubsection{Capacidade Total de Água no Solo}

Tanto a quantidade de água de chuva como de irrigação só devem ser consideradas disponíveis para a cultura no perfil do solo que esteja ocupada pelo seu sistema radicular. Sendo assim a capacidade total de água do solo (CTA) foi calculada por:

$$
\mathrm{CTA}=\mathrm{DTA} \cdot \mathrm{Z}_{\mathrm{r}}
$$

em que : 
- CTA = capacidade total de água disponível do solo [mm];

- DTA = disponibilidade total de água no solo [mm/cm], Equações 5 ou 6 ;

- $\mathrm{Z}_{\mathrm{r}}=$ profundidade efetiva do sistema radicular [cm], Tabela 2 no ANEXO.

\subsubsection{Capacidade Real de Água do Solo}

Em um manejo adequado de irrigação nunca se deve permitir que o teor de umidade do solo atinja o PMP, isto é, deve-se somente usar entre duas irrigações sucessivas, uma fração da capacidade total de água do solo, ou seja:

$$
\mathrm{CRA}=\mathrm{CTA} \cdot \mathrm{f}
$$

em que:

- CRA = capacidade real de água no solo $[\mathrm{mm}]$;

- CTA = capacidade total de água no solo [mm], Equações 5 ou 6;

- $\mathrm{f}=$ fração de esgotamento de água disponível no solo. A escolha de f depende da cultura e da $\mathrm{ET}_{\mathrm{p}}$, Tabelas 5 e 6 no ANEXO, respectivamente.

\subsection{BALANÇO HÍDRICO NO SOLO}

As relações existentes entre cultura, clima, água e solo são complexas envolvendo muitos processos biológicos, fisiológicos, físicos e químicos. Grande quantidade de informações de pesquisa sobre esses processos em relação à água, encontra-se disponível; contudo, para a sua aplicação prática, esse conhecimento deve 
ser reduzido a um número manejável de componentes principais para permitir uma análise significativa do efeito da água sobre a cultura, a nível de campo.

A finalidade básica da irrigação é proporcionar água às culturas de maneira a atender às exigências hídricas durante todo o seu ciclo, possibilitando alta produtividade. A quantidade de água necessária às culturas é função da espécie cultivada, do local do cultivo, do estádio de desenvolvimento da cultura, do tipo de solo e da época de plantio.

\subsubsection{Irrigação Real Necessária}

A irrigação real necessária (IRN) é a quantidade real de água necessária a ser aplicada a cultura por irrigação. Considerando-se dois casos:

a) Com irrigação total: quando toda água necessária à cultura é suprida pela irrigação. Nesse caso utilizou-se:

$$
\mathrm{IRN} \leq \mathrm{CRA}
$$

em que:

- IRN = irrigação real necessária [mm];

- CRA = capacidade real de água no solo [mm], Equação 8.

b) Com irrigação suplementar: quando parte da água necessária à cultura for suprida pela irrigação e a outra parte pela precipitação efetiva. Neste caso.

$$
\mathrm{IRN} \leq \mathrm{CRA}-\mathrm{PP}_{\mathrm{e}}-\mathrm{AS}
$$


em que:

- IRN = irrigação real necessária [mm];

- CRA = capacidade real de água no solo [mm], Equação 8.

- $\mathrm{PP}_{\mathrm{e}}=$ precipitação efetiva [mm], Tabelas 3 e 4 no ANEXO;

- AS = água no solo antes da irrigação [mm], deve ser de conhecimento do usuário.

\subsubsection{Irrigação Total Necessária}

São comuns os vazamentos de água nas tubulações e nos canais de alimentação e de distribuição de água. A manutenção, quando existe, é praticada desordenadamente. Os valores médios de $\varepsilon$ variam consideravelmente em função de diversos fatores, conforme pode ser verificado na Tabela 8 no ANEXO.

Definiu-se a irrigação total necessária (ITN) como a quantidade total de água a ser suprida por irrigação, admitindo-se as perdas existentes no sistema de irrigação, ou seja:

$$
\mathrm{ITN}=\frac{\mathrm{IRN}}{\varepsilon}
$$

em que:

- ITN = quantidade total de irrigação necessária [mm];

- IRN = quantidade real de irrigação necessária [mm], Equações 9 ou 10, dependendo se é irrigação total ou suplementar, respectivamente; 
- $\varepsilon=$ eficiência de aplicação da irrigação [fração], Tabela 8 no ANEXO.

\subsubsection{Determinação do Calendário de Irrigação}

O método utilizado neste trabalho foi baseado na determinação da $\mathrm{ET}_{\mathrm{a}}$. Neste método é definida a IRN para cada estádio de desenvolvimento da cultura. Através do cálculo diário da $\mathrm{ET}_{\mathrm{a}}$, verificou-se quando aquela lâmina foi consumida pela planta e aplicou-se nova irrigação.

\subsubsection{Procedimento de Cálculo}

\section{a) Dados necessários:}

- $\mathrm{ET}_{\mathrm{o}}$ : para o caso de dados diários, dividir o total mensal pelo número de dias do mês;

- $\mathrm{K}_{\mathrm{c}}$ : Tabela 2 no ANEXO;

- CC: característica do solo da região;

- PMP: característica do solo da região;

- $Z_{\mathrm{r}}$ : Tabela 2 no ANEXO;

- f: Tabela 6 no ANEXO;

- $\varepsilon$ : Tabela 8 no ANEXO. 


\section{b) Dados calculados:}

- ET : Equação 1, para o caso de dados diários dividir o total mensal pelo número de dias do mês;

- $\mathrm{ET}_{\mathrm{a}}$ : Equação 3, para o caso de dados diários dividir o total mensal pelo número de dias do mês;

- $\mathrm{K}_{\mathrm{s}}$ : Equação 3;

- DTA: Equações 5 ou 6;

- CTA: Equação 7;

- CRA: Equação 8;

- IRN: Equações 9 ou 10, dependendo se é irrigação total ou suplementar, respectivamente;

- ITN: Equação 11.

c) Seqüência:

- Primeiro dia: 
- irrigar o solo até a CC;

- calcular a $\mathrm{ET}_{\mathrm{p}}$ (Equação 1). Para $\mathrm{K}_{\mathrm{s}}=1, \mathrm{ET}_{\mathrm{a}}=\mathrm{ET}_{\mathrm{p}}$.

- Segundo dia:

- fazer o balanço hídrico do solo com os dados do dia anterior: CAA = $\mathrm{CTA}-\mathrm{ET}_{\mathrm{a}}+\mathrm{PP}_{\mathrm{e}}$, caso não tenha ocorrido nenhuma chuva: $\mathrm{PP}_{\mathrm{e}}=0$;

- calcular o novo $K_{s}($ Equação 4);

- calcular a nova $\mathrm{ET}_{\mathrm{a}}$ (Equação 3);

\section{- Dias subseqüentes:}

- seguir o mesmo procedimento do segundo dia obedecendo ao limite preestabelecido da disponibilidade total de água no solo, ou seja, (IRN $\leq$ CRA). Caso a relação não seja cumprida, deve-se irrigar na noite do mesmo dia ou na manhã do dia seguinte, sendo: IRN = CTA - CAA;

- calcular a ITN (Equação 11);

- irrigar o solo com ITN. Caso a água disponível seja suficiente CAA = CTA, caso não, abastecer o solo com o máximo de água possível a fim de garantir uma produção satisfatória;

- recomeçar os cálculos como no primeiro dia.

No final de cada mês contar quantas irrigações foram feitas, podendo-se assim quantificar o montante total de água. 
$\mathrm{ITM}=\sum_{\mathrm{i}}^{\mathrm{n}} \mathrm{ITN}_{\mathrm{i}}$

em que:

- ITM = irrigação total no mês [mm/mês];

- $\mathrm{n}$ = número de irrigações no mês;

- ITN $_{\mathrm{i}}$ - irrigação total necessária no dia i [mm/dia].

\subsubsection{Resposta da Cultura ao Suprimento Hídrico}

A indicação sobre o $Y_{p}$ corresponde aos máximos obtidos nas condições agrícolas do momento com alto nível de manejo de cultura e água.

A maioria das culturas apresenta variedades que diferem tanto quanto as necessidades climáticas gerais específicas como em relação à duração do ciclo fenológico total (desde a semeadura até a colheita). Essa variação permite que a cultura se adapte a uma ampla faixa de condições climáticas e ao período de tempo necessário e disponível para a produção.

Além da necessidade climática, o período de crescimento disponível é determinado pela duração de um suprimento garantido de água de boa qualidade. Neste caso, as demandas de água devem estar sincronizadas com sua disponibilidade, como por exemplo: uma variação da vazão do rio e a descarga de uma barragem. Para algumas culturas, o período total de crescimento necessário para uma $Y_{\mathrm{p}}$ pode ser manipulado mediante o nível de suprimento de água. Para outras culturas, o período 
necessário para $\mathrm{Y}_{\mathrm{p}}$ deve ser manejado também mediante o nível de suprimento de água, durante determinado estádio de crescimento.

A relação entre o rendimento da cultura e o suprimento de água pode ser determinada quando se puder quantificar, de um lado, as necessidades hídricas da cultura e os efeitos hídricos e, de outro, os rendimentos máximo e real da cultura. Os déficits hídricos nas culturas e o conseqüente estresse hídrico na planta, têm certos efeitos sobre a evapotranspiração e o rendimento da cultura.

O efeito do estresse hídrico na planta foi quantificado através da relação entre a queda de rendimento relativo $\left(1-\mathrm{Y}_{\mathrm{a}} / \mathrm{Y}_{\mathrm{p}}\right)$ e o déficit de evapotranspiração relativa $(1-$ $\left.\mathrm{ET}_{\mathrm{a}} / \mathrm{ET}_{\mathrm{p}}\right)$, dada pelo coeficiente de resposta da cultura $\left(\mathrm{K}_{\mathrm{y}}\right)$ obtido empiricamente, ou seja:

$$
\left(1-\mathrm{Y}_{\mathrm{a}} / \mathrm{Y}_{\mathrm{p}}\right)=\mathrm{K}_{\mathrm{y}}\left(1-\mathrm{ET}_{\mathrm{a}} / \mathrm{ET}_{\mathrm{p}}\right)
$$

em que:

- $\mathrm{Y}_{\mathrm{a}}=$ rendimento real obtido;

- $\mathrm{Y}_{\mathrm{p}}=$ rendimento potencial ou máximo obtido;

- $\mathrm{K}_{\mathrm{y}}=$ coeficiente de resposta da cultura, Tabela 8 no ANEXO;

- $\mathrm{ET}_{\mathrm{a}}=$ evapotranspiração atual, Equação 3;

- $\mathrm{ET}_{\mathrm{p}}=$ evapotranspiração potencial, Equação 1.

Como não se dispõem de valores padrões de referências para comparação, supôs-se que a confiabilidade dos valores de $\mathrm{K}_{\mathrm{y}}$ apresentados na Tabela 8 no ANEXO é semelhante ao procedente da análise dos resultados experimentais de campo (Doorenbos e Kassam, 1979). 


\subsubsection{Procedimento de Cálculo}

a) Dados Necessários

- ET : Equação 1;

- ETa: Equação 3.

\section{b) Dados calculados}

- $\mathrm{ET}_{\mathrm{a}} / \mathrm{ET}_{\mathrm{p}}$

- $\mathrm{K}_{\mathrm{y}}$ : Tabela 8 no ANEXO;

$-Y_{a} / Y_{p}$

c) Seqüência

Para o período total de crescimento, calcular:

- ITN; Equação 11;

- ETp : Equação 1;

- escolher adequadamente o $\mathrm{K}_{\mathrm{y}}$ (Tabela 8 no ANEXO); 
- $\mathrm{Y}_{\mathrm{a}} / \mathrm{Y}_{\mathrm{p}}$ : Equação 13.

\subsubsection{Produção}

\subsubsection{Procedimento de Cálculo}

a) Dados Necessários

- ETp: Equação 1;

- ETa: Equação 3.

b) Dados Calculados

- $\mathrm{ET}_{\mathrm{a}} / \mathrm{ET}_{\mathrm{p}}$

- $\mathrm{K}_{\mathrm{y}}$ : Tabela 8 no ANEXO.

c) Seqüência

Para o período total de crescimento, calcular:

- ITN:Equação 11;

- ET $_{\mathrm{p}}$ : Equação 1; 
- $\mathrm{ET}_{\mathrm{a}} / \mathrm{ET}_{\mathrm{p}}$

- escolher adequadamente o $\mathrm{K}_{\mathrm{y}}$, Tabela 8 no ANEXO;

- $\mathrm{P}_{\mathrm{a}} / \mathrm{P}_{\mathrm{p}}$ : Tabela 9 no ANEXO

\subsection{O MODELO MODSIMLS}

A condição básica para utilização do ModSimLS é que o sistema de recursos hídricos possa ser representado como rede de fluxo. Os componentes do sistema são representados na rede como nós, sendo nós de volume (reservatórios) e nós de passagem (confluências, pontos de desvio, pontos de entrada e pontos de demanda) e arcos ou elos (canais, adutoras e trechos naturais de rios). Para considerar as demandas, vazões afluentes e as normas de operação desejadas do reservatório, diversos nós e arcos artificiais devem ser criados de forma a assegurar que o balanço de massa seja satisfeito em toda a rede. Esses nós e arcos artificiais são criados automaticamente pelo ModSimLS restando ao usuário a criação dos nós e arcos reais do sistema.

As hipóteses básicas vinculadas ao modelo são:

- todos os nós de armazenamento e arcos do sistema devem possuir limites (deve-se fornecer valores máximos e mínimos para os volumes dos reservatórios e para a capacidade dos arcos). Permite-se que a capacidade dos arcos varie ao longo do tempo. As perdas resultantes da evaporação e da infiltração são estimados iterativamente;

- cada arco deve ser unidirecional no que diz respeito ao sentido de fluxo; e

- todos os influxos, demandas, perdas por infiltração e vazões de retorno devem se acumular nos nós. 
Matematicamente, o algoritmo Out-of-Kilter resolve o seguinte problema de fluxo de rede, de forma sequencial, ao longo do tempo.

Minimizar

$$
\min \sum_{i=1}^{N} \sum_{j=1}^{N} c_{i j} \cdot q_{i j}
$$

em que:

- $\mathrm{q}_{\mathrm{ij}}=$ a vazão média entre o nó $\mathrm{i}$ e o nó j durante o intervalo de tempo considerado;

- $\mathrm{c}_{\mathrm{ij}}=$ custo unitário, que pode ser um custo monetário ou um fator de ponderação que represente direitos de água ou prioridades operacionais (um custo negativo é tratado como um benefício ou prioridade).

A resolução do algoritmo está sujeita a:

a) Satisfação do equilíbrio de massa em todos os nós $\mathbf{j}=1,2, \ldots . ., \mathrm{N}$ (inclusive os nós artificiais)

$$
\sum_{i \in \mathrm{F}_{\mathrm{j}}} \mathrm{q}_{\mathrm{ij}}-\sum_{\mathrm{k} \in \mathrm{O}_{\mathrm{j}}} \mathrm{q}_{\mathrm{jk}}=0
$$

em que:

- $F_{j}=$ conjunto de todos os nós com arcos que terminam no nó j;

- $\mathrm{O}_{\mathrm{j}}=$ conjunto de todos os nós com arcos que se originam no nó j.

b) A vazão mínima em todos os arcos (i, j) 


$$
\mathrm{q}_{\mathrm{ij}} \geq \mathrm{I}_{\mathrm{ij}}
$$

sendo:

$$
\text { - } \mathrm{I}_{\mathrm{ij}}=\text { vazão mínima no } \operatorname{arco}(\mathrm{i}, \mathrm{j}) \text {. }
$$

\section{c) A vazão máxima em todos os arcos (i, j)}

$$
\mathrm{q}_{\mathrm{ij}} \leq \mathrm{U}_{\mathrm{ij}}
$$

sendo:

- $U_{\mathrm{ij}}=$ vazão máxima no $\operatorname{arco}(\mathrm{i}, \mathrm{j})$.

Os parâmetros $c_{\mathrm{ij}}, \mathrm{I}_{\mathrm{ij}}$ e $\mathrm{U}_{\mathrm{ij}}$ são definidos para os principais componentes de um sistema de recursos hídricos de acordo com a descrição feita nos itens a seguir.

\subsubsection{Vazões não Reguladas}

As vazões não reguladas utilizadas no ModSimLS podem ser baseadas em séries históricas, previsões ou geração sintética, podendo ser utilizadas em qualquer um dos nós reais do modelo (pontos de entrada de vazões afluentes).

A adição de vazões não reguladas ao modelo é feita através da criação de um único nó artificial de influxo, que é ligado a todos os nós reais da rede através de arcos artificiais. Esses nós e arcos artificiais são criados para manter o equilíbrio de massa em cada um dos nós de influxo.

Os nós reais 1, 2, 3 e 4 são automaticamente ligados pelo ModSimLS a um nó artificial I, através da criação de quatro arcos artificiais, Figura 5. 


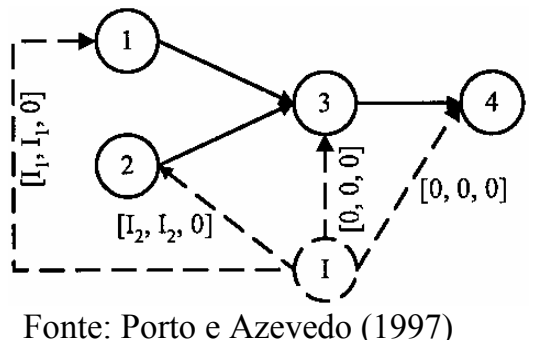

Figura 5. Arcos e nós artificiais de vazões não reguladas

Os parâmetros dos arcos representam respectivamente o limite inferior $\left(\mathrm{I}_{\mathrm{ij}}\right)$, o limite superior $\left(\mathrm{U}_{\mathrm{ij}}\right)$ e o custo do $\operatorname{arco}\left(\mathrm{c}_{\mathrm{ij}}\right)$, e são automaticamente definidos pelo ModSimLS. O conjunto $\mathrm{I}_{\mathrm{j}}$ é fornecido pelo usuário e representa as vazões afluentes aos nós j durante o intervalo de tempo. Nos elementos que possuem vazões afluentes (nós 1 e 2) os limites inferior e superior são igualados a $I_{j}$ para garantir que o valor exato fornecido pelo usuário seja utilizado. Já nos elementos que não possuem vazões afluentes (nós 3 e 4) os limites inferior e superior são automaticamente igualados a zero.

Para os nós de volume (reservatórios) a definição dos parâmetros nos arcos muda. Além das vazões afluentes aos reservatórios, existe também a água que ficou armazenada nos mesmos ao final do período anterior (volume final no período $(\mathrm{i}-1)$ ) e que passa a ser o volume inicial no período atual (período i). Assim, os arcos artificiais para vazões afluentes que chegam em reservatórios passam a ter limites inferior e superior iguais a $I_{j}+S_{j}$, onde $S_{j}$ é o volume armazenado no reservatório $j$ ao final do período anterior e que passa a ser o volume armazenado no mesmo reservatório no início do período atual. Supondo que os nós 1 e 2 sejam reservatórios, os novos valores dos parâmetros nos arcos artificiais são mostrados na Figura 6.

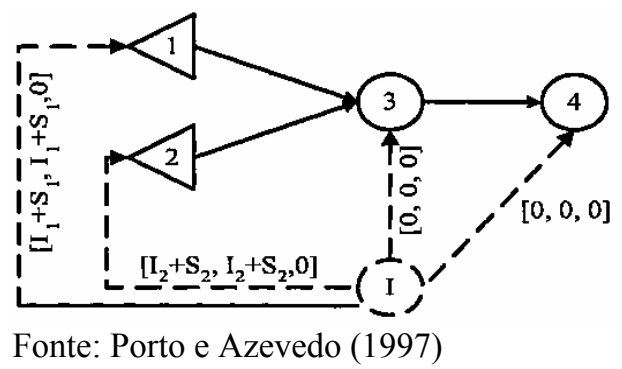

Fonte: Porto e Azevedo (1997) 
Figura 6. Arcos e nós artificiais de vazões não reguladas com adição do volume inicial

\subsubsection{Perdas nos Reservatórios e por Evaporação}

\subsection{Limites nos Arcos}

Nos elementos de volume da rede (reservatórios) é necessário que a água armazenada no final de um período de simulação seja transportada para o período seguinte. Isso é feito através de arcos artificiais que se originam em cada reservatório e terminam em um único nó artificial de volume (nó S), conforme mostrado na Figura 7.

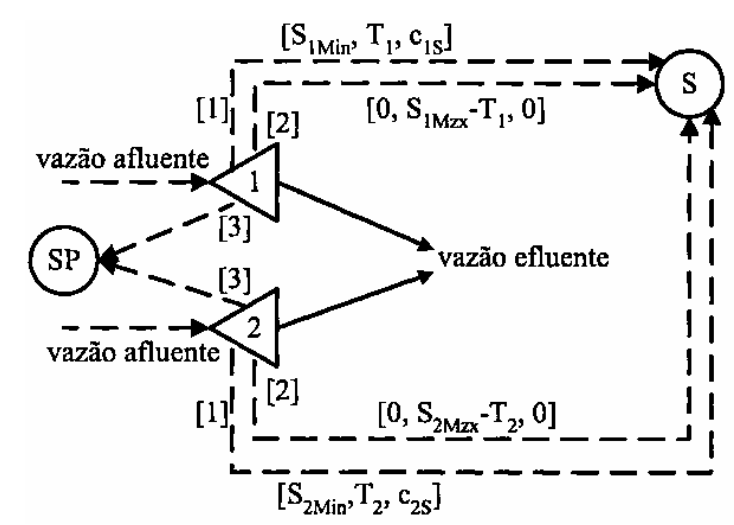

Fonte: Porto e Azevedo (1997)

Figura 7. Arcos e nós artificiais de volume

O primeiro arco artificial (arco [1] na Figura 7) é chamado de arco de volume meta, cujos limites são:

- Limite inferior $\left(\mathrm{S}_{\mathrm{imin}}\right)$ : volume mínimo ou volume morto do reservatório i;

- Limite superior $\left(\mathrm{T}_{\mathrm{i}}\right)$ : volume meta a ser atingido no final do período atual, fornecido pelo usuário do modelo. 
Quando o volume armazenado superar o volume meta, o excesso de volume é transportado pelo arco artificial de volume final (arco [2] na Figura 7), cujos limites são:

- Limite inferior: é zero porque qualquer volume excedente (acima de $\mathrm{T}_{\mathrm{i}}$ ) vai ser transportado por este arco;

- Limite superior $\left(\mathrm{S}_{\text {imáx }}-\mathrm{T}_{\mathrm{i}}\right)$ : é o volume máximo de excesso, ou seja, é a diferença entre o volume máximo e o volume meta do reservatório i.

Se, ao final do período atual, o volume a ser transportado para o período seguinte for menor que o volume mínimo em algum dos reservatórios, ocorre uma inviabilidade. Para resolver este problema, o ModSim altera o valor de $\mathrm{S}_{\text {imin }}$ no período atual, igualando-o ao volume final real a ser transportado.

\subsection{Vertimentos}

No modelo ModSimLS ocorrem vertimentos quando o volume afluente mais o volume armazenado superar a capacidade máxima de algum reservatório. Esses vertimentos são coletados pelo nó SP, que está conectado aos reservatórios através do link artificial [3] (Figura 7). O link [3] tem limite inferior igual a zero e limite superior equivalente à capacidade total de armazenamento do sistema multiplicada por dez.

\subsection{Custos nos Arcos}

Os arcos artificiais de volume meta (arcos [1] na Figura 7) tem um custo, representado por $\mathrm{c}_{\mathrm{is}}$, que é calculado de forma a refletir as prioridades associadas ao volume meta ou aos direitos de armazenamento de água. A prioridade do volume meta é representada por um valor inteiro fornecido pelo usuário, variando de 1 a $99\left(\mathrm{OPRP}_{\mathrm{i}}\right)$. 
Quanto menor o valor numérico da prioridade, maior será a tendência do ModSim em tentar manter o volume meta durante os cálculos. $\mathrm{O}$ custo $\mathrm{c}_{\mathrm{is}}$, obtido em função da prioridade $\mathrm{OPRP}_{\mathrm{i}}$, é calculado através da seguinte expressão:

$$
\mathrm{c}_{\mathrm{is}}=-\left[1000-\left(\mathrm{OPRP}_{\mathrm{i}} \cdot 10\right)\right]
$$

na qual é possível notar que o custo $\mathrm{c}_{\text {is }}$ sempre será negativo, ou seja, na realidade ele é um benefício associado ao volume meta.

O custo no arco artificial de volume final (arco [2] na Figura 7) sempre é configurado como zero. Já o custo no arco artificial de vertimento (arco [3] na Figura 7) recebe o maior valor positivo entre todos os arcos existentes.

\subsection{Evaporação}

A evaporação é calculada através de um processo iterativo, que faz estimativas sucessivas da área média da superfície do reservatório, durante cada intervalo de tempo de simulação. O funcionamento desse método iterativo é:

\section{(a) Calcula-se em cada reservatório:}

$$
\begin{aligned}
& \mathrm{E}_{\mathrm{imax}}=\mathrm{e}_{\mathrm{i}}\left[\mathrm{A}\left(\mathrm{S}_{\mathrm{i}}\right)+\mathrm{A}\left(\mathrm{S}_{\mathrm{imax}}\right)\right] / 2 \\
& \mathrm{E}_{\mathrm{i} \text { min }}=\mathrm{e}_{\mathrm{i}}\left[\mathrm{A}\left(\mathrm{S}_{\mathrm{i}}\right)+\mathrm{A}\left(\mathrm{S}_{\mathrm{i} \text { min }}\right)\right] / 2 \\
& \mathrm{E}_{\text {imeta }}=\mathrm{e}_{\mathrm{i}}\left[\mathrm{A}\left(\mathrm{S}_{\mathrm{i}}\right)+\mathrm{A}\left(\mathrm{T}_{\mathrm{i}}\right)\right] / 2
\end{aligned}
$$

em que:

- $\mathrm{e}_{\mathrm{i}}=$ taxa de evaporação para o reservatório que está sendo calculado;

- $\mathrm{A}\left(\mathrm{S}_{\mathrm{i}}\right)=$ área da superfície do reservatório para o volume $\mathrm{S}$; 
- $\mathrm{S}_{\mathrm{i}}=$ volume do reservatório no início do período $\mathrm{i}$;

- $\mathrm{S}_{\text {imax }}=$ capacidade máxima do reservatório;

- $\mathrm{S}_{\mathrm{imin}}=$ volume mínimo ou volume morto do reservatório; e

- $\mathrm{T}_{\mathrm{i}}=$ volume meta fornecido pelo usuário.

(b) Ajustam-se os parâmetros do arco de volume meta e do arco de volume final respectivamente para os seguintes valores:

$$
\begin{aligned}
& {\left[\left(\mathrm{S}_{\text {imin }}+\mathrm{E}_{\mathrm{imin}}\right),\left(\mathrm{T}_{\mathrm{i}}+\mathrm{E}_{\text {imeta }}\right), \mathrm{c}_{\text {is }}\right]} \\
& {\left[0,\left(\mathrm{~S}_{\text {imax }}-\mathrm{T}_{\mathrm{i}}\right)+\left(\mathrm{E}_{\text {imax }}-\mathrm{E}_{\text {imeta }}\right), 0\right]}
\end{aligned}
$$

(c) Calcula-se o volume total de transporte, através dos arcos de volume meta e de volume final, incluindo as perdas por evaporação, através da expressão:

$$
\mathrm{q}_{\text {itotal }}=\mathrm{q}_{\text {is (meta) }}+\mathrm{q}_{\text {is(final })}
$$

(d) Estima-se um valor inicial para a perda por evaporação $\left(E_{\mathrm{i}}\right)$. Assim, o volume final passa a ser:

$$
\mathrm{q}_{\text {itotal }}-\mathrm{E}_{\mathrm{i}}
$$

(e) Calcula-se a área média A da superfície do reservatório:

$$
\mathrm{A}=0.5 \cdot\left[\overline{\mathrm{A}}\left(\mathrm{q}_{\text {itotal }}-\mathrm{E}_{\mathrm{i}}\right)\right]
$$

(f) Atualiza-se a estimativa da evaporação: 


$$
\mathrm{E}_{\mathrm{i}}=\mathrm{e}_{\mathrm{i}} \cdot \mathrm{A}
$$

(g) Volta-se ao passo dado pela expressão ( 25 ) e repete-se o processo até que a diferença entre duas estimativas sucessivas de evaporação esteja dentro do nível desejado de tolerância

\subsection{Estados Hidrológicos}

No ModSim existem duas opções de cálculo conhecidas como "calibração" e “estados hidrológicos”. Na primeira opção, o usuário deve fornecer volumes meta mensais, para cada reservatório, cujos valores podem variar durante todos os anos de simulação. Já na segunda opção o usuário deve fornecer volumes meta mensais, constantes ao longo dos anos, que podem variar entre os três estados hidrológicos existentes no modelo. O estado hidrológico é definido como:

$$
\mathrm{R}=\sum_{\mathrm{i} \in \mathrm{H}}\left[\mathrm{S}_{\mathrm{i}}+\mathrm{I}_{\mathrm{i}}\right]
$$

em que:

- H = conjunto de reservatórios que farão parte do cálculo do estado hidrológico, também chamado de subsistema de reservatórios;

- $\mathrm{S}_{\mathrm{i}}=$ volume inicial do reservatório i;

- $\mathrm{I}_{\mathrm{i}}=$ vazão afluente ao reservatório $\mathrm{i}$.

O usuário deve fornecer dois valores $\left(x_{1} \quad\right.$ e $\left.x_{2}\right)$ que são utilizados para estabelecer, mensalmente, o estado hidrológico do sistema. Esses valores, multiplicados pelo volume total existente no subsistema de reservatórios, definem as fronteiras entre os três estados hidrológicos. 
Os estados hidrológicos usualmente são denominados seco, médio e úmido mas podem ser também chamados de médio, seco e sequíssimo no caso de simulações durante um período de vazões baixas. Neste capítulo, o estado de menor volume armazenado é chamado de $E_{1}$, o de volume médio de $E_{2}$ e o de maior volume de $E_{3}$. Os limites entre os estado $E_{1}$ e $E_{2}$ e entre os estados $E_{2}$ e $E_{3}$ são, respectivamente:

$$
\begin{aligned}
& \mathrm{E}_{1} \mathrm{E}_{2}=\mathrm{x}_{1} \cdot \mathrm{W} \\
& \mathrm{E}_{2} \mathrm{E}_{3}=\mathrm{x}_{2} \cdot \mathrm{W}
\end{aligned}
$$

sendo:

$$
\mathrm{W}=\sum_{\mathrm{i} \in \mathrm{H}} \mathrm{S}_{\mathrm{imax}}
$$

Os estados hidrológicos são definidos da seguinte forma:

$$
\begin{aligned}
& \mathrm{E}_{1}: \text { se } \mathrm{R}<\mathrm{E}_{1} \mathrm{E}_{2} \\
& \mathrm{E}_{2}: \text { se } \mathrm{E}_{1} \mathrm{E}_{2} \leq \mathrm{R} \leq \mathrm{E}_{2} \mathrm{E}_{3} \\
& \mathrm{E}_{3}: \text { se } \mathrm{R}>\mathrm{E}_{2} \mathrm{E}_{3}
\end{aligned}
$$

Observação: Quando o usuário escolhe a opção de cálculo estados hidrológicos deve ser fornecido um valor de prioridade por estado para cada reservatório. A opção estados hidrológicos aumenta a flexibilidade da simulação, já que os cálculos passam a considerar, mensalmente, o estado do sistema.

\subsubsection{Demandas e Direitos de Água}




\subsection{Demandas Terminais}

Considere a rede apresentada na Figura 8, na qual os nós 3 e 4 são demandas. $O$ modelo ModSim cria e configura automaticamente os arcos artificias originados em cada um dos nós de demanda da rede e conecta esses arcos a um único nó artificial de demanda.. Os valores dos parâmetros $\mathrm{I}_{\mathrm{ij}}$, $\mathrm{U}_{\mathrm{ij}}$, e $\mathrm{c}_{\mathrm{ij}}$ nos arcos artificiais de demanda são mostrados na Figura 8 , sendo $\mathrm{D}_{3}$ e $\mathrm{D}_{4}$ os valores de demanda em cada um dos nós. As demandas podem ser volumes legalmente outorgados, retiradas históricas, demandas agrícolas, municipais ou industriais.

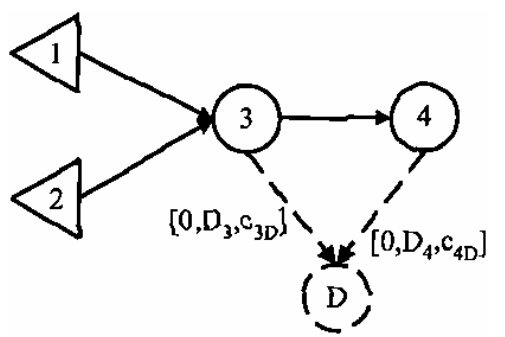

Fonte: Porto e Azevedo (1997)

\section{Figura 8. Demandas terminais}

Os custos $\mathrm{c}_{\mathrm{iD}}$ são calculados através da seguinte expressão:

$$
\mathrm{c}_{\mathrm{iD}}=-\left[1000-\left(\mathrm{DEMR}_{\mathrm{i}} \cdot 10\right)\right]
$$

em que

- $\mathrm{DEMR}_{\mathrm{i}}$ é a prioridade da demanda i, variando de 1 a 99.

Observe que $\mathrm{c}_{\mathrm{iD}}$ é um número negativo assim como $\mathrm{c}_{\mathrm{is}}$ (custo associado ao volume meta nos reservatórios). O usuário do modelo precisa escolher valores de prioridades para as demandas e os volumes meta. Quando todas as demandas não puderem ser atendidas, as primeiras a sofrerem déficits serão aquelas com menor valor de prioridade. Se a opção escolhida for Estados Hidrológicos podem ser fornecidos três 
valores de prioridade, sendo um para cada estado. Esses valores permanecem constantes para todos os anos.

\subsection{Demandas de Passagem}

Demandas de passagem são demandas não consuntivas, incluídas no modelo com o objetivo de manter a magnitude da vazão em algum ponto específico do sistema em estudo. Podem ser utilizadas, por exemplo, para a manutenção da vazão mínima em um trecho de rio, estabelecida para peixes e fauna, controle da qualidade da água ou recreação.

Geralmente as demandas de passagem destinadas a manutenção de vazões mínimas podem ser substituídas pelo estabelecimento de vazões mínimas nos arcos. Entretanto, se a vazão mínima em algum arco não puder ser atingida (o que pode ocorrer em períodos secos), o modelo não irá encontrar uma solução possível para o problema e irá encerrar os cálculos.

O esquema de funcionamento de uma demanda de passagem será explicado com o auxílio do exemplo existente na Figura 9, que apresenta a parte final da rede mostrada na Figura 8.

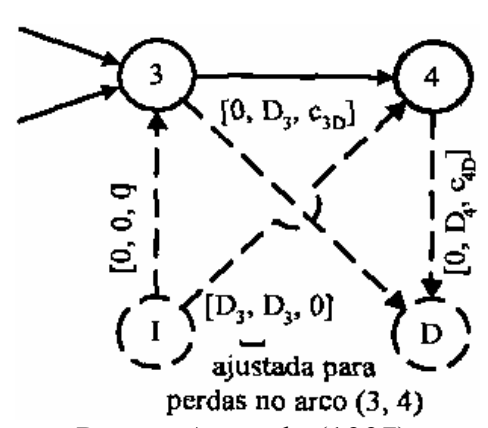

Fonte: Porto e Azevedo (1997)

Figura 9. Demandas de passagem 
No exemplo, é necessário manter uma vazão mínima $\mathrm{D}_{3}$ no $\operatorname{arco}(3,4)$ e o nó 4 representa uma demanda terminal. Além dos arcos artificiais de demanda são mostrados também os arcos de vazão artificial, com origem no nó I e término nos nós de demanda. $\mathrm{O}$ arco artificial que termina na demanda 4 recebe os parâmetros $\left[\mathrm{D}_{3}, \mathrm{D}_{3}, 0\right]$. Se uma vazão $I_{4}$ tivesse sido aportada ao nó 4 os parâmetros passariam a ser $\left[I_{4}+D_{3}, I_{4}+D_{3}\right.$, 0].

A demanda de passagem é definida no nó 3 mas o fluxo irá se acumular na demanda 4. Para simular uma demanda de passagem em um certo arco, o ModSim retira a vazão do nó de montante e coloca a vazão de volta no nó de jusante do respectivo arco.

\subsubsection{Perdas de Condução e de Infiltração}

O modelo ModSimLS possui a capacidade de simular as perdas por infiltração nos canais, através do fornecimento de um coeficiente de perda. Esse coeficiente deve ser fornecido pelo usuário e representa a fração do fluxo que seria perdida durante o percurso através do canal. O procedimento utilizado pelo modelo para simular as perdas é o seguinte:

i. em cada período de simulação a perda no canal é inicialmente igualada a zero (primeira iteração);

ii. a seguir, a perda no canal é calculada em função do fluxo que chega a montante do mesmo. Essa perda é transportada como uma demanda para o nó de jusante do canal;

iii. a iteração seguinte é efetuada utilizando a perda calculada no item ii; 
iv. repete-se o processo até que o fluxo no canal não mude entre duas iterações sucessivas (dentro da margem de tolerância).

O procedimento descrito anteriormente é mostrado na Figura 10, na qual $\mathrm{c} 1_{\mathrm{ij}}$ é o coeficiente de perda no canal ij. O procedimento termina quando $\mathrm{q}_{\mathrm{ij}}{ }^{(\mathrm{k})}=\mathrm{q}_{\mathrm{ij}}{ }^{(\mathrm{k}-1)}$ para todos os canais, dentro da margem de tolerância, ou seja, $\mathrm{q}_{\mathrm{ij}}^{(\mathrm{k})}=\mathrm{q}_{\mathrm{ij}}{ }^{(\mathrm{k}-1)} \pm \tau$.

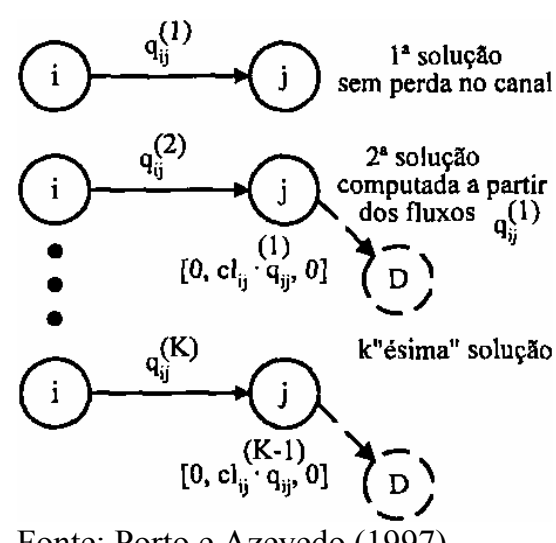

Fonte: Porto e Azevedo (1997)

Figura 10. Iterações para se determinar as perdas por infiltração nos canais

Quando não existe demanda no nó de jusante (nó j na Figura 10) então a perda no canal passa a ser a única demanda nesse nó. Essa demanda recebe uma alta prioridade para garantir que as perdas no canal sejam sempre removidas em primeiro lugar, já que se trata de uma demanda que precisa ser satisfeita. Por outro lado, se já existir uma demanda no nó $\mathrm{j}$, as perdas no canal são simplesmente acrescentadas a essa demanda, mantendo-se o valor de prioridade existente. Isso pode criar problemas quando houver pouca água disponível no sistema e a demanda existente tiver baixa prioridade. 


\subsection{O MODELO IRRIGALS}

A interface IrrigaLS foi desenvolvida no formato típico de um sistema de suporte a decisões, ou seja, estão presentes em sua estrutura um módulo de diálogo, uma base de dados e uma base de modelos, que no presente caso é constituída apenas pelo IrrigaLS.

O módulo de diálogo permite que a topologia do sistema seja formulada com a utilização do mouse e de uma série de ícones (que representam reservatórios, canais, nós de passagem, etc.). Ao se acionar o botão dois do mouse sobre cada um destes ícones tem-se acesso à base de dados da estrutura representada pelo ícone acionado. Após a execução do programa os resultados podem ser consultados em forma tabular ou gráfica. Os dados e resultados podem ser facilmente exportados para planilhas eletrônicas e processadores de texto. Da mesma forma, os dados de entrada podem ser importados de planilhas.

Como inovação o modelo oferece a demanda de irrigação por ser uma das principais concorrentes pelo uso da água. O modelo adaptado calcula as necessidades hídricas da cultura obedecendo aos critérios de irrigação, ou seja, a relação clima-soloágua-cultura, utilizando, antes de fazer uso da água do reservatório superficial, a água armazenada no solo. Espera-se com isto, dependendo da disponibilidade hídrica da bacia, que uma quantidade ideal de água seja fornecida à planta.

O modelo oferece, também, a opção de comparação das variáveis obtidas pelo método do balanço hídrico de determinação da lâmina irrigada e os valores simulados pelo IrrigaLS. É possível, também, analisar o rendimento e a produção de acordo com a 
quantidade de água aplicada a cultura para ambos os métodos (balanço hídrico e IrrigaLS).

\subsubsection{Reservatório do Solo no IrrigaLS}

Para o modelo IrrigaLS efetuar a análise do planejamento da irrigação, a fim de fornecer informações mais precisas do balanço de água no solo de acordo com a exigência da cultura, tornou-se necessário adaptá-lo. O reservatório do modelo foi adaptado para funcionar também como um reservatório do solo no ModSimLS. Nesta simulação, enquanto a água armazenada no solo satisfizer as exigências hídricas da cultura afim de obter máxima produção não é necessário utilizar água do reservatório superficial.

A Figura 11 apresenta a relação entre o reservatório superficial e do solo.

Observa-se pela figura que:

- a capacidade máxima $\left(\mathrm{C}_{\max }\right)$ do reservatório superficial esta relacionada a capacidade de campo (CC) no reservatório do solo;

- a capacidade mínima $\left(\mathrm{C}_{\min }\right)$ do reservatório superficial esta relacionada ao ponto de murcha permanente (PMP) no reservatório do solo;

- a capacidade mínima admitida $\left(\mathrm{C}_{\min }{ }^{*}\right)$ do reservatório superficial esta relacionada ao limite crítico de umidade no reservatório do solo (PMP*); Abaixo do $\mathrm{PMP}^{*}$ a planta não retira água do solo;

- a perda de água por evaporação (E) do reservatório superficial corresponde a perda de água por evapotranspiração (ET) no reservatório do solo. 
$\mathrm{O}$ que resulta para uma área irrigada $\left(\mathrm{A}_{\mathrm{i}}\right)$ e profundidade efetiva do sistema radicular $\left(Z_{\mathrm{r}}\right)$ do reservatório do solo em:

\section{a) O volume total de água no solo}

$$
\mathrm{V}_{\text {total }}=\mathrm{CTA} \cdot \mathrm{A}_{\mathrm{i}} \cdot 10^{-3}
$$

em que:

$-\mathrm{V}_{\text {total }}=$ volume total de água no solo $\left[\mathrm{Hm}^{3}\right]$;

- CTA = capacidade total de água no solo $[\mathrm{mm}]$;

- $\mathrm{A}_{\mathrm{i}}=$ área irrigada $\left[\mathrm{Km}^{2}\right]$.

b) O volume útil de água no solo, ou seja, o volume de água no solo realmente disponível para as plantas

$$
\mathrm{V}_{\text {útil }}=\mathrm{V}_{\text {total }} \cdot \mathrm{f}
$$

em que:

- $\mathrm{V}_{\text {útil }}=$ volume útil de água no solo $\left[\mathrm{Hm}^{3}\right]$;

- $\mathrm{V}_{\text {total }}=$ volume total de água no solo $\left[\mathrm{Hm}^{3}\right]$;

- $\mathrm{f}=$ fator de esgotamento de água no solo [adimensional], (Tabelas 6 no ANEXO). 
c) o volume morto de água no solo, ou seja, o volume de água no solo não disponível para as plantas $\left[\mathrm{Hm}^{3}\right]$.

$\mathrm{V}_{\text {morto }}=\mathrm{V}_{\text {total }} \cdot(1-\mathrm{f})$

em que:

- $\mathrm{V}_{\text {morto }}=$ volume morto de água no solo, ou seja, o volume de água no solo não disponível para as plantas $\left[\mathrm{Hm}^{3}\right]$;

$-\mathrm{V}_{\text {total }}=$ volume total de água no solo $\left[\mathrm{Hm}^{3}\right]$;

$\mathrm{f}=$ fator de esgotamento de água no solo [adimensional], Tabelas 5 e 6 no ANEXO. 
RESERVATÓRIO SUPERFICIAL

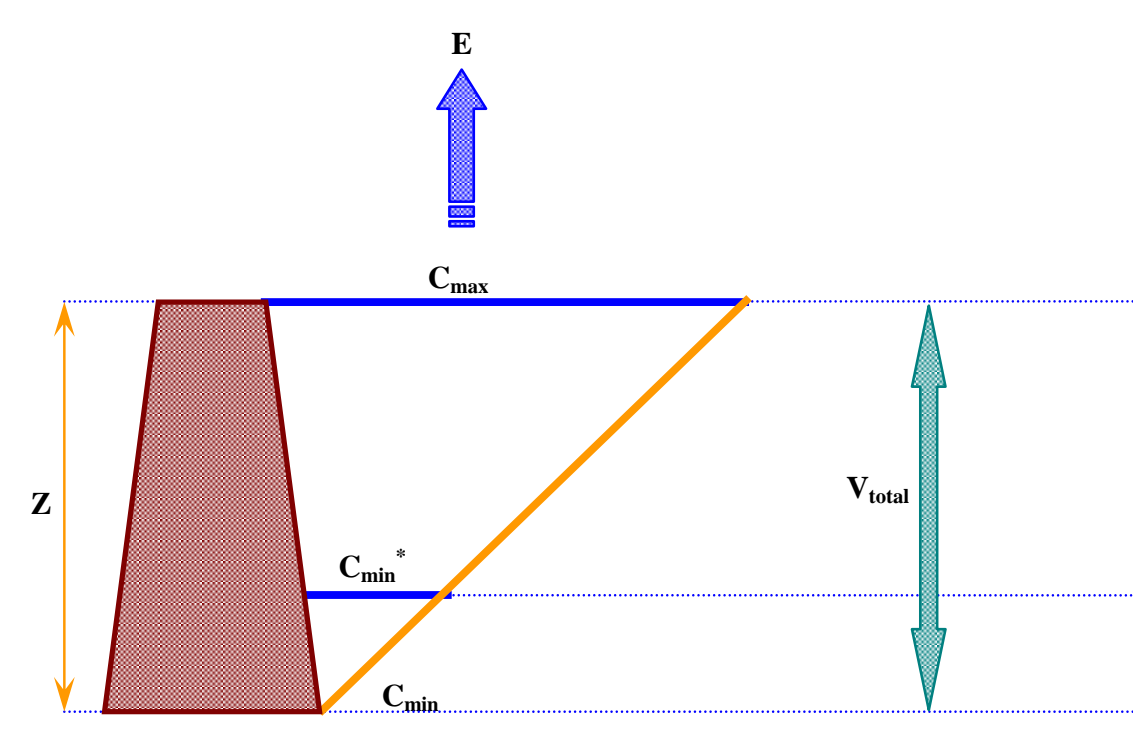

$\mathrm{C}_{\max }=$ capacidade máxima no reservatório superficial

$\mathrm{C}_{\min }=$ capacidade mínima no reservatório superficial

$\mathrm{C}_{\min }{ }^{*}=$ capacidade mínima admissível no reservatório superficial

$\mathrm{z}=$ profundidade do reservatório superficial

$\mathrm{E}=$ evaporação no reservatório superficial

\section{RESERVATÓRIO DO SOLO}

T

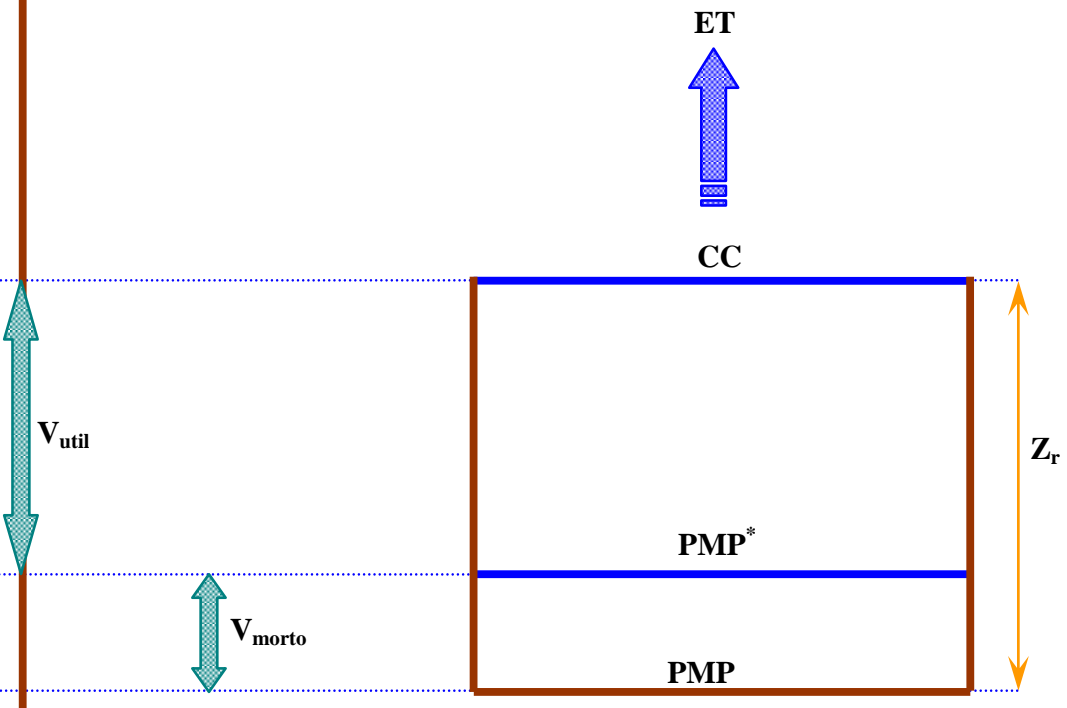

$\mathrm{CC}=$ umidade na capacidade de campo no reservatório do solo

PMP = umidade no ponto de murcha permanente no reservatório do solo

PMP $^{*}=$ umidade mínima admissível no reservatório do solo

$Z_{\mathrm{r}}=$ profundidade efetiva do sistema radicular

ET = evapotranspiração no reservatório no solo

$$
\begin{aligned}
& \mathrm{V}_{\text {total }}=\text { volume total } \\
& \mathrm{V}_{\text {útil }}=\text { volume útil } \\
& \mathrm{V}_{\text {morto }}=\text { volume morto }
\end{aligned}
$$

Figura 11. Representação esquemática das relações existentes entre os reservatórios superficial e do solo 


\subsubsection{A interface do IrrigaLS}

O IrrigaLS é um modelo de rede de fluxo para simulação de bacias hidrográficas. Com ele o usuário além de poder montar redes com um grande número de reservatórios, demandas e trechos de canais, poderá também, caso queira, considerar a demanda de irrigação (reservatório do solo), representando o problema em estudo de forma ainda mais detalhada.

Em linhas gerais, o modelo IrrigaLS funciona da seguinte maneira:

- durante a utilização do IrrigaLS, todas as ações feitas pelo usuário são imediatamente armazenadas em um banco de dados temporário;

- ao iniciar o modelo, o usuário pode começar um novo projeto ou abrir um projeto previamente gravado;

- se for iniciado um novo projeto, um novo banco de dados temporário será criado;

- quando o usuário abre um projeto existente, o ModSimLS cria imediatamente uma cópia desse projeto, que passa a ser o banco de dados temporário;

- no banco de dados temporário são armazenadas todas as informações fornecidas pelo usuário (traçado e dados de entrada).

A utilização de um banco de dados temporário durante o funcionamento do modelo apresenta as seguintes vantagens:

- não é necessário alocar memória para guardar valores em variáveis, já que os mesmos estarão automaticamente armazenados no banco de dados;

- ao abrir um projeto só uma pequena parte do banco é lida. Todos os dados e resultados só serão lidos (diretamente do banco) quando for necessário; 
- um projeto só será alterado quando o usuário salvá-lo. Nesse instante será criada uma cópia do banco de dados temporário com o nome e no local fornecido pelo usuário.

As adaptações, as principais partes e as novidades existentes no IrrigaLS são descritas nos próximos itens.

\subsubsection{Tipos de Simulação}

Os dois tipos de simulação existentes no IrrigaLS são Simulação Contínua e Planejamento Tático. Atualmente, os cálculos são efetuados de maneira seqüencial no tempo (Simulação Contínua), o Planejamento Tático está em desenvolvimento.

Na Simulação Contínua, o valor mais importante é o número total de anos de simulação (denotado por de NT). O usuário deve fornecer séries de vazões afluentes mensais com duração igual a NT. O modelo efetua os cálculos continuamente, para todos os anos da série. Os resultados são fornecidos em escala mensal para todos os anos.

Quando as séries de vazões são relativamente longas, percebe-se que os volumes iniciais dos reservatórios passam a ter pequena influência nos resultados. Assim, este tipo de simulação é recomendado para se obter uma idéia inicial do comportamento do sistema em estudo, das prioridades a serem adotadas, etc. Se o usuário pretende ter uma idéia do comportamento do sistema ao longo do tempo então a Simulação Contínua é a opção recomendada.

No Planejamento Tático, o usuário deve fornecer, além do número total de anos de simulação (NT), o número de anos do horizonte de simulação (NH). O horizonte de simulação é o número de anos durante os quais pretende-se estudar o comportamento do 
sistema em análise. Neste tipo de simulação, os cálculos são efetuados da seguinte maneira:

- partindo, no primeiro ano, com os volumes iniciais dos reservatórios fornecidos pelo usuário, o modelo efetua os cálculos seqüencialmente para NH anos;

- no segundo ano o procedimento acima é repetido partindo-se novamente com os volumes iniciais fornecidos pelo usuário;

- o procedimento acima é repetido até que seja efetuado o cálculo partindo-se do ano $\mathrm{NT}-\mathrm{NH}+1$;

- os resultados fornecidos são valores estatísticos para todos os meses do horizonte de simulação.

Esta opção de cálculo é a mais recomendada quando o objetivo é fazer o planejamento e/ou a operação de sistemas de reservatórios.

\subsubsection{Opções de Cálculo}

As duas opções de cálculo existentes no IrrigaLS são Estados Hidrológicos e Calibração. Atualmente os cálculos são realizados por Calibração (Estados Hidrológicos está em desenvolvimento).

As diferenças entre estas duas opções estão na entrada de dados e na maneira como o modelo irá efetuar os cálculos. Na opção Estados Hidrológicos, o modelo considera o estado hidrológico (quantidade de água armazenada nos reservatórios) para determinar qual o valor de demanda, de volume meta e as prioridades que serão utilizadas no cálculo de cada um dos meses. Quando a opção selecionada for 
Calibração, o modelo efetua os cálculos com os valores fornecidos sem considerar o estado atual do sistema.

\subsubsection{O Traçado}

Para criar/editar elementos o usuário deve selecionar um dos botões mostrados na Figura 12 e clicar na área de trabalho do modelo. A Figura 14 apresenta um exemplo de traçado.

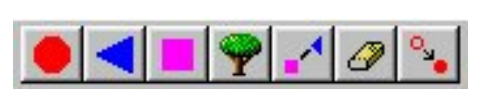

\section{Figura 12. Botões de traçado}

O IrrigaLS possibilita criar vários links entre dois nós, sendo possível atribuir custos diferentes a cada um desses links, direcionando o caminhamento da água. A Figura 13 apresenta um exemplo dessa montagem.

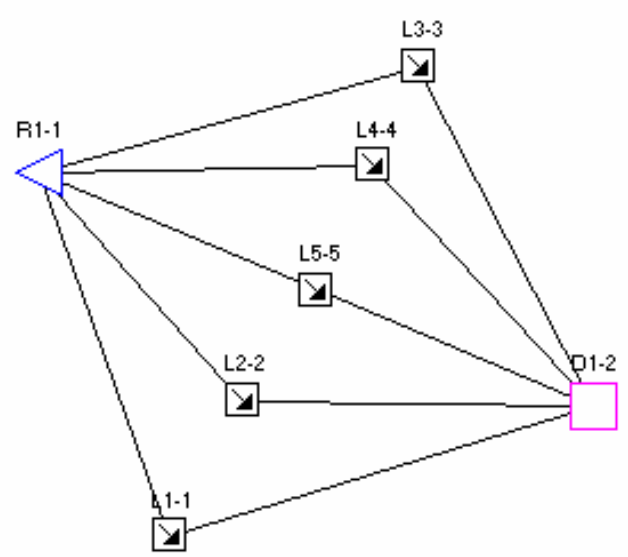

Figura 13. Vários links entre dois nós 
Considerando que as plantas apresentam exigências hídricas diferentes, na montagem da topologia da rede, cada área ocupada por determinada cultura será tratada como uma demanda de irrigação. Apesar do IrrigaLS possibilitar criar vários links entre dois nós, para um melhor controle das perdas no sistema de irrigação nos nós de demanda de irrigação só é permitido chegada de um único link. A Figura 14 apresenta um exemplo de traçado quando se considera a demanda de irrigação.

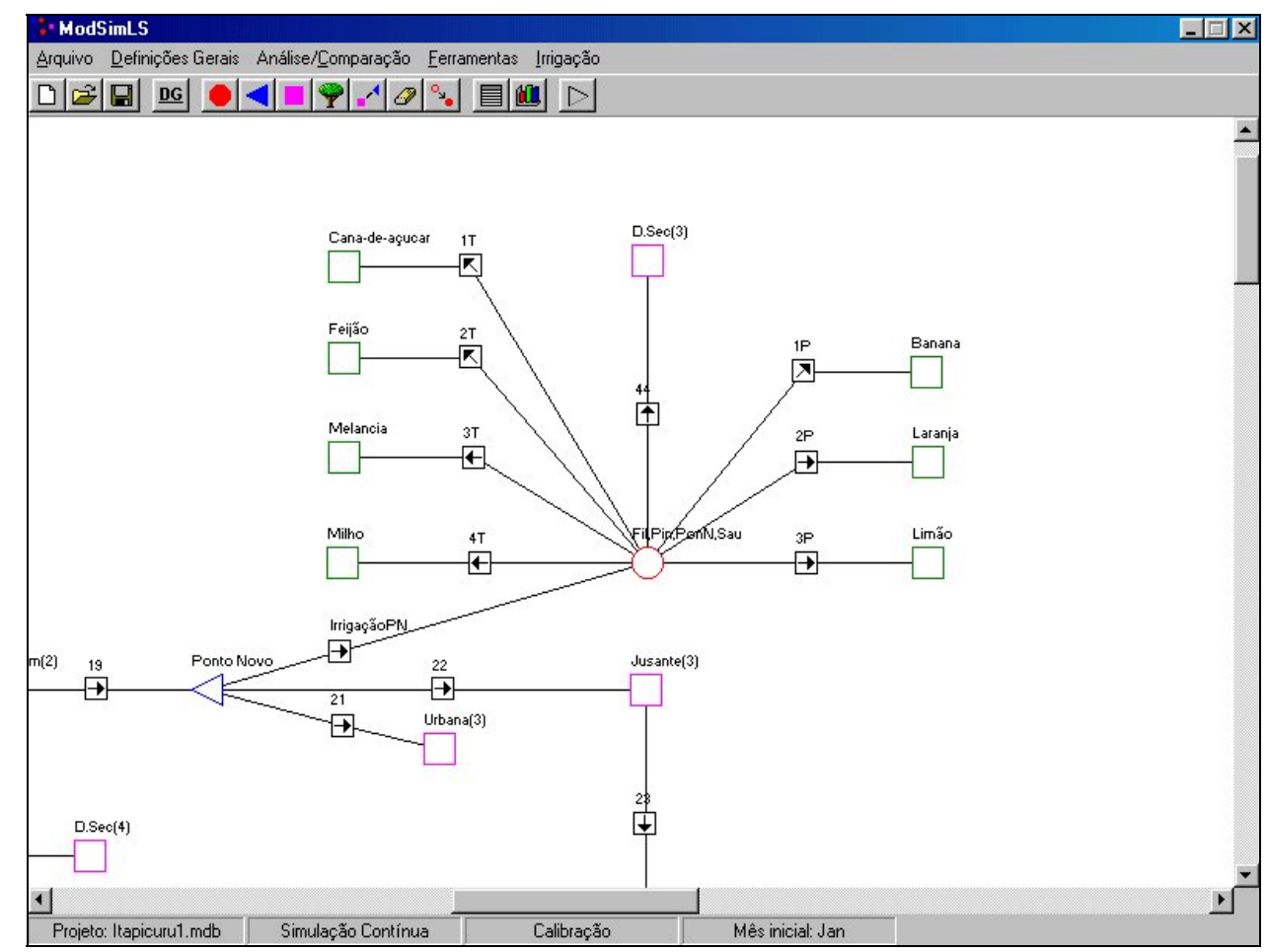

Figura 14. Exemplo de traçado

\subsubsection{Definições Gerais}

Ao iniciar uma nova simulação, o usuário deve fornecer ao modelo diversas informações que servirão de base para a entrada de dados, o cálculo e os resultados. Para isto, existe a tela de definições gerais (Figura 15), na qual é escolhido o tipo de simulação, as opções de cálculo e os valores relacionados com estas opções. 
O usuário pode, a qualquer momento, alterar as definições de uma simulação bastando, para isso, clicar no menu ou no botão respectivo.

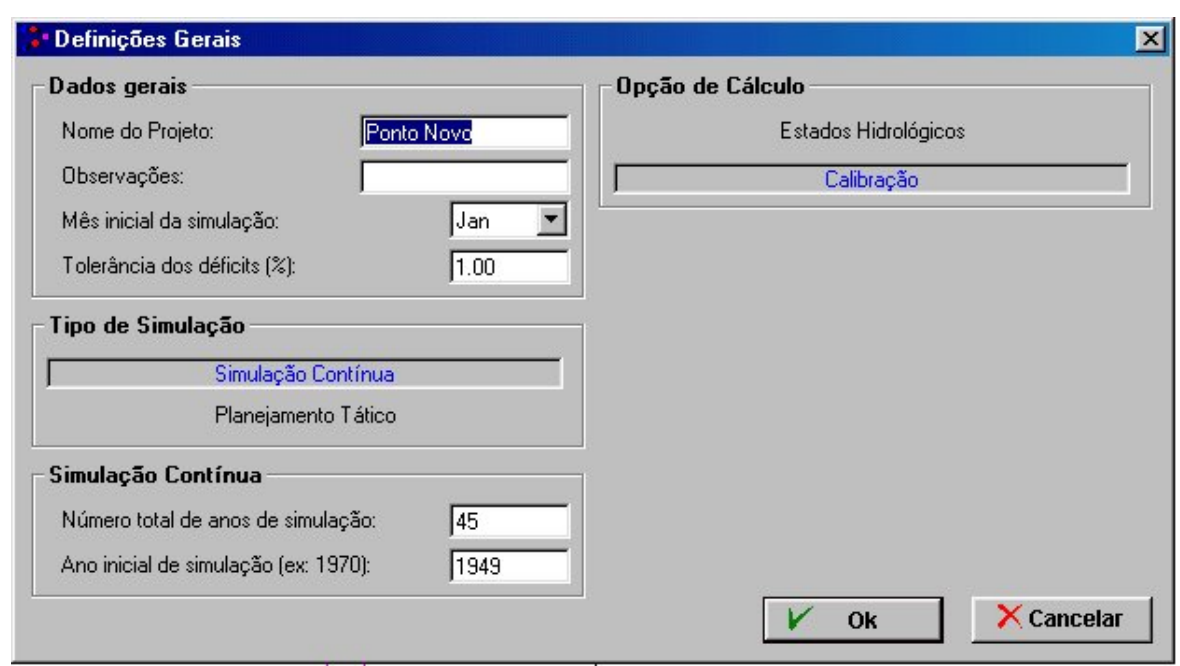

Figura 15. Tela de definições gerais

\subsubsection{Entrada/Edição de Dados}

Como a demanda de irrigação é a inovação do modelo, essa será explicada com mais detalhes. Para entrar/editar os dados basta clicar com o botão dois do mouse sobre qualquer um dos elementos existentes na área de trabalho. Ao clicar aparece uma tela com todos os dados necessários ao elemento escolhido.

A tela de dados para a demanda de irrigação consta de três partes:

- Características;

- Água (perda e contribuições);

- Volume Meta.

Para aceitar os valores apresentados basta clicar no botão Ok. Para sair sem aceitar as alterações basta clicar no botão Cancelar.

Cada parte da planilha entrar/editar da demanda de irrigação é descrita a seguir: 
a) Características Gerais - (Figura 16)

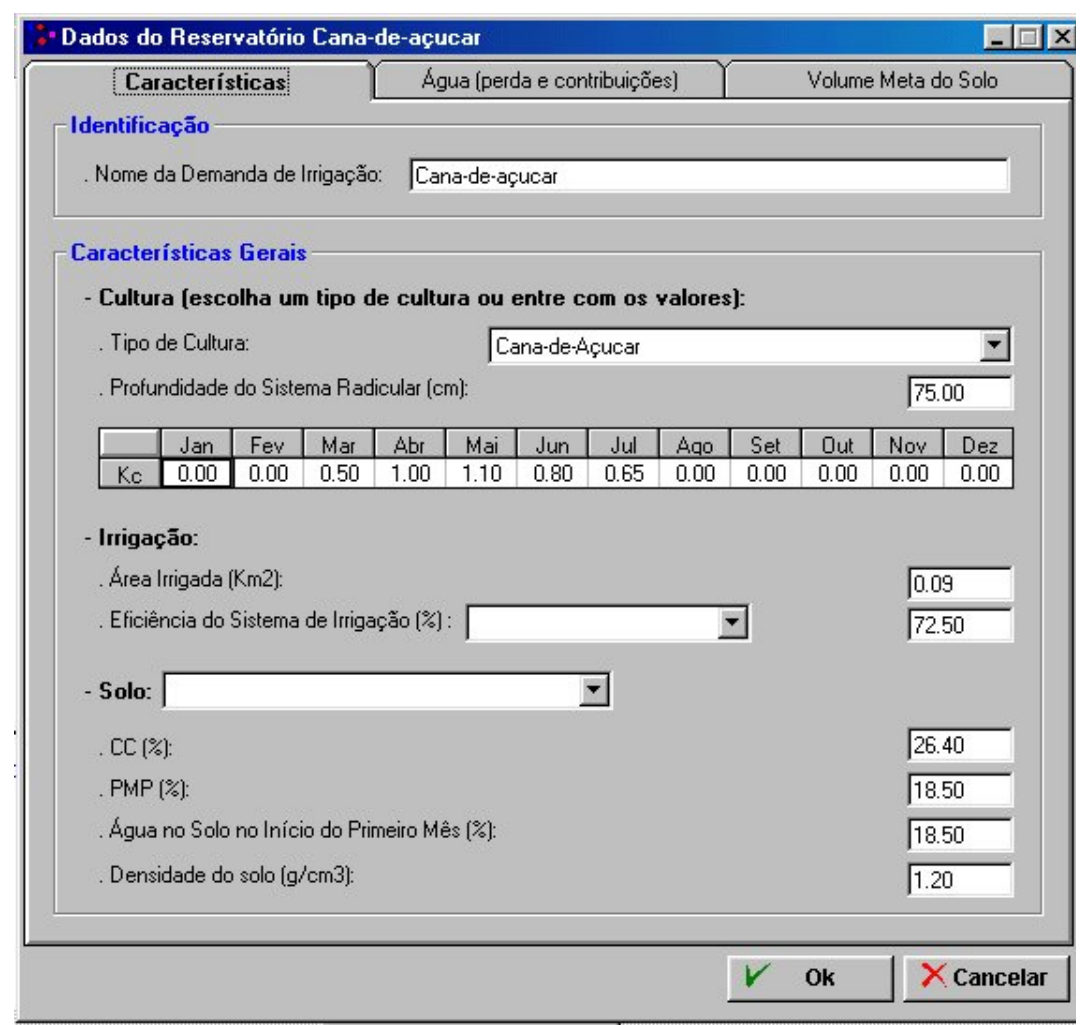

Figura 16. Planilha de entrada/edição de dados quando se utiliza o solo como reservatório - Características gerais

- Identificação: corresponde ao nome que o usuário deseja para a demanda de irrigação;

- Cultura: corresponde as características da cultura implantada na região. Após a escolha da cultura as planilhas do coeficiente de cultura $\left(\mathrm{K}_{\mathrm{c}}\right)$ e da profundidade do sistema radicular $\left(\mathrm{Z}_{\mathrm{r}}\right)$ são preenchidas automaticamente. Caso o usuário opte por outros valores basta preencher a planilha manualmente. 
- Irrigação: corresponde a área irrigada, ao sistema de irrigação e a eficiência. A escolha do sistema implicará no preenchimento automático do valor da eficiência do sistema de irrigação (e). As perdas serão consideradas no link ligado a esta demanda como um coeficiente de perda (Figura 7). Caso o usuário opte por outros valores basta preencher o campo manualmente.

- Solo: corresponde às características do solo da região. São solicitados: a CC; o PMP; a umidade inicial do solo; se esses dados estão em percentagem de peso ou em percentagem de volume. Caso os dados estejam em percentagem de peso, automaticamente aparecerá o item $\mathrm{D}_{\mathrm{a}}$. Neste estudo, o solo é composto por uma única camada e os valores de CC e PMP, quando especificado para vários perfis de solo podem ser tomados como os valores médios. O campo é preenchido manualmente.

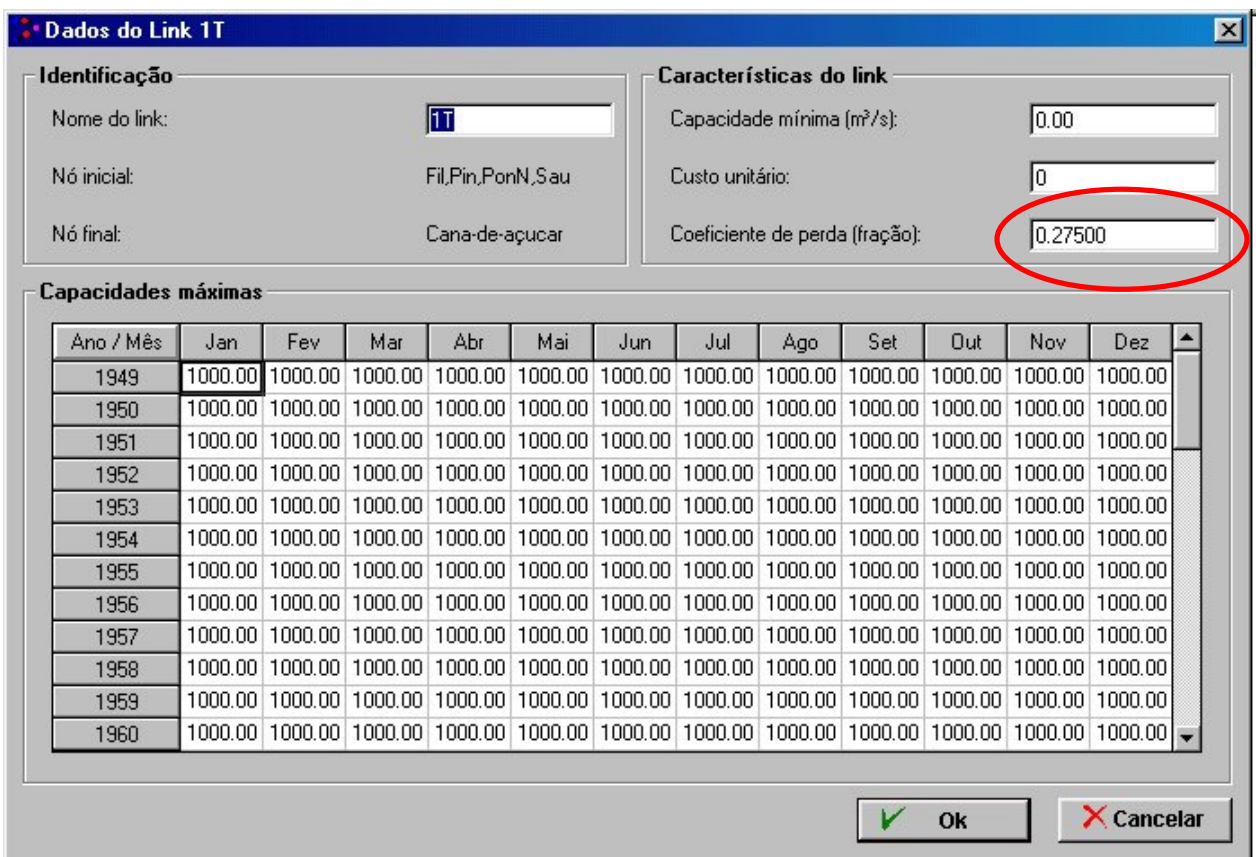

Figura 17. Planilha do link com coeficiente de perda preenchido automaticamente de acordo com a eficiência do sistema 
b) Água (Perdas e Contribuições) - (Figura 18)

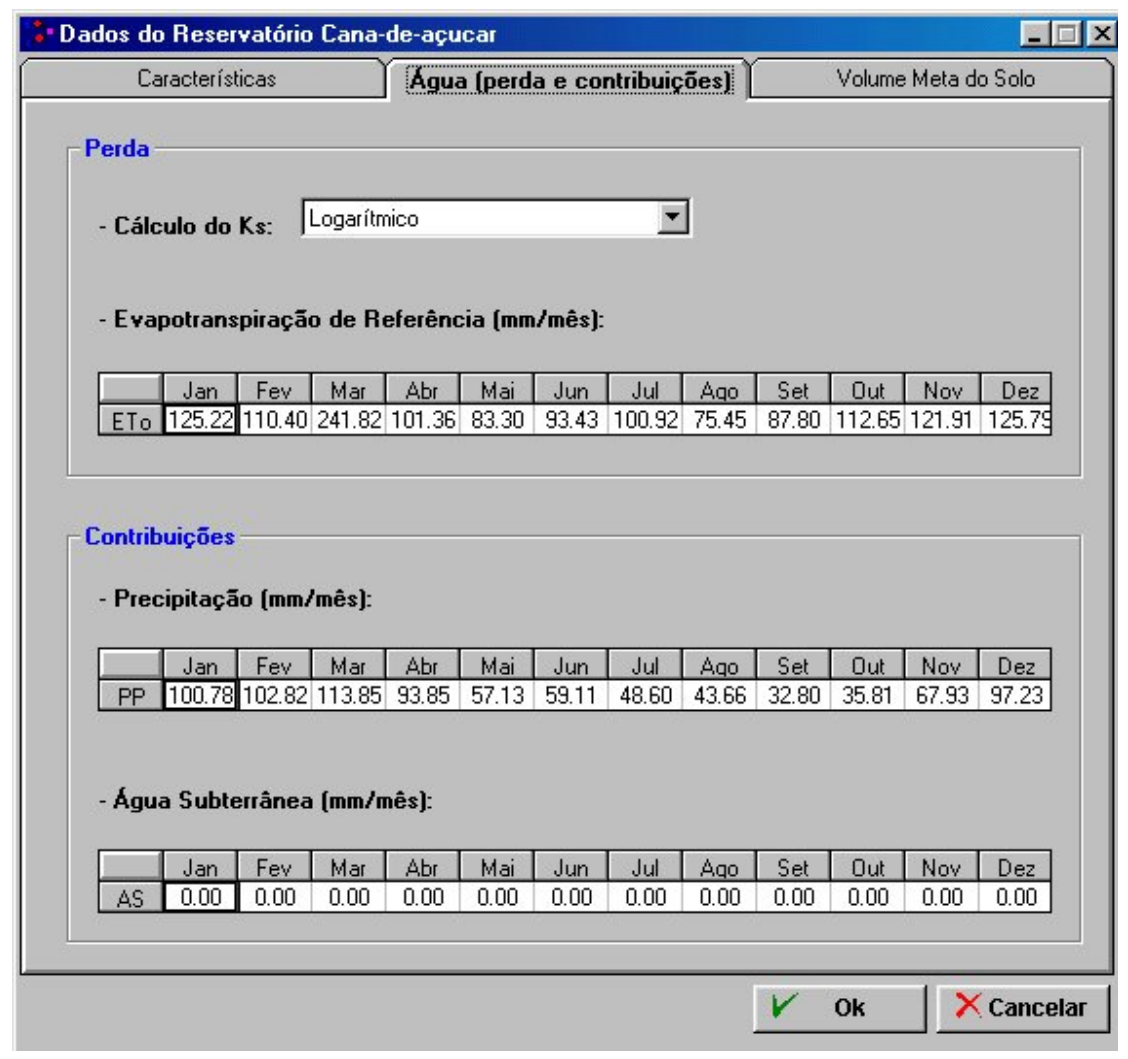

Figura 18. Planilha de entrada de dados quando se utiliza o solo como reservatório - Água (Perda e Contribuições)

- Perdas:

- Cálculo do Ks: o usuário pode selecionar o método de determinação do coeficiente $\left(\mathrm{K}_{\mathrm{s}}\right)$ que relaciona a umidade do solo e que, conseqüentemente, está relacionado com a evapotranspiração (Equações 3 e 4).

- Evapotranspiração de referência [mm/mês]: corresponde as características climáticas da região. O cálculo preenchimento do campo é manual. 
- Contribuições:

- Precipitação [mm/mês]: corresponde aos dados da precipitação média mensal da região. O preenchimento do campo é manual;

- Água no Solo [mm/mês]: corresponde a água no solo antes do primeiro dia de irrigação. Caso este dado não seja disponível o valor assumido é zero. O preenchimento do campo é manual.

c) Volume Meta do Solo - (Figura 19)

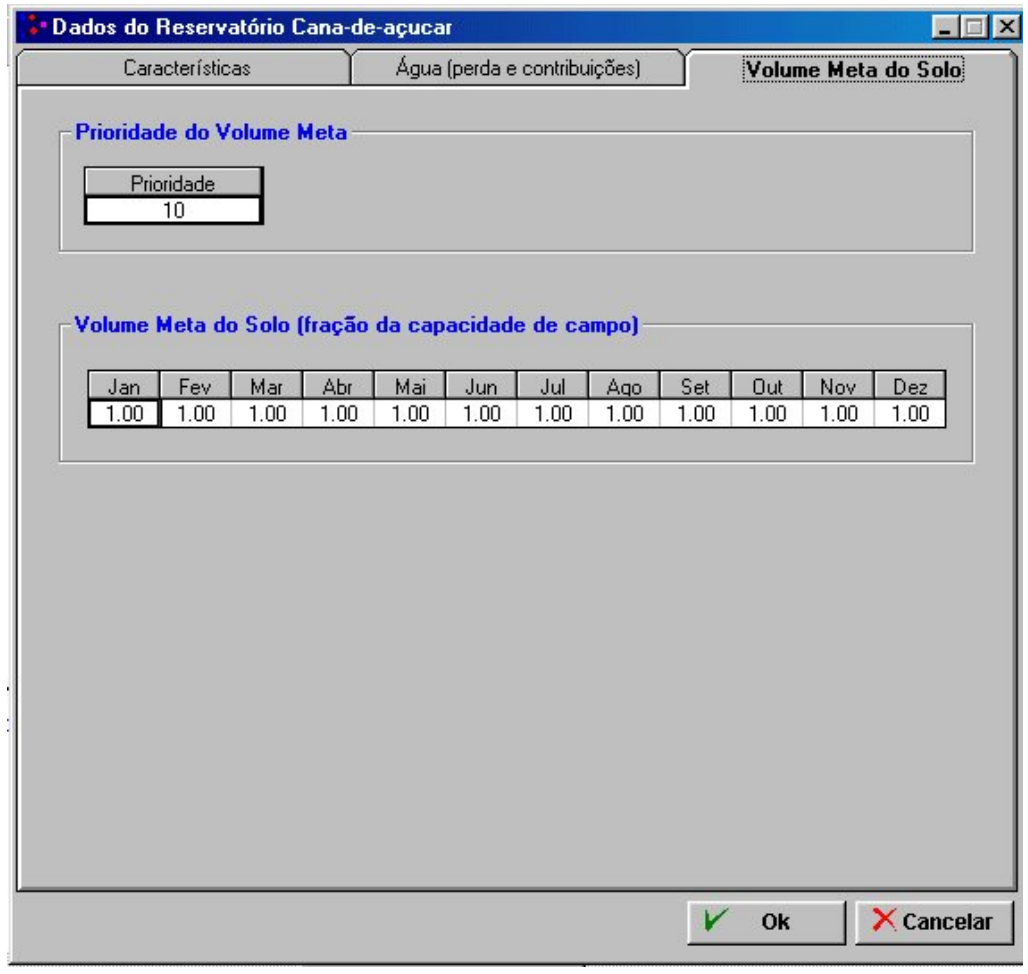

Figura 19. Planilha de entrada de dados quando se utiliza o solo como reservatório - Volume Meta no Solo 
- Prioridade do Volume Meta: como padrão assume-se 99, podendo ser modificado de acordo com as características admitidas;

- Volume Meta (fração do volume total): corresponde a fração do volume total que será necessária no solo para produção máxima. Como padrão foi admitido o valor 1 (volume do solo na $\mathrm{CC}$ ), podendo ser modificado manualmente pelo usuário.

O IrrigaLS permite ao usuário entrar/editar, de uma só vez, os dados de todos os elementos existentes na tela, para isso basta escolher os elementos cujos dados vão ser fornecidos/editados na tela mostrada na Figura 20. O IrrigaLS mostra somente os dados escolhidos pelo usuário, aumentando a eficiência deste processo.

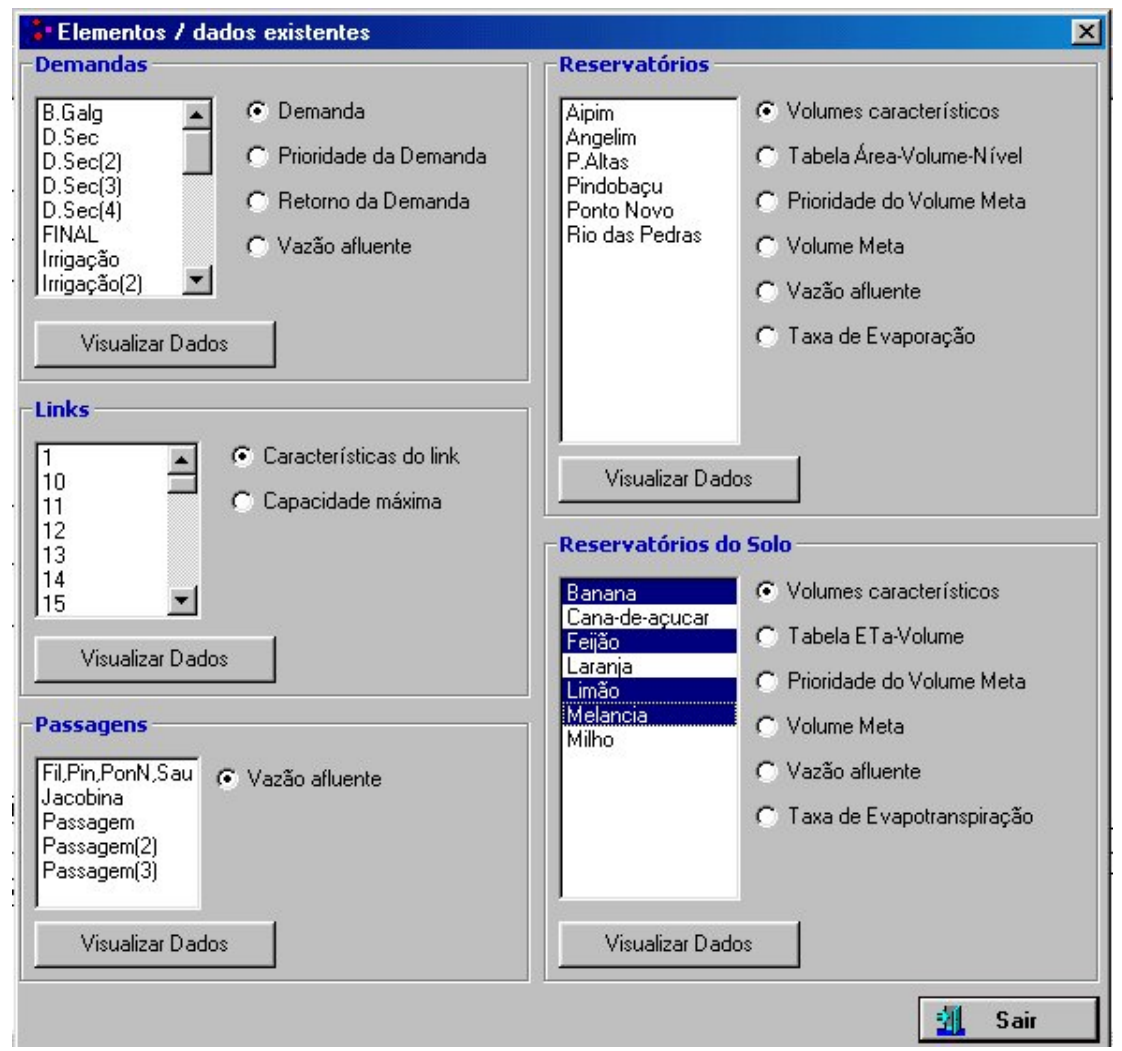

Figura 20. Tela para escolha dos elementos cujos dados serão fornecidos/editados 


\subsubsection{Resultados}

A parte de resultados do IrrigaLS apresenta as seguintes características:

- os resultados são acessados somente através do botão respectivo;

- os resultados são escolhidos através da tela mostrada na Figura 21. Somente os resultados escolhidos pelo usuário serão lidos do banco de dados;

- é possível visualizar volumes e vazões no mesmo gráfico, com cada uma das grandezas em um eixo respectivo (Figura 22);

- além de mostrar os resultados em planilha, os mesmos são mostrados em forma de gráfico. É possível editar diversas propriedades do gráfico e efetuar “zoom” em qualquer parte do gráfico;

- o resumo dos resultados são apresentados em planilha e em formato gráfico, conforme mostrado na Figura 23, porém para a demanda de irrigação (reservatório do solo) este recurso ainda não encontra-se disponível;

- todos os resultados podem ser mostrados individualmente ou como sistema (todos os elementos de um mesmo tipo são mostrados como se fossem um único); 


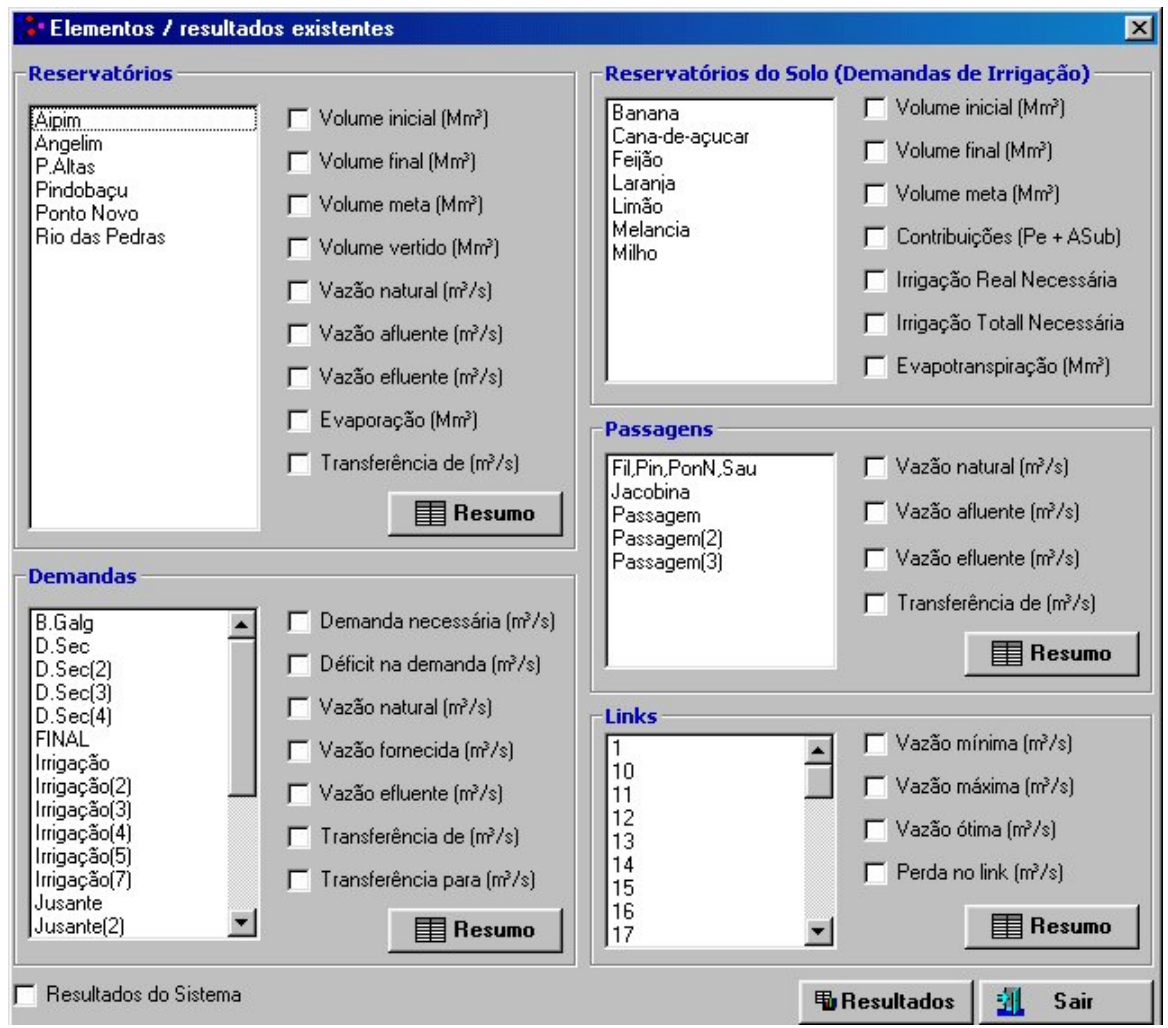

Figura 21. Tela de escolha dos resultados

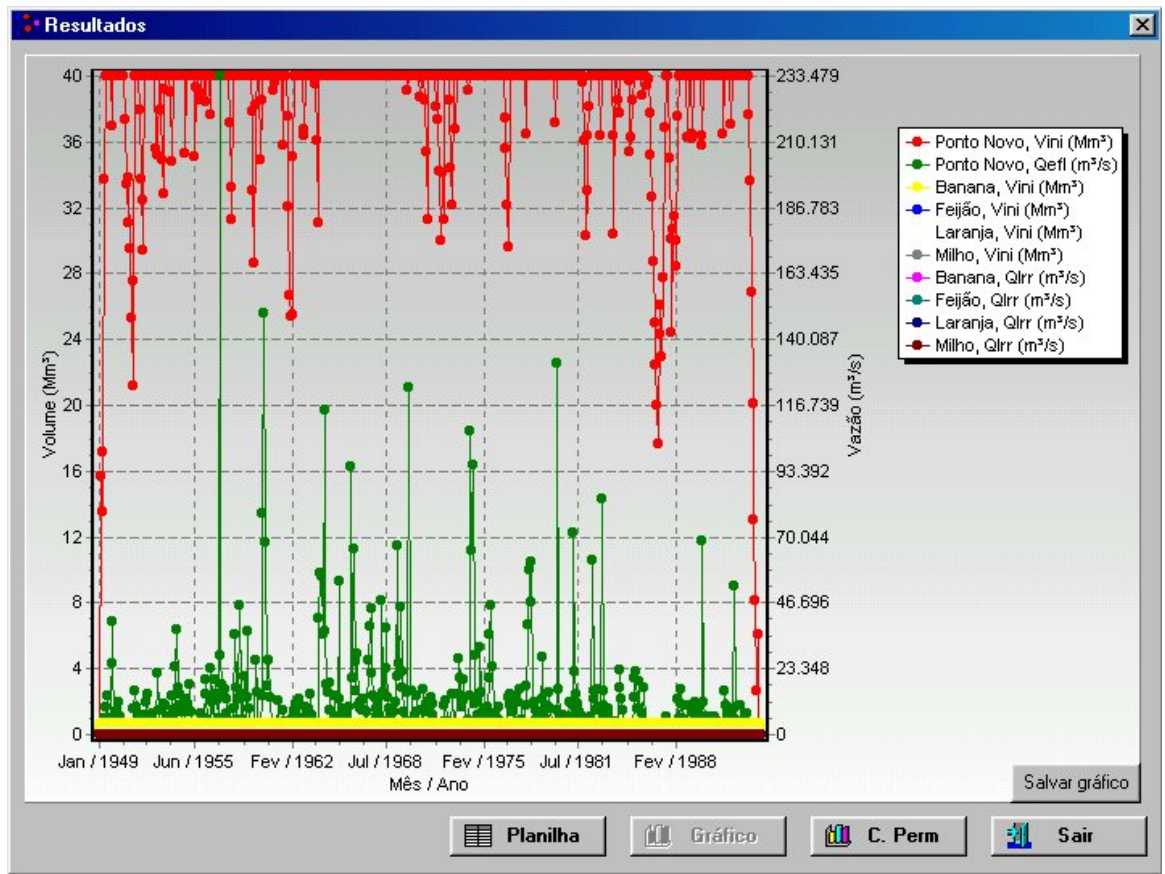

Figura 22. Tela de resultados mostrando volumes e vazões no mesmo gráfico 


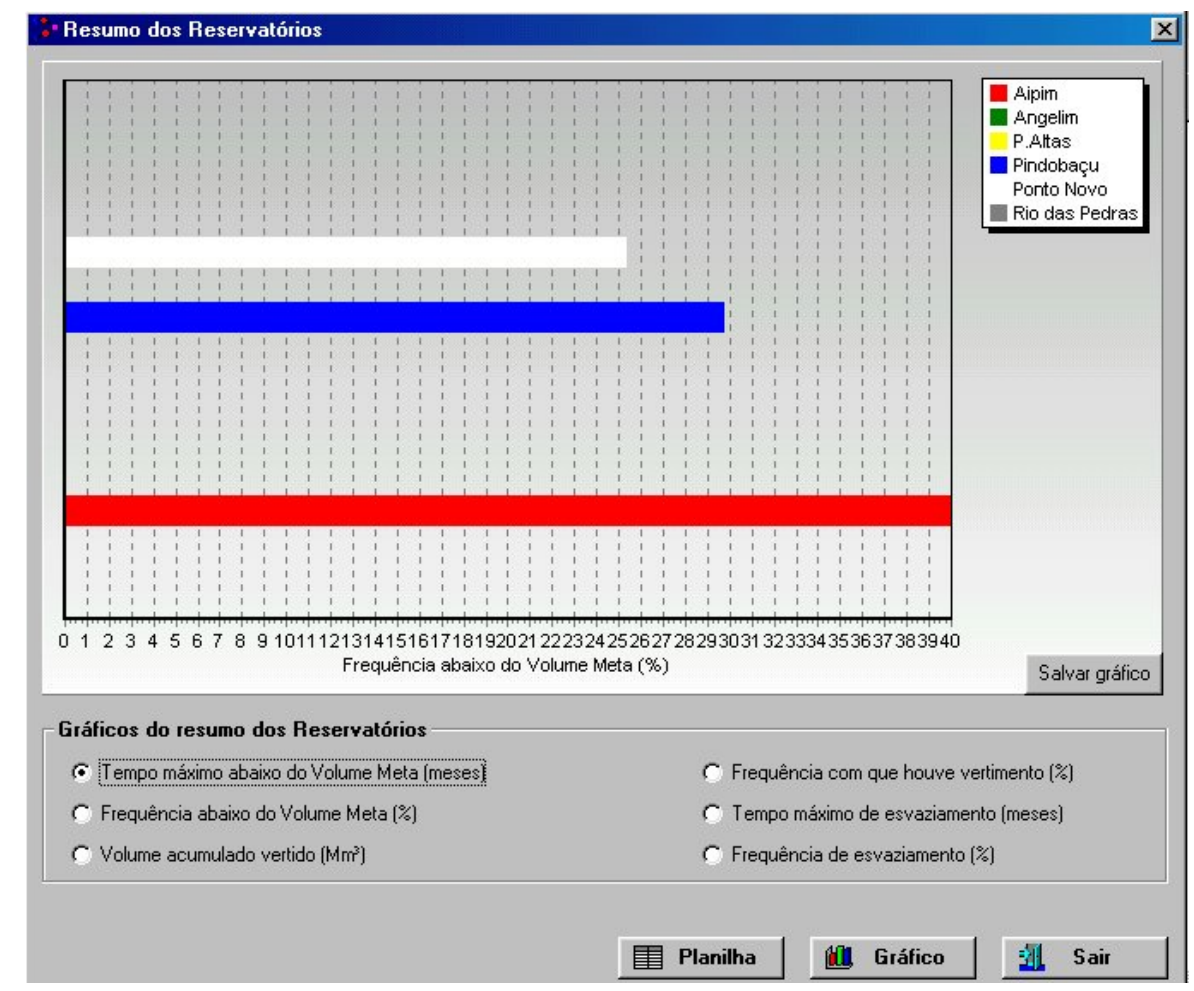

Figura 23. Resumo dos resultados em formato gráfico

\subsection{Demanda de Irrigação: Comparação dos métodos de Cálculo}

Além das planilhas e gráficos de resultados já apresentados, o IrrigaLS oferece duas opções de avaliação sobre a irrigação, que podem ser acessadas através do menu Irrigação, conforme visto na Figura 24.

As duas opções são:

- Método do balanço hídrico e comparação dos resultados: os resultados são acessados através da planilha mostrada na Figura 25. Verifica-se pela figura que é possível fazer a análise da demanda de irrigação desejada de acordo com a quantidade de água disponível na rede, optando: pelo intervalo de interesse da simulação; pela forma de determinação do coeficiente de umidade 
do solo $\left(\mathrm{K}_{\mathrm{s}}\right)$; e pela unidade de interesse $\left[\mathrm{mm} \mathrm{ou} \mathrm{m}^{3} / \mathrm{s}\right]$. No estágio atual a água é considerada suficiente para suprir as necessidades hídricas das culturas.

- Método do balanço hídrico: para o método do balanço hídrico a análise dos resultados é feita em base diária, em forma de gráfico (Figura 26) e/ou planilha (Figura 27). É possível analisar todas as variáveis envolvidas na rotina de cálculo, que segue os passos descritos no item 3.4.3.

- Comparação dos resultados: a comparação dos resultados obtidos pelo dois métodos (IrrigaLS e balanço hídrico do solo), é em base mensal devido ao próprio intervalo de simulação do IrrigaLS (Figura 28).

- Comparação da queda de produção: permite a análise das variáveis obtidas através da simulação no IrrigaLS e através de cálculos diretos pelo método do balanço hídrico (Figura 29). As variáveis envolvidas são: o coeficiente de resposta $\left(\mathrm{K}_{\mathrm{y}}\right)$ (armazenadas em banco de dados e varia de acordo com a cultura); a evapotranspiração relativa $\left(\mathrm{ET}_{\mathrm{a}} / \mathrm{ET}_{\mathrm{p}}\right)$; o rendimento relativo $\left(\mathrm{Y}_{\mathrm{a}} / \mathrm{Y}_{\mathrm{p}}\right)$; e a produção relativa $\left(\mathrm{P}_{\mathrm{a}} / \mathrm{P}_{\mathrm{p}}\right)$. A análise do rendimento e da produção de acordo com a lâmina irrigada, fornece ao usuário uma visão sobre o efeito da água na produção da cultura, permitindo a tomada de decisão quando esta quantidade de água não for suficiente para manter a produção em níveis desejados. Os métodos de cálculo para $\mathrm{Y}_{\mathrm{a}} / \mathrm{Y}_{\mathrm{p}}$ e a produção relativa $\mathrm{P}_{\mathrm{a}} / \mathrm{P}_{\mathrm{p}}$ seguem os item 3.4.4 e 3.4.5, respectivamente. 
Ao comparar as variáveis obtidas pelos dois métodos de determinação da demanda de irrigação, o usuário passa a ter uma visão crítica, podendo avaliar melhor o critério adotado.

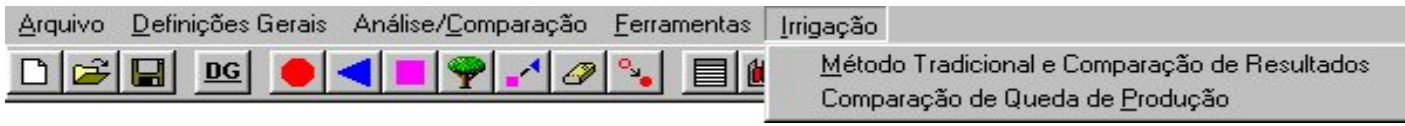

Figura 24. Menu irrigação com as opções de comparação entre os métodos: simulação do IrrigaLS e cálculos diretos (tradicional)

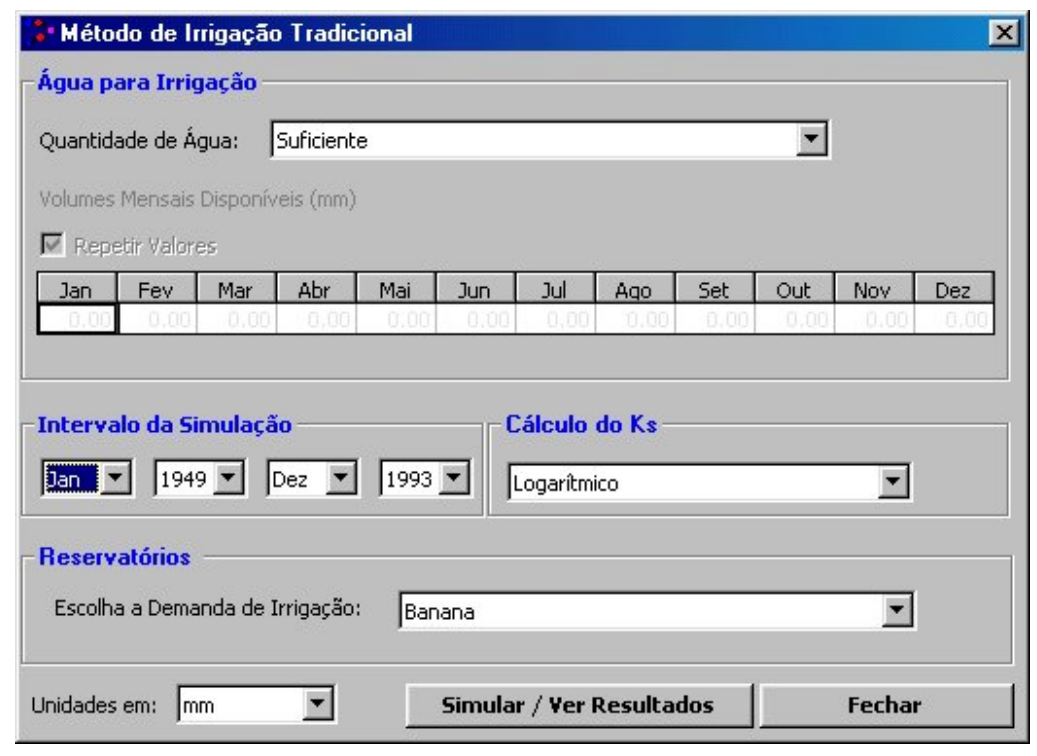

Figura 25. Planilha de comparação das variáveis de irrigação obtidas através da simulação no IrrigaLS e através de cálculos diretos pelo método do balanço hídrico 


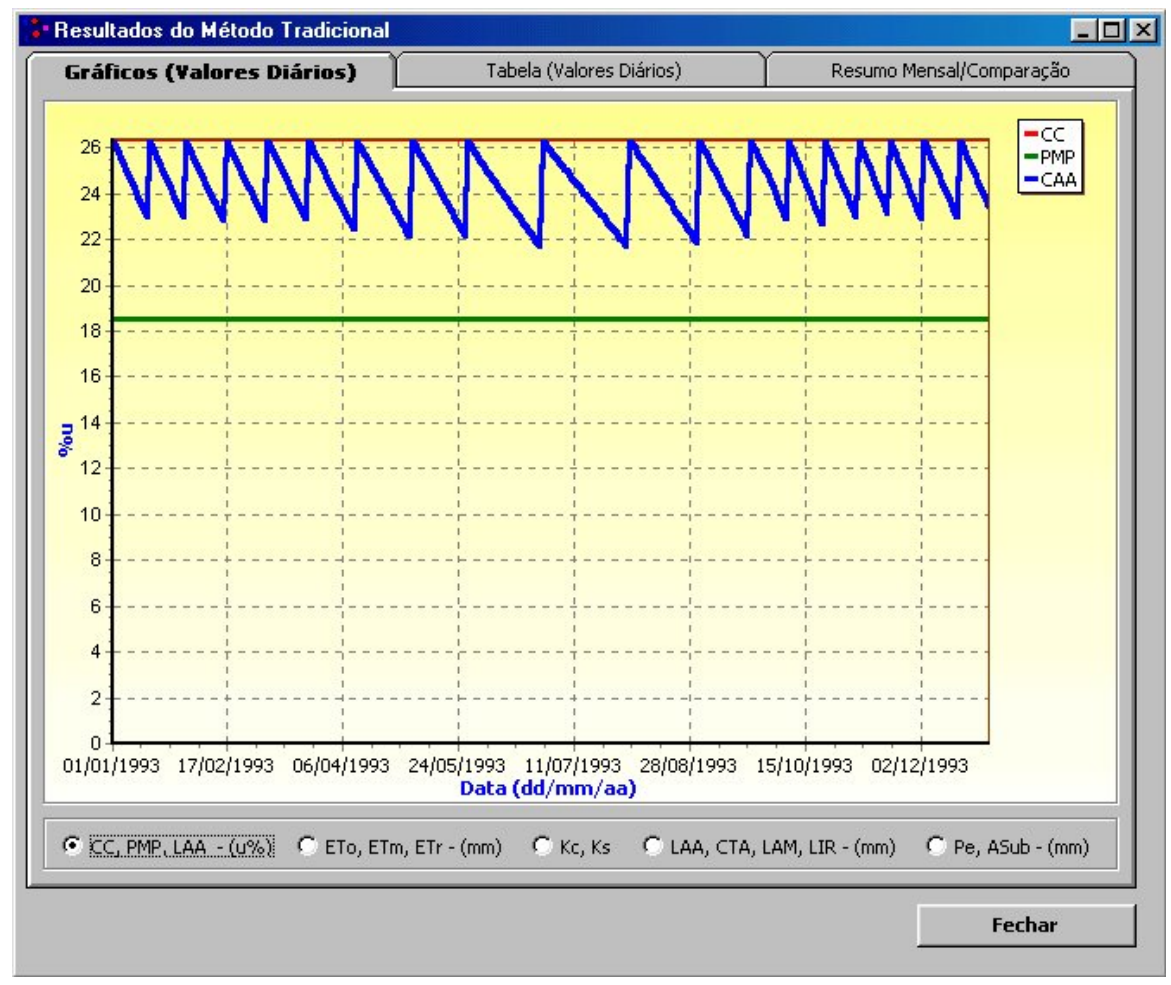

Figura 26. Resultado em forma de gráfico comparando a capacidade de campo, o ponto de murcha permanente e a lâmina atual de água no solo obtidos pelo método do balanço hídrico de cálculo da irrigação

\begin{tabular}{|c|c|c|c|c|c|c|c|c|c|}
\hline \multicolumn{9}{|c|}{ - Resultados do Método Tradicional } & $-(a \mid) \times$ \\
\hline \multicolumn{3}{|c|}{ Gráficos (Valores Diários) } & \multicolumn{3}{|c|}{ Tabela (Valores Diários) } & \multicolumn{3}{|c|}{ Resumo Mensal//Comparação } & \\
\hline Data & CC (\%) & PMP (\%) & CAA (\%) & CTA $(\mathrm{mm})$ & CAA $(\mathrm{mm})$ & LAM $(\mathrm{mm})$ & LIR (mm) & ETo $(\mathrm{mm})$ & $\Delta$ \\
\hline $01 / 01 / 1949$ & 26.400 & 18.500 & 26.400 & 94.800 & 94.800 & 42.230 & --- & 3.908 & \\
\hline $02 / 01 / 1949$ & 26.400 & 18.500 & 26.231 & 94.800 & 92.768 & 42.230 & --- & 3.908 & \\
\hline $03 / 01 / 1949$ & 26.400 & 18.500 & 26.061 & 94.800 & 90.737 & 42.230 & --- & 3.908 & \\
\hline $04 / 01 / 1949$ & 26.400 & 18.500 & 25.892 & 94.800 & 88.705 & 42.230 & --- & 3.908 & \\
\hline $05 / 01 / 1949$ & 26.400 & 18.500 & 25.723 & 94.800 & 86.674 & 42.230 & --- & 3.908 & \\
\hline $06 / 01 / 1949$ & 26.400 & 18.500 & 25.554 & 94.800 & 84.642 & 42.230 & --- & 3.908 & \\
\hline $07 / 01 / 1949$ & 26.400 & 18.500 & 25.384 & 94.800 & 82.611 & 42.230 & --- & 3.908 & \\
\hline $08 / 01 / 1949$ & 26.400 & 18.500 & 25.215 & 94.800 & 80.579 & 42.230 & --- & 3.908 & \\
\hline $09 / 01 / 1949$ & 26.400 & 18.500 & 25.046 & 94.800 & 78.547 & 42.230 & --- & 3.908 & \\
\hline $10 / 01 / 1949$ & 26.400 & 18.500 & 24.876 & 94.800 & 76.516 & 42.230 & --- & 3.908 & \\
\hline $11 / 01 / 1949$ & 26.400 & 18.500 & 24.707 & 94.800 & 74.484 & 42.230 & --- & 3.908 & \\
\hline $12 / 01 / 1949$ & 26.400 & 18.500 & 24.538 & 94.800 & 72.453 & 42.230 & --- & 3.908 & \\
\hline $13 / 01 / 1949$ & 26.400 & 18.500 & 24.368 & 94.800 & 70.421 & 42.230 & --- & 3.908 & \\
\hline $14 / 01 / 1949$ & 26.400 & 18.500 & 24.199 & 94.800 & 68.390 & 42.230 & --- & 3.908 & \\
\hline $15 / 01 / 1949$ & 26.400 & 18.500 & 24.030 & 94.800 & 66.358 & 42.230 & --- & 3.908 & \\
\hline $16 / 01 / 1949$ & 26.400 & 18.500 & 23.861 & 94.800 & 64.326 & 42.230 & --- & 3.908 & \\
\hline $17 / 01 / 1949$ & 26.400 & 18.500 & 23.691 & 94.800 & 62.295 & 42.230 & --- & 3.908 & \\
\hline $18 / 01 / 1949$ & 26.400 & 18.500 & 23.522 & 94.800 & 60.263 & 42.230 & --- & 3.908 & \\
\hline $19 / 01 / 1949$ & 26.400 & 18.500 & 23.353 & 94.800 & 58.232 & 42.230 & --- & 3.908 & \\
\hline $20 / 01 / 1949$ & 26.400 & 18.500 & 23.183 & 94.800 & 56.200 & 42.230 & --- & 3.908 & \\
\hline $21 / 01 / 1949$ & 26.400 & 18.500 & 23.014 & 94.800 & 54.169 & 42.230 & --- & 3.908 & \\
\hline $22 / 01 / 1949$ & 26.400 & 18.500 & 22.845 & 94.800 & 52.137 & 42.230 & --- & 3.908 & \\
\hline $23 / 01 / 1949$ & 26.400 & 18.500 & 22.675 & 94.800 & 50.105 & 42.230 & --- & 3.908 & \\
\hline $24 / 01 / 1949$ & 26.400 & 18.500 & 22.506 & 94.800 & 48.074 & 42.230 & --- & 3.908 & \\
\hline \multirow[t]{2}{*}{$25 / n$} & 26 ann & $1850 n$ & 22337 & 94 8חก & de na? & 4) 33n & & 3 ans, & - \\
\hline & & & & & & & & Fechar & \\
\hline
\end{tabular}

Figura 27. Resultados em forma de planilha comparando a capacidade de campo, o ponto de murcha permanente e a lâmina atual de água no solo obtidos pelo método do balanço hídrico de cálculo da irrigação 


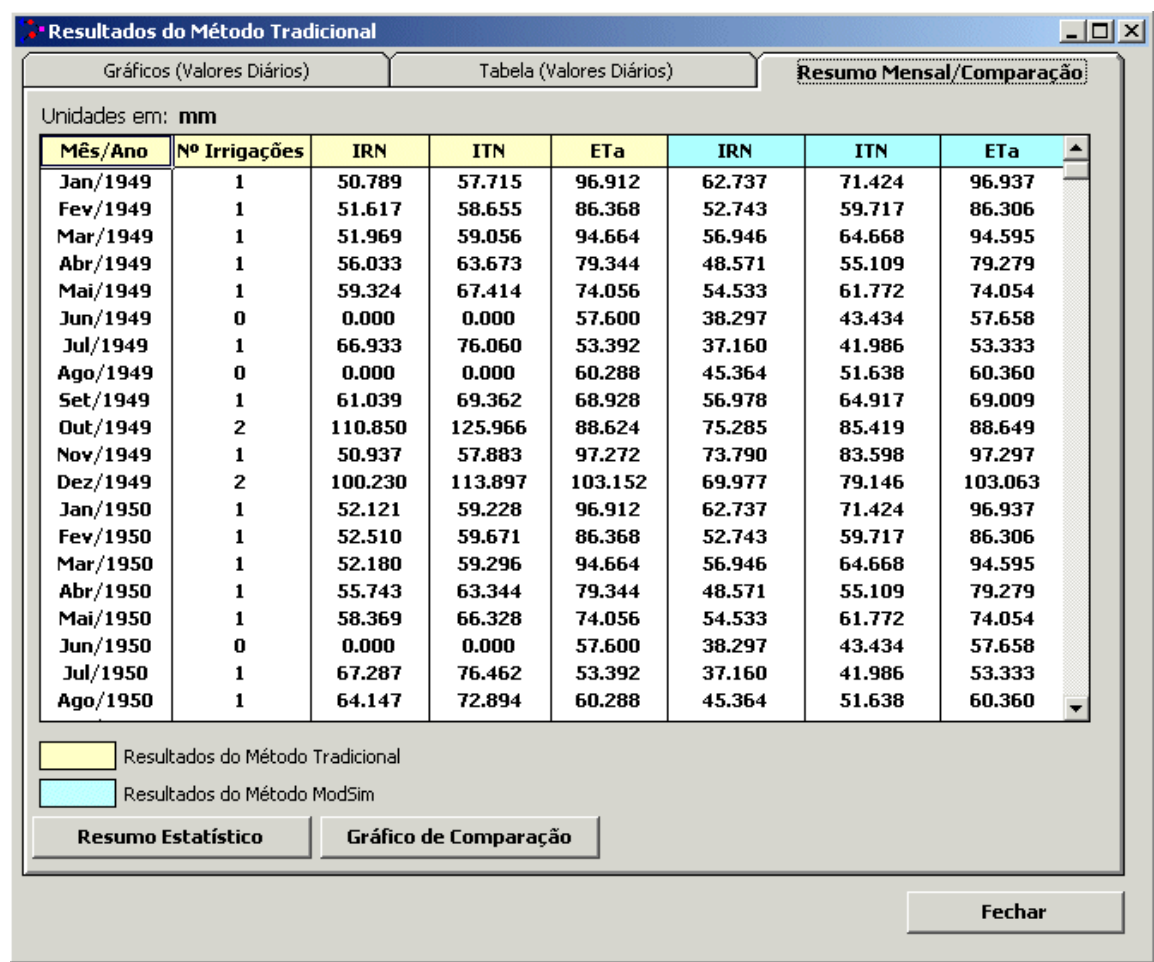

Figura 28. Comparação entre os resultados obtidos pelo métodos ModSim e do balanço hídrico

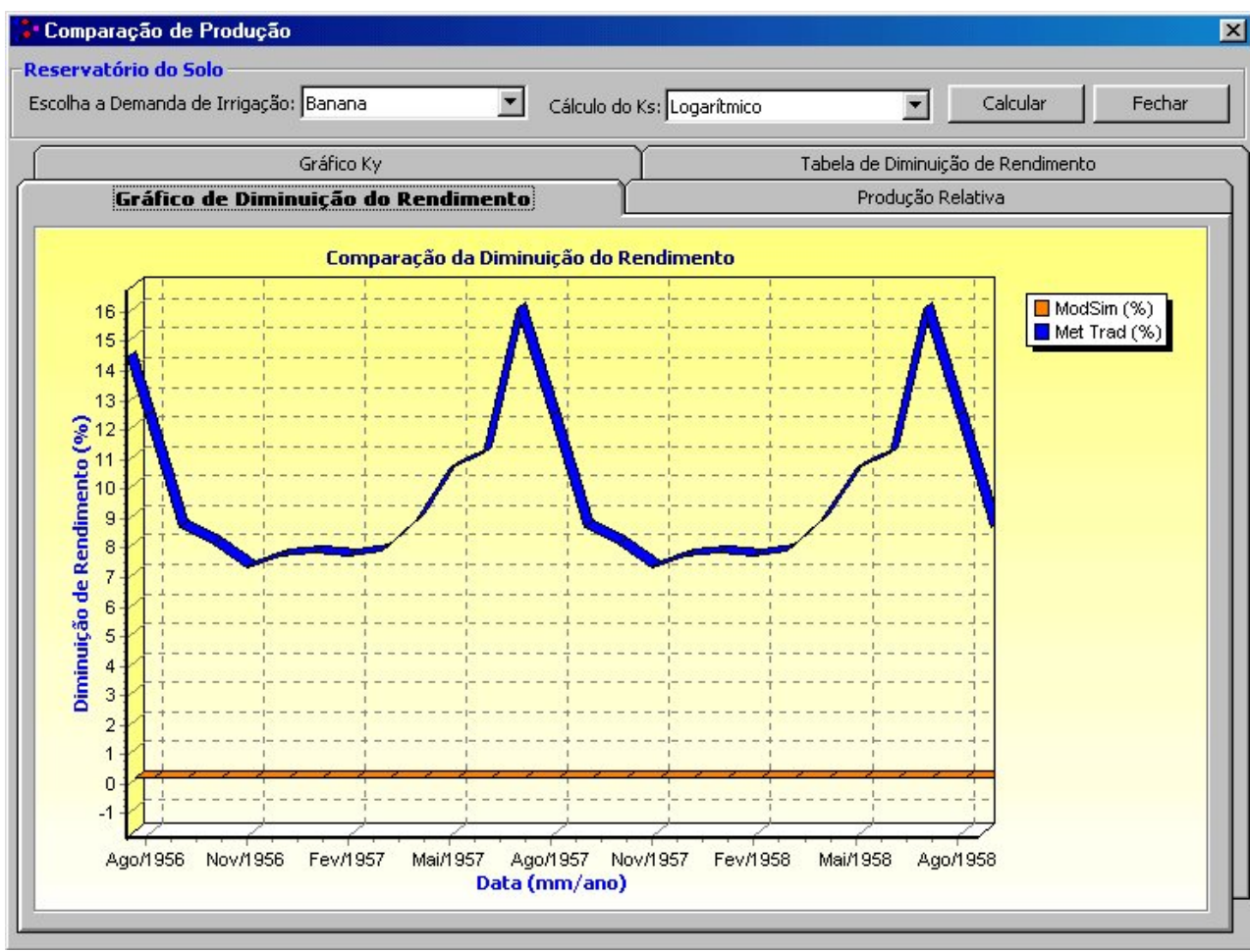

Figura 29. Análise do rendimento relativo e da produção relativa obtidos através da simulação no ModSim e através de cálculos diretos pelo método do balanço hídrico 


\subsubsection{Análise/Comparação de projetos}

O modelo IrrigaLS permite ao usuário visualizar os dados e comparar os resultados de quaisquer projetos previamente calculados.

\subsubsection{Ferramentas especiais}

O IrrigaLS apresenta duas ferramentas especiais para auxiliar o usuário na manipulação da rede representativa do sistema em estudo. Estas ferramentas são:

- Dimensionar: permite, através da tela mostrada na Figura 30, alterar o tamanho dos elementos. Isto é útil quando o desenho fica muito carregado devido ao grande número de elementos;

- Localizar: mostra a posição de qualquer um dos elementos existentes na rede através da tela mostrada na Figura 31. Um exemplo de elemento localizado está na Figura 32.

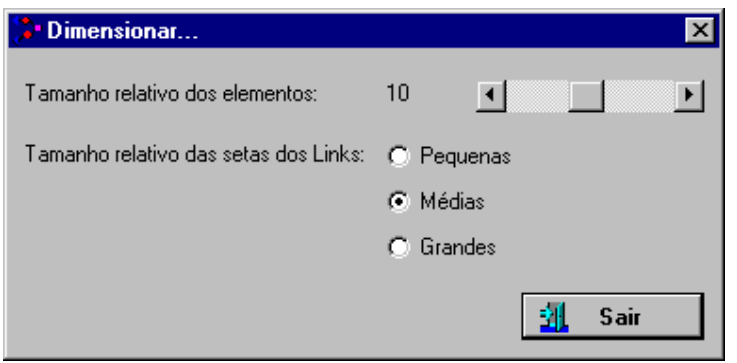

Figura 30. Tela para dimensionar os elementos 


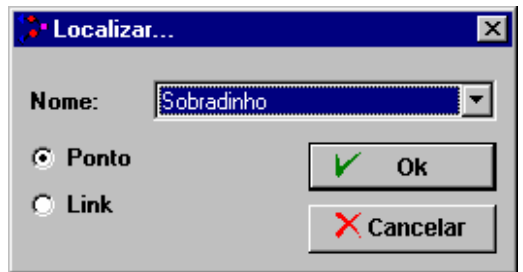

Figura 31. Tela para localizar elementos

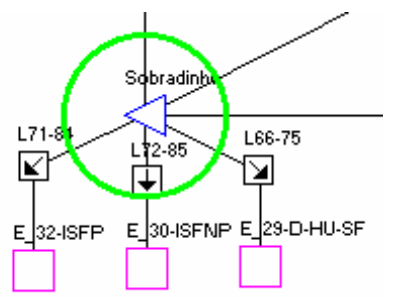

Figura 32. Exemplo de elemento localizado

\subsubsection{Adaptações}

Para considerar o solo como um reservatório no processo de simulação do IrrigaLS, foram necessárias algumas adaptações no reservatório superficial do modelo. As relações existentes entre o reservatório superficial e o reservatório do solo encontram-se descritas no item 3. 6. e na Figura 11. As adaptações de cálculo são descritas a seguir.

\subsubsection{Volume de Água no Solo}

O volume de água considerado disponível para a planta no perfil do solo e na $Z_{\mathrm{r}}$ corresponde a Equação 37. 


\subsubsection{Volume meta}

O volume meta no reservatório superficial do ModSimLS corresponde a fração do volume total que deve permanecer no reservatório durante o período de simulação.

No reservatório do solo, com a finalidade de suprir as necessidades hídricas da cultura e manter a produção a níveis satisfatórios obedecendo a relação clima-soloágua-cultura. Assumiu-se como padrão para o volume meta o próprio volume na $\mathrm{CC}$, ou seja, a fração do volume na $\mathrm{CC}=1$ (Figura 19). Caso a água disponível para cultura não seja suficiente para suprir as necessidades hídricas da planta, o usuário poderá optar por um outro valor de fração do volume total. Vale lembrar que a umidade do solo nunca deve igualar ao PMP afim de que a planta não morra.

Para optar pela prioridade do volume meta será necessário que o usuário tenha conhecimento das prioridades de uso da água na região.

\subsubsection{Evapotranspiração Real}

Cada cultura tem uma necessidade hídrica; cada solo tem uma capacidade de armazenamento; e a perda de água para a atmosfera esta condicionada ao clima da região. Como no nosso estudo o solo é um reservatório de água, que serve de suporte para as plantas, que por sua vez dependem das características climáticas da região, viuse a necessidade de achar um coeficiente que relacionasse essas quatro variáveis (climasolo-água-cultura). $\mathrm{O}$ coeficiente escolhido foi o $\mathrm{K}_{\mathrm{s}}$, que relaciona a umidade do solo (Equação 4) e, conseqüentemente, as $\mathrm{ET}_{\mathrm{a}}$ e ET (Equação 3). 
No ModSimLS a perda de água por evaporação é avaliada considerando o volume atual de água no reservatório superficial. Com base no volume o modelo interpola a área, multiplica pela taxa evaporada e determina a evaporação atual. Os dados de entrada necessários são os da tabela cota-área-volume do reservatório superficial e a da taxa evaporada.

No reservatório do solo além da perda por evaporação deve-se considerar também a perda por transpiração, ou seja, a $\mathrm{ET}_{\mathrm{a}}$. Partindo deste princípio, por analogia com o ModSimLS, no IrrigaLS os dados de entrada necessários ao cálculo da evapotranspiração são os dados da tabela cota-área-volume do reservatório do solo e a $\mathrm{ET}_{\mathrm{p}}$. O procedimento de cálculo é o mesmo do ModSimLS, ou seja, o modelo com base no volume de água do solo, interpola a área, multiplica por $\mathrm{ET}_{\mathrm{p}}$ e determina a $\mathrm{ET}_{\mathrm{a}}$.

A adaptação da tabela cota-área-volume no IrrigaLS parte das definições da capacidade de armazenamento de água no solo e do $\mathrm{K}_{\mathrm{s}}$. A tabela não aparece ao usuário, a montagem da mesma é feita internamente, já que as variáveis envolvidas dependem das condições de umidade do solo, do clima e da cultura, dados estes fornecidos pelo usuário antes da simulação pelo modelo. A Tabela 1 mostra as adaptações feitas, as colunas em cinza correspondem a tabela cota-área-volume do reservatório do solo.

Verifica-se pela Tabela 1 que partindo-se da umidade do solo, é possível determinar o volume de água no solo e o equivalente a área do reservatório superficial. Para um melhor entendimento segue a explicação de cada coluna da tabela: 
Tabela 1. Demonstração da montagem da Tabela Cota-Area-volume no IrrigaLS

\begin{tabular}{|c|c|c|c|c|c|}
\hline Cota & $\begin{array}{c}\text { Umidade do Solo } \\
{[\%]}\end{array}$ & $\begin{array}{l}\text { CAA } \\
{[\mathrm{mm}]}\end{array}$ & $\begin{array}{l}\text { Volume } \\
{\left[\mathrm{Mm}^{3}\right]}\end{array}$ & $\begin{array}{c}\mathrm{K}_{\mathrm{s}} \\
\text { [adimensional] }\end{array}$ & $\begin{array}{l}\text { Área } \\
{\left[\mathrm{km}^{2}\right]}\end{array}$ \\
\hline 1 & PMP & 0 & \multirow{5}{*}{$\mathrm{CAA} \cdot \mathrm{A}_{\mathrm{i}} \cdot 10^{-3}$} & 0 & \multirow{5}{*}{$\mathrm{Ks} . \mathrm{A}_{\mathrm{i}}$} \\
\hline 2 & \multirow{3}{*}{ interpolação } & \multirow{3}{*}{ Interpolação } & & & \\
\hline 3 & & & & interpolação & \\
\hline 4 & & & & & \\
\hline 5 & $\mathrm{CC}$ & CTA & & 1 & \\
\hline
\end{tabular}

- Coluna Cota: o IrrigaLS considera cinco pontos de variação do volume para proceder à determinação da evapotranspiração. Como o valor da cota não entra nos cálculos foram arbitrados 5 pontos $(1,2, \ldots, 5)$ apenas como seqüência de preenchimento;

- Coluna Umidade do Solo [\%]: corresponde a variação da umidade no solo, que tem como limites mínimo e máximo o PMP e a $\mathrm{CC}$, respectivamente. PMP e CC são dados de entrada;

- Coluna Capacidade Atual de Água no Solo - CAA [mm]: corresponde a lâmina atual de água no solo. Quando o solo está no PMP $(\mathrm{CAA}=0)$, e quando está na $\mathrm{CC}(\mathrm{CAA}=\mathrm{CTA})$.

- Coluna Volume $\left[\mathrm{Mm}^{3}\right]$ : corresponde ao volume atual de água no solo, que é a CAA multiplicada pela área irrigada, ou seja, Volume $=\mathrm{CAA} \cdot \mathrm{Ai} \cdot 10^{-3} \cdot \mathrm{O}$ valor de Ai é dado de entrada.

- Coluna Ks [fração]: $K_{s}$ é o coeficiente de umidade do solo que também relaciona a evapotranspiração atual e potencial $\left(\mathrm{ET}_{\mathrm{a}} / \mathrm{ET}_{\mathrm{p}}\right)$. Quando o solo está 
na $\mathrm{CC}\left(\mathrm{CAA}=\mathrm{CTA}\right.$ e $\left.\mathrm{K}_{\mathrm{s}}=1\right)$, quando está no PMP $\left(\mathrm{CAA}=0\right.$ e $\left.\mathrm{K}_{\mathrm{s}}=0\right) . \mathrm{O}$ usuário pode optar pela forma de determinação do $\mathrm{K}_{\mathrm{s}}$.

- Coluna Área $\left[\mathrm{Km}^{2}\right]$ : corresponde a multiplicação do coeficiente de umidade do solo pela área irrigada, ou seja, Área $=\mathrm{Ks} . \mathrm{A}_{\mathrm{i}}$.

Depois de feita a interpolação na tabela cota-área-volume, o valor resultante será multiplicado pela $\mathrm{ET}_{\mathrm{p}}$, Equação 1, ou seja;

$$
\mathrm{K}_{\mathrm{s}} \cdot \mathrm{A}_{\mathrm{i}} \cdot \mathrm{ET}_{\mathrm{p}}=\frac{\mathrm{ET}_{\mathrm{a}}}{E T_{\mathrm{p}}} \cdot \mathrm{A}_{\mathrm{i}} \cdot \mathrm{ET}_{\mathrm{p}}=\mathrm{ET}_{\mathrm{a}} \cdot \mathrm{A}_{\mathrm{i}}=\text { volume de água evapotranspirado }
$$

\subsubsection{Precipitação efetiva}

A PP no IrrigaLS é admitida como vazão de contribuição (vazão natural ou afluente), sendo dado de entrada e a $\mathrm{PP}_{\mathrm{e}}$ é determinada pelo método do SCS dos USA.

\subsubsection{5. Água no Solo}

Corresponde a água no solo $\left(\mathrm{A}_{\mathrm{s}}\right)$ que antecede a primeira irrigação feita dentro do calendário de irrigação pré-estabelecido. Este valor no IrrigaLS também é considerado como vazão de contribuição (vazão natural ou afluente) e é um dado de entrada. 


\subsection{REGIÃO DE ESTUDO}

A região de estudo, a da Bacia do Itapicuru, localiza-se no semi-árido brasileiro, mais especificamente no Estado da Bahia, conforme pode ser verificado na Figura 33. O ambiente semi-árido do Nordeste brasileiro é diversificado nos seus recursos naturais, e complexo na convivência do homem com o seu clima seco e quente. Se por um lado, o regime hídrico irregular se constitui num sério fator limitante para a produção agropecuária, por outro existem áreas com boa disponibilidade de águas superficiais e subterrâneas, bem como recursos de solo apropriados para desenvolver agricultura irrigada, em condições competitivas com outros semi-áridos do mundo.

A bacia possui área de drenagem de $36.440 \mathrm{~km}^{2}$ e é formada principalmente pelos rios Itapicuru, Itapicuru-Açu, Itapicuru-Mirim, Rio Peixe, Cariaça e Quinjingue (Figura 34).

Os principais usos da água são para:

- Abastecimento;

- Irrigação; e

- Dessedentação de animais. 


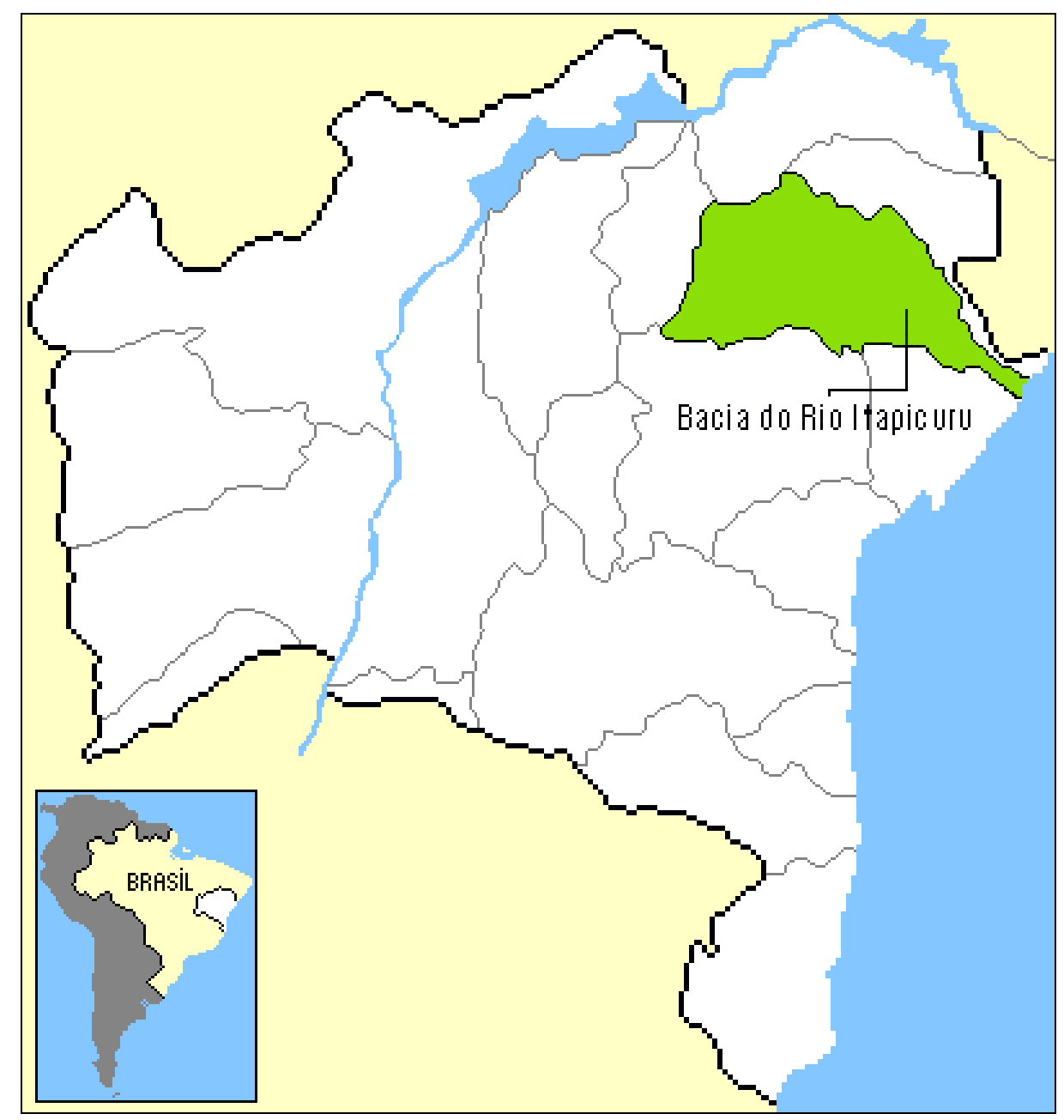

Figura 33. Localização da bacia do Rio Itapicuru

Quanto ao potencial das águas subterrâneas, o sistema aqüífero de maior potencialidade de exploração na bacia é a da bacia sedimentar de Tucano, onde os poços tubulares aí localizados apresentam as maiores vazões.

$\mathrm{Na}$ bacia, ocorrem conflitos em trechos onde a qualidade das águas é alterada devido a lançamentos de resíduos provenientes da atividade de mineração, esgotamento sanitário ou resíduos sólidos.

A relação dos municípios e população que fazem parte da bacia estão apresentadas na Tabela 10 no ANEXO. 


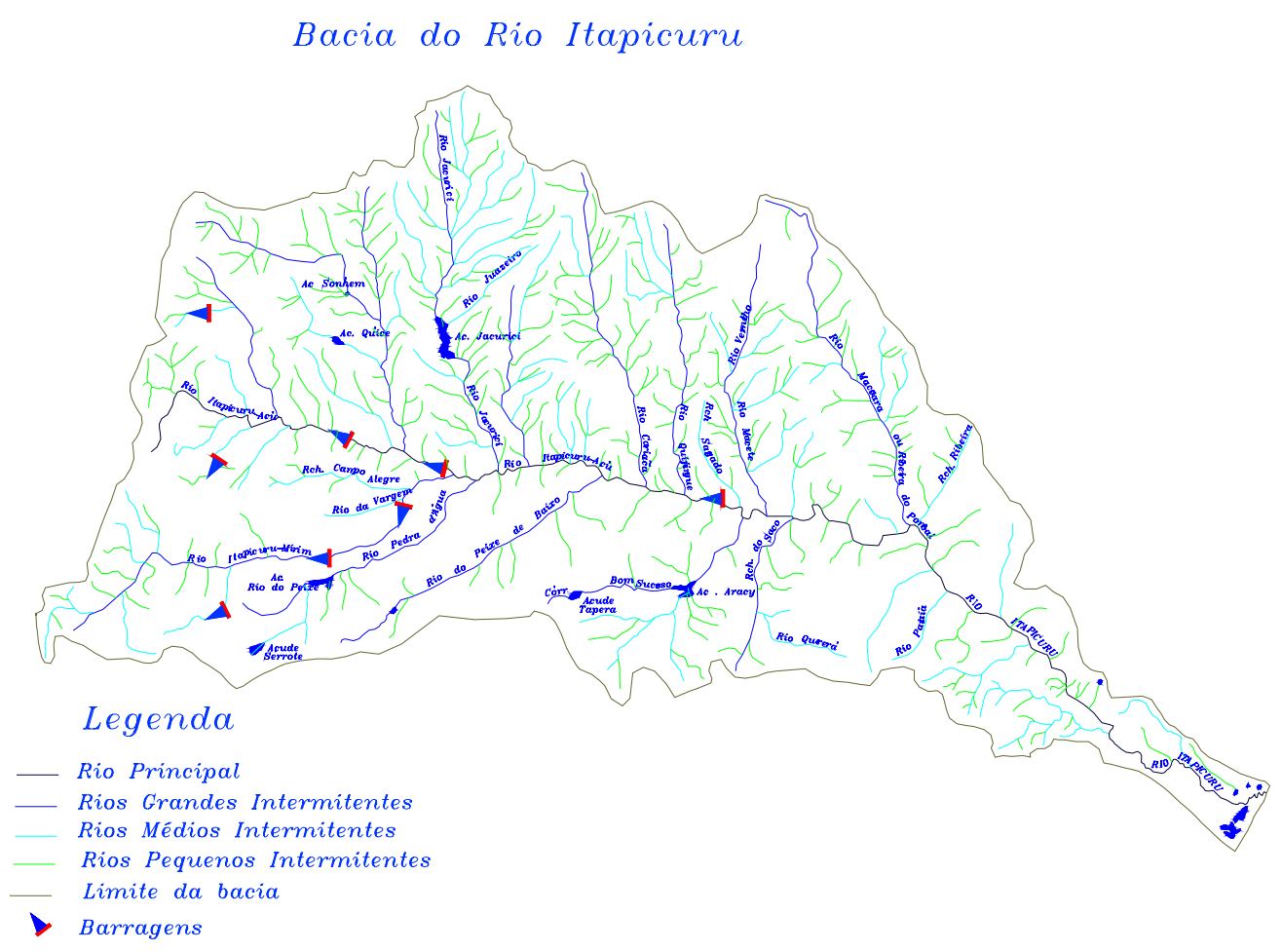

\section{Figura 34. Área de drenagem da bacia do Rio Itapicuru}

\subsubsection{Clima}

Predomínio do clima semi-árido, que transaciona para semi-úmido a úmido no litoral. Com temperatura: média de $24,0^{\circ} \mathrm{C}$; mínima de $21,3^{\circ} \mathrm{C}$; e máxima de $25,5^{\circ} \mathrm{C}$. A umidade relativa do ar média é de $70 \%$, a mínima de $62 \%$ e máxima de $78 \%$. Quanto a pluviosidade as características das regiões são:

- Baixo Itapicuru: abrange a porção da bacia compreendida entre a ponte rodoviária da BA-349, no município de Crisópolis até sua foz no oceano Atlântico. A precipitação anual varia de $530 \mathrm{~mm}$ a $1.439 \mathrm{~mm}$, sendo o período chuvoso de maio a junho e o período seco de setembro a novembro.

- Médio Itapicuru: parte média da bacia, entre Queimadas até a ponte rodoviária da BA-349, no município de Crisópolis. A precipitação anual varia de 411,2 
$\mathrm{mm}$ a $718,1 \mathrm{~mm}$, com o período chuvoso de fevereiro a abril e o período seco de agosto a outubro

- Alto Itapicuru: compreende a parte superior da bacia até a cidade de Queimadas. A precipitação anual varia de $477,6 \mathrm{~mm}$ a $1.129,3 \mathrm{~mm}$ com o período chuvoso de maio a junho e o período seco de setembro a novembro.

Toda a região apresenta diferença hídrica durante praticamente todos os meses do ano.

\subsubsection{Solo}

Devido à grande extensão geográfica e à grande variedade de condições geomorfológica, a bacia do rio Itapicuru apresenta uma grande diversificação de tipos de solos. Foram identificados:

- Solódicos;

- Solos litólicos,;

- Latossolos Vermelho-Amarelo;

- Areias;

- Quartzosas;

- Podzólicos Vermelho-Amarelos eutróficos;

- Regossolos;

- Vertissolos;

- Brunes não Cálcicos;

- Solonetz Solodizados.

A predominância é da classe dos Planossolos Sólodicos, que ocupam mais de $50 \%$ da bacia. Os Latossolos Vermelho-Amarelos aparecem em segundo lugar, seguido 
das Areias Quartzosas, Podzólicos Vermelho-Amarelos, Vertissolos, Regossolos e Solos Litólicos.

A Tabela 12 no ANEXO apresenta as características de alguns solos do nordeste.

\subsection{TOPOLOGIA DO SISTEMA DA BACIA DO ITAPICURU}

$\mathrm{Na}$ análise da validade das adaptações e da eficiência do IrrigaLS foram comparadas duas redes que diferem somente pela inclusão, em uma delas, do reservatório solo (reservatório superficial adaptado). No estudo considerou-se as adaptações no reservatório superficial de Ponto Novo, mais especificamente à região dos municípios de Filadélfia, Pindobaçu, Ponto Novo e Saúde. A descrição dos municípios encontra-se na Tabela 10 no ANEXO.

Na rede da Figura 35 não foram consideradas as adaptações do modelo, e a demanda de irrigação total foi calculada no SSD. Na da Figura 36, consideraram-se as adaptações do modelo e as demandas foram calculadas e analisadas individualmente. 


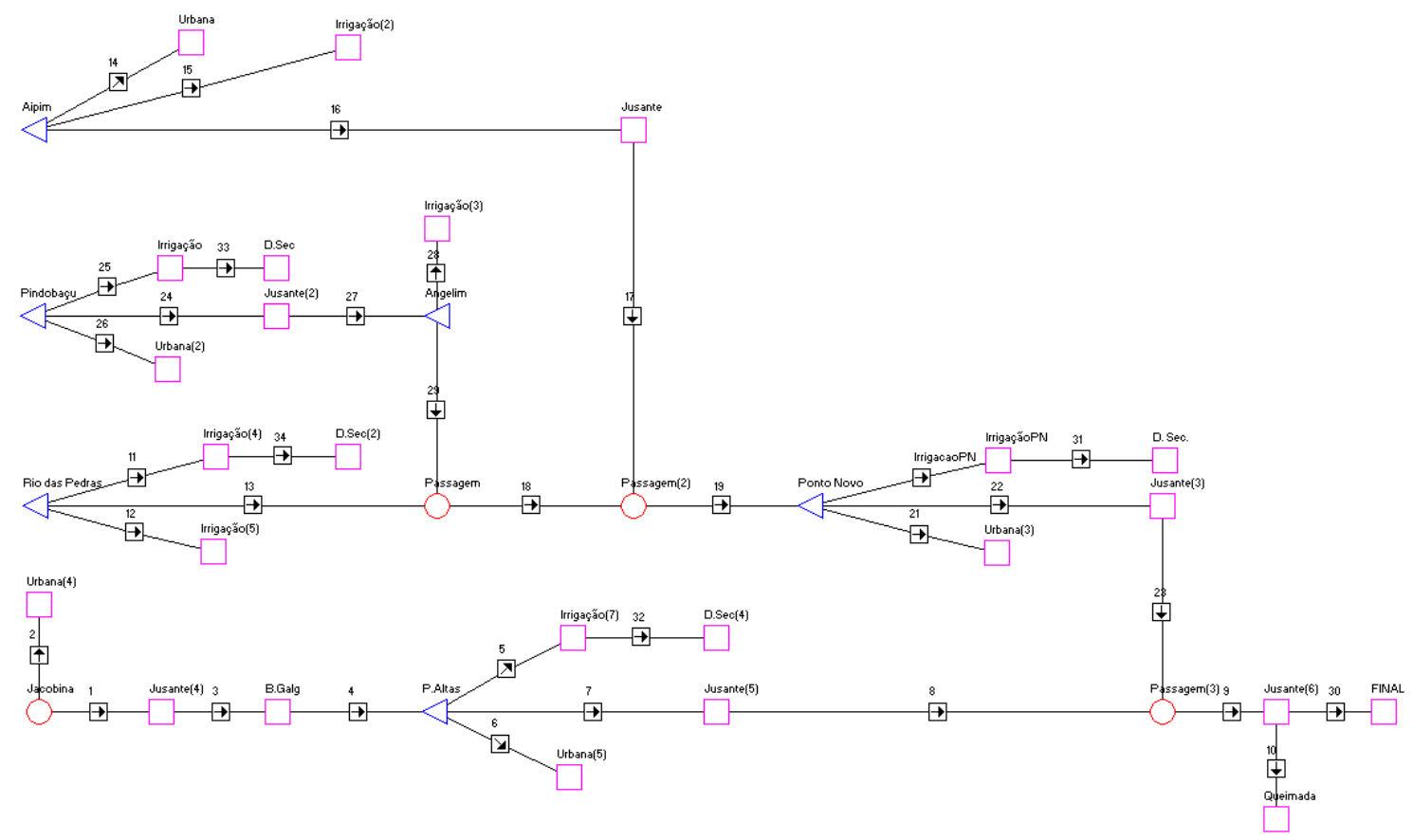

Figura 35. Topologia usada na simulação do sistema da Bacia do Itapicuru, não considerando-se o solo como um reservatório

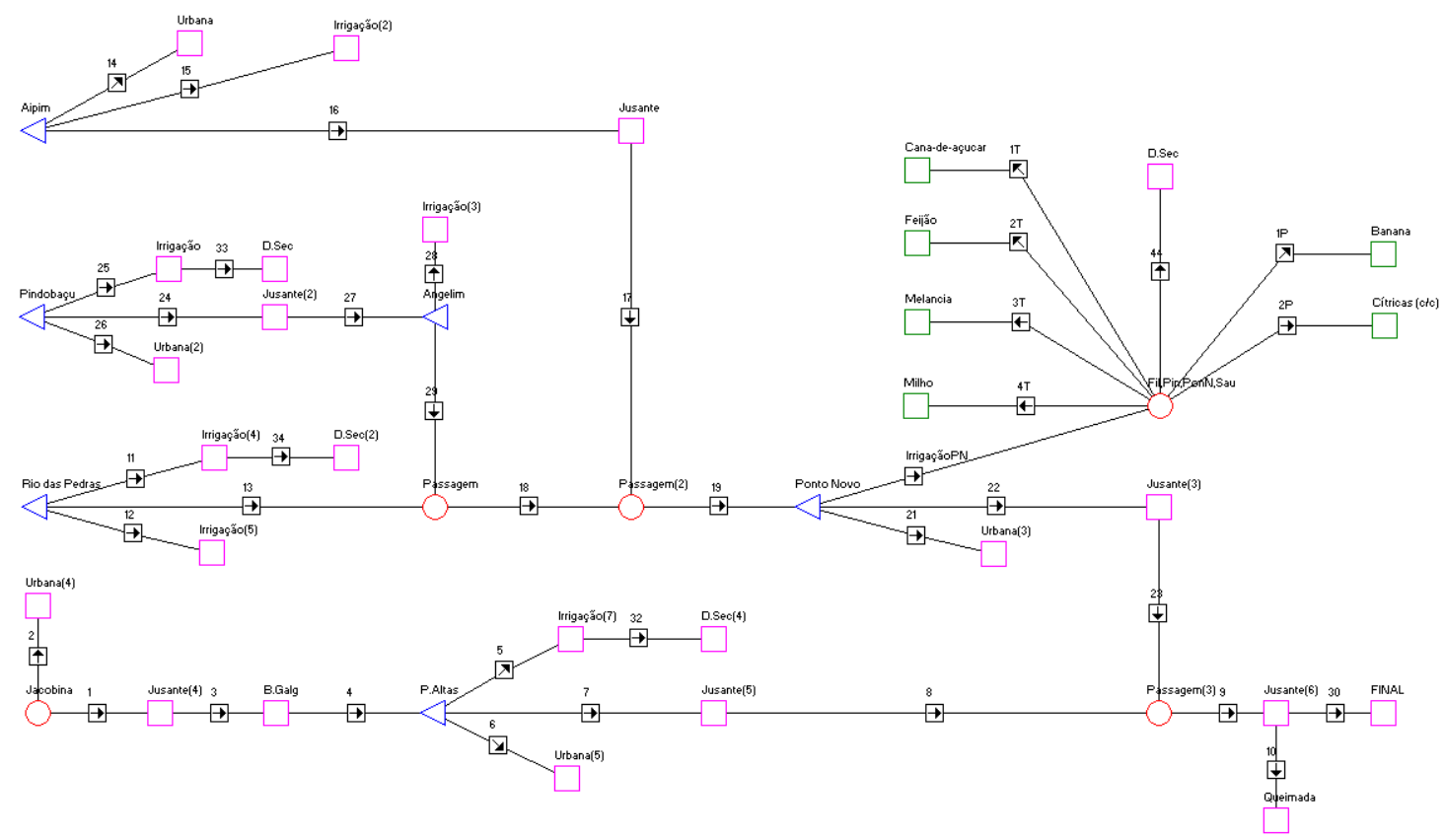

Figura 36. Topologia usada na simulação do sistema da Bacia do Itapicuru, considerando-se o solo como um reservatório 


\subsubsection{Dados de Entrada}

\subsubsection{Climáticos}

Foram considerados os dados de $\mathrm{ET}_{\mathrm{o}}$ das estações de medição consideradas de influência para bacia do Rio Itapicuru. A Tabela 11 no ANEXO apresenta as estações de medição.

Os valores médios de $\mathrm{ET}_{\mathrm{o}}$ e de $\mathrm{PP}$, para a área irrigada, foram obtidos por interpolação através das Equações 40 e 41, respectivamente.

$$
\mathrm{ET}_{\mathrm{o}}=\frac{\sum_{\mathrm{i}=1}^{\mathrm{n}}\left(\mathrm{ET}_{\mathrm{oi}} \cdot \mathrm{d}_{\mathrm{i}}^{-2}\right)}{\sum_{\mathrm{i}=1}^{\mathrm{n}} \mathrm{d}_{\mathrm{i}}^{-2}}
$$

em que:

- $\mathrm{ET}_{\mathrm{o}}=$ evapotranspiração de referência $[\mathrm{mm} / \mathrm{mês}]$;

- $\mathrm{ET}_{\mathrm{oi}}=$ evapotranspiração de referência na estação i $[\mathrm{mm} / \mathrm{mês}]$;

- $\mathrm{d}_{\mathrm{i}}=$ distancia da estação i ao ponto desejado; $\left[\mathrm{km}^{2}\right]$.

$$
P P=\frac{\sum_{i=1}^{n}\left(P P_{i} \cdot d_{i}^{-2}\right)}{\sum_{i=1}^{n} d_{i}^{-2}}
$$

em que:

- PP = precipitação [mm/mês];

- $\mathrm{PP}_{\mathrm{i}}=$ precipitação na estação i $[\mathrm{mm} / \mathrm{mês}]$; 
- $\mathrm{d}_{\mathrm{i}}=$ distancia da estação i ao ponto desejado; $\left[\mathrm{km}^{2}\right]$.

\subsubsection{Solo}

O solo da região dos municípios de Filadélfia, Pindobaçu, Ponto Novo e Saúde apresenta horizonte B Latossólico. As propriedades do mesmo foram extrapoladas de estudos realizados, por diversos pesquisadores, no Nordeste (Tabela 12 no ANEXO).

Considerou-se no estudo o solo como constituído por apenas uma camada. A Tabela 2 apresenta os valores médios da $\mathrm{CC}$, do PMP e a $\mathrm{D}_{\mathrm{a}}$, para o solo da região de estudo.

Tabela 2. Valores característicos do solo da região de estudo

\begin{tabular}{|c|c|c|c|}
\hline Classe de Solo & CC [\% peso] & PMP [\% peso] & D $_{\text {a }}$ [adimensional] \\
\hline Horizonte B Latossólico & 26.43 & 18.46 & 1.2 \\
\hline
\end{tabular}

Fonte: Cavalcanti (1979)

\subsubsection{Sistema de Irrigação}

Os valores da $\varepsilon$ foram armazenados em banco de dados e podem ser conferidos na Tabela 7 no ANEXO

\subsubsection{Culturas}

Considerou-se apenas algumas culturas representativas da região. A Tabela 3 apresenta a relação das culturas e suas respectivas áreas irrigadas. 
Os valores da $Z_{r}$ e do $K_{c}$ foram armazenados em banco de dados e podem ser conferidos nas Tabelas 1 e 2 no ANEXO, respectivamente.

Tabela 3. Culturas consideradas no estudo e suas respectivas áreas

\begin{tabular}{|l|c|c|}
\hline \multicolumn{1}{|c|}{ Cultura } & \multicolumn{2}{|c|}{ Área Irrigada [ha] } \\
\hline & Cenário Atual & Cenário Futuro \\
\hline Banana & 222 & 287 \\
\hline Cana-de-açúcar & 9 & 105 \\
\hline Cítricas & 8 & 23 \\
\hline Feijão & 15 & 175 \\
\hline Melancia & 4 & 47 \\
\hline Milho & 4 & 47 \\
\hline
\end{tabular}

Fonte: SRH do Estado da Bahia 


\section{RESULTADOS E DISCUSSÃO}

A eficiência do IrrigaLS e a validade das adaptações foram verificadas mediante comparação com dois outros métodos em diferentes etapas.

Os resultados comparados referem-se a diferentes culturas. As culturas em estudo diferenciam-se com relação ao ciclo vegetativo (permanentes e temporárias), ao $K_{c}$, à $Z_{r}$, à $K_{y}$ e as $A_{i}$. Baseando-se nesta diversidade de parâmetros pôde-se chegar à algumas conclusões em relação ao IrrigaLS.

Os métodos e as etapas encontram-se descritos a seguir:

\section{a) Métodos}

- Balanço hídrico: as demandas de irrigação das culturas individuais foram calculadas a partir do balanço hídrico do solo (veja item 3.4);

- ModSimLS: o solo não foi considerado como um reservatório e as demandas de irrigação das culturas foram calculadas no SSD e admitidas na topologia do sistema como um único nó (veja item 3.5). A topologia do sistema encontra-se na Figura 35;

- IrrigaLS: o solo foi considerado como um reservatório e as demandas de irrigação das culturas foram calculadas pelo próprio modelo e admitidas na topologia do sistema como nós individuais (veja item 3.6). A topologia do sistema encontra-se na Figura 36. 


\section{b) Etapas}

- primeira: verificou-se a viabilidade do IrrigaLS na determinação da demanda de irrigação e da evapotranspiração da cultura, mediante comparação dos resultados obtidos pelo modelo com os obtidos pelo método do balanço hídrico;

- segunda: verificou-se as vantagens do IrrigaLS sobre o ModSimLS mediante comparação das demandas de irrigação;

- terceira: analisou-se o efeito do déficit hídrico sobre rendimento e sobre a produção das culturas;

- quarta: verificou-se a influência das adaptações feitas no IrrigaLS e a viabilidade do modelo para simular sistemas. Nesta fase compararam-se os resultados obtidos pelo IrrigaLS com os obtidos pelo ModSimLS na simulação do sistema da bacia do Itapicuru.

\subsection{RESUMO DOS PROJETOS}

Considerou-se a bacia do Itapicuru em dois projetos, um foi analisado no ModSimLS e outro no IrrigaLS. A Tabela 4 apresenta o resumo dos projetos e as características dos sistemas encontram-se descritas a seguir. 
Tabela 4. Resumo dos projetos considerados no estudo da eficiência do IrrigaLS e na validação das adaptações

\begin{tabular}{|l|c|c|}
\hline \multirow{2}{*}{ Características } & \multicolumn{2}{|c|}{ Bacia do Itapicuru } \\
\cline { 2 - 3 } & Projeto 1 & Projeto 2 \\
\hline Nome do Projeto & ModSimLS & IrrigaLS \\
\hline Total de Nós & 35 & 40 \\
\hline Reservatórios & 6 & 6 \\
\hline Demandas & 25 & 23 \\
\hline Reservatórios do Solo & 0 & 5 \\
\hline Nós de Passagens & 4 & 5 \\
\hline Links & 34 & 39 \\
\hline Tipo de Simulação & Simulação Contínua & Simulação Contínua \\
\hline Opção de Cálculo & Calibração & Calibração \\
\hline Mês inicial & Janeiro & Janeiro \\
\hline Ano inicial & 1949 & 1949 \\
\hline Série histórica (anos) & 45 & 45 \\
\hline
\end{tabular}

\section{a) Volumes nos reservatórios superficiais}

- Aipim: $2.3 \mathrm{Mm}^{3}$

- Pindobaçu: $9.0 \mathrm{Mm}^{3}$

- Ponto Novo: $40.0 \mathrm{Mm}^{3}$

c) Política de operação (prioridade)

- Reservatórios do solo:

- culturas permanentes: 8 
- culturas temporárias: 10

- Reservatórios Superficiais: 90

- Demandas

- irrigação: 10

- jusante: 5

- queimada: 1

- final: 99

- urbana: 1

\subsection{AJUSTE DOS VALORES DAS TABELAS}

$\mathrm{Na}$ rotina de cálculos do programa computacional do IrrigaLS utilizaram-se algumas tabelas (veja item 3). Com o intuito de facilitar e agilizar esse processo, representaram-se os valores tabelados em forma de gráficos a fim de verificar a existência de alguma relação entre eles. Observou-se que alguns desses conjuntos de valores apresentavam uma tendência, sendo portanto possível representá-los por funções. As funções obtidas dizem respeito à $\mathrm{PP}_{\mathrm{e}}$, ao fator de correção da $P P_{e}\left(\mathrm{~K}_{\mathrm{PP}}\right)$, à $\mathrm{f}$, e a $\mathrm{P}_{\mathrm{a}} / \mathrm{P}_{\mathrm{p}}$. As curvas de ajuste e as funções que representam os valores de $\mathrm{PP}_{\mathrm{e}}, \mathrm{K}_{\mathrm{PP}}$, $\mathrm{f}$ e $\mathrm{P}_{\mathrm{a}} / \mathrm{P}_{\mathrm{p}}$, encontram-se nas Figuras $37,38,39$ e 40 e nas Tabelas 5, 6, 7 e 8, respectivamente. 


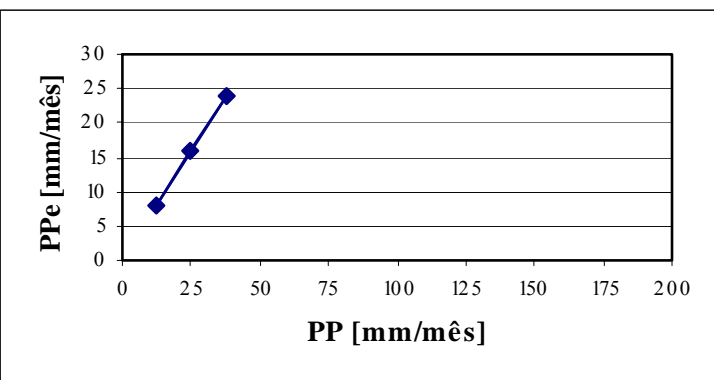

(a) $\mathrm{ET}_{\mathrm{p}}=25 \mathrm{~mm} / \mathrm{mês}$

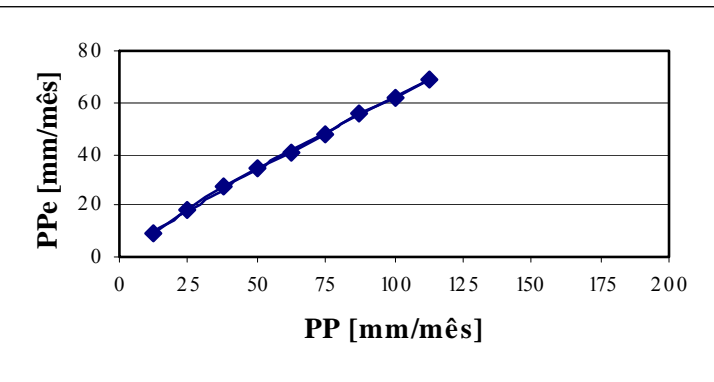

(c) $\mathrm{ET}_{\mathrm{p}}=75 \mathrm{~mm} / \mathrm{mês}$

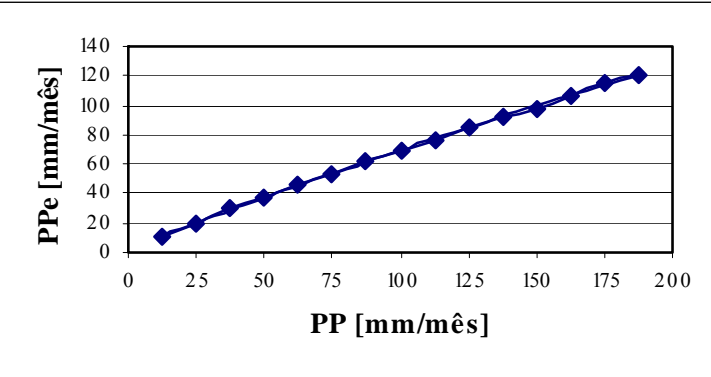

(e) $\mathrm{ET}_{\mathrm{p}}=125 \mathrm{~mm} / \mathrm{mês}$

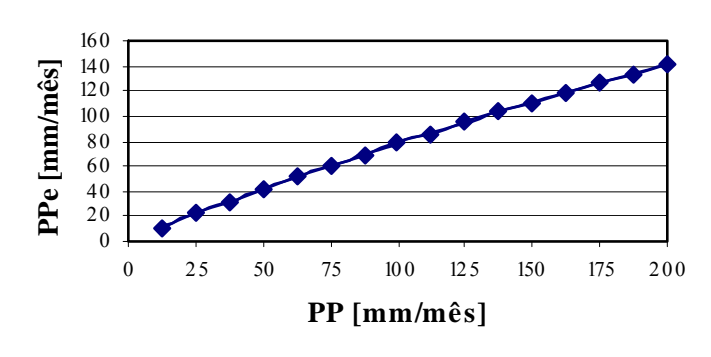

(g) $\mathrm{ET}_{\mathrm{p}}=175 \mathrm{~mm} / \mathrm{mês}$

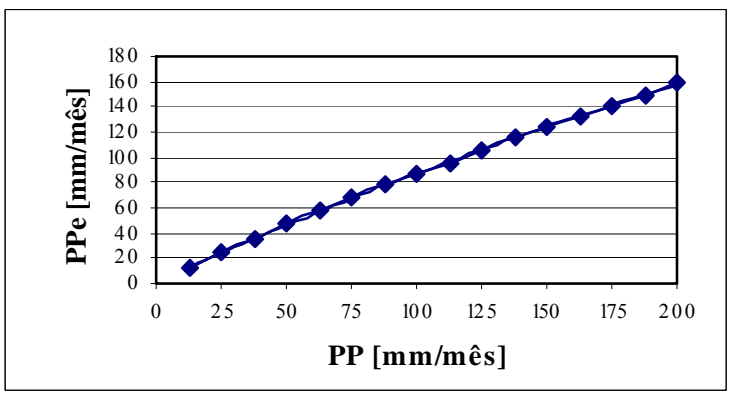

(i) $\mathrm{ET}_{\mathrm{p}}=225 \mathrm{~mm} / \mathrm{mês}$

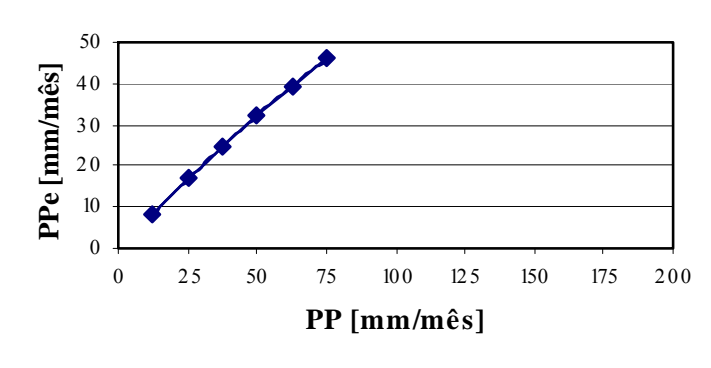

(b) $\mathrm{ET}_{\mathbf{p}}=50 \mathrm{~mm} / \mathrm{mês}$

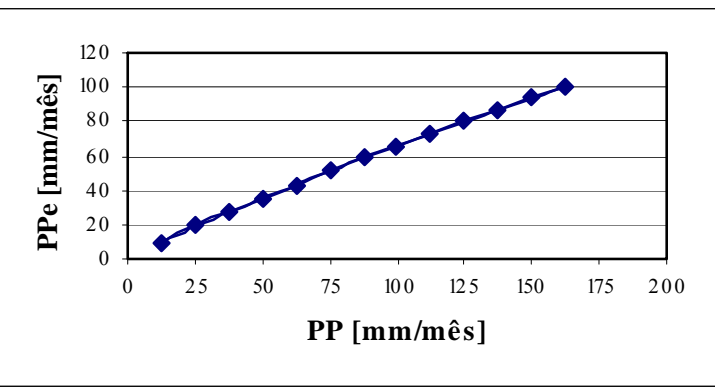

(d) $\mathrm{ET}_{\mathrm{p}}=100 \mathrm{~mm} / \mathrm{mês}$

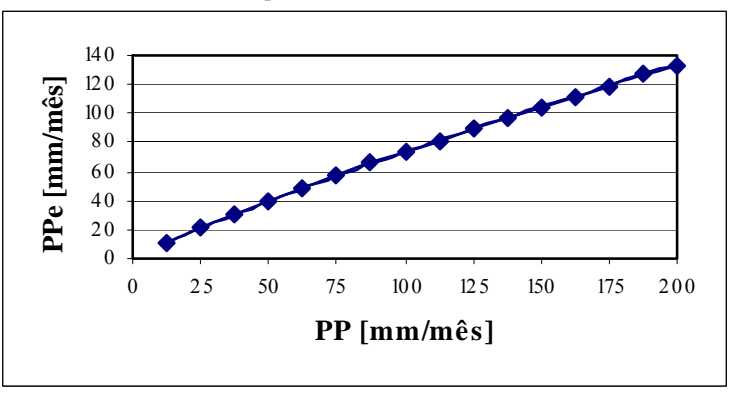

(f) $\mathrm{ET}_{\mathbf{p}}=150 \mathrm{~mm} / \mathrm{mês}$

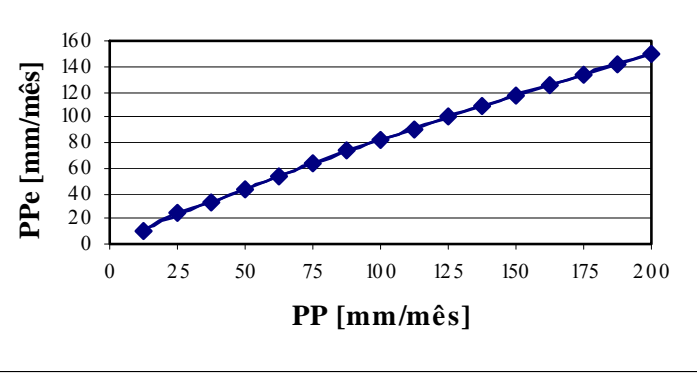

(h) $\mathrm{ET}_{\mathbf{p}}=200 \mathrm{~mm} / \mathrm{mês}$

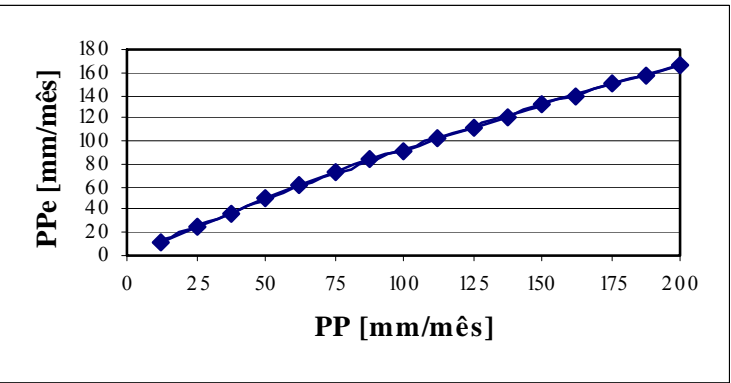

(j) $\mathrm{ET}_{\mathrm{p}}=250 \mathrm{~mm} / \mathrm{mês}$

Figura 37. Curvas de ajuste da precipitação efetiva $\left(\mathbf{P P}_{\mathrm{e}}\right)$ quando a capacidade total de água no solo (CTA) for de $75 \mathrm{~mm} / \mathrm{mês}$ 
Tabela 5. Equações da precipitação efetiva $\left(\mathrm{PP}_{\mathbf{e}}\right)$ quando a capacidade total de água no solo (CTA) for de $75 \mathrm{~mm}$

\begin{tabular}{|c|c|c|}
\hline $\mathrm{ET}_{\mathrm{p}}[\mathrm{mm} / \mathrm{mês}]$ & $\mathrm{PP}_{\mathrm{e}}[\mathrm{mm} / \mathrm{mês}]$ & $\mathrm{R}^{2}$ \\
\hline 25 & $0,64 . \mathrm{PP}$ & 1,0000 \\
\hline 50 & $-0,0016 \mathrm{PP}^{2}+0,7411 \mathrm{PP}-0,8$ & 0,9996 \\
\hline 75 & $-0,0009 \mathrm{PP}^{2}+0,708 \mathrm{PP}+0,7857$ & 0,9993 \\
\hline 100 & $-0,0007 \mathrm{PP}^{2}+0,7258 \mathrm{PP}+0,8531$ & 0,9997 \\
\hline 125 & $-0,0005 \mathrm{PP}^{2}+0,7213 \mathrm{PP}+2,2615$ & 0,9992 \\
\hline 150 & $-0,0006 \mathrm{PP}^{2}+0,785 \mathrm{PP}+1,5661$ & 0,9997 \\
\hline 175 & $-0,0007 \mathrm{PP}^{2}+0,8295 \mathrm{PP}+1,9464$ & 0,9998 \\
\hline 200 & $-0,0007 \mathrm{PP}^{2}+0,8738 \mathrm{PP}+1,5268$ & 0,9998 \\
\hline 225 & $-0,0007 \mathrm{PP}^{2}+0,9258 \mathrm{PP}+1,7393$ & 0,9998 \\
\hline 250 & $-0,0009 \mathrm{PP}^{2}+1,0142 \mathrm{PP}+0,4982$ & 0,9997 \\
\hline
\end{tabular}

$\mathrm{PP}[\mathrm{mm} / \mathrm{mês}]$

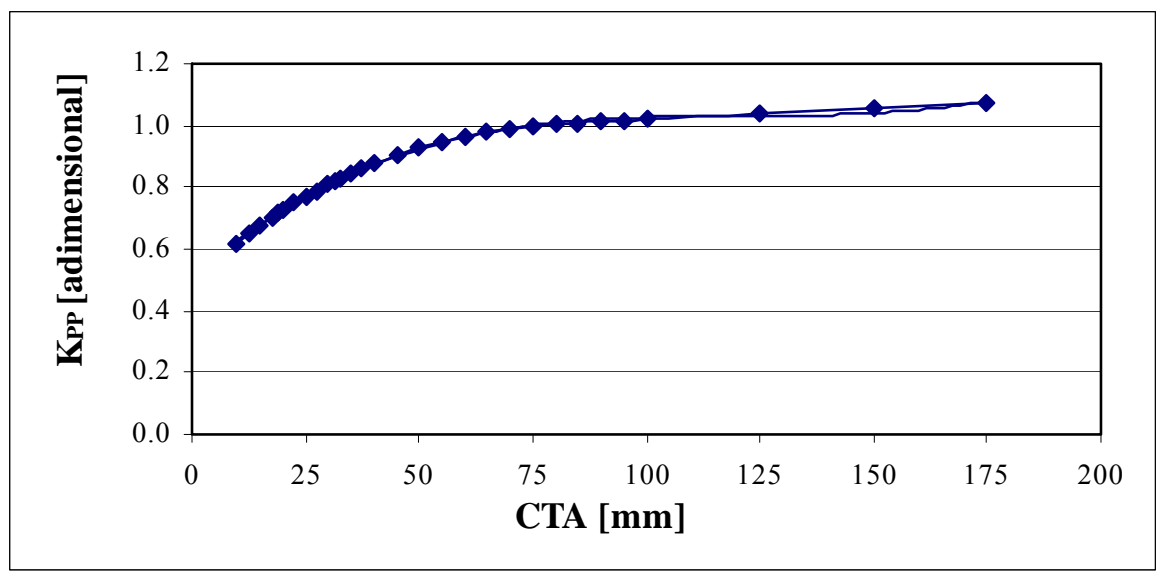

Figura 38. Curva de ajuste da correção da precipitação efetiva $\left(\mathrm{PP}_{\mathrm{e}}\right)$ quando a capacidade total de água no solo (CTA) for diferente de 75 mm

Tabela 6. Equação que representa o Fator de correção da precipitação efetiva $\left(\mathrm{PP}_{\mathrm{e}}\right)$ quando a capacidade total de água no solo (CTA) for diferente de $75 \mathrm{~mm}$

\begin{tabular}{|c|c|}
\hline $\mathrm{K}_{\mathrm{PP}}$ [adimensional] & $\mathrm{R}^{2}$ \\
\hline $3,10^{-7} \cdot \mathrm{CTA}^{3}-0,0001 \cdot \mathrm{CTA}^{2}+0,0128 \cdot \mathrm{CTA}+0,51$ & 0,9979 \\
\hline
\end{tabular}

CTA $[\mathrm{mm}]$ 


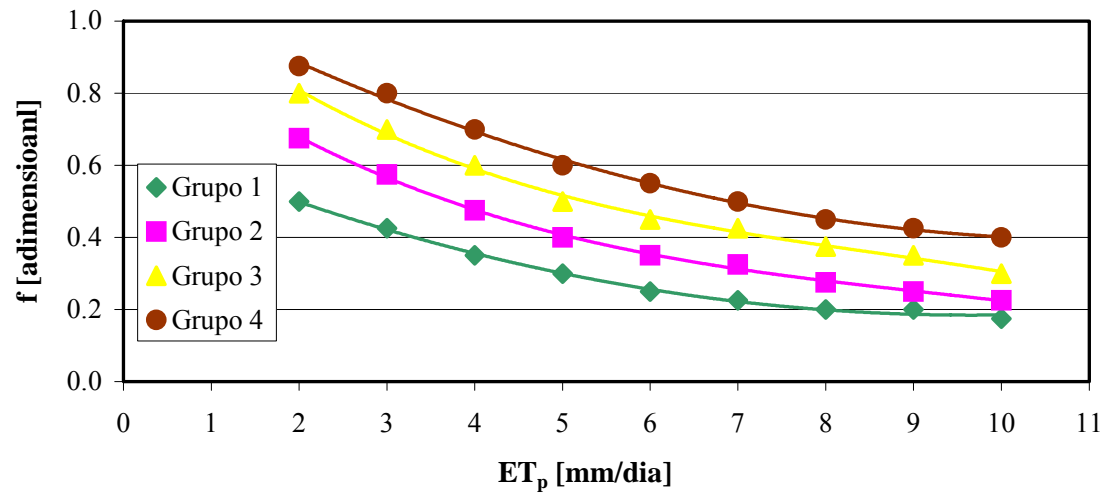

os grupos de culturas encontram-se na Tabela 20 do ANEXO

Figura 39. Curvas de ajuste da fração de esgotamento de água no solo (f) para diferentes grupos de cultura

Tabela 7. Equações que representam a fração de esgotamento de água no solo (f) para diferentes grupos de cultura

\begin{tabular}{|c|c|c|}
\hline Grupo de Culturas ${ }^{1}$ & $\mathrm{f}$ [adimensional] & $\mathrm{R}^{2}$ \\
\hline Grupo 1 & $0,0054 \cdot \mathrm{ET}_{\mathrm{p}}^{2}-0,1035 \cdot \mathrm{ET}_{\mathrm{p}}+0,6838$ & 0,9964 \\
\hline Grupo 2 & $-0,0006 \cdot \mathrm{ET}_{\mathrm{p}}{ }^{3}+0,0175 \cdot \mathrm{ET}_{\mathrm{p}}{ }^{2}-0,1883 \cdot \mathrm{ET}_{\mathrm{p}}+0,9905$ & 0,9982 \\
\hline Grupo 3 & $-0,0008 \cdot \mathrm{ET}_{\mathrm{p}}{ }^{3}+0,0205 \cdot \mathrm{ET}_{\mathrm{p}}{ }^{2}-0,2096 \mathrm{x}+1,1522$ & 0,9960 \\
\hline Grupo 4 & $0,0058 \cdot \mathrm{ET}_{\mathrm{p}}^{2}-0,1302 \cdot \mathrm{ET}_{\mathrm{p}}+1,122$ & 0,9969 \\
\hline
\end{tabular}

$\mathrm{ET}_{\mathrm{p}}[\mathrm{mm} / \mathrm{dia}]$

${ }^{1}$ encontram-se na Tabela 20 do ANEXO 


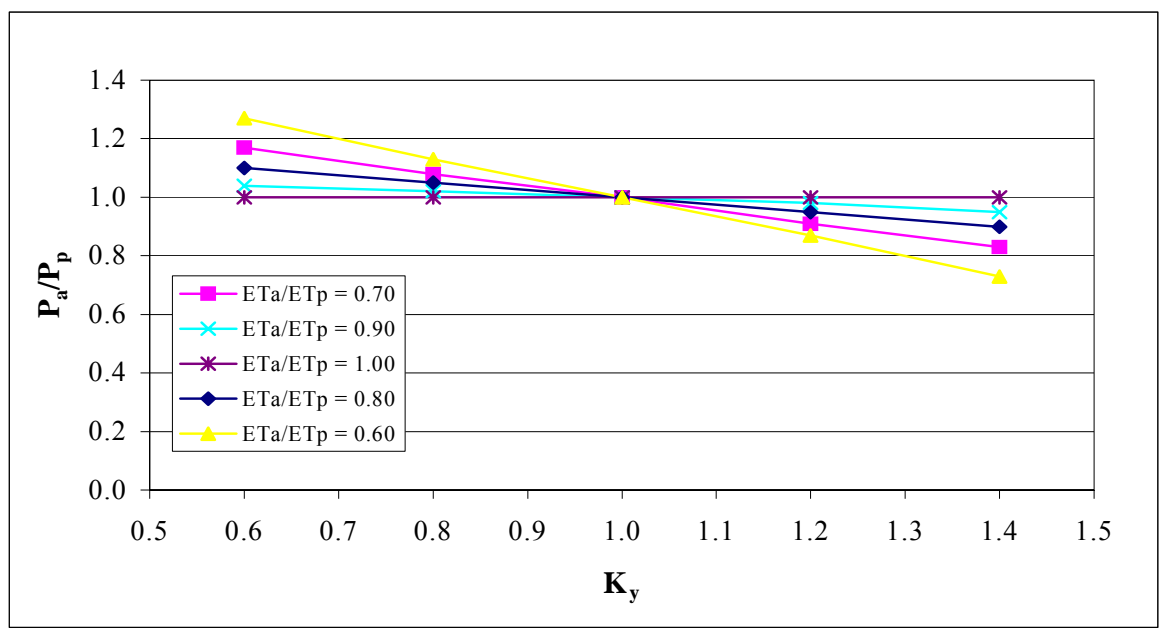

Figura 40. Curvas de ajuste da produção relativa $\left(P_{a} / P_{p}\right)$, em função do coeficiente $K_{y}$ e da evapotranspiração relativa $\left(\mathrm{ET}_{\mathrm{a}} / \mathrm{ET}_{\mathrm{p}}\right)$

Tabela 8. Equações que representam a produção relativa $\left(P_{a} / P_{p}\right)$, em função do coeficiente $K_{y}$ e da evapotranspiração relativa $\left(E T_{a} / E T_{p}\right)$

\begin{tabular}{|c|c|c|}
\hline $\mathrm{ET}_{\mathrm{a}} / \mathrm{ET}_{\mathrm{p}}$ & $\mathrm{P}_{\mathrm{a}} / \mathrm{P}_{\mathrm{p}}$ & $\mathrm{R}^{2}$ \\
\hline 0,60 & $-0,67 \cdot \mathrm{K}_{\mathrm{y}}+1,67$ & 0,9998 \\
\hline 0,70 & $-0,425 \cdot \mathrm{K}_{\mathrm{y}}+1,423$ & 0,9996 \\
\hline 0,80 & $-0,25 \cdot \mathrm{K}_{\mathrm{y}}+1,25$ & 1,0000 \\
\hline 0,90 & $-0,11 \cdot \mathrm{K}_{\mathrm{y}}+1,108$ & 0,9918 \\
\hline 1,00 & 1 & 1,0000 \\
\hline
\end{tabular}

$\mathrm{K}_{\mathrm{y}}$ [adimensional], encontram-se na Tabela 8 no ANEXO

Verifica-se pelas Figuras 37, 38, 39 e 40 e pelos valores de $\mathrm{R}^{2}$ nas Tabelas 6, 7, 8 e 9, que as funções representam bem os valores de $P P_{e}, K_{P P}, f$ e $P_{a} / P_{p}$, sendo portanto possíveis de serem utilizadas na rotina de cálculos do modelo. Os valores intermediários foram obtidos por interpolação linear. 


\subsection{COMPONENTES DO BALANÇO HÍDRICO}

Os componentes do balanço hídrico, para cada cultura, encontram-se nas Figuras $41,42,43,44,45$ e 46.

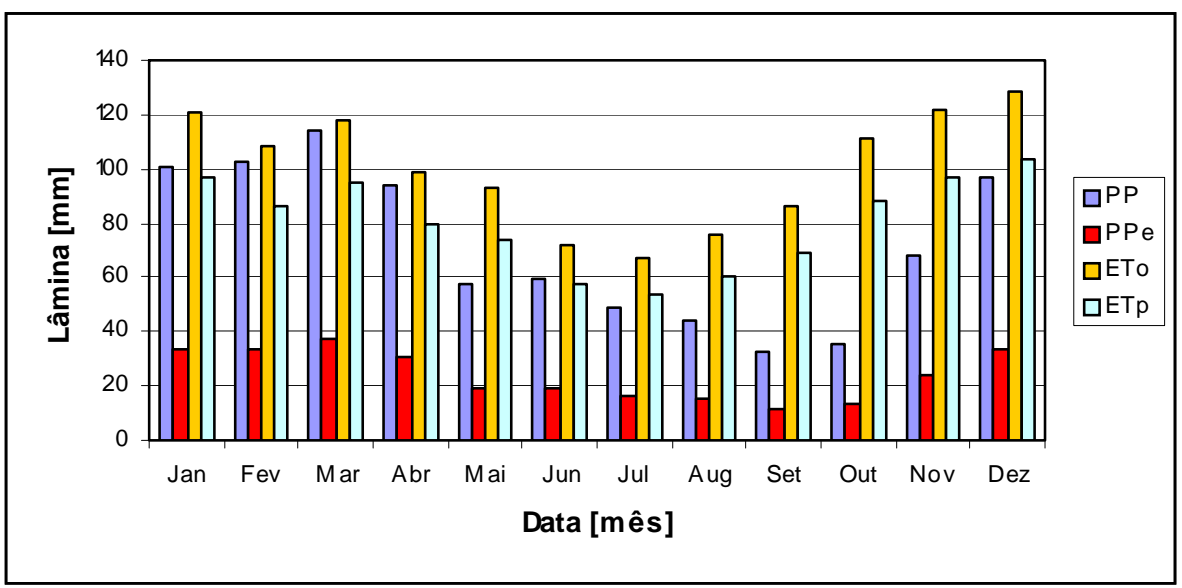

Figura 41. Variação dos componentes do balanço hídrico para a banana

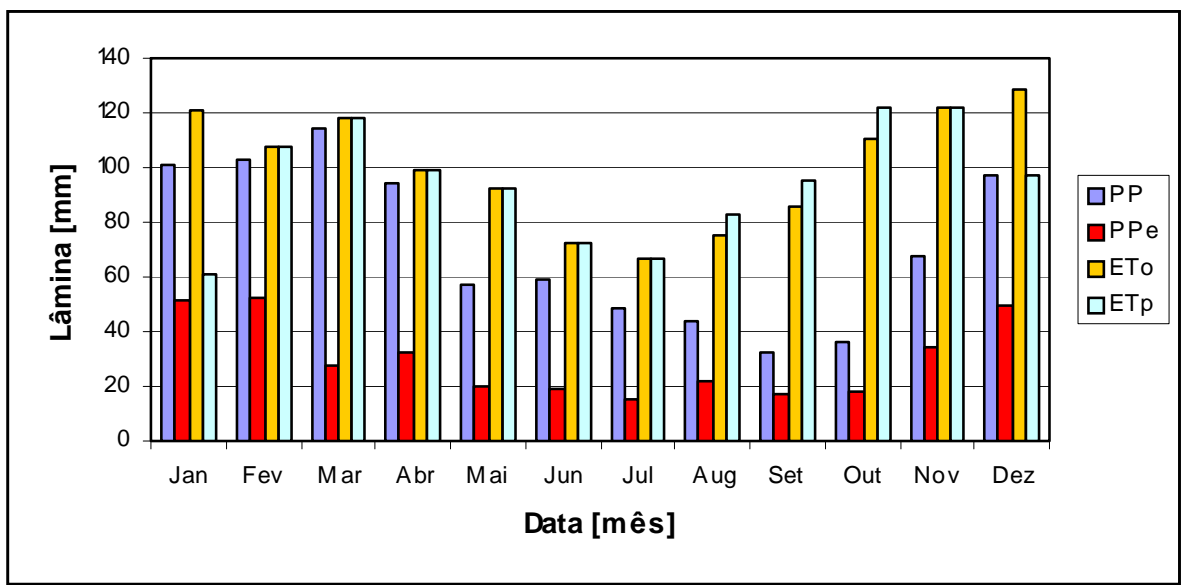

Figura 42. Variação dos componentes do balanço hídrico para a cana-de-açúcar 


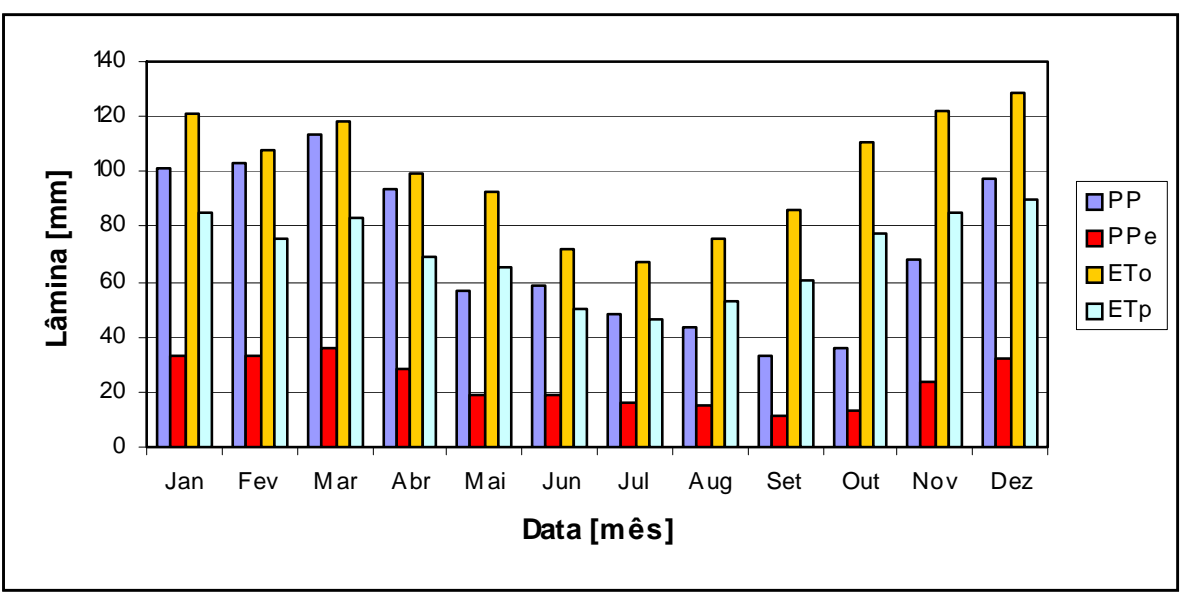

Figura 43. Variação dos componentes do balanço hídrico para as cítricas

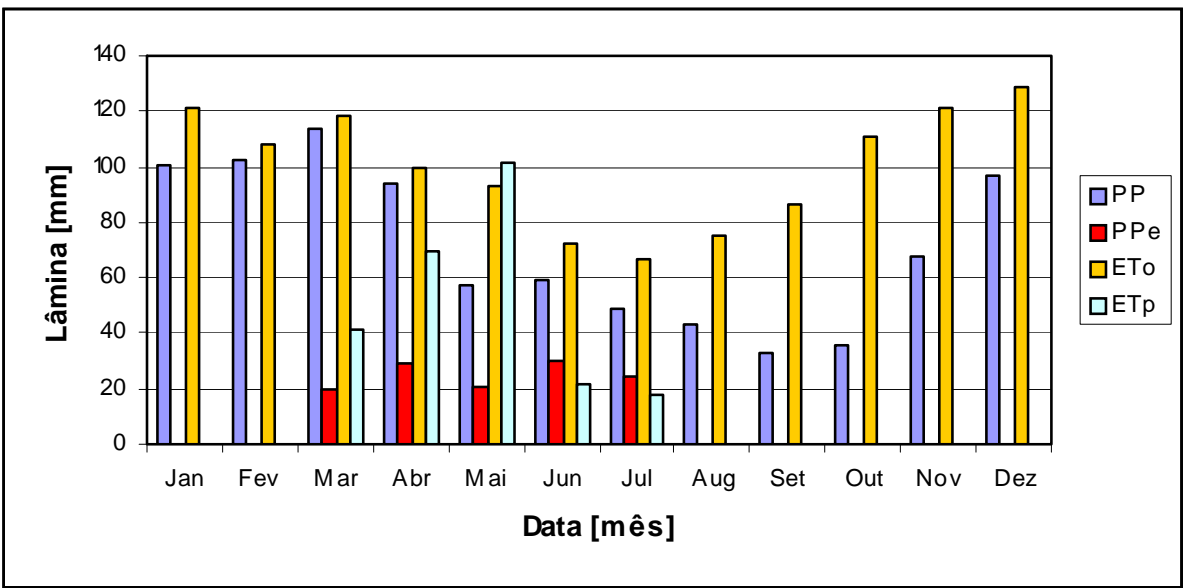

Figura 44. Variação dos componentes do balanço hídrico para o feijão

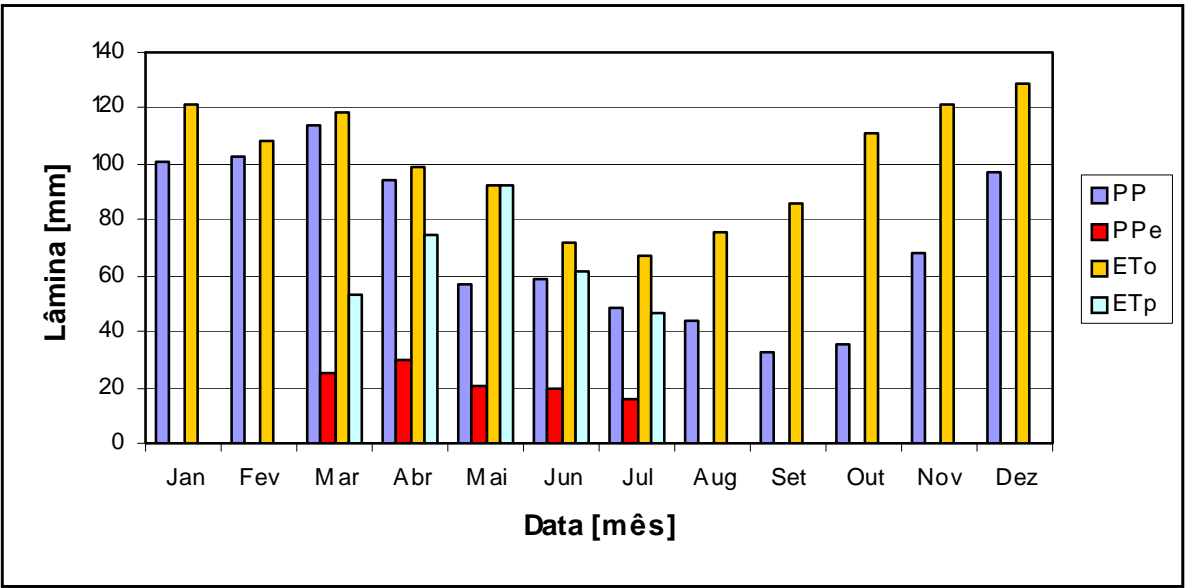

Figura 45. Variação dos componentes do balanço hídrico para a melancia 


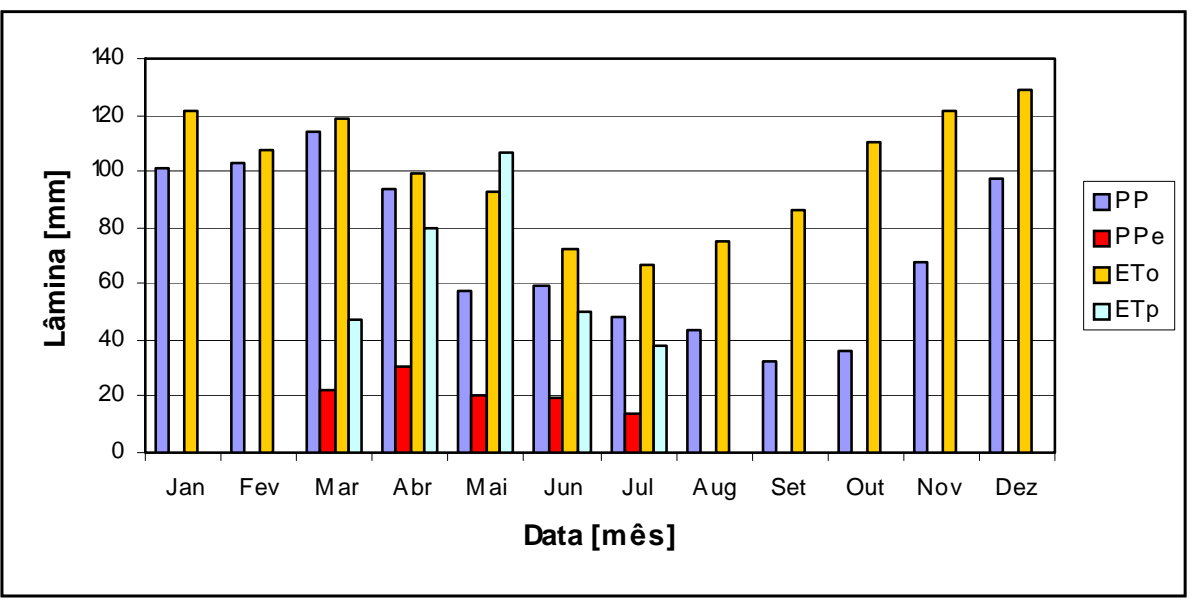

Figura 46. Variação dos componentes do balanço hídrico para o milho

Verifica-se nas Figuras 41, 42, 43, 44, 45 e 46, mediante observação da precipitação e da evapotranspiração, que apesar da ocorrência da chuva durante todo ano existe a necessidade de irrigação.

\subsection{IRRIGALS E MÉTODO DO BALANÇO HÍDRICO}

Conforme descrito no item 3.6.2.6.1, o IrrigaLS, como recurso alternativo, calcula o balanço hídrico diário do solo e apresenta as variáveis envolvidas no cálculo em forma de tabelas e gráficos. A análise do comportamento diário das variáveis fornece uma alternativa a mais ao usuário possibilitando, inclusive, a determinação do calendário de irrigação. Por exemplo, a Tabela 9 apresenta o balanço hídrico diário do solo para a cultura da banana. Verifica-se na tabela que, para o mês de Jan/1993, no dia 30/01/1993, foi necessário repor no solo uma lâmina de água de $52.025 \mathrm{~mm}$ (coluna LIR). Portanto no mês de janeiro daquele ano foi necessário realizar uma única irrigação. Os comportamentos das variáveis podem, também, ser verificados nas Figuras 47, 48, 49 e 50. 
Tomando outro exemplo pode-se ainda verificar o comportamento das variáveis de acordo com a umidade do solo. Pela Figura 47 (b) observa-se que, para solos com umidade constante, a evapotranspiração potencial $\left(\mathrm{ET}_{\mathrm{p}}\right)$ coincide com a evapotranspiração atual da cultura $\left(\mathrm{ET}_{\mathrm{a}}\right)$. e na Figura 48 (b) que $\mathrm{K}_{\mathrm{s}}$ permanece invariável.

Tabela 9. Variáveis envolvidas no cálculo do método do balanço hídrico, fornecidas pelo IrrigaLS

\begin{tabular}{|c|c|c|c|c|c|c|c|c|c|c|c|c|c|c|}
\hline Data & CC $(\%)$ & $\mid$ PMP (\%) & CAA (\%) & CTA $(\mathrm{mm})$ & CAA (mm) & $\operatorname{LAM}(\mathrm{mm})$ & LIR (mm) & ETo $(\mathrm{mm})$ & $\operatorname{ETp}(\mathrm{mm})$ & $|\mathrm{ETa}(\mathrm{mm})|$ & Kc & Ks & $\operatorname{Pe}(\mathrm{mm})$ & ASub $(\mathrm{mm})$ \\
\hline $01 / 01 / 1993$ & 26.400 & 18.500 & 26.400 & 94.800 & 94.800 & 42.230 & --- & 3.908 & 3.126 & 3.126 & 0.800 & \begin{tabular}{|l|}
1.000 \\
\end{tabular} & 1.095 & 0.000 \\
\hline $02 / 01 / 1993$ & 26.400 & 18.500 & 26.231 & 94.800 & 92.768 & 42.230 & --- & 3.908 & 3.126 & 3.112 & 0.800 & 0.995 & 1.095 & 0.000 \\
\hline $03 / 01 / 1993$ & 26.400 & 18.500 & 26.063 & 94.800 & 90.752 & 42.230 & --- & 3.908 & 3.126 & 3.097 & 0.800 & 0.991 & 1.095 & 0.000 \\
\hline $04 / 01 / 1993$ & 26.400 & 18.500 & 25.896 & 94.800 & 88.750 & 42.230 & --- & 3.908 & 3.126 & 3.081 & 0.800 & 0.986 & 1.095 & 0.000 \\
\hline $05 / 01 / 1993$ & 26.400 & 18.500 & 25.730 & 94.800 & 86.763 & 42.230 & --- & 3.908 & 3.126 & 3.066 & 0.800 & 0.981 & 1.095 & 0.000 \\
\hline $06 / 01 / 1993$ & 26.400 & 18.500 & 25.566 & 94.800 & 84.791 & 42.230 & --- & 3.908 & 3.126 & 3.051 & 0.800 & 0.976 & 1.095 & 0.000 \\
\hline $07 / 01 / 1993$ & 26.400 & 18.500 & 25.403 & 94.800 & 82.835 & 42.230 & --- & 3.908 & 3.126 & 3.035 & 0.800 & 0.971 & 1.095 & 0.000 \\
\hline $08 / 01 / 1993$ & 26.400 & 18.500 & 25.241 & 94.800 & 80.895 & 42.230 & --- & 3.908 & 3.126 & 3.019 & 0.800 & 0.966 & 1.095 & 0.000 \\
\hline $09 / 01 / 1993$ & 26.400 & 18.500 & 25.081 & 94.800 & 78.971 & 42.230 & --- & 3.908 & 3.126 & 3.002 & 0.800 & 0.960 & 1.095 & 0.000 \\
\hline $10 / 01 / 1993$ & 26.400 & 18.500 & 24.922 & 94.800 & 77.063 & 42.230 & --- & 3.908 & 3.126 & 2.986 & 0.800 & 0.955 & 1.095 & 0.000 \\
\hline $11 / 01 / 1993$ & 26.400 & 18.500 & 24.764 & 94.800 & 75.172 & 42.230 & --- & 3.908 & 3.126 & 2.969 & 0.800 & 0.950 & 1.095 & 0.000 \\
\hline $12 / 01 / 1993$ & 26.400 & 18.500 & 24.608 & 94.800 & 73.297 & 42.230 & --- & 3.908 & 3.126 & 2.952 & 0.800 & 0.944 & 1.095 & 0.000 \\
\hline $13 / 01 / 1993$ & 26.400 & 18.500 & 24.453 & 94.800 & 71.440 & 42.230 & --- & 3.908 & 3.126 & 2.935 & 0.800 & 0.939 & 1.095 & 0.000 \\
\hline $14 / 01 / 1993$ & 26.400 & 18.500 & 24.300 & 94.800 & 69.600 & 42.230 & --- & 3.908 & 3.126 & 2.917 & 0.800 & 0.933 & 1.095 & 0.000 \\
\hline $15 / 01 / 1993$ & 26.400 & 18.500 & 24.148 & 94.800 & 67.778 & 42.230 & --- & 3.908 & 3.126 & 2.899 & 0.800 & 0.927 & 1.095 & 0.000 \\
\hline $16 / 01 / 1993$ & 26.400 & 18.500 & 23.998 & 94.800 & 65.973 & 42.230 & --- & 3.908 & 3.126 & 2.881 & 0.800 & 0.922 & 1.095 & 0.000 \\
\hline $17 / 01 / 1993$ & 26.400 & 18.500 & 23.849 & 94.800 & 64.187 & 42.230 & --- & 3.908 & 3.126 & 2.862 & 0.800 & 0.916 & 1.095 & 0.000 \\
\hline $18 / 01 / 1993$ & 26.400 & 18.500 & 23.702 & 94.800 & 62.419 & 42.230 & --- & 3.908 & 3.126 & 2.844 & 0.800 & 0.910 & 1.095 & 0.000 \\
\hline $19 / 01 / 1993$ & 26.400 & 18.500 & 23.556 & 94.800 & 60.670 & 42.230 & --- & 3.908 & 3.126 & 2.824 & 0.800 & 0.903 & 1.095 & 0.000 \\
\hline $20 / 01 / 1993$ & 26.400 & 18.500 & 23.412 & 94.800 & 58.940 & 42.230 & --- & 3.908 & 3.126 & 2.805 & 0.800 & 0.897 & 1.095 & 0.000 \\
\hline $21 / 01 / 1993$ & 26.400 & 18.500 & 23.269 & 94.800 & 57.230 & 42.230 & --- & 3.908 & 3.126 & 2.785 & 0.800 & 0.891 & 1.095 & 0.000 \\
\hline $22 / 01 / 1993$ & 26.400 & 18.500 & 23.128 & 94.800 & 55.540 & 42.230 & --- & 3.908 & 3.126 & 2.765 & 0.800 & 0.884 & 1.095 & 0.000 \\
\hline $23 / 01 / 1993$ & 26.400 & 18.500 & 22.989 & 94.800 & 53.869 & 42.230 & --- & 3.908 & 3.126 & 2.744 & 0.800 & 0.878 & 1.095 & 0.000 \\
\hline $24 / 01 / 1993$ & 26.400 & 18.500 & 22.852 & 94.800 & 52.220 & 42.230 & --- & 3.908 & 3.126 & 2.723 & 0.800 & 0.871 & 1.095 & 0.000 \\
\hline $25 / 01 / 1993$ & 26.400 & 18.500 & 22.716 & 94.800 & 50.591 & 42.230 & --- & 3.908 & 3.126 & 2.702 & 0.800 & 0.864 & 1.095 & 0.000 \\
\hline $26 / 01 / 1993$ & 26.400 & 18.500 & 22.582 & 94.800 & 48.983 & 42.230 & --- & 3.908 & 3.126 & 2.680 & 0.800 & 0.857 & 1.095 & 0.000 \\
\hline $27 / 01 / 1993$ & 26.400 & 18.500 & 22.450 & 94.800 & 47.398 & 42.230 & --- & 3.908 & 3.126 & 2.658 & 0.800 & 0.850 & 1.095 & 0.000 \\
\hline $28 / 01 / 1993$ & 26.400 & 18.500 & 22.319 & 94.800 & 45.834 & 42.230 & --- & 3.908 & 3.126 & 2.636 & 0.800 & 0.843 & 1.095 & 0.000 \\
\hline $29 / 01 / 1993$ & 26.400 & 18.500 & 22.191 & 94.800 & 44.293 & 42.230 & --- & 3.908 & 3.126 & 2.613 & 0.800 & 0.836 & 1.095 & 0.000 \\
\hline $30 / 01 / 1993$ & 26.400 & 18.500 & 26.400 & 94.800 & 94.800 & 42.230 & 52.025 & 3.908 & 3.126 & 3.126 & 0.800 & 1.000 & 1.095 & 0.000 \\
\hline $31 / 01 / 1993$ & 26.400 & 18.500 & 26.231 & 94.800 & 92.768 & 42.230 & -- & 3.908 & 3.126 & 3.112 & 0.800 & 0.995 & 1.095 & 0.000 \\
\hline
\end{tabular}




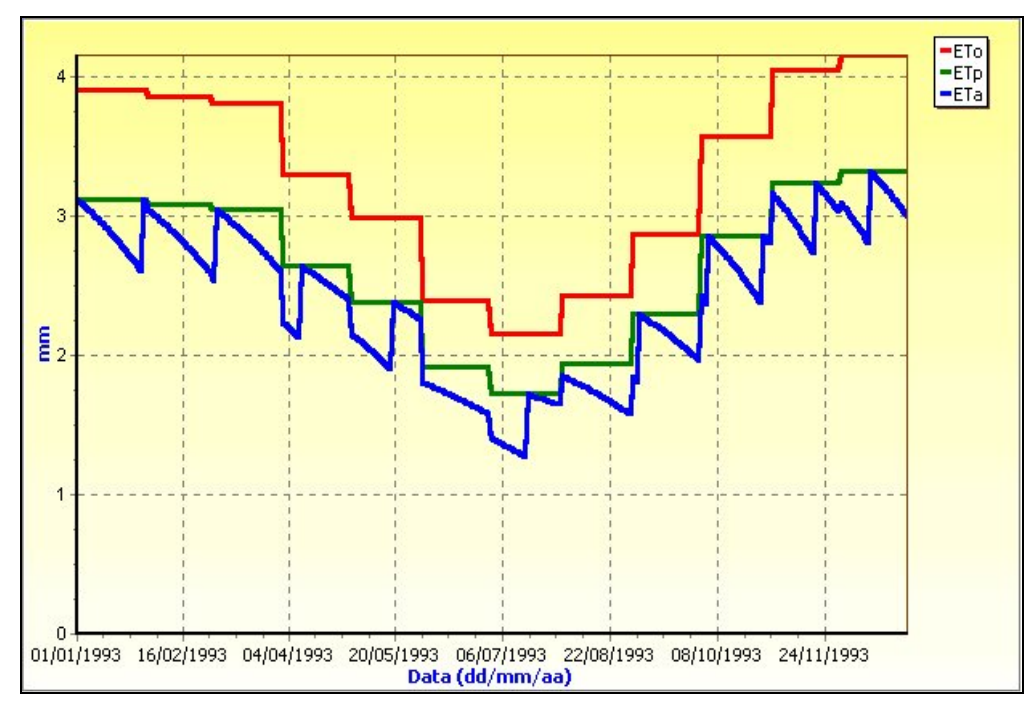

(a) umidade no solo variável

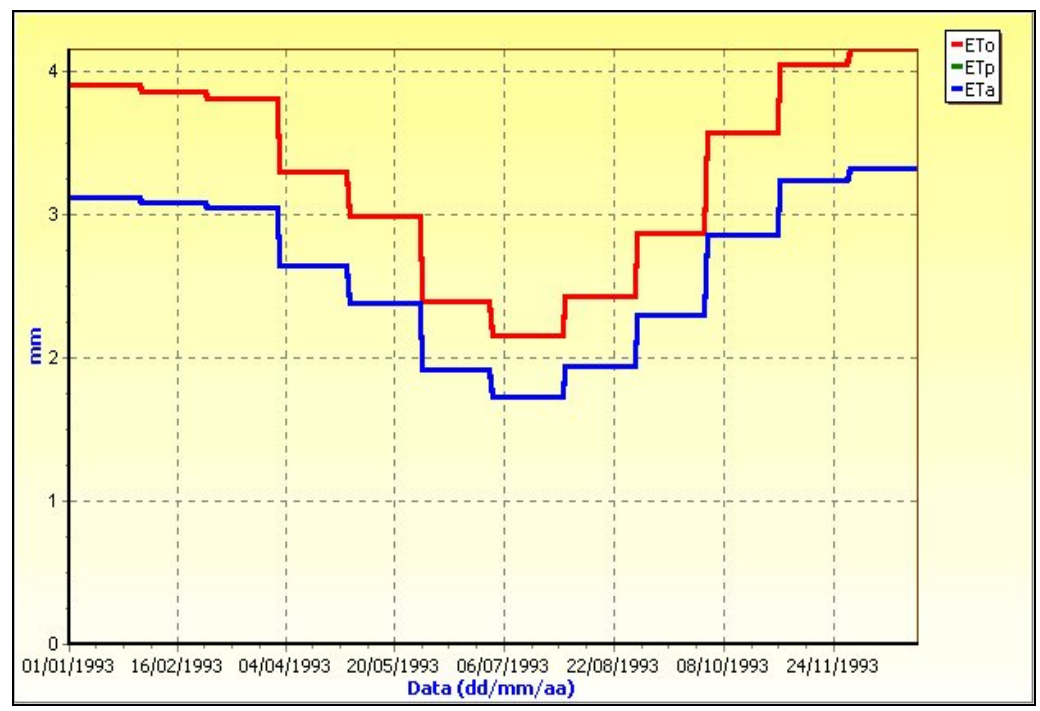

(b) umidade no solo constante

Figura 47. Gráfico da variação da evapotranspiração de referência $\left(\mathrm{ET}_{0}\right)$, da evapotranspiração potencial $\left(\mathrm{ET}_{\mathrm{p}}\right)$ e da evapotranspiração atual da cultura $\left(\mathrm{ET}_{\mathrm{a}}\right)$, fornecido pelo IrrigaLS, considerando a umidade do solo variável (a) e constante (b) 


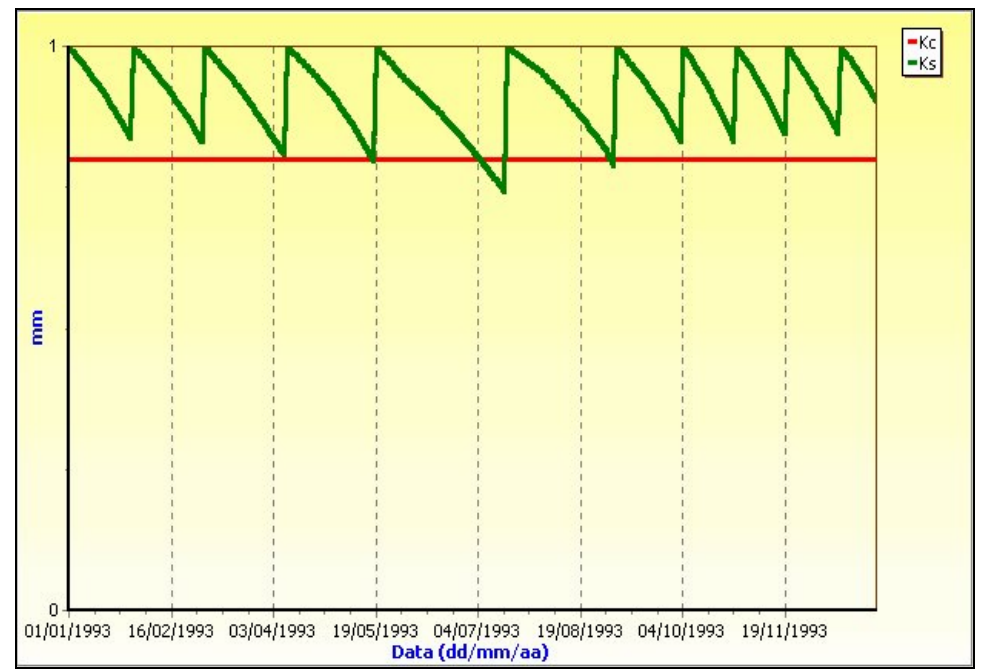

(a) umidade no solo variável

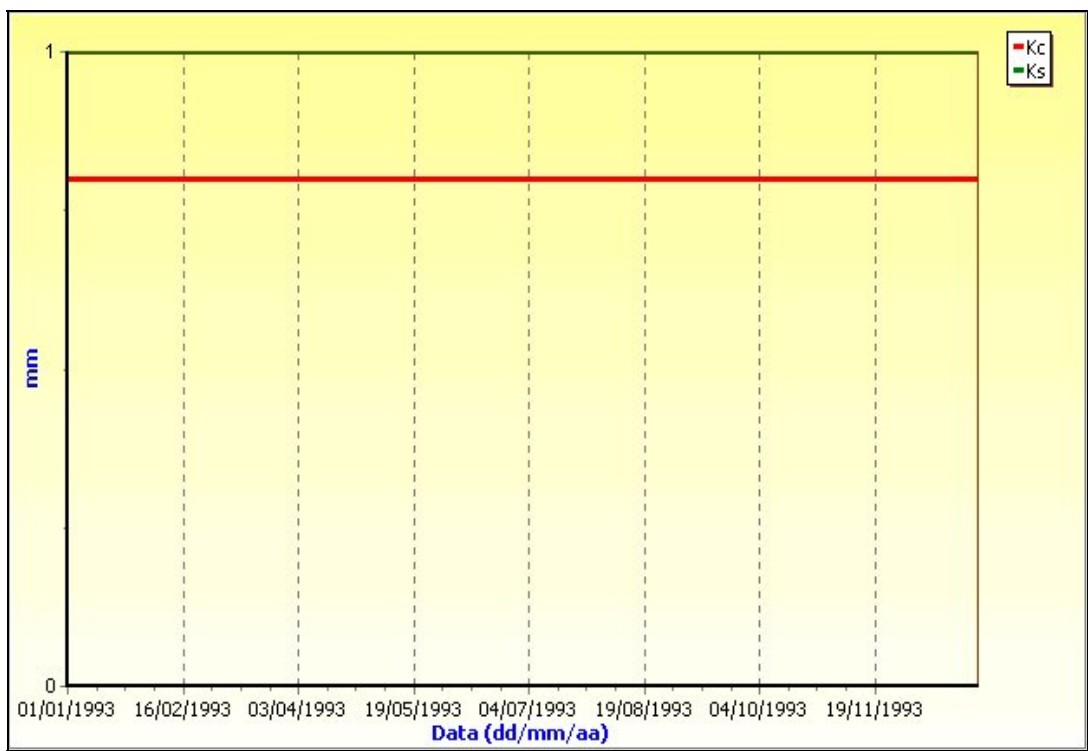

(b) umidade no solo constante

Figura 48. Gráfico da variação do coeficiente de cultura $\left(K_{c}\right)$ e do fator de variação da umidade do solo $\left(\mathrm{K}_{\mathrm{s}}\right)$, fornecido pelo IrrigaLS, considerando a umidade do solo variável (a) e constante (b) 


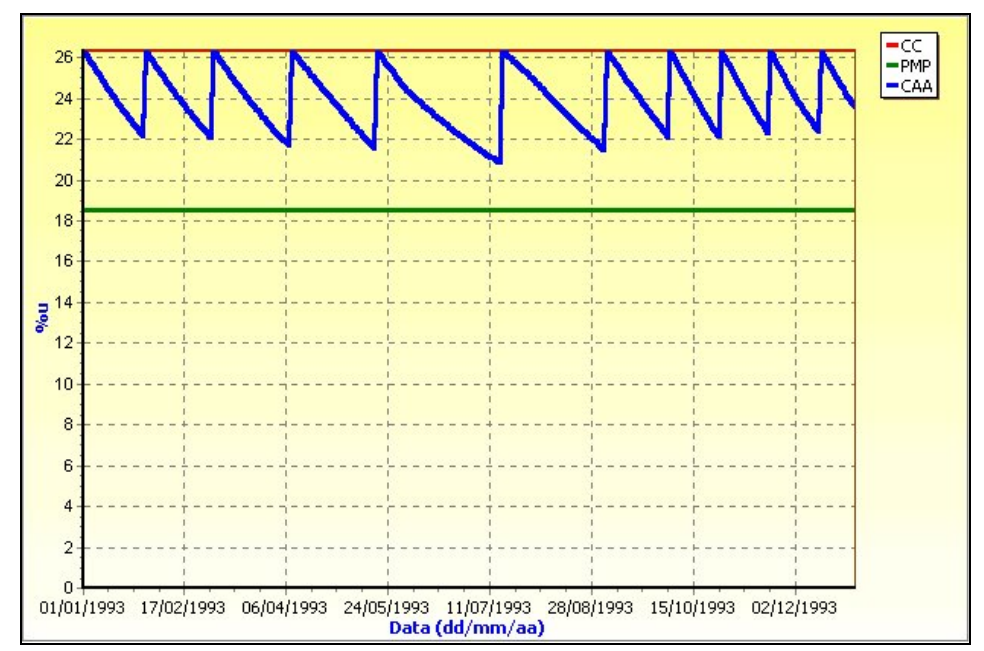

Figura 49. Gráfico da variação da capacidade de campo (CC), do ponto de murcha permanente (PM) e da capacidade atual de água no solo (CAA), fornecido pelo IrrigaLS

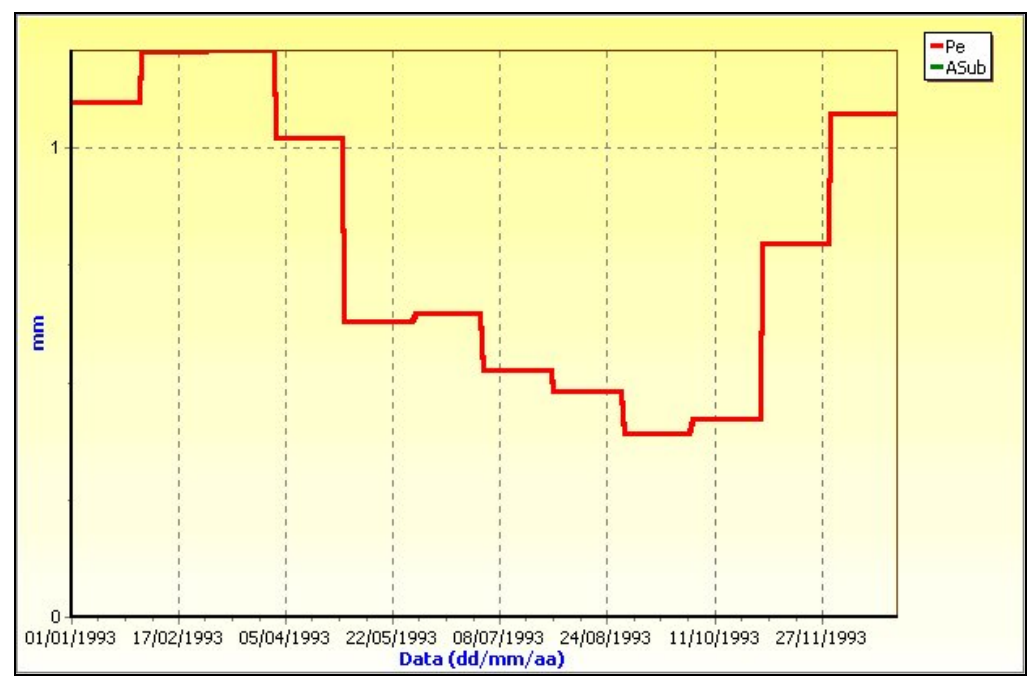

Figura 50. Gráfico da variação da precipitação efetiva $\left(\mathrm{PP}_{\mathrm{e}}\right)$ e da água no solo antes da primeira irrigação (AS), fornecido pelo IrrigaLS 


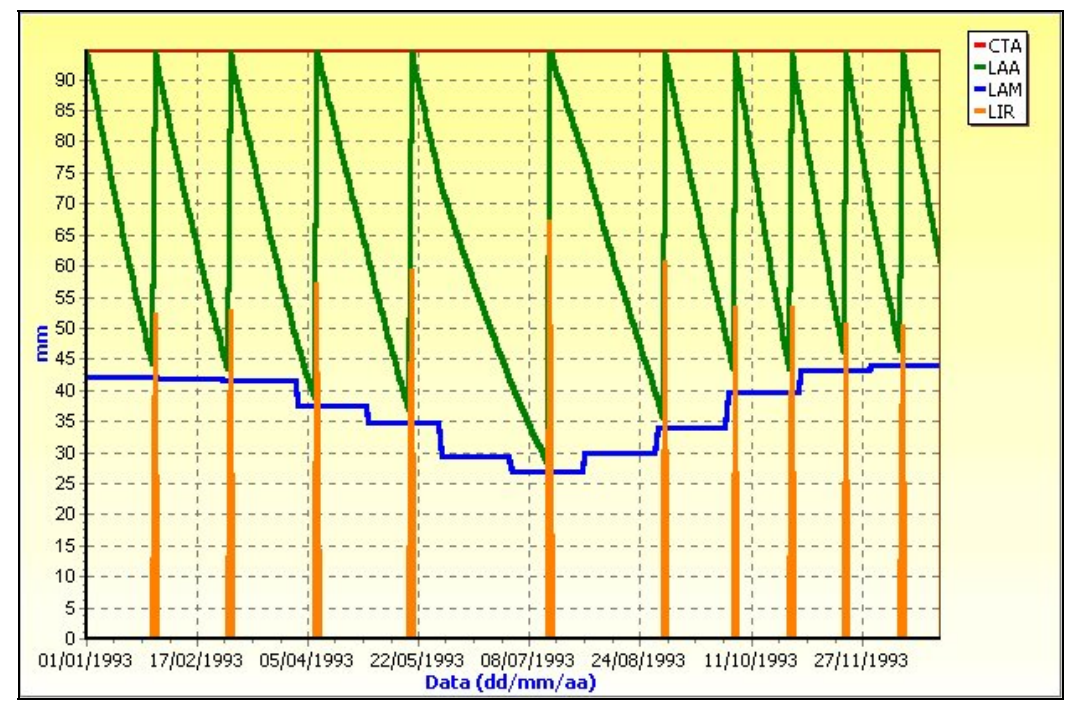

Figura 51. Gráfico que relaciona a capacidade total de água no solo e a variação das lâminas irrigadas (atual, máxima e real), fornecido pelo IrrigaLS

O IrrigaLS apresenta, também, os valores mensais do número de irrigação $\left(\mathrm{N}_{\mathrm{i}}\right)$, da IRN e da ITN), e da $\mathrm{ET}_{\mathrm{a}}$, calculados pelo próprio modelo e pelo método do balanço hídrico (Tabela 10). Aproveitou-se deste recurso para comparar os resultados obtidos pelos dois métodos e verificar se o IrrigaLS é apto para calcular demandas de irrigação.

Tabela 10. Valores mensais do número de irrigação $\left(\mathrm{N}_{\mathrm{i}}\right)$, das irrigações real e total (IRN e ITN), e da evapotranspiração atual da cultura (ET $\left.{ }_{a}\right)$, fornecidos pelo IrrigaLS

\begin{tabular}{|c|c|c|c|c|c|c|c|}
\hline Mês/Ano & No Irrigaçốes & IRN & ITN & ETa & IRN & ITN & ETa \\
\hline $\operatorname{Jan} / 1993$ & 1 & 52.025 & 59.120 & 90.007 & 62.737 & 71.424 & 96.937 \\
\hline Fev $/ 1993$ & $\mathbf{0}$ & 0.000 & 0.000 & 79.674 & 52.743 & 59.717 & 86.306 \\
\hline Mar/1993 & 1 & 52.644 & 59.823 & 87.672 & 56.946 & 64.668 & 94.595 \\
\hline Abr $/ 1993$ & $\mathbf{1}$ & 57.141 & 64.932 & 73.233 & 48.571 & 55.109 & 79.279 \\
\hline Mai/1993 & $\mathbf{1}$ & 59.082 & 67.139 & 66.974 & 54.533 & 61.772 & 74.054 \\
\hline Jun $/ 1993$ & $\mathbf{0}$ & 0.000 & 0.000 & 51.062 & 38.297 & 43.434 & 57.658 \\
\hline Jul/1993 & $\mathbf{1}$ & 67.034 & 76.175 & 46.853 & 37.160 & 41.986 & 53.333 \\
\hline Ago $/ 1993$ & $\mathbf{0}$ & 0.000 & 0.000 & 53.608 & 45.364 & 51.638 & 60.360 \\
\hline Set $/ 1993$ & 1 & 60.569 & 68.828 & 63.435 & 56.978 & 64.917 & 69.009 \\
\hline Out $/ 1993$ & 2 & 106.588 & 121.123 & 81.904 & 75.285 & 85.419 & 88.649 \\
\hline Noy $/ 1993$ & 1 & 50.581 & 57.479 & 90.991 & 0.000 & 0.000 & 97.297 \\
\hline Dez/1993 & 1 & 50.186 & 57.029 & 95.485 & 0.000 & 0.000 & 0.000 \\
\hline
\end{tabular}

colunas em amarelo corresponde ao método do balanço hídrico colunas em azul corresponde ao IrrigaLS 


\subsubsection{Coeficiente de Umidade do Solo Constante e Volume Meta no Solo Igual ao Volume na Capacidade de Campo}

A Tabela 11 apresenta as diferenças relativas e os valores de IRN, ITN e ETa (média anual) obtidos pelo IrrigaLS e pelo método do balanço hídrico para $\mathrm{K}_{\mathrm{s}}$ constante $\left(\mathrm{K}_{\mathrm{s}}=1\right)$ e volume meta (Vmeta) do solo igual ao volume na CC.

Tabela 11. Lâminas irrigadas real e total (IRN e ITN) e a evapotranspiração atual $\left(\mathrm{ET}_{\mathrm{a}}\right)$ obtidos pelo IrrigaLS e pelo método do balanço hídrico

\begin{tabular}{|c|c|c|c|c|c|c|c|c|c|c|}
\hline \multirow[t]{3}{*}{ Cultura } & \multicolumn{4}{|c|}{ Balanço Hídrico } & \multicolumn{3}{|c|}{ IrrigaLS $^{3}$} & \multirow{2}{*}{\multicolumn{3}{|c|}{ Diferença relativa $[\%]$}} \\
\hline & \multirow[t]{2}{*}{$\mathrm{N}_{\mathrm{i}}{ }^{1}$} & \multicolumn{6}{|c|}{ Lâminas [mm] } & & & \\
\hline & & IRN & ITN & $\mathrm{ET}_{\mathrm{a}}$ & IRN & ITN & $\mathrm{ET}_{\mathrm{a}}$ & IRN & ITN & $\mathrm{ET}_{\mathrm{a}}$ \\
\hline Banana & 12 & 672,78 & 764,52 & 960,60 & 672,38 & 762,83 & 960,54 & 0,06 & 0,22 & 0,01 \\
\hline Cana-de-açúcar & 11 & 245,94 & 336,91 & 361,15 & 246,14 & 328,32 & 360,00 & $-0,08$ & 2,55 & 0,32 \\
\hline Cítricas $(\mathrm{c} / \mathrm{c})^{2}$ & 10 & 561,44 & 638,00 & 840,53 & 578,02 & 617,76 & 830,00 & $-2,95$ & 3,17 & 1,25 \\
\hline Feijão & 9 & 128,59 & 176,16 & 252,29 & 141,47 & 191,00 & 253,33 & $-10,01$ & $-8,43$ & $-0,41$ \\
\hline Melancia & 9 & 217,04 & 297,32 & 328,12 & 210,82 & 287,60 & 320,00 & 2,87 & 3,27 & 2,48 \\
\hline Milho & 9 & 214,24 & 293,49 & 321,57 & 221,60 & 290,30 & 330,00 & $-3,44$ & 1,08 & $-2,62$ \\
\hline
\end{tabular}

Verifica-se pela Tabela 11 que as diferenças relativas para $\mathrm{ET}_{\mathrm{a}}$ apresentam-se inferiores a 2,62\% para as culturas em estudo, mostrando que as adaptações na tabela cota-área-volume do reservatório do solo no IrrigaLS são válidas.

A Figura 52 apresenta as curvas coincidentes de $\mathrm{ET}_{\mathrm{a}}$ média mensal para as culturas permanentes e temporárias, respectivamente. 


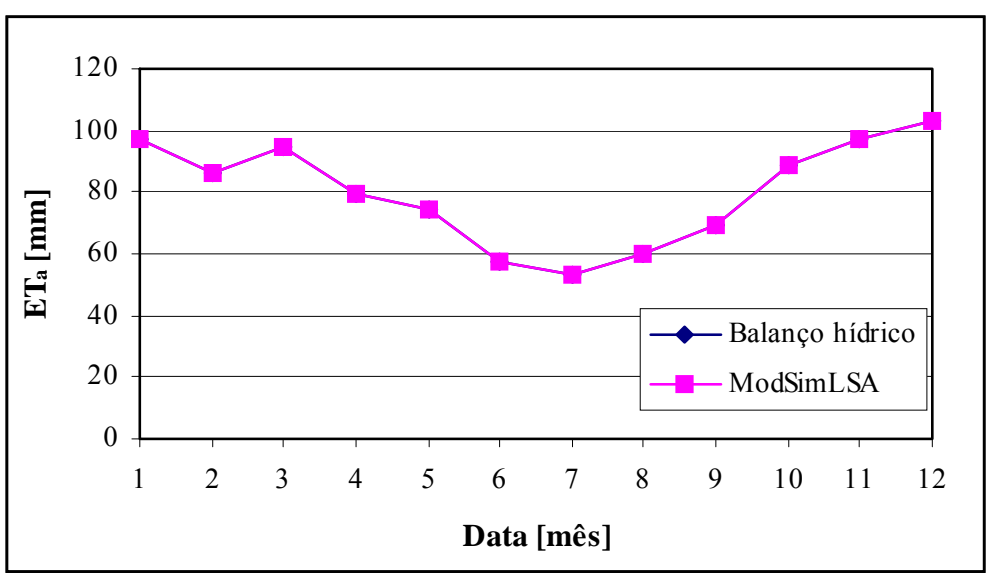

(a) culturas permanentes

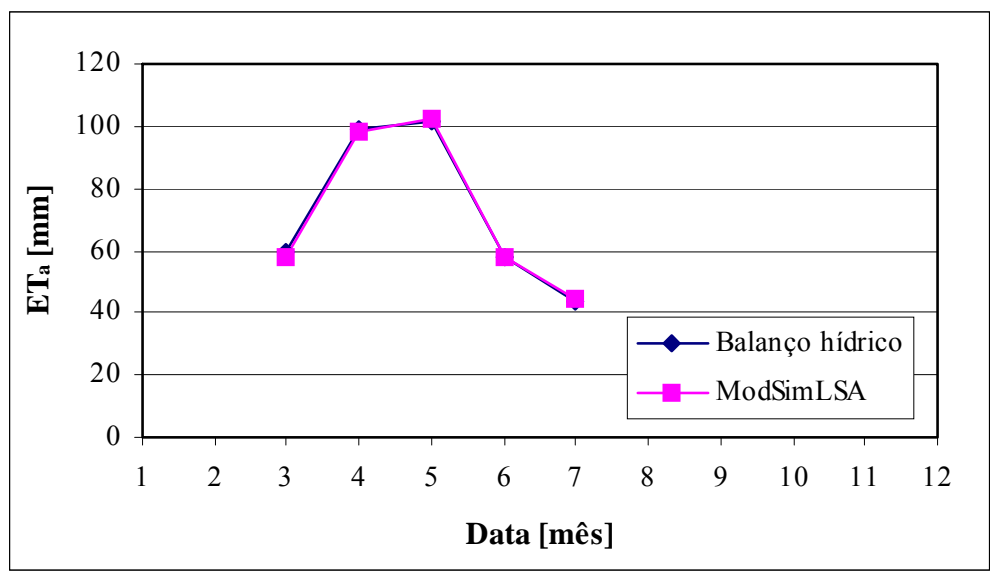

(b) culturas temporárias

Figura 52. Evapotranspiração atual média mensal $\left(\mathrm{ET}_{\mathrm{a}}\right)$ para as culturas permanentes (a) e temporárias (b), para coeficiente de umidade do solo constante $\left(K_{s}=1\right)$ e volume meta no solo igual ao volume na capacidade de campo $($ Vmeta $=1)$

Verifica-se, também, pela Tabela 11 que as diferenças relativas apesar de aceitáveis (menor que 10\%) não mantêm a mesma proporção entre IRN, ITN e ET $\mathrm{a}$ nem entre as culturas. $\mathrm{Na}$ tentativa de explicar tais diferenças analisou-se os resultados mediante a variação a $\mathrm{A}_{\mathrm{i}}$. 


\subsubsection{Variação da Área Irrigada}

Os efeitos da variação de $\mathrm{A}_{\mathrm{i}}$ sobre IRN, ITN e $\mathrm{ET}_{\mathrm{a}}$ (média anual) podem ser verificados na Tabela 12. Verifica-se que no IrrigaLS IRN, ITN e $\mathrm{ET}_{\mathrm{a}}$ variam com a área, permanecendo praticamente constantes para áreas acima de 40 ha. Apesar dos valores serem aceitáveis, exceto para $A_{i}=1$ ha, observou-se que tal variação acontece pelo fato de internamente os cálculos do ModSimLS envolverem números inteiros. A velocidade de processamento é favorecida mas, em se tratando de pequenos volumes, há uma limitação na precisão do modelo. 
Tabela 12. Lâminas irrigadas real e total (IRN e ITN) e a evapotranspiração atual (ET $\left.{ }_{a}\right)$, obtidos pelo IrrigaLS e pelo método do balanço hídrico, para diferentes áreas irrigadas $\left(A_{i}\right)$

\begin{tabular}{|c|c|c|c|c|c|c|c|c|c|c|c|}
\hline \multirow[t]{3}{*}{ Cultura } & \multirow[t]{3}{*}{$\mathrm{A}_{\mathrm{i}}[\mathrm{ha}]$} & \multicolumn{4}{|c|}{ Balanço Hídrico } & \multicolumn{3}{|c|}{ IrrigaLS $^{3}$} & \multirow{2}{*}{\multicolumn{3}{|c|}{ Diferença relativa [\%] }} \\
\hline & & \multirow[t]{2}{*}{$\mathrm{N}_{\mathrm{i}}{ }^{1}$} & \multicolumn{6}{|c|}{ Lâminas [mm] } & & & \\
\hline & & & IRN & ITN & $\mathrm{ET}_{\mathrm{a}}$ & IRN & ITN & $\mathrm{ET}_{\mathrm{a}}$ & IRN & ITN & $\mathrm{ET}_{\mathrm{a}}$ \\
\hline \multirow{12}{*}{ Banana } & 1 & 12 & 672,78 & 764,52 & 960,60 & 532,22 & 532,22 & 920,00 & 20,89 & 30,38 & 4,23 \\
\hline & 5 & 12 & 672,78 & 764,52 & 960,60 & 693,27 & 693,27 & 968,00 & $-3,05$ & 9,32 & $-0,77$ \\
\hline & 10 & 12 & 672,78 & 764,52 & 960,60 & 672,19 & 756,17 & 956,00 & 0,09 & 1,09 & 0,48 \\
\hline & 20 & 12 & 672,78 & 764,52 & 960,60 & 683,42 & 751,68 & 958,00 & $-1,58$ & 1,68 & 0,27 \\
\hline & 40 & 12 & 672,78 & 764,52 & 960,60 & 677,98 & 756,95 & 960,00 & $-0,77$ & 0,99 & 0,06 \\
\hline & 80 & 12 & 672,78 & 764,52 & 960,60 & 674,05 & 758,20 & 961,00 & $-0,19$ & 0,83 & $-0,04$ \\
\hline & 160 & 12 & 672,78 & 764,52 & 960,60 & 671,54 & 762,20 & 960,50 & 0,18 & 0,30 & 0,01 \\
\hline & 320 & 12 & 672,78 & 764,52 & 960,60 & 673,77 & 764,09 & 960,38 & $-0,15$ & 0,06 & 0,02 \\
\hline & 640 & 12 & 672,78 & 764,52 & 960,60 & 673,11 & 764,93 & 960,69 & $-0,05$ & $-0,05$ & $-0,01$ \\
\hline & 1280 & 12 & 672,78 & 764,52 & 960,60 & 673,27 & 764,84 & 960,62 & $-0,07$ & $-0,04$ & 0,00 \\
\hline & 2560 & 12 & 672,78 & 764,52 & 960,60 & 673,23 & 764,92 & 960,58 & $-0,07$ & $-0,05$ & 0,00 \\
\hline & 5120 & 12 & 672,78 & 764,52 & 960,60 & 672,82 & 764,51 & 960,19 & $-0,01$ & 0,00 & 0,04 \\
\hline \multirow{12}{*}{ Cana-de-açúcar } & 1 & 11 & 245,94 & 336,91 & 361,15 & 107,14 & 107,14 & 320,00 & 56,44 & 68,20 & 11,39 \\
\hline & 5 & 11 & 245,94 & 336,91 & 361,15 & 253,67 & 316,57 & 352,00 & $-3,14$ & 6,04 & 2,53 \\
\hline & 10 & 11 & 245,94 & 336,91 & 361,15 & 242,61 & 327,28 & 360,00 & 1,35 & 2,86 & 0,32 \\
\hline & 20 & 11 & 245,94 & 336,91 & 361,15 & 253,50 & 338,00 & 364,00 & $-3,07$ & $-0,32$ & $-0,79$ \\
\hline & 40 & 11 & 245,94 & 336,91 & 361,15 & 248,23 & 335,41 & 361,00 & $-0,93$ & 0,45 & 0,04 \\
\hline & 80 & 11 & 245,94 & 336,91 & 361,15 & 245,59 & 335,36 & 361,00 & 0,14 & 0,46 & 0,04 \\
\hline & 160 & 11 & 245,94 & 336,91 & 361,15 & 246,24 & 336,03 & 361,00 & $-0,12$ & 0,26 & 0,04 \\
\hline & 320 & 11 & 245,94 & 336,91 & 361,15 & 246,57 & 337,01 & 361,13 & $-0,26$ & $-0,03$ & 0,01 \\
\hline & 640 & 11 & 245,94 & 336,91 & 361,15 & 246,58 & 337,52 & 361,19 & $-0,26$ & $-0,18$ & $-0,01$ \\
\hline & 1280 & 11 & 245,94 & 336,91 & 361,15 & 246,42 & 337,27 & 361,13 & $\begin{array}{l}-0,19 \\
\end{array}$ & $-0,11$ & 0,01 \\
\hline & 2560 & 11 & 245,94 & 336,91 & 361,15 & 246,46 & 337,48 & 361,13 & $-0,21$ & $-0,17$ & 0,01 \\
\hline & 5120 & 11 & 245,94 & 336,91 & 361,15 & 246,44 & 337,54 & 361,16 & $-0,20$ & $-0,19$ & 0,00 \\
\hline
\end{tabular}




\begin{tabular}{|c|c|c|c|c|c|c|c|c|c|c|c|}
\hline \multirow[t]{3}{*}{ Cultura } & \multirow[t]{3}{*}{$\mathrm{A}_{\mathrm{i}}[\mathrm{ha}]$} & \multicolumn{4}{|c|}{ Balanço Hídrico } & \multicolumn{3}{|c|}{ IrrigaLS $^{3}$} & \multirow{2}{*}{\multicolumn{3}{|c|}{ Diferença relativa [\%] }} \\
\hline & & \multirow[t]{2}{*}{$\mathrm{N}_{\mathrm{i}}{ }^{1}$} & \multicolumn{6}{|c|}{ Lâminas [mm] } & & & \\
\hline & & & IRN & ITN & $\mathrm{ET}_{\mathrm{a}}$ & IRN & ITN & $\mathrm{ET}_{\mathrm{a}}$ & IRN & ITN & $\mathrm{ET}_{\mathrm{a}}$ \\
\hline \multirow{12}{*}{ Cítricas $(\mathrm{c} / \mathrm{c})^{2}$} & 1 & 10 & 561,44 & 638,00 & 840,53 & 214,27 & 214,27 & 800,00 & 61,84 & 66,42 & 4,82 \\
\hline & 5 & 10 & 561,44 & 638,00 & 840,53 & 631,76 & 631,76 & 824,00 & $-12,52$ & 0,98 & 1,97 \\
\hline & 10 & 10 & 561,44 & 638,00 & 840,53 & 556,76 & 620,35 & 840,00 & 0,83 & 2,77 & 0,06 \\
\hline & 20 & 10 & 561,44 & 638,00 & 840,53 & 562,46 & 630,72 & 838,00 & $-0,18$ & 1,14 & 0,30 \\
\hline & 40 & 10 & 561,44 & 638,00 & 840,53 & 565,14 & 638,75 & 841,00 & $-0,66$ & $-0,12$ & $-0,06$ \\
\hline & 80 & 10 & 561,44 & 638,00 & 840,53 & 563,89 & 638,75 & 841,50 & $-0,44$ & $-0,12$ & $-0,12$ \\
\hline & 160 & 10 & 561,44 & 638,00 & 840,53 & 561,90 & 636,77 & 840,25 & $-0,08$ & 0,19 & 0,03 \\
\hline & 320 & 10 & 561,44 & 638,00 & 840,53 & 561,48 & 636,39 & 840,38 & $-0,01$ & 0,25 & 0,02 \\
\hline & 640 & 10 & 561,44 & 638,00 & 840,53 & 561,50 & 637,73 & 840,50 & $-0,01$ & 0,04 & 0,00 \\
\hline & 1280 & 10 & 561,44 & 638,00 & 840,53 & 561,75 & 638,05 & 840,47 & $-0,05$ & $-0,01$ & 0,01 \\
\hline & 2560 & 10 & 561,44 & 638,00 & 840,53 & 561,54 & 638,05 & 840,53 & $-0,02$ & $-0,01$ & 0,00 \\
\hline & 5120 & 10 & 561,44 & 638,00 & 840,53 & 561,49 & 637,98 & 840,40 & $-0,01$ & 0,00 & 0,02 \\
\hline \multirow{12}{*}{ Feijão } & 1 & 9 & 128,59 & 176,16 & 252,29 & 0,00 & 0,00 & 240,00 & 100,00 & 100,00 & 4,8714 \\
\hline & 5 & 9 & 128,59 & 176,16 & 252,29 & 140,61 & 190,008 & 256,00 & $-9,348$ & $-8,29$ & $-1,47$ \\
\hline & 10 & 9 & 128,59 & 176,16 & 252,29 & 127,53 & 191,10 & 244,00 & 0,824 & $-8,49$ & 3,28 \\
\hline & 20 & 9 & 128,59 & 176,16 & 252,29 & 139,97 & 201,70 & 254,00 & $-8,85$ & $-14,50$ & $-0,68$ \\
\hline & 40 & 9 & 128,59 & 176,16 & 252,29 & 142,25 & 193,70 & 252,00 & $-10,62$ & $-9,96$ & 0,12 \\
\hline & 80 & 9 & 128,59 & 176,16 & 252,29 & 142,3 & 195,10 & 252,50 & $-10,66$ & $-10,70$ & $-0,08$ \\
\hline & 160 & 9 & 128,59 & 176,16 & 252,29 & 142,29 & 195,10 & 252,30 & $-10,65$ & $-10,80$ & 0,02 \\
\hline & 320 & 9 & 128,59 & 176,16 & 252,29 & 142,28 & 195,00 & 252,30 & $-10,65$ & $-10,70$ & 0,02 \\
\hline & 640 & 9 & 128,59 & 176,16 & 252,29 & 142,27 & 194,90 & 252,30 & $-10,64$ & $-10,60$ & $-0,01$ \\
\hline & 1280 & 9 & 128,59 & 176,16 & 252,29 & 142,26 & 194,80 & 252,30 & $-10,63$ & $-10,60$ & 0,00 \\
\hline & 2560 & 9 & 128,59 & 176,16 & 252,29 & 142,25 & 194,70 & 252,30 & $-10,62$ & $-10,50$ & 0,00 \\
\hline & 5120 & 9 & 128,59 & 176,16 & 252,29 & 142,24 & 194,60 & 252,30 & $-10,62$ & $-10,50$ & 0,00 \\
\hline
\end{tabular}




\begin{tabular}{|c|c|c|c|c|c|c|c|c|c|c|c|}
\hline \multirow[t]{3}{*}{ Cultura } & \multirow[t]{3}{*}{$\mathrm{A}_{\mathrm{i}}[\mathrm{ha}]$} & \multicolumn{4}{|c|}{ Balanço Hídrico } & \multicolumn{3}{|c|}{ IrrigaLS $^{3}$} & \multirow{2}{*}{\multicolumn{3}{|c|}{ Diferença relativa [\%] }} \\
\hline & & \multirow[t]{2}{*}{$\mathrm{N}_{\mathrm{i}}{ }^{1}$} & \multicolumn{6}{|c|}{ Lâminas [mm] } & & & \\
\hline & & & IRN & ITN & $\mathrm{ET}_{\mathrm{a}}$ & IRN & ITN & $\mathrm{ET}_{\mathrm{a}}$ & IRN & ITN & $\mathrm{ET}_{\mathrm{a}}$ \\
\hline \multirow{12}{*}{ Melancia } & 1 & 9 & 217,04 & 297,32 & 328,12 & 103,68 & 103,68 & 320,00 & 52,23 & 65,13 & 2,48 \\
\hline & 5 & 9 & 217,04 & 297,32 & 328,12 & 211,99 & 275,93 & 329,27 & 2,33 & 7,19 & $-0,35$ \\
\hline & 10 & 9 & 217,04 & 297,32 & 328,12 & 201,14 & 285,47 & 328,00 & 7,33 & 3,99 & 0,04 \\
\hline & 20 & 9 & 217,04 & 297,32 & 328,12 & 216,69 & 290,65 & 328,00 & 0,16 & 2,24 & 0,04 \\
\hline & 40 & 9 & 217,04 & 297,32 & 328,12 & 219,46 & 293,50 & 328,00 & $-1,11$ & 1,28 & 0,04 \\
\hline & 80 & 9 & 217,04 & 297,32 & 328,12 & 216,78 & 294,75 & 327,50 & 0,12 & 0,86 & 0,19 \\
\hline & 160 & 9 & 217,04 & 297,32 & 328,12 & 218,07 & 297,39 & 328,25 & $-0,48$ & $-0,02$ & $-0,04$ \\
\hline & 320 & 9 & 217,04 & 297,32 & 328,12 & 217,76 & 297,74 & 328,25 & $-0,33$ & $-0,14$ & $-0,04$ \\
\hline & 640 & 9 & 217,04 & 297,32 & 328,12 & 217,77 & 298,07 & 328,06 & $-0,34$ & $-0,25$ & 0,02 \\
\hline & 1280 & 9 & 217,04 & 297,32 & 328,12 & 217,60 & 297,99 & 328,10 & $-0,26$ & $-0,22$ & 0,01 \\
\hline & 2560 & 9 & 217,04 & 297,32 & 328,12 & 217,77 & 298,19 & 328,13 & $-0,33$ & $-0,29$ & 0,00 \\
\hline & 5120 & 9 & 217,04 & 297,32 & 328,12 & 217,73 & 298,23 & 328,12 & $-0,32$ & $-0,31$ & 0,00 \\
\hline \multirow{12}{*}{ Milho } & 1 & 9 & 214,24 & 293,49 & 321,57 & 107,14 & 107,14 & 320,00 & 49,99 & 63,50 & 0,49 \\
\hline & 5 & 9 & 214,24 & 293,49 & 321,57 & 211,51 & 253,67 & 320,00 & 1,28 & 13,57 & 0,49 \\
\hline & 10 & 9 & 214,24 & 293,49 & 321,57 & 201,14 & 285,81 & 324,00 & 6,12 & 2,61 & $-0,75$ \\
\hline & 20 & 9 & 214,24 & 293,49 & 321,57 & 222,22 & 296,35 & 322,00 & $-3,72$ & $-0,98$ & $-0,13$ \\
\hline & 40 & 9 & 214,24 & 293,49 & 321,57 & 214,27 & 288,40 & 320,00 & $-0,01$ & 1,73 & 0,49 \\
\hline & 80 & 9 & 214,24 & 293,49 & 321,57 & 215,61 & 290,99 & 322,00 & $-0,64$ & 0,85 & $-0,13$ \\
\hline & 160 & 9 & 214,24 & 293,49 & 321,57 & 216,28 & 294,32 & 321,50 & $-0,95$ & $-0,29$ & 0,02 \\
\hline & 320 & 9 & 214,24 & 293,49 & 321,57 & 215,28 & 293,65 & 321,63 & $-0,48$ & $-0,06$ & $-0,02$ \\
\hline & 640 & 9 & 214,24 & 293,49 & 321,57 & 214,95 & 293,99 & 321,56 & $-0,33$ & $-0,17$ & 0,00 \\
\hline & 1280 & 9 & 214,24 & 293,49 & 321,57 & 214,78 & 293,99 & 321,59 & $-0,25$ & $-0,17$ & $-0,01$ \\
\hline & 2560 & 9 & 214,24 & 293,49 & 321,57 & 214,83 & 294,15 & 321,58 & $-0,27$ & $-0,23$ & 0,00 \\
\hline & 5120 & 9 & 214,24 & 293,49 & 321,57 & 214,74 & 294,11 & 321,56 & $-0,23$ & $-0,21$ & 0,00 \\
\hline
\end{tabular}

${ }^{1}$ número total de irrigações

${ }^{2}$ com controle de ervas

${ }^{3} \mathrm{~K}_{\mathrm{s}}=1$ e volume meta do solo igual ao volume na CC 


\subsubsection{Coeficiente de Umidade do Solo Logarítmico e Volume Meta do Solo Abaixo da Capacidade de Campo}

A Tabela 13 apresenta as diferenças relativas e os valores de IRN, ITN e ETa (média anual), para o método do balanço hídrico e para o IrrigaLS. Em ambos os métodos considerou-se a umidade do solo variando logaritmicamente.

Tabela 13. Lâminas irrigadas real e total (IRN e ITN) e a evapotranspiração atual $\left(\mathrm{ET}_{\mathrm{a}}\right)$ obtidos pelo IrrigaLS e pelo método do balanço hídrico

\begin{tabular}{|c|c|c|c|c|c|c|c|c|c|c|}
\hline \multirow[t]{3}{*}{ Cultura } & \multicolumn{4}{|c|}{ Balanço Hídrico } & \multicolumn{3}{|c|}{ IrrigaLS $^{3}$} & \multirow{2}{*}{\multicolumn{3}{|c|}{ Diferença relativa [\%] }} \\
\hline & \multirow[t]{2}{*}{$\mathrm{N}_{\mathrm{i}}{ }^{1}$} & \multicolumn{6}{|c|}{ Lâminas [mm] } & & & \\
\hline & & IRN & ITN & $\mathrm{ET}_{\mathrm{a}}$ & IRN & ITN & $\mathrm{ET}_{\mathrm{a}}$ & IRN & ITN & $\mathrm{ET}_{\mathrm{a}}$ \\
\hline Banana & 11 & 590,99 & 671,58 & 879,03 & 672,38 & 762,83 & 960,54 & -13.77 & -13.6 & -9.273 \\
\hline Cana-de-açúcar & 9 & 173,08 & 237,10 & 288,29 & 246,14 & 328,32 & 360,00 & -42.21 & -38.5 & -24.87 \\
\hline Cítricas $(\mathrm{c} / \mathrm{c})^{2}$ & 8 & 446,33 & 507,20 & 725,50 & 578,02 & 617,76 & 830,00 & -29.51 & -21.8 & -14.4 \\
\hline Feijão & 9 & 106,77 & 146,26 & 230,46 & 141,47 & 191,00 & 253,33 & -32.5 & -30.6 & -9.924 \\
\hline Melancia & 8 & 177,38 & 242,99 & 288,46 & 210,82 & 287,60 & 320,00 & -18.85 & -18.4 & -10.93 \\
\hline Milho & 9 & 178,46 & 244,47 & 285,79 & 221,60 & 290,30 & 330,00 & -24.17 & -18.7 & -15.47 \\
\hline
\end{tabular}

Comparando-se as Tabelas 11 e 13 verifica-se que no método do balanço hídrico as lâminas para $\mathrm{K}_{\mathrm{s}}$ logarítmico resultaram menores que para $\mathrm{K}_{\mathrm{s}}=1$ e para IrrigaLS as lâminas são iguais. Tais resultados justificam-se pela diferença das metodologias de cálculo entre os dois métodos. No método do balanço hídrico, a menos que se opte por considerar a umidade no solo constante $\left(\mathrm{K}_{\mathrm{s}}=1\right)$, a cultura retira do solo uma lâmina igual a CRA, só depois de esgotada esta lâmina irriga-se até que o solo atinja novamente a CC. Neste processo a umidade no solo é variável. Já na simulação, o IrrigaLS procura manter o reservatório do solo sempre no volume meta seja para $\mathrm{K}_{\mathrm{s}}=1$ ou para $\mathrm{K}_{\mathrm{s}}$ logarítmico. 
Verifica-se na Tabela 13 que as lâminas no método do balanço hídrico resultaram menores que no IrrigaLS. Como o método do balanço hídrico calcula a lâmina que realmente é utilizada pela planta, sem comprometer da produção, achou-se conveniente reduzir o Vmeta dos reservatórios do solo no IrrigaLS e analisar este efeito sobre a economia de água. O Vmeta no IrrigaLS foi encontrado através de tentativas, o melhor valor foi aquele que apresentou menor diferença relativa em comparação ao método do balanço hídrico.

A Tabela 14 mostra os valores de IRN, ITN e $\mathrm{ET}_{\mathrm{a}}$ (média anual) e as diferenças relativas obtidas com a redução do volume meta e a Tabela 15 as economias conseguidas com esta redução.

Tabela 14. Lâminas obtidas pelo método do balanço hídrico e pelo IrrigaLS com redução do volume meta (Vmeta)

\begin{tabular}{|c|c|c|c|c|c|c|c|c|c|c|c|}
\hline \multirow[t]{3}{*}{ Cultura } & \multirow[t]{3}{*}{ Vmeta } & \multicolumn{4}{|c|}{ Balanço Hídrico } & \multicolumn{3}{|c|}{ IrrigaLS $^{3}$} & \multicolumn{3}{|c|}{ Diferença relativa [\%] } \\
\hline & & \multirow[t]{2}{*}{$\mathrm{N}_{\mathrm{i}}{ }^{1}$} & \multicolumn{6}{|c|}{ Lâminas [mm] } & & & \\
\hline & & & IRN & ITN & $\mathrm{ET}_{\mathrm{a}}$ & IRN & ITN & $\mathrm{ET}_{\mathrm{a}}$ & IRN & ITN & $\mathrm{ET}_{\mathrm{a}}$ \\
\hline Banana & 0.90 & 11 & 590.99 & 671.58 & 879.03 & 589.88 & 669.33 & 878.80 & 0.19 & 0.34 & 0.03 \\
\hline Cana-de-açúcar & 0.82 & 9 & 173.08 & 237.10 & 288.29 & 160.65 & 221.79 & 310.10 & 7.18 & 6.46 & -7.57 \\
\hline Cítricas $(\mathrm{c} / \mathrm{c})^{2}$ & 0.81 & 8 & 446.33 & 507.20 & 725.50 & 440.29 & 456.35 & 680.80 & 1.35 & 10.03 & 6.16 \\
\hline Feijão & 0.88 & 9 & 106.77 & 106.77 & 230.46 & 104.65 & 104.65 & 237.45 & 1.99 & 1.99 & -3.03 \\
\hline Melancia & 0.90 & 8 & 177.38 & 242.99 & 288.46 & 179.38 & 266.48 & 310.00 & -1.13 & -9.67 & -7.47 \\
\hline Milho & 0.86 & 9 & 178.46 & 244.47 & 285.79 & 195.89 & 236.34 & 309.59 & -9.77 & 3.33 & -8.33 \\
\hline
\end{tabular}

${ }^{1}$ número total de irrigações

2 com controle de ervas

${ }^{3} \mathrm{~K}_{\mathrm{s}}$ logarítmico e Vmeta abaixo do volume na $\mathrm{CC}$ 
Tabela 15. Economia conseguida, no IrrigaLS, na lâmina total irrigada (ITN) com a redução do volume meta (Vmeta)

\begin{tabular}{|l|c|c|c|}
\cline { 2 - 3 } \multicolumn{1}{|c|}{ Culturas } & \multicolumn{2}{c|}{ ITN $[\mathrm{mm}]$} & \multirow{2}{*}{$\begin{array}{c}\text { Economia } \\
{[\%]}\end{array}$} \\
\cline { 2 - 3 } & Vmeta $=1$ & Vmeta $<1$ & 12.26 \\
\hline Banana & 762,83 & 669.33 & 32.45 \\
\hline Cana-de-açúcar & 328,32 & 221.79 & 26.13 \\
\hline Cítricas (c/c) ${ }^{1}$ & 617,76 & 456.35 & 45.21 \\
\hline Feijão & 191,00 & 104.65 & 7.34 \\
\hline Melancia & 287,60 & 266.48 & 18.59 \\
\hline Milho & 290,30 & 236.34 & \\
\hline
\end{tabular}

${ }^{1}$ com controle de ervas

Pela Tabela 15 observa-se que a economia conseguida com a redução do volume meta justifica o uso de tal processo.

Finalmente, verifica-se pelas comparações dos resultados das Tabelas 11 e 14 a validade das adaptações sugeridas nesse estudo, comprovando que o IrrigaLS é apto para determinar a demanda de irrigação.

\subsection{IRRIGALS E MODSIMLS}

Nas comparações entre os modelos considerou-se para o ModSimLS as hipóteses de cálculos utilizadas até o momento, ou seja, demanda de irrigação total calculada pelo método do balanço hídrico no SSD. No IrrigaLS variaram-se os recursos oferecidos pelo modelo, ou seja, a $\mathrm{PP}_{\mathrm{e}}$ e o Vmeta.

É importante citar previamente algumas vantagens do IrrigaLS sobre o ModSimLS. Além de calcular as demandas de irrigação total e suplementar sem a necessidade de cálculos externos por tratar o solo como um reservatório, no IrrigaLS, é possível estipular um volume máximo e mínimo de água armazenada no solo. A fixação de um volume mínimo, que corresponde ao PMP garante, que em períodos de seca, a 
planta pelo menos não morra. É possível, também, determinar-se quantidades ótimas de água para a cultura (CRA) pela inclusão da f, e a inclusão do $\mathrm{K}_{\mathrm{s}}$ permite determinar-se a necessidade hídrica real da cultura.

\subsubsection{Com Irrigação Total}

A Tabela 16 e a Figura 53 apresentam as demandas de irrigação médias mensais obtidas pelas simulações do IrrigaLS e do ModSimLS. Em ambos os métodos considerou-se a $\mathrm{PP}_{\mathrm{e}}=0$ e o solo na CC.

Tabela 16. Demandas de irrigação no IrrigaLS e no ModSimLS

\begin{tabular}{|c|c|c|c|}
\hline \multirow[t]{2}{*}{ Data } & IrrigaLS $^{1}$ & ModSimLS $^{1}$ & \multirow{2}{*}{$\begin{array}{c}\text { Diferença } \\
\text { relativa } \\
{[\%]}\end{array}$} \\
\hline & \multicolumn{2}{|c|}{ Demanda de Irrigação $\left[\mathrm{m}^{3} / \mathrm{s}\right]$} & \\
\hline Jan & 0,094 & 0,100 & $-6,38$ \\
\hline Fev & 0,092 & 0,090 & 2,17 \\
\hline Mar & 0,100 & 0,100 & 0,00 \\
\hline Abr & 0,092 & 0,090 & 2,17 \\
\hline Mai & 0,088 & 0,090 & $-2,27$ \\
\hline Jun & 0,064 & 0,060 & 6,25 \\
\hline Jul & 0,057 & 0,060 & $-5,26$ \\
\hline Ago & 0,058 & 0,060 & $-3,45$ \\
\hline Set & 0,069 & 0,070 & $-1,45$ \\
\hline Out & 0,086 & 0,090 & $-4,65$ \\
\hline Nov & 0,098 & 0,100 & $-2,04$ \\
\hline Dez & 0,100 & 0,100 & 0,00 \\
\hline Média & 0,083 & 0,084 & $-1,20$ \\
\hline
\end{tabular}

${ }^{1} \mathrm{PP}_{\mathrm{e}}=0$ e solo na CC 


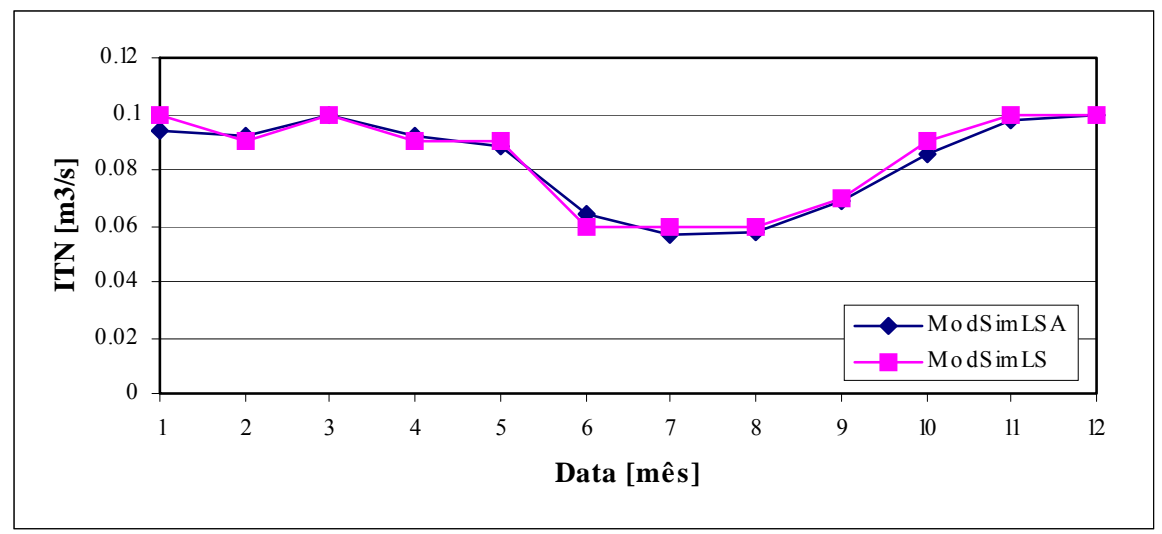

Figura 53. Demandas de irrigação obtidas por simulação no IrrigaLS e no ModSimLS, considerando-se a precipitação igual a zero $\left(\mathrm{PP}_{\mathrm{e}}=\mathbf{0}\right)$ e solo na capacidade de campo(CC)

Verifica-se pela Figura 53 que as lâminas são praticamente coincidentes e pela Tabela 16 que a diferença relativa média é de $-1,20 \%$. Tal diferença não é considerada significativa mostrando que os dois métodos de simulação, para a proposta de $\mathrm{PP}_{\mathrm{e}}=0 \mathrm{e}$ Vmeta do solo na CC, são equivalentes.

\subsubsection{Com Irrigação Suplementar}

O IrrigaLS oferece a possibilidade da inclusão da AS e o aporte da água da $\mathrm{PP}_{\mathrm{e}}$, sem necessidade de cálculos externos ao modelo. Analisou-se o efeito da inclusão da $\mathrm{PP}_{\mathrm{e}}$ mediante a comparação com o ModSimLS. A Tabela 17 e a Figura 54 apresentam as economias obtidas pela inclusão da $\mathrm{PP}_{\mathrm{e}}$.

Verifica-se na Tabela 17 que a economia média ao considerar-se a água de precipitação é de $31 \%$. Esse é um bom resultado, e para regiões com maior pluviosidade do que a região de estudo a economia tende a aumentar. Na Figura 54 verifica-se, também, a diferença entre as demandas de irrigação obtidas pelos dois métodos. 
Tabela 17. Economia de água obtida pela inclusão da precipitação no IrrigaLS

\begin{tabular}{|c|c|c|c|}
\hline \multirow[t]{2}{*}{ Data } & IrrigaLS $^{1}$ & ModSimLS $^{2}$ & \multirow{2}{*}{$\begin{array}{c}\text { Economia } \\
{[\%]}\end{array}$} \\
\hline & \multicolumn{2}{|c|}{ Demanda de irrigação $\left[\mathrm{m}^{3} / \mathrm{s}\right]$} & \\
\hline Jan & 0,061 & 0,100 & 39,00 \\
\hline Fev & 0,056 & 0,090 & 37,78 \\
\hline Mar & 0,060 & 0,100 & 40,00 \\
\hline Abr & 0,057 & 0,090 & 36,67 \\
\hline Mai & 0,066 & 0,090 & 26,67 \\
\hline Jun & 0,041 & 0,060 & 31,67 \\
\hline Jul & 0,038 & 0,060 & 36,67 \\
\hline Ago & 0,044 & 0,060 & 26,67 \\
\hline Set & 0,058 & 0,070 & 17,14 \\
\hline Out & 0,073 & 0,090 & 18,89 \\
\hline Nov & 0,074 & 0,100 & 26,00 \\
\hline Dez & 0,068 & 0,100 & 32,00 \\
\hline Média & 0,058 & 0,084 & 30,95 \\
\hline
\end{tabular}

${ }^{1} \mathrm{PP}_{\mathrm{e}} \neq 0$ e solo na $\mathrm{CC}$

${ }^{2} \mathrm{PP}_{\mathrm{e}}=0$ e solo na $\mathrm{CC}$

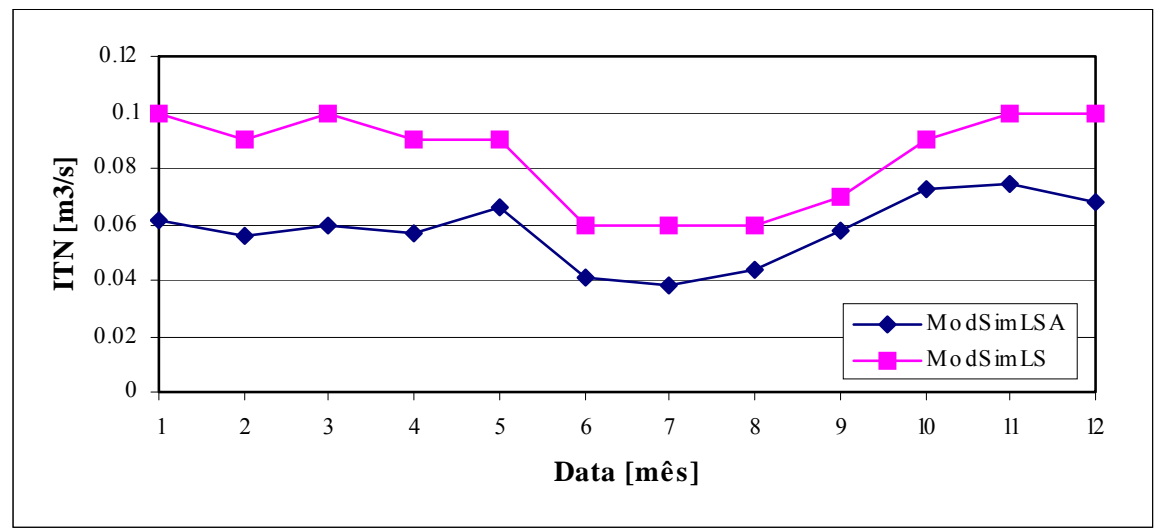

Figura 54. Demandas de irrigação obtidas por simulação no IrrigaLS (PP $\neq 0$ ) e no ModSimLS (PP $=0)$, considerando-se o solo na capacidade de campo

Vale lembrar que no ModSimLS a $\mathrm{PP}_{\mathrm{e}}$ pode ser incluída como vazão natural, necessitando para tanto de cálculos externos ao modelo. 


\subsubsection{Economia Total de Água}

A Tabela 18 apresenta os valores anuais médios da demanda de irrigação e os resultados da economia de água conseguida pelo IrrigaLS em comparação com o ModSimLS. A tabela apresenta, também, as demandas obtidas pelo método do balanço hídrico.

Tabela 18. Econômica de água obtida pelo IrrigaLS em comparação com o ModSimLS

\begin{tabular}{|c|c|c|c|c|c|c|c|c|}
\hline \multicolumn{9}{|c|}{ Demandas de irrigação $\left[\mathrm{m}^{3} / \mathrm{s}\right]$} \\
\hline \multirow{2}{*}{$\begin{array}{c}\text { ModSimLS } \\
\mathrm{PP}_{\mathrm{e}}=0 \\
\text { Vmeta }=1\end{array}$} & \multicolumn{2}{|c|}{$\mathrm{PP}_{\mathrm{e}}=0$ e $\mathrm{K}_{\mathrm{s}}=1$} & \multicolumn{2}{|c|}{$\mathrm{PP}_{\mathrm{e}}=0$ e $\mathrm{K}_{\mathrm{s}}$ logarítmico } & \multicolumn{2}{|c|}{$\mathrm{PP}_{\mathrm{e}} \neq 0$ e $\mathrm{K}_{\mathrm{s}}=1$} & \multicolumn{2}{|c|}{$\mathrm{PP}_{\mathrm{e}} \neq 0$ e $\mathrm{K}_{\mathrm{s}}$ logarítmico } \\
\hline & $\begin{array}{c}\text { IrrigaLS } \\
\text { Vmeta }=1\end{array}$ & $\begin{array}{l}\text { Balanço } \\
\text { hídrico }\end{array}$ & $\begin{array}{c}\text { IrrigaLS } \\
\text { Vmeta } \neq 1\end{array}$ & $\begin{array}{l}\text { Balanço } \\
\text { hídrico }\end{array}$ & $\begin{array}{c}\text { IrrigaLS } \\
\text { Vmeta }=1\end{array}$ & $\begin{array}{l}\text { Balanço } \\
\text { hídrico }\end{array}$ & $\begin{array}{c}\text { IrrigaLS } \\
\text { Vmeta } \neq 1\end{array}$ & $\begin{array}{l}\text { Balanço } \\
\text { hídrico }\end{array}$ \\
\hline 0,083 & 0,083 & 0,083 & 0,075 & 0,076 & 0,058 & 0,058 & 0,050 & 0,051 \\
\hline \multicolumn{9}{|c|}{ Economia de água conseguida com o IrrigaLS em comparação com o ModSimLS [\%] } \\
\hline \multicolumn{7}{|c|}{ IrrigaLS $\left(\mathrm{PP}_{\mathrm{e}}=0\right.$ e $\left.\mathrm{K}_{\mathrm{s}}=1: \mathrm{V}_{\text {meta }}=1\right)$ e ModSimLS $\left(\mathrm{PP}_{\mathrm{e}}=0\right.$ e Vmeta $\left.=1\right)$} & \multicolumn{2}{|c|}{0,74} \\
\hline \multicolumn{7}{|c|}{ IrrigaLS $\left(\mathrm{PP}_{\mathrm{e}}=0\right.$ e $\mathrm{K}_{\mathrm{s}}$ logarítmico: $\left.\mathrm{V}_{\text {meta }} \neq 1\right)$ e ModSimLS $\left(\mathrm{PP}_{\mathrm{e}}=0\right.$ e Vmeta $\left.=1\right)$} & \multicolumn{2}{|c|}{9,71} \\
\hline \multicolumn{7}{|c|}{ IrrigaLS $\left(\mathrm{PP}_{\mathrm{e}} \neq 0\right.$ e $\left.\mathrm{K}_{\mathrm{s}}=1: \mathrm{V}_{\text {meta }}=1\right)$ e ModSimLS $\left(\mathrm{PP}_{\mathrm{e}}=0\right.$ e Vmeta $\left.=1\right)$} & \multicolumn{2}{|c|}{30,95} \\
\hline \multicolumn{7}{|c|}{ IrrigaLS $\left(\mathrm{PP}_{\mathrm{e}} \neq 0\right.$ e $\mathrm{K}_{\mathrm{s}}$ logarítmico: $\left.\mathrm{V}_{\text {meta }} \neq 1\right)$ e ModSimLS $\left(\mathrm{PP}_{\mathrm{e}}=0\right.$ e Vmeta $\left.=1\right)$} & \multicolumn{2}{|c|}{40,42} \\
\hline
\end{tabular}

Verifica-se pela Tabela 18 que as demandas de irrigação obtidas pelo IrrigaLS estão de acordo com as demandas obtidas pelo método do balanço hídrico. Verifica-se também, que com a inclusão da $\mathrm{PP}_{\mathrm{e}}$ e a variação do Vmeta obteve-se no IrrigaLS em relação ao ModSimLS, uma economia na quantidade de água, chegando essa economia à $40,42 \%$. 


\subsection{SUPRIMENTO DE ÁGUA E RENDIMENTO DAS CULTURAS}

O IrrigaLS oferece, também, como opção alternativa a análise do efeito do déficit hídrico sobre as diferentes culturas.

A Figura 55 apresenta a relação entre a diminuição de rendimento relativo (1 $\left.\mathrm{Y}_{\mathrm{a}} / \mathrm{Y}_{\mathrm{p}}\right)$ e o déficit de evapotranspiração relativa $\left(1-\mathrm{ET}_{\mathrm{a}} / \mathrm{ET}_{\mathrm{p}}\right)$ para as culturas da banana, cana-de-açúcar, cítricas, feijão, melancia e milho. A Figura 56 apresenta a faixa de valores obtida pela simulação no IrrigaLS. Nas análises utilizaram-se coeficientes de resposta da cultura $\left(\mathrm{K}_{\mathrm{y}}\right)$ referente ao período total de crescimento das culturas.

Verifica-se pelas Figuras 55 e 56 que para as cítricas a eficiência de utilização da água aumenta com a variação do déficit hídrico, isso deve-se ao fato de $\mathrm{K}_{\mathrm{y}}$ para essa cultura ser menor que a unidade. Em outras palavras, o efeito do suprimento reduzido de água sobre o rendimento das cítricas é menos pronunciado do que em relação as outras culturas que têm valores de $\mathrm{K}_{\mathrm{y}}$ maiores que a unidade durante o período de escassez de água. Quando se envolve o cultivo de várias culturas, o suprimento de irrigação para as cítricas pode ser reduzido em detrimento de outras culturas mais sensíveis. Também pode se dizer que sob condições de déficit hídrico limitado de água, a produção total das cítricas é incrementada através da ampliação da área irrigada, em vez de atender plenamente às necessidades hídricas da cultura numa área limitada.

Verifica-se, também, na Figura 56 o efeito da variação do volume no reservatório do solo. Como a variação foi pequena os valores no gráfico concentram-se na parte inicial, mostrando que não houve queda significativa no rendimento das culturas. 


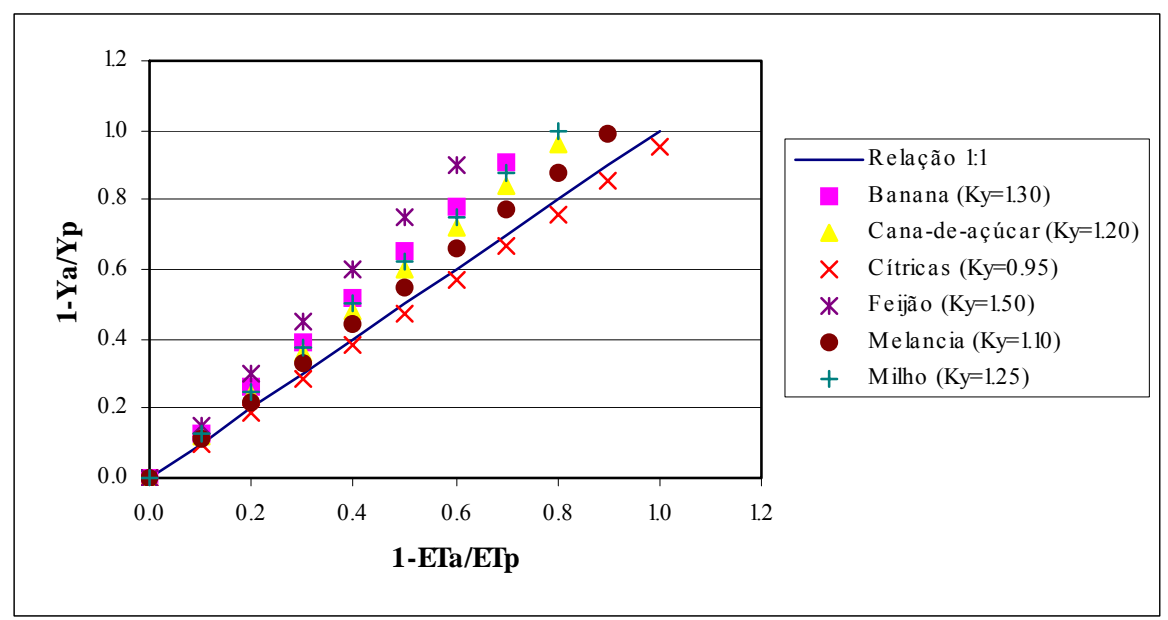

Figura 55. Relação entre a diminuição de rendimento relativo (1 - $\left.\mathbf{Y}_{a} / \mathbf{Y}_{\mathrm{p}}\right)$ e o déficit de evapotranspiração relativa (1 - ET $\left.\mathrm{a} / \mathrm{ET}_{\mathrm{p}}\right)$ para as culturas da banana, cana-deaçúcar, cítricas, feijão, melancia e milho

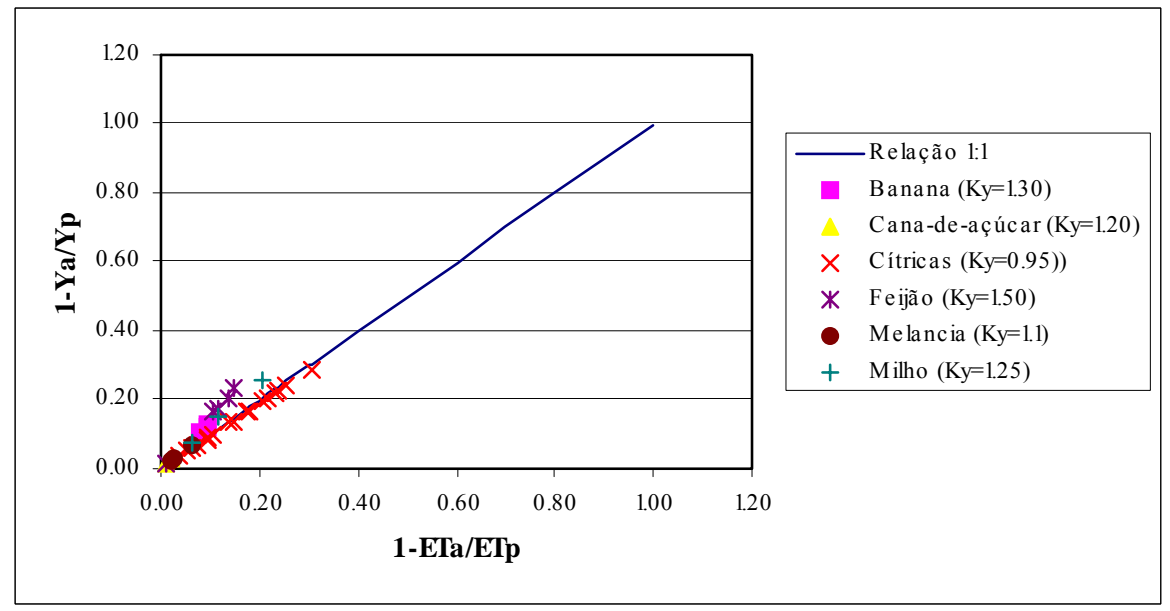

Figura 56. Relação entre a diminuição de rendimento relativo $\left(1-Y_{a} / Y_{p}\right)$ e o déficit de evapotranspiração relativa $\left(1-\mathrm{ET}_{\mathrm{a}} / \mathrm{ET}_{\mathrm{p}}\right)$ para as culturas da banana, cana-deaçúcar, cítricas, feijão, melancia e milho, obtida no método adaptado

A explicação acima pode também ser observada nas Figuras 57 e 58, que representam, para as culturas em estudo, a relação entre a diminuição da produção relativa $\left(1-\mathrm{P}_{\mathrm{a}} / \mathrm{P}_{\mathrm{p}}\right)$ e $\left(1-\mathrm{ET}_{\mathrm{a}} / \mathrm{ET}_{\mathrm{p}}\right)$. A Figura 58 apresenta os resultados obtidos com a simulação no modelo. 


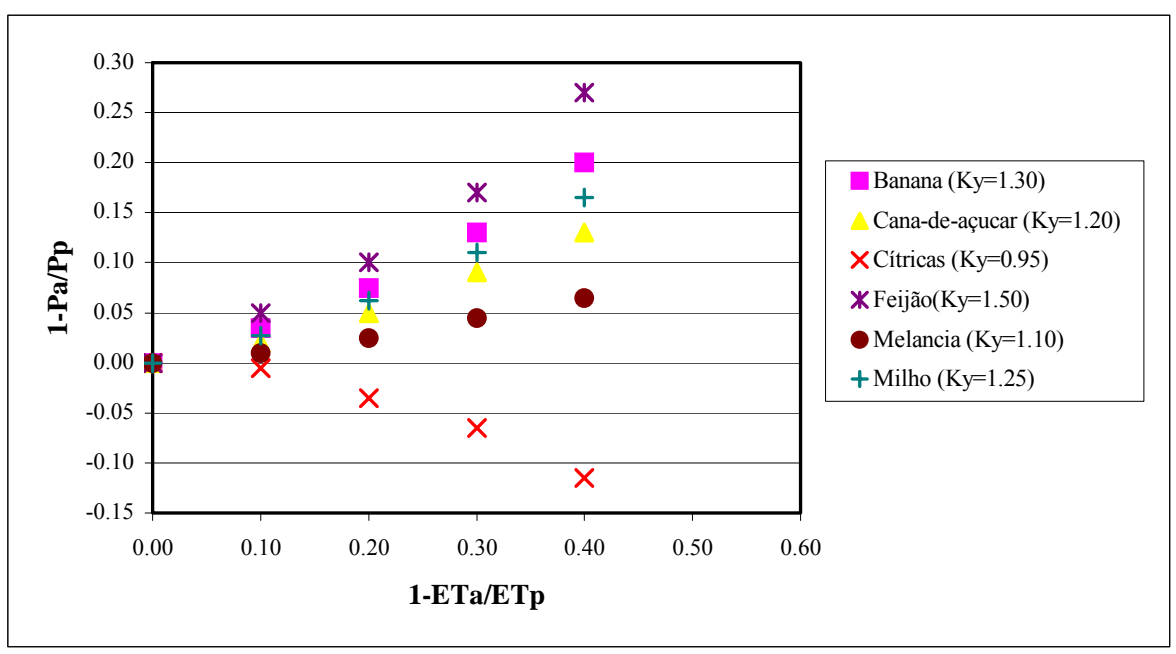

Figura 57. Relação entre a diminuição da produção relativa $\left(1-\mathbf{P}_{\mathrm{a}} / \mathbf{P}_{\mathrm{p}}\right)$ e 0 déficit de evapotranspiração relativa ( 1 - $\left.E T_{a} / E T_{p}\right)$ para as culturas da banana, cana-deaçúcar, cítricas, feijão, melancia e milho

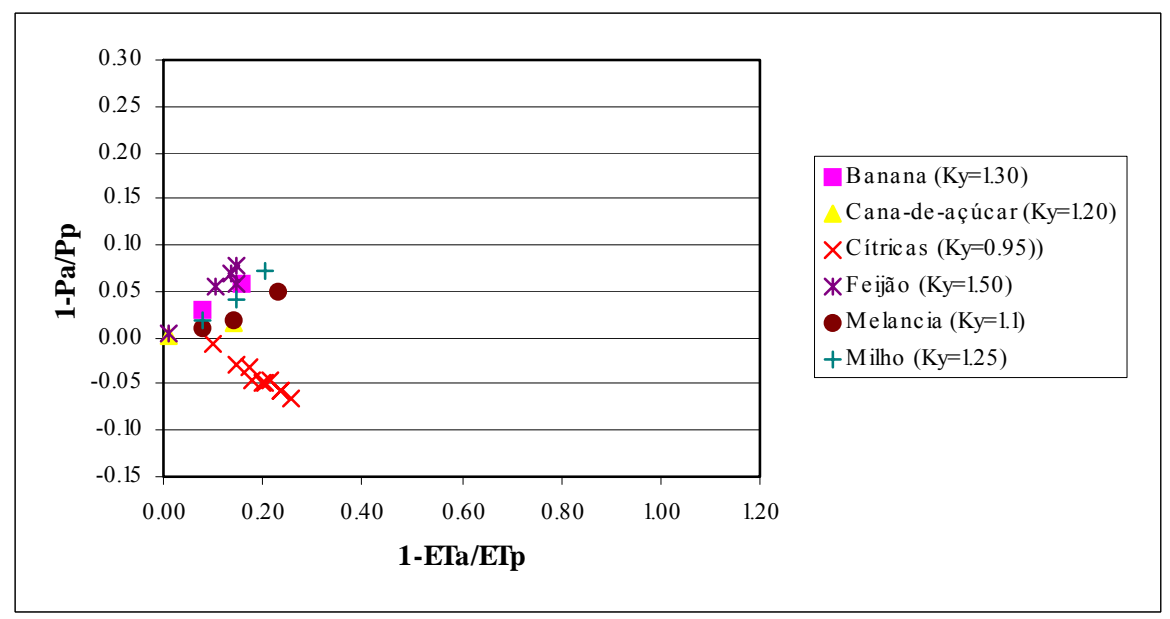

Figura 58. Relação entre a diminuição da produção relativa $\left(1-\mathbf{P}_{\mathrm{a}} / \mathbf{P}_{\mathrm{p}}\right)$ e o déficit de evapotranspiração relativa $\left(1-\mathrm{ET}_{\mathrm{a}} / \mathrm{ET}_{\mathrm{p}}\right)$ para as culturas da banana, cana-deaçúcar, cítricas, feijão, melancia e milho, obtida no método adaptado

\subsection{ANÁLISE DO SISTEMA DA BACIA DO ITAPICURU}

Com a finalidade de verificar as vantagens do IrrigaLS, em relação ao ModSimLS, na simulação de sistemas complexos, analisou-se o sistema da bacia do Itapicuru. Verificou-se a situação dos reservatórios superficiais e das demandas, 
mediante a comparação de dois projetos. O primeiro projeto diz respeito a simulação no IrrigaLS e o segundo a simulação no ModSimLS. Para o ModSimLS, como citado anteriormente, consideraram-se as hipóteses de cálculo utilizadas até o momento. Para o IrrigaLS considerou-se a demanda de irrigação suplementar e Vmeta do solo igual ao volume na CC. As topologias das redes simuladas no ModSimLS e no IrrigaLS encontram-se nas Figuras 35 e 36, respectivamente.

A Tabela 19 apresenta a situação das demandas de irrigação, jusante e urbana no sistema da bacia do Itapicuru para o IrrigaLS e ModSimLS. As demandas de irrigação referentes ao reservatório de Ponto Novo foram analisadas separadamente.

Tabela 19. Cenário atual da situação das demandas de irrigação, jusante e urbana no sistema da bacia do Itapicuru para o IrrigaLS e ModSimLS

\begin{tabular}{|l|c|c|c|}
\hline \multicolumn{1}{|c|}{ Projetos } & $\begin{array}{c}\text { Tempo máximo abaixo da } \\
\text { demanda necessária } \\
{[\mathrm{meses}]}\end{array}$ & $\begin{array}{c}\text { Freqüência abaixo da } \\
\text { demanda necessária } \\
{[\%]}\end{array}$ & $\begin{array}{c}\text { Vazão média fornecida } \\
{\left[\mathrm{m}^{3} / \mathrm{s}\right]}\end{array}$ \\
\hline \multicolumn{5}{|c|}{ Demanda de irrigação do reservatório de Ponto Novo } \\
\hline IrrigaLS & 0 & 0,00 & 0,058 \\
\hline ModSimLS & 4 & 0,93 & 0,083 \\
\hline \multicolumn{5}{|c|}{ Demanda de irrigação no sistema } \\
\hline IrrigaLS & 8 & 4,81 & 0,861 \\
\hline ModSimLS & 8 & 4,81 & 0,861 \\
\hline \multicolumn{5}{|c|}{ Demanda de jusante no sistema ${ }^{1}$} \\
\hline IrrigaLS & 2 & 0,37 & 26,24 \\
\hline ModSimLS & 2 & 0,37 & 26,194 \\
\hline \multicolumn{5}{|c|}{ Demanda de urbana no sistema } \\
\hline IrrigaLS & 4 & 5,93 & 1,044 \\
\hline ModSimLS & 4,93 & 1,044 \\
\hline
\end{tabular}

${ }^{1}$ demanda que tem a função de forçar a passagem de água no link

Verifica-se na Tabela 19, pela comparação dos projetos, que houve alteração nos valores da demanda de irrigação do reservatório de Ponto Novo. No ModSimLS a 
demanda fica abaixo do necessário durante quatro meses consecutivos, enquanto que no IrrigaLS isso não acontece. Em se tratando de irrigação e dependo da sensibilidade da cultura ao déficit hídrico, quatro meses pode representar uma queda significativa no rendimento da cultura ou até mesmo a morte da planta. Verifica-se, também, pela tabela uma diferença entre os valores da vazão média fornecida, sendo o valor da mesma menor no IrrigaLS. Essa diferença para menos representa um aspecto positivo já que os critérios de cálculos já foram verificados anteriormente e mostraram-se corretos.

A Tabela 20 apresenta a situação dos reservatórios de Aipim, Pindobaçu e Ponto Novo no sistema da bacia do Itapicuru.

\section{Tabela 20. Cenário atual da situação dos reservatórios de Aipim, Pindobaçu e Ponto Novo no sistema da bacia do Itapicuru para o IrrigaLS e ModSimLS}

\begin{tabular}{|l|c|c|c|c|c|c|}
\hline Projetos & $\begin{array}{c}\text { Tempo } \\
\text { máximo } \\
\text { abaixo do } \\
\text { Volume Meta } \\
{[\text { meses }]}\end{array}$ & $\begin{array}{c}\text { Freqüência } \\
\text { abaixo do } \\
\text { Volume Meta } \\
{[\%]}\end{array}$ & $\begin{array}{c}\text { Volume } \\
\text { acumulado } \\
\text { vertido } \\
{\left[\mathrm{Mm}^{3}\right]}\end{array}$ & $\begin{array}{c}\text { Freqüência } \\
\text { com que } \\
\text { houve } \\
\text { vertimento } \\
{[\%]}\end{array}$ & $\begin{array}{c}\text { Tempo } \\
\text { máximo de } \\
\text { esvaziamento } \\
{[\text { meses] }}\end{array}$ & $\begin{array}{c}\text { Freqüência } \\
\text { de } \\
\text { esvaziamento } \\
{[\%]}\end{array}$ \\
\hline Reservatório de Aipim \\
\hline IrrigaLS & 19 & 40 & 86,302 & 4,44 & 6 & 3,52 \\
\hline ModSimLS & 19 & 40 & 86,302 & 4,44 & 6 & 3,52 \\
\hline \multicolumn{7}{|c|}{ Reservatório de Pindobaçu } \\
\hline IrrigaLS & 16 & 32,22 & $1.155,247$ & 6,67 & 4 & 2,96 \\
\hline ModSimLS & 16 & 32,22 & $1.155,055$ & 6,67 & 4 & 2,96 \\
\hline & 17 & 28,52 & $2.107,049$ & 4,44 & 4 & 0,93 \\
\hline IrrigaLS & 17 & 29,07 & $2.104,758$ & 4,44 & 4 & 0,93 \\
\hline ModSimLS & 17 & \multicolumn{7}{|c|}{ Reservatório de Ponto Novo } & 4 \\
\hline
\end{tabular}

Verifica-se pela Tabela 20 que a situação dos reservatórios Aipim e Pindobaçu não varia com os projetos, porém, no reservatório de Ponto Novo a freqüência abaixo do volume meta é maior no ModSimLS. Como visto na Tabela 19 a única demanda que apresenta variação é a demanda de irrigação do reservatório de Ponto Novo, assim, 
concluí-se que a mesma é a responsável por essa diferença. É importante verificar que o montante da demanda de irrigação de Ponto Novo é pequeno em relação as outras demandas, por isso os valores da freqüência abaixo do volume meta apresentam-se próximos. Caso o valor da demanda de irrigação de Ponto Novo fosse igual ou maior ao das outras demandas a diferença seria mais significativa.

A partir dos dados de proposta de ampliação da área irrigada na região do reservatório de Ponto Novo (Tabela 3), fornecidos pela SRH, analisou-se o cenário futuro da região de estudo. As Tabelas 21 e 22 apresentam a situação futura das demandas e dos reservatórios.

Tabela 21. Cenário futuro da situação das demandas de irrigação, jusante e urbana no sistema da bacia do Itapicuru para o IrrigaLS e ModSimLS

\begin{tabular}{|l|c|c|c|}
\hline \multicolumn{1}{|c|}{ Projetos } & $\begin{array}{c}\text { Tempo máximo abaixo da } \\
\text { demanda necessária } \\
{[\text { meses] }}\end{array}$ & $\begin{array}{c}\text { Freqüência abaixo da } \\
\text { demanda necessária } \\
{[\%]}\end{array}$ & $\begin{array}{c}\text { Vazão média fornecida } \\
{\left[\mathrm{m}^{3} / \mathrm{s}\right]}\end{array}$ \\
\hline \multicolumn{5}{|c|}{ Demanda de irrigação do reservatório de Ponto Novo } \\
\hline IrrigaLS & 0 & 0,00 & 0,104 \\
\hline ModSimLS & 4 & 0,93 & 0,156 \\
\hline \multicolumn{5}{|c|}{ Demanda de irrigação no sistema } \\
\hline IrrigaLS & 8 & 4,81 & 0,861 \\
\hline ModSimLS & 8 & 4,81 & 0,861 \\
\hline \multicolumn{5}{|c|}{ Demanda de jusante no sistema ${ }^{1}$} \\
\hline IrrigaLS & 2 & 0,37 & 26,157 \\
\hline ModSimLS & 2 & 0,37 & 26,067 \\
\hline \multicolumn{5}{|c|}{ Demanda de urbana no sistema } \\
\hline IrrigaLS & 4 & 5,93 & 1,044 \\
\hline ModSimLS & 4 & 5,93 & 1,044 \\
\hline
\end{tabular}

${ }^{1}$ demanda que tem a função de forçar a passagem de água no link 
Tabela 22. Cenário futuro da situação dos reservatórios de Aipim, Pindobaçu e Ponto Novo no sistema da bacia do Itapicuru para o IrrigaLS e ModSimLS

\begin{tabular}{|l|c|c|c|c|c|c|}
\hline Projetos & $\begin{array}{c}\text { Tempo } \\
\text { máximo } \\
\text { abaixo do } \\
\text { Volume Meta } \\
{[\text { meses }]}\end{array}$ & $\begin{array}{c}\text { Freqüência } \\
\text { abaixo do } \\
\text { Volume Meta } \\
{[\%]}\end{array}$ & $\begin{array}{c}\text { Volume } \\
\text { acumulado } \\
\text { vertido } \\
{\left[\mathrm{Mm}^{3}\right]}\end{array}$ & $\begin{array}{c}\text { Freqüência } \\
\text { com que } \\
\text { houve } \\
\text { vertimento } \\
{[\%]}\end{array}$ & $\begin{array}{c}\text { Tempo } \\
\text { máximo de } \\
\text { esvaziamento } \\
{[\text { meses }]}\end{array}$ & $\begin{array}{c}\text { Freqüência } \\
\text { de } \\
\text { esvaziamento } \\
{[\%]}\end{array}$ \\
\hline IrrigaLS & 19 & 40 & 86,302 & 4,44 & 6 & 3,52 \\
\hline ModSimLS & 19 & 40 & 86,302 & 4,44 & 6 & 3,52 \\
\hline \multicolumn{7}{|c|}{ Reservatório de Pindobaçu } \\
\hline IrrigaLS & 16 & 32,22 & $1.154,744$ & 6,67 & 4 & 2,96 \\
\hline ModSimLS & 16 & 32,22 & $1.154,168$ & 6,67 & 4 & 2,96 \\
\hline \multicolumn{7}{|c|}{ Reservatório de Ponto Novo } \\
\hline IrrigaLS & 17 & 29,07 & $2.102,95$ & 4,44 & 4 & 0,93 \\
\hline ModSimLS & 17 & 29,44 & $2.098,191$ & 4,44 & 4 & 0,93 \\
\hline
\end{tabular}

Verifica-se pelas Tabelas 21 e 22 que apesar do aumento da vazão média fornecida, não houve variação no cenário, mostrando que o sistema mostra-se apto à ampliação.

\subsubsection{Relação entre o Reservatório do Solo e o Reservatório Superficial}

Verificou-se a relação existente entre o reservatório de Ponto Novo e os reservatórios do solo, analisando-se a variação dos volumes dos mesmos mediante as respectivas $\mathrm{E}_{\mathrm{a}}$ e $\mathrm{ET}_{\mathrm{a}}$, médias mensais.

Os volumes dos reservatórios do solo para as culturas consideradas encontramse na Tabela 23 e o volume do reservatório de Ponto Novo corresponde a $40 \mathrm{Mm}^{3}$. 
Tabela 23. Volume no reservatório do solo de acordo com a área irrigada $\left(A_{i}\right)$ e a profundidade do sistema radicular $\left(\mathrm{Z}_{\mathbf{r}}\right)$

\begin{tabular}{|l|c|}
\hline \multicolumn{1}{|c|}{ Cultura } & Volume $\left[\mathrm{m}^{3}\right]$ \\
\hline Banana & 2.220 .000 \\
\hline Cana-de-açúcar & 67.500 \\
\hline Cítricas (c/c) & 63.600 \\
\hline Feijão & 120.000 \\
\hline Melancia & 50.000 \\
\hline Milho & 36.000 \\
\hline Volume total & 2.557 .100 \\
\hline
\end{tabular}

A Tabela 24 apresenta os valores de $\mathrm{ET}_{\mathrm{a}}$ e $\mathrm{E}_{\mathrm{a}}$ para os reservatórios do solo e superficial, respectivamente, quando considerou-se a $\mathrm{PP}_{\mathrm{e}}$ e a variação do Vmeta.

Tabela 24. Relação entre a evapotranspiração real média mensal das culturas $\left(E T_{a}\right)$ e a evaporação real média mensal $\left(E_{a}\right)$ do reservatório de Ponto Novo

\begin{tabular}{|l|c|c|}
\hline \multirow{2}{*}{\multicolumn{1}{c|}{$\begin{array}{c}\text { Projeto } \\
\text { IrrigaLS }\end{array}$}} & \multicolumn{2}{|c|}{ Reservatórios } \\
\cline { 2 - 3 } & $\left.\mathrm{Solo}_{\mathrm{a}} \mathrm{m}^{3}\right]$ & Ponto Novo $\left[\mathrm{m}^{3}\right]$ \\
\cline { 2 - 3 } & $82.584,00$ & $\mathrm{E}_{\mathrm{a}}$ \\
\hline $\mathrm{PP}_{\mathrm{e}}=0$ e Vmeta na CC & $75.609,82$ & $973.545,45$ \\
\hline $\mathrm{PP}_{\mathrm{e}}=0$ e Vmeta abaixo da CC & $82.584,00$ & $97.918,56$ \\
\hline $\mathrm{PP}_{\mathrm{e}} \neq 0$ e Vmeta na CC & $75.490,36$ & $974.924,24$ \\
\hline $\mathrm{PP}_{\mathrm{e}} \neq 0$ e Vmeta abaixo da CC & \\
\hline
\end{tabular}

Verifica-se pela Tabela 24 que quanto menos água o reservatório no solo necessitar mais água será armazenada no reservatório superficial, resultando em um aumento na $\mathrm{E}_{\mathrm{a}}$. Isso mostra que existe sinergia entre os reservatórios do solo e superficial. A importância da sinergia esta no fato de que a água do reservatório superficial que vai para o reservatório do solo passa a ser armazenada por este. Sendo a 
evaporação em uma superfície livre maior do que a evaporação do solo tem-se um aumento da água útil para irrigação. 


\section{CONCLUSÕES}

Neste trabalho fez-se a adaptação do reservatório superficial do ModSimLS para trabalhar como reservatório do solo. O novo modelo, o IrrigaLS, visou possibilitar a determinação das demandas de irrigação total ou suplementar pelo próprio modelo, considerando a produção agrícola como o resultado da interação dos fatores água-climaplanta-solo.

Na rotina computacional do IrrigaLS fez-se necessário o uso de tabelas. Com a finalidade de simplificar e agilizar os cálculos plotou-se os dados tabelados e verificouse que os valores podiam ser ajustados através de funções. As funções utilizadas dizem respeito a precipitação efetiva, ao fator de correção da precipitação efetiva, a fração de esgotamento de água no solo e a produção total relativa.

Verificou-se pela comparação do IrrigaLS com o método do balanço hídrico que o modelo é apto para determinar as demandas de irrigação e a evapotranspiração da cultura. Verificou-se, também, que pelo fato de internamente os cálculos do IrrigaLS envolverem números inteiros o modelo apresenta alguma limitação para pequenos volumes.

Pela comparação dos modelos de simulação, verificou-se que o IrrigaLS é apto para simular sistemas, apresentando algumas vantagens com relação ao ModSimLS. Dentre estas vantagens cita-se a possibilidade de determinação da demanda de irrigação total ou suplementar pelo próprio modelo sem necessidades de cálculos externos. Além disso, por tratar o solo como um reservatório fica possível estipular o volume máximo e mínimo de água admissível pela planta. A fixação de um volume mínimo garante que 
em períodos de seca a planta pelo menos não morra. É possível, também, determinar quantidades ótimas de água para a cultura pela inclusão da fração de esgotamento de água no solo. Além disso, a inclusão do coeficiente de variação da umidade do solo permite determinar a necessidade hídrica real da cultura.

O IrrigaLS oferece como opção alternativa o cálculo do balanço hídrico diário do solo. Esta alternativa permite ao usuário informações sobre o calendário de irrigação e sobre o comportamento das variáveis de acordo com as características da região.

Outra alternativa corresponde a possibilidade de diferenciar as culturas com relação a sensibilidade ao déficit hídrico, facilitando a tomada de decisões em cultivo de várias culturas. Permitindo, por exemplo, que o usuário opte por reduzir o suprimento de irrigação em culturas mais resistentes ao déficit hídrico em detrimento de outras culturas mais sensíveis.

A economia conseguida pelo IrrigaLS pôde ser verificada na análise do sistema da bacia do Itapicuru. No ModSimLS a demanda ficou abaixo do necessário durante quatro meses consecutivos, enquanto que no IrrigaLS isto não aconteceu. Em se tratando de irrigação e dependo da sensibilidade da cultura ao déficit hídrico, quatro meses pode representar uma queda significativa no rendimento da cultura ou até mesmo a morte da planta.

Verificou-se, também, a existência de sinergia entre os reservatórios do solo e superficial, resultando em uma minimização da perda por evaporação.

Embora o IrrigaLS seja adequado para determinar demandas de irrigação e simular sistemas complexos de recursos hídricos, sugere-se considerar na rotina de cálculos mais de uma camada de solo. Esta inclusão pode aumentar a precisão dos 
resultados. Sugere-se, também, a elaboração de um modelo de simulação diária, a inclusão da análise da qualidade da água e o estudo do custo da irrigação. 


\section{ANEXO - TABELAS E GRÁFICOS}

Tabela 1. Profundidade efetiva das raízes $\left(Z_{r}\right)$ para diferentes tipos de culturas

\begin{tabular}{|c|c|c|c|}
\hline Cultura & $\mathrm{Z}_{\mathrm{r}}(\mathrm{cm})$ & Cultura & $\mathrm{Z}_{\mathrm{r}}(\mathrm{cm})$ \\
\hline Abacate & $60-90$ & Espinafre & $40-60$ \\
\hline Abóbora & $75-100$ & Ervilha & $60-90$ \\
\hline Alface & $20-40$ & Feijão verde & $25-50$ \\
\hline Algodão & $80-120$ & Feijão (grãos secos) & $60-100$ \\
\hline Amendoim & $40-60$ & Forragem (gramíneas) & $30-60$ \\
\hline Arroz & $30-40$ & Forragem leguminosa & $60-80$ \\
\hline Aspargo & $100-150$ & Melancia & $100-150$ \\
\hline Banana & $60-80$ & Melão & $70-100$ \\
\hline Batata & $25-40$ & Milho & $60-120$ \\
\hline Beterraba açucareira & $100-180$ & Morango & $40-60$ \\
\hline Beterraba leguminosa & $60-80$ & Pepino & $60-80$ \\
\hline Cana de açúcar & $50-100$ & Pimentão & $40-50$ \\
\hline Cebola & $20-40$ & Soja & $60-90$ \\
\hline Cevada & $80-100$ & Sorgo & $90-120$ \\
\hline Cenoura & $45-75$ & Tabaco & $60-100$ \\
\hline Cereais & $60-120$ & Tomate & $60-120$ \\
\hline Cítricos & $90-150$ & Trigo & $80-100$ \\
\hline Couve & $30-60$ & Vinha & $90-120$ \\
\hline
\end{tabular}

Fonte: Gomes (1999) 
Tabela 2. Coeficiente de cultura $\left(K_{c}\right)$

\begin{tabular}{|c|c|c|c|c|c|c|}
\hline \multirow[t]{2}{*}{ Culturas } & \multicolumn{5}{|c|}{ Fases de desenvolvimento } & \multirow{2}{*}{$\begin{array}{c}\text { Período } \\
\text { vegetativo total }\end{array}$} \\
\hline & Inicial & Desenvolvimento & Intermediário & Final & Colheita & \\
\hline Alfafa & $0.3-0.4$ & & & & 1.05 & $0.85-1.05$ \\
\hline Algodão & $0.4-0.5$ & $0.7-0.8$ & $1.05-1.25$ & $0.8-0.9$ & $0.65-0.7$ & $0.8-0.9$ \\
\hline Amendoim & $0.4-0.5$ & $0.7-0.8$ & $0.95-1.1$ & $0.75-0.85$ & $0.55-0.6$ & $0.75-0.8$ \\
\hline Arroz & $1.1-1.15$ & $1.1-1.15$ & $1.1-1.3$ & $0.95-1.05$ & $0.95-1.05$ & $1.05-1.2$ \\
\hline $\begin{array}{l}\text { Banana } \\
\text { - tropical } \\
\text { - subtropical } \\
\end{array}$ & $\begin{array}{c}0.4-0.5 \\
0.5-0.65\end{array}$ & $\begin{array}{c}0.7-0.85 \\
0.8-0.9 \\
\end{array}$ & $\begin{array}{l}1.0-1.1 \\
1.0-1.2 \\
\end{array}$ & $\begin{array}{c}0.9-1.0 \\
1.0-1.15 \\
\end{array}$ & $\begin{array}{c}0.75-0.85 \\
1.0-1.15 \\
\end{array}$ & $\begin{array}{c}0.7-0.8 \\
0.85-0.95\end{array}$ \\
\hline Batata & $0.4-0.5$ & $0.7-0.8$ & $1.05-1.2$ & $0.85-0.95$ & $0.7-0.75$ & $0.75-0.9$ \\
\hline Beterraba açucareira & $0.4-0.5$ & $0.75-0.85$ & $1.05-1.2$ & $0.9-1.0$ & $0.6-0.7$ & $0.8-0.9$ \\
\hline Cana-de-açúcar & $0.4-0.5$ & $0.7-1.0$ & $1.0-1.3$ & $0.75-0.8$ & $0.5-0.6$ & $0.85-1.05$ \\
\hline Cártamo & $0.3-0.4$ & $0.7-0.8$ & $1.05-1.2$ & $0.65-0.7$ & $0.2-0.25$ & $0.65-0.7$ \\
\hline $\begin{array}{l}\text { Cebola } \\
\text { - seca } \\
\text { - verde }\end{array}$ & $\begin{array}{l}0.4-0.6 \\
0.4-0.6 \\
\end{array}$ & $\begin{array}{c}0.7-0.8 \\
0.6-0.75 \\
\end{array}$ & $\begin{array}{c}0.95-1.1 \\
0.95-1.05\end{array}$ & $\begin{array}{c}0.85-0.9 \\
0.95-1.05\end{array}$ & $\begin{array}{l}0.75-0.85 \\
0.95-1.05 \\
\end{array}$ & $\begin{array}{c}0.8-0.9 \\
0.65-0.8 \\
\end{array}$ \\
\hline $\begin{array}{l}\text { Citros } \\
\text { - com tratos culturais } \\
\text { - sem tratos culturais }\end{array}$ & & & & & & $\begin{array}{c}0.65-0.75 \\
0.85-0.9 \\
\end{array}$ \\
\hline Ervilha verde & $0.4-0.5$ & $0.7-0.85$ & $1.05-1.2$ & $1.0-1.15$ & $0.95-1.1$ & $0.8-0.95$ \\
\hline $\begin{array}{l}\text { Feijão } \\
\text { - verde } \\
\text { - seco } \\
\end{array}$ & $\begin{array}{l}0.3-0.4 \\
0.3-0.4 \\
\end{array}$ & $\begin{array}{c}0.65-0.75 \\
0.7-0.8 \\
\end{array}$ & $\begin{array}{c}0.95-1.05 \\
1.05-1.2 \\
\end{array}$ & $\begin{array}{c}0.9-0.95 \\
0.65-0.75 \\
\end{array}$ & $\begin{array}{c}0.85-0.95 \\
0.25-0.3 \\
\end{array}$ & $\begin{array}{c}0.85-0.9 \\
0.7-0.8 \\
\end{array}$ \\
\hline Girassol & $0.3-0.4$ & $0.7-0.8$ & $1.05-1.2$ & $0.7-0.8$ & $0.35-0.45$ & $0.75-0.85$ \\
\hline Melancia & $0.4-0.5$ & $0.7-0.8$ & $0.95-1.05$ & 0.8-0.9 & $0.65-0.75$ & $0.75-0.85$ \\
\hline
\end{tabular}




\begin{tabular}{|c|c|c|c|c|c|c|}
\hline \multirow[t]{2}{*}{ lturas } & \multicolumn{5}{|c|}{ Fases de desenvolvimento } & \multirow{2}{*}{$\begin{array}{c}\text { Período } \\
\text { vegetativo tota }\end{array}$} \\
\hline & Inicial & Desenvolvimento & Intermediário & Final & Colheita & \\
\hline \multicolumn{7}{|l|}{ ilho } \\
\hline - doce & $0.3-0.5$ & $0.7-0.9$ & $1.05-1.2$ & $1.0-1.15$ & 0.95 & $0.8-0.95$ \\
\hline - grão & $0.3-0.5$ & $0.7-0.85$ & $1.05-1.2$ & $0.8-0.95$ & $0.55-0.6$ & $0.75-0.9$ \\
\hline iveira & & & & & & $0.4-0.6$ \\
\hline então verde & $0.3-0.4$ & $0.6-0.75$ & $0.95-1.1$ & $0.85-1.0$ & $0.8-0.9$ & $0.7-0.8$ \\
\hline epolho & $0.4-0.5$ & $0.7-0.8$ & $0.95-1.1$ & $0.9-1.0$ & $0.8-0.95$ & $0.7-0.8$ \\
\hline ja & $0.3-0.4$ & $0.7-0.8$ & $1.0-1.15$ & $0.7-0.8$ & $0.4-0.5$ & $0.75-0.9$ \\
\hline go & $0.3-0.4$ & $0.7-0.75$ & $1.0-1.15$ & $0.75-0.8$ & $0.5-0.55$ & $0.75-0.85$ \\
\hline o & $0.3-0.4$ & $0.7-0.8$ & $1.0-1.2$ & $0.9-1.0$ & $0.75-0.85$ & $0.85-0.95$ \\
\hline ate & $0.4-0.5$ & $0.7-0.8$ & $1.05-1.25$ & $0.8-0.95$ & $0.6-0.65$ & $0.75-0.9$ \\
\hline \multirow[t]{2}{*}{ go } & $0.3-0.4$ & $0.7-0.8$ & $1.05-1.2$ & $0.65-0.75$ & $0.2-0.25$ & $0.8-0.9$ \\
\hline & $0.35-0.55$ & $0.6-0.8$ & $0.7-0.9$ & $0.6-0.8$ & $0.55-0.7$ & $0.55-0.75$ \\
\hline
\end{tabular}

Fonte: Doorenbos e Kassam (1974) 
Tabela 3. Precipitação efetiva mensal em mm, em função da precipitação e da evapotranspiração potencial da cultura, quando a capacidade total de água no solo for $75 \mathrm{~mm}$, segundo o USDA-SCS.

\begin{tabular}{|c|c|c|c|c|c|c|c|c|c|c|c|c|c|c|c|c|}
\hline \multirow[t]{2}{*}{ ETa Média Mensal [mm] } & \multicolumn{16}{|c|}{ Precipitação Média Mensal [mm] } \\
\hline & 12.5 & 25.0 & 37.5 & 50.0 & 62.5 & 75.0 & 87.5 & 100.0 & 112.5 & 125.0 & 137.5 & 150.0 & 162.5 & 175.0 & 187.5 & 200.0 \\
\hline 25 & 8 & 16 & 24 & & & & & & & & & & & & & \\
\hline 50 & 8 & 17 & 25 & 32 & 39 & 46 & & & & & & & & & & \\
\hline 75 & 9 & 18 & 27 & 34 & 41 & 48 & 56 & 62 & 69 & & & & & & & \\
\hline 100 & 9 & 19 & 28 & 35 & 43 & 52 & 59 & 66 & 73 & 80 & 87 & 94 & 100 & & & \\
\hline 125 & 10 & 20 & 30 & 37 & 46 & 54 & 62 & 70 & 76 & 85 & 92 & 98 & 107 & 116 & 120 & \\
\hline 150 & 10 & 21 & 31 & 39 & 49 & 57 & 66 & 74 & 81 & 89 & 97 & 104 & 112 & 119 & 127 & 133 \\
\hline 175 & 11 & 23 & 32 & 42 & 52 & 61 & 69 & 78 & 86 & 95 & 103 & 111 & 118 & 126 & 134 & 141 \\
\hline 200 & 11 & 24 & 33 & 44 & 54 & 64 & 73 & 82 & 91 & 100 & 109 & 117 & 125 & 134 & 142 & 150 \\
\hline 225 & 12 & 25 & 35 & 47 & 57 & 68 & 78 & 87 & 96 & 106 & 115 & 124 & 132 & 141 & 150 & 159 \\
\hline 250 & 12 & 25 & 37 & 50 & 61 & 72 & 84 & 92 & 102 & 112 & 121 & 132 & 140 & 150 & 158 & 167 \\
\hline
\end{tabular}

Fonte: Bernardo (1995) 
Tabela 4. Fator de correção $\left(K_{\mathrm{PP}}\right)$ quando a capacidade total de água do solo for diferente de 75 mm, segundo o USDA-SCS.

\begin{tabular}{|c|c|c|c|c|c|}
\hline CTA $[\mathrm{mm}]$ & Fator & CTA $[\mathrm{mm}]$ & Fator & CTA [mm] & Fator \\
\hline 10.00 & 0.620 & 31.25 & 0.818 & 70.00 & 0.990 \\
\hline 12.50 & 0.650 & 32.50 & 0.826 & 75.00 & 1.000 \\
\hline 15.00 & 0.676 & 35.00 & 0.842 & 80.00 & 1.004 \\
\hline 17.50 & 0.703 & 37.50 & 0.860 & 85.00 & 1.008 \\
\hline 18.75 & 0.720 & 40.00 & 0.876 & 90.00 & 1.012 \\
\hline 20.00 & 0.728 & 45.00 & 0.905 & 95.00 & 1.016 \\
\hline 22.50 & 0.749 & 50.00 & 0.930 & 100.00 & 1.020 \\
\hline 25.00 & 0.770 & 55.00 & 0.947 & 125.00 & 1.040 \\
\hline 27.50 & 0.790 & 60.00 & 0.963 & 150.00 & 1.060 \\
\hline 30.00 & 0.808 & 65.00 & 0.977 & 175.00 & 1.070 \\
\hline
\end{tabular}

Fonte: Bernardo (1995)

Tabela 5. Grupos de Culturas de acordo com o esgotamento de água do solo

\begin{tabular}{|c|l|}
\hline Grupos de Culturas & \multicolumn{1}{|c|}{ Culturas } \\
\hline 1 & Cebola, Pimentão, e Batata \\
\hline 2 & Banana, Repolho, Uva e Tomate \\
\hline 3 & $\begin{array}{l}\text { Alfafa, Feijão, Citros, Amendoim, Abacaxi, Girassol, } \\
\text { Melancia e Trigo }\end{array}$ \\
\hline 4 & $\begin{array}{l}\text { Algodão, Milho, Oliveira, Cártamo, Sorgo, Soja, } \\
\text { Beterraba Açucareira, cana-de-açúcar e Tabaco }\end{array}$ \\
\hline
\end{tabular}

Fonte: Doorenbos e Kassam (1974)

Tabela 6. Fração de esgotamento de água no solo (f) para grupos de culturas e evapotranspiração potencial $\left(\mathrm{ET}_{\mathrm{p}}\right)$

\begin{tabular}{|c|c|c|c|c|}
\hline \multirow{2}{*}{$\mathrm{ET}_{\mathbf{p}}(\mathrm{mm} / \mathrm{dia})$} & \multicolumn{4}{|c|}{ Grupo de Culturas } \\
\cline { 2 - 5 } & 1 & 2 & 3 & 4 \\
\hline 2 & 0.500 & 0.675 & 0.800 & 0.875 \\
\hline 3 & 0.425 & 0.575 & 0.700 & 0.800 \\
\hline 4 & 0.350 & 0.475 & 0.600 & 0.700 \\
\hline 5 & 0.300 & 0.400 & 0.500 & 0.600 \\
\hline 6 & 0.250 & 0.350 & 0.450 & 0.550 \\
\hline 7 & 0.225 & 0.325 & 0.425 & 0.500 \\
\hline 8 & 0.200 & 0.275 & 0.375 & 0.450 \\
\hline 9 & 0.200 & 0.250 & 0.350 & 0.425 \\
\hline 10 & 0.175 & 0.225 & 0.300 & 0.400 \\
\hline
\end{tabular}

Fonte: Doorenbos e Kassam (1974) 
Tabela 7. Eficiência média dos métodos de irrigação $(\varepsilon)$ na aplicação da água

\begin{tabular}{|l|l|l|}
\hline \multicolumn{1}{|c|}{ Método } & \multicolumn{1}{c|}{ Condicionante } & Eficiência Média (\%) \\
\hline Sulcos de infiltração & Sulcos longos e/ou solos arenosos & 65 \\
\hline Sulcos de infiltração & Solo e comprimento adequados & 40 \\
\hline Inundação (tabuleiros) & Solo arenoso - lençol profundo & 60 \\
\hline Inundação (tabuleiros) & Solo argiloso - lençol superficial & 50 \\
\hline Aspersão convencional & Sob ação dos ventos & 75 \\
\hline Aspersão convencional & Com ventos leves ou sem & 50 \\
\hline Autopropelido/montagem direta & Sob ação dos ventos & 75 \\
\hline Autopropelido/montagem direta & Com ventos leves ou sem & 75 \\
\hline Pivô central & Vento/condições razoáveis & 85 \\
\hline Pivô central & Em condições favoráveis & 80 \\
\hline Microaspersão & Condições razoáveis & 90 \\
\hline Microaspersão & Em condições favoráveis & 85 \\
\hline Gotejamento & Condições razoáveis & 95 \\
\hline Gotejamento & Em condições favoráveis & 65 \\
\hline Tubos perfurados & Perfuração manual & 80 \\
\hline Tubos perfurados & Em condições favoráveis & \\
\hline Fonte: Tellos, l999 & & \\
\hline
\end{tabular}

Fonte: Telles, 1999 
Tabela 8. Fator de resposta da cultura $\left(K_{\mathbf{y}}\right)$

\begin{tabular}{|c|c|c|c|c|c|c|c|}
\hline \multirow[t]{2}{*}{ Culturas } & \multicolumn{3}{|c|}{ Período vegetativo } & \multirow{2}{*}{$\begin{array}{l}\text { Período } \\
\text { de } \\
\text { floração }\end{array}$} & \multirow{2}{*}{$\begin{array}{c}\text { Formação } \\
\text { da } \\
\text { colheita }\end{array}$} & \multirow[t]{2}{*}{ Maturação } & \multirow{2}{*}{$\begin{array}{c}\text { Período } \\
\text { total de } \\
\text { crescimento }\end{array}$} \\
\hline & $\begin{array}{c}\text { Inicial } \\
\text { (1a) }\end{array}$ & $\begin{array}{c}\text { Final } \\
(1 \mathrm{~b})\end{array}$ & Total & & & & \\
\hline \multicolumn{8}{|l|}{ Abacaxi } \\
\hline Alfafa & & & $0.70-1.10$ & & & & $0.70-1.10$ \\
\hline Algodão & & & 0.20 & 0.50 & & 0.25 & 0.85 \\
\hline Amendoim & & & 0.20 & 0.80 & 0.60 & 0.20 & 0.70 \\
\hline \multicolumn{8}{|l|}{ Arroz } \\
\hline Banana & & & & & & & $1.20-1.35$ \\
\hline Batata & 0.45 & 0.80 & & & 0.70 & 0.20 & 1.10 \\
\hline $\begin{array}{l}\text { Beterraba } \\
\text { - tubérculo } \\
\text { - açucareira }\end{array}$ & & & & & & & $\begin{array}{l}0.60-1.00 \\
0.70-1.10\end{array}$ \\
\hline Cana-de-açúcar & & & 0.75 & & 0.50 & 0.10 & 1.20 \\
\hline Cártamo & & 0.30 & & 0.55 & 0.60 & & 0.80 \\
\hline Cebola & & & 0.50 & & 0.80 & 0.30 & 1.10 \\
\hline Citros & & & & & & & $0.80-1.10$ \\
\hline Ervilha & 0.20 & & & 0.90 & 0.70 & 0.20 & 1.15 \\
\hline Feijão & & & 0.20 & 1.10 & 0.75 & 0.20 & 1.15 \\
\hline Girassol & 0.25 & 0.50 & & 1.00 & 0.80 & & 0.95 \\
\hline Melancia & 0.45 & 0.70 & & 0.80 & 0.80 & 0.30 & 1.10 \\
\hline Milho & & & 0.40 & 1.50 & 0.50 & 0.20 & 1.25 \\
\hline \multicolumn{8}{|l|}{ Oliveira } \\
\hline Pimentão & & & & & & & 1.10 \\
\hline Repolho & 0.20 & & & & 0.45 & 0.60 & 0.95 \\
\hline Soja & & & 0.20 & 0.80 & 1.00 & & 0.85 \\
\hline Sorgo & & & 0.20 & 0.55 & 0.45 & 0.20 & 0.90 \\
\hline Tabaco & 0.20 & 1.00 & & & 0.50 & 0.50 & 0.90 \\
\hline Tomate & & & 0.40 & 1.10 & 0.80 & 0.40 & 1.05 \\
\hline $\begin{array}{l}\text { Trigo } \\
\text { - de inverno } \\
\text { - de primavera }\end{array}$ & & & $\begin{array}{l}0.20 \\
0.20 \\
\end{array}$ & $\begin{array}{l}0.60 \\
0.65\end{array}$ & $\begin{array}{l}0.50 \\
0.55\end{array}$ & & $\begin{array}{l}1.00 \\
1.15 \\
\end{array}$ \\
\hline Uva & & & & & & & 0.85 \\
\hline
\end{tabular}

Fonte: Doorenbos e Kassam (1979) 
Tabela 9. Produção total relativa $\left(P_{a} / P_{p}\right)$ para diferentes valores de $\left(E T_{a} / E T_{p}\right)$ e fatores $K_{y}$, para o período total de crescimento

\begin{tabular}{|c|c|c|c|c|c|}
\hline \multicolumn{7}{|c|}{$\mathrm{ET}_{\mathrm{a}} / \mathrm{ET}_{\mathrm{p}}$} \\
\hline $\mathrm{ky}$ & 0.6 & 0.7 & 0.8 & 0.9 & 1.0 \\
\hline 0.6 & 1.27 & 1.17 & 1.10 & 1.04 & 1.00 \\
\hline 0.8 & 1.13 & 1.08 & 1.05 & 1.02 & 1.00 \\
\hline 1.0 & 1.00 & 1.00 & 1.00 & 1.00 & 1.00 \\
\hline 1.2 & 0.87 & 0.91 & 0.95 & 0.98 & 1.00 \\
\hline 1.4 & 0.73 & 0.83 & 0.90 & 0.95 & 1.00 \\
\hline
\end{tabular}

Fonte: Doorenbos e Kassam (1979)

Tabela 10. Relação dos municípios e população da Bacia do Itapicuru

\begin{tabular}{|c|c|c|}
\hline Municípios & $\begin{array}{c}\text { População } \\
\text { (estimada para 2000) }\end{array}$ & Área $\left(\mathrm{Km}^{2}\right)$ \\
\hline \multicolumn{3}{|c|}{ Totalmente inseridos na bacia } \\
\hline Andorinha & 15,774 & $1,212.50$ \\
\hline Antônio Gonçalves & 9,716 & 317.40 \\
\hline Araci & 47,584 & $1,576.30$ \\
\hline Banzaê $^{*}$ & 11,156 & 213.10 \\
\hline Caém & 12,563 & 499.50 \\
\hline Caldeirão Grande ${ }^{*}$ & 11,395 & 497.90 \\
\hline Cansanção & 31,947 & $1,324.90$ \\
\hline Capim Grosso & 23,908 & 351.50 \\
\hline Cipó & 14,285 & 165.30 \\
\hline Crisópolis & 19,037 & 464.90 \\
\hline Filadélfia & 17,194 & 566.20 \\
\hline Itiúba & 35,543 & $1,737.80$ \\
\hline Monte Santo & 54,552 & $3,298.40$ \\
\hline Nordestina & 11,800 & 472.80 \\
\hline Nova Soure & 24,405 & 672.00 \\
\hline Olindina & 23,909 & 540.40 \\
\hline Pindobaçu & 20,869 & 529.90 \\
\hline Ponto Novo & 17,187 & 467.10 \\
\hline Queimadas & 24,613 & $2,105.90$ \\
\hline Quijingue & 26,376 & $1,276.20$ \\
\hline Santaluz & 30,955 & $1,603.60$ \\
\hline Saúde & 11,488 & 501.70 \\
\hline Senhor do Bonfim & 67,723 & 820.00 \\
\hline Tucano & 50,948 & $3,214.80$ \\
\hline Subtotal 1 & 614,927 & $24,430.10$ \\
\hline
\end{tabular}


Continuação

\begin{tabular}{|c|c|c|}
\hline Municípios & $\begin{array}{c}\text { População } \\
\text { (estimada para 2000) }\end{array}$ & Área $\left(\mathrm{Km}^{2}\right)$ \\
\hline \multicolumn{3}{|c|}{ Parcialmente inseridas na Bacia } \\
\hline Acajutiba & 14,322 & 268.50 \\
\hline Aporá & 16,769 & 600.90 \\
\hline Biritinga & 14,641 & 594.70 \\
\hline Campo Formoso & 61,942 & $6,833.60$ \\
\hline Canudos & 13,761 & $3,000.60$ \\
\hline Cícero Dantas & 30,934 & 726.60 \\
\hline Conceição do Coité & 56,317 & $1,090.50$ \\
\hline Conde & 20,426 & 954.40 \\
\hline Esplanada & 27,230 & $1,408.50$ \\
\hline Euclides da Cunha & 53,885 & $2,383.80$ \\
\hline Heliópolis & 13,108 & 313.20 \\
\hline Inhambupe & 29,589 & $1,250.00$ \\
\hline Itapicuru & 27,315 & $1,552.50$ \\
\hline Jacobina & 76,492 & $2,328.90$ \\
\hline Jaguarari & 27,412 & $2,578.00$ \\
\hline Jandaíra & 10,027 & 646.80 \\
\hline Miguel Calmon & 28,267 & $1,471.20$ \\
\hline Mirangaba & 14,261 & $1,960.30$ \\
\hline Quixabeira & 9,466 & 369.60 \\
\hline Retirolândia & 10,891 & 204.50 \\
\hline Ribeira do Amparo & 13,903 & 658.80 \\
\hline Ribeira do Pombal & 46,270 & 816.00 \\
\hline Rio Real & 33,260 & 736.90 \\
\hline São José do Jacuípe & 9,233 & 370.70 \\
\hline Sátiro Dias & 17,251 & 688.60 \\
\hline Serrolândia & 12,616 & 375.20 \\
\hline Teofilândia & 20,432 & 266.90 \\
\hline Uauá & 25,993 & $2,962.80$ \\
\hline Valente & 19,145 & 372.50 \\
\hline Vázea do Poço & 7,515 & 221.30 \\
\hline Subtotal 2 & 762,673 & $38,006.80$ \\
\hline TOTAL GERAL & $1,377,600$ & $62,436,90$ \\
\hline
\end{tabular}

Fonte: IBGE (Instituto Brasileiro de Geografia e Estatística) 
Tabela 11. Identificação das estações de medição da evapotranspiração de referência da Bacia do Rio Itapicuru

\begin{tabular}{|c|c|c|c|c|c|}
\hline Id posto & Nome & Latitude* & Longitude* & $\mathrm{N}$ anos & Fonte \\
\hline EPBH02 & Caetité & 14.05 & 42.62 & 30 & INMET \\
\hline ЕРBH03 & Camaçari & 12.67 & 38.32 & 30 & INMET \\
\hline EPBH04 & Carinhanha & 14.17 & 43.92 & 30 & INMET \\
\hline EPBH05 & Cipó & 11.08 & 38.52 & 30 & INMET \\
\hline EPBH06 & Irecê & 11.30 & 41.87 & 30 & INMET \\
\hline EPBH07 & Itaberaba & 12.55 & 40.43 & 30 & INMET \\
\hline EPBH08 & Ituruçu & 13.36 & 39.57 & 30 & INMET \\
\hline EPBH09 & Jacobina & 11.18 & 40.47 & 30 & INMET \\
\hline EPBH10 & Lençois & 12.57 & 41.38 & 30 & INMET \\
\hline EPBH11 & Monte Santo & 10.43 & 39.30 & 30 & INMET \\
\hline EPBH12 & Morro do Chapéu & 11.22 & 41.22 & 30 & INMET \\
\hline EPBH13 & Paulo Afonso & 9.40 & 38.22 & 30 & INMET \\
\hline EPBH14 & Remanso & 9.63 & 42.10 & 30 & INMET \\
\hline EPBH15 & Salvador & 13.02 & 38.52 & 30 & INMET \\
\hline EPBH16 & Senhor do Bonfim & 10.47 & 40.18 & 30 & INMET \\
\hline EPBH17 & Serrinha & 11.63 & 38.97 & 30 & INMET \\
\hline EPCW01 & Água Branca & 12.42 & 38.93 & 15 & CWEB \\
\hline EPCW02 & Anádia & 9.63 & 36.33 & 14 & CWEB \\
\hline EPCW03 & Aracajú-Sergipe & 10.90 & 37.05 & 56 & CWEB \\
\hline EPCW04 & Aracajú1 & 10.92 & 37.08 & 30 & CWEB \\
\hline EPCW05 & Aracajú2 & 10.90 & 37.10 & 20 & CWEB \\
\hline EPCW06 & Barra & 11.08 & 43.17 & 30 & CWEB \\
\hline EPCW07 & Barra-Bahia & 11.08 & 43.15 & 57 & CWEB \\
\hline EPCW08 & Caiteté-Bahia & 14.07 & 42.48 & 57 & CWEB \\
\hline EPCW09 & Caiteté1 & 14.10 & 42.60 & 44 & CWEB \\
\hline EPCW10 & Caiteté2 & 14.07 & 42.48 & 30 & CWEB \\
\hline EPCW11 & Catu & 12.32 & 38.37 & 14 & CWEB \\
\hline EPCW12 & Ilhéus & 14.70 & 39.05 & 30 & CWEB \\
\hline EPCW13 & Itabaianinha1 & 10.68 & 37.42 & 54 & CWEB \\
\hline EPCW14 & Itabaianinha2 & 11.28 & 37.82 & 30 & CWEB \\
\hline EPCW15 & Jacobina & 11.18 & 40.52 & 30 & CWEB \\
\hline EPCW16 & Jacobina-Bahia & 11.17 & 40.52 & 56 & CWEB \\
\hline EPCW17 & Monte Santo-Bahia & 10.43 & 39.33 & 56 & CWEB \\
\hline EPCW18 & Monte Santo & 10.45 & 39.30 & 30 & CWEB \\
\hline EPCW19 & Morro do Chapéu & 11.55 & 41.23 & 27 & CWEB \\
\hline EPCW20 & Ondina & 13.00 & 38.52 & 30 & CWEB \\
\hline EPCW21 & Palmeira dos Índios & 9.42 & 36.67 & 14 & CWEB \\
\hline EPCW22 & Pão de Açucar & 9.77 & 37.45 & 28 & CWEB \\
\hline EPCW23 & Paratinga-Bahia & 12.70 & 43.00 & 56 & CWEB \\
\hline EPCW24 & Paratinga & 12.68 & 43.18 & 30 & CWEB \\
\hline EPCW25 & Petrolina & 9.40 & 40.50 & 8 & CWEB \\
\hline EPCW26 & Própria-Sergipe & 10.22 & 36.83 & 55 & CWEB \\
\hline
\end{tabular}


continuação

\begin{tabular}{|l|l|c|c|c|c|}
\hline \multicolumn{1}{|c|}{ Id posto } & Nome & Latitude* & Longitude* & N_anos & Fonte \\
\hline EPCW27 & Própria & 10.20 & 36.87 & 30 & CWEB \\
\hline EPCW28 & Remanso & 9.70 & 42.10 & 12 & CWEB \\
\hline EPCW29 & Remanso-Bahia & 9.68 & 42.07 & 56 & CWEB \\
\hline EPCW30 & Salvador1 & 13.00 & 38.50 & 54 & CWEB \\
\hline EPCW31 & Salvador2 & 12.95 & 38.50 & 30 & CWEB \\
\hline EPCW32 & Salvador-Ondina & 13.00 & 38.50 & 11 & CWEB \\
\hline EPCW33 & São Benta dos Lage & 12.58 & 38.75 & 27 & CWEB \\
\hline EPCW34 & São FranciscoCond. & 12.62 & 38.67 & 30 & CWEB \\
\hline EPCW35 & São Gonsalo dos Ca. & 12.42 & 39.93 & 16 & CWEB \\
\hline
\end{tabular}

* graus decimais

Fonte: SRH do Estado da Bahia 
Tabela 12. Perfis representativos de classes de solos, com dados sobre retenção de umidade e outras propriedades

\begin{tabular}{|c|c|c|c|c|c|c|c|c|c|c|c|}
\hline Solo & \multirow{3}{*}{\begin{tabular}{|c} 
Horizonte \\
A1
\end{tabular}} & \multirow{3}{*}{$\begin{array}{c}\begin{array}{c}\text { Profundidade } \\
(\mathrm{cm})\end{array} \\
0-8\end{array}$} & \multirow{3}{*}{$\begin{array}{c}\begin{array}{c}\text { Silte } \\
\%\end{array} \\
19\end{array}$} & \multirow{3}{*}{\begin{tabular}{|c|}
$\begin{array}{c}\text { Argila } \\
\%\end{array}$ \\
34 \\
\end{tabular}} & \multirow{3}{*}{$\begin{array}{c}\text { CTC } \\
\text { meq/100g solo } \\
6,6\end{array}$} & \multirow{3}{*}{\begin{tabular}{|c|}
$\begin{array}{c}\text { Volume } \\
\%\end{array}$ \\
27 \\
\end{tabular}} & $1 / 3 \mathrm{~atm}$ & $15 \mathrm{~atm}$ & \multicolumn{2}{|c|}{$\mathrm{AD}$} & \multirow[t]{2}{*}{ Perfil } \\
\hline & & & & & & & \multicolumn{2}{|c|}{$\%$ peso } & \multicolumn{2}{|c|}{$\%$ volume $\mathrm{mm} / \mathrm{cm}$} & \\
\hline \multirow{5}{*}{$\begin{array}{l}\text { ossolo Distrófico textura argilosa fase } \\
\text { sta }\end{array}$} & & & & & & & 17,9 & 10,2 & 10,9 & 1,09 & \multirow{5}{*}{ P. 2} \\
\hline & A3 & $8-16$ & 27 & 36 & 5,3 & 15 & 18,6 & 12,2 & 9,0 & 0,90 & \\
\hline & B1 & 16-39 & 22 & 41 & 2,0 & 14 & 18,0 & 11,1 & 9,6 & 0,96 & \\
\hline & B21 & $39-72$ & 27 & 36 & 2,1 & 10 & 18,1 & 13,3 & 9,5 & 0,95 & \\
\hline & B22 & $72-110$ & 22 & 41 & 3,6 & 15 & 18,4 & 12,1 & 8,9 & 0,89 & \\
\hline \multirow{4}{*}{$\begin{array}{l}\text { ossolo Álico textura argilosa fase } \\
\text { do }\end{array}$} & A & $0-12$ & 10 & 45 & 11,7 & 5 & 20,9 & 16,8 & 5,0 & 0,50 & \multirow{4}{*}{ P.13 } \\
\hline & $\mathrm{B} 1$ & $12-30$ & 7 & 53 & 8,6 & 3 & 22,5 & 17,5 & 6,0 & 0,60 & \\
\hline & B21 & $30-65$ & 6 & 55 & 7,9 & 3 & 22,3 & 17,0 & 6,6 & 0,66 & \\
\hline & B22 & $65-120$ & 7 & 55 & 4,7 & 4 & 21,8 & 17,1 & 6,2 & 0,62 & \\
\hline \multirow{5}{*}{$\begin{array}{l}\text { ossolo Distrófico textura média fase } \\
\text { sta }\end{array}$} & A1 & $0-24$ & 3 & 21 & 10,9 & 11 & 11,1 & 8,0 & 4,3 & 0,43 & \multirow{5}{*}{ P.6 } \\
\hline & A3 & $24-47$ & 5 & 24 & 9,2 & 3 & 11,9 & 8,5 & 4,7 & 0,47 & \\
\hline & B1 & $47-65$ & 5 & 25 & 6,3 & 5 & 10,9 & 8,0 & 4,2 & 0,42 & \\
\hline & $\mathrm{B} 21$ & $65-90$ & 4 & 26 & 4,1 & 7 & 10,6 & 8,0 & 3,9 & 0,39 & \\
\hline & B22 & $90-120$ & 4 & 26 & 4,2 & 6 & 10,8 & 7,7 & 4,5 & 0,45 & \\
\hline \multirow{3}{*}{ ossolo Álico textura média fase cerrado } & A1 & $0-22$ & 5 & 21 & 7,0 & 7 & 10,3 & 7,1 & 4,6 & 0,46 & \multirow{3}{*}{ P.19 } \\
\hline & A3 & $22-55$ & 6 & 22 & 3,9 & 7 & 11,2 & 7,0 & 5,8 & 0,58 & \\
\hline & B1 & $55-102$ & 6 & 24 & 3,1 & 6 & 9,8 & 6,8 & 4,0 & 0,40 & \\
\hline \multirow{4}{*}{$\begin{array}{l}\text { ossolo Distrófico textura média fase } \\
\text { inga hiperxerófila }\end{array}$} & A1 & $0-18$ & 2 & 10 & 2,7 & 48 & & 3,0 & & & \multirow{4}{*}{ P.22 } \\
\hline & $\mathrm{B} 1$ & $18-55$ & 3 & 17 & 3,0 & 27 & 6,9 & 4,0 & 4,5 & 0,45 & \\
\hline & $\mathrm{B} 21$ & $55-100$ & 4 & 23 & 2,9 & 42 & 8,2 & 5,3 & 4,6 & 0,45 & \\
\hline & $\mathrm{B} 22$ & $100-150$ & 8 & 22 & 2,9 & 44 & 8,8 & 5,3 & 5,9 & 0,59 & \\
\hline
\end{tabular}




\begin{tabular}{|c|c|c|c|c|c|c|c|c|c|c|c|}
\hline \multirow[t]{2}{*}{ Solo } & \multirow[t]{2}{*}{ Horizonte } & \multirow{2}{*}{$\begin{array}{l}\text { Profundidade } \\
(\mathrm{cm})\end{array}$} & \multirow{2}{*}{$\begin{array}{c}\text { Silte } \\
\%\end{array}$} & \multirow{2}{*}{$\underset{\%}{\text { Argila }}$} & \multirow{2}{*}{$\begin{array}{c}\text { CTC } \\
\text { meq/100g solo }\end{array}$} & \multirow{2}{*}{$\underset{\%}{\text { Volume }}$} & $1 / 3 \mathrm{~atm}$ & $15 \mathrm{~atm}$ & \multicolumn{2}{|c|}{$\mathrm{AD}$} & \multirow[t]{2}{*}{ Perfil } \\
\hline & & & & & & & \multicolumn{2}{|c|}{$\%$ peso } & $\%$ volun & $\mathrm{mm} / \mathrm{cm}$ & \\
\hline \multirow{4}{*}{$\begin{array}{l}\text { ossolo Eutrófico textura argilosa fase } \\
\text { resta/caatinga }\end{array}$} & A1 & $0-10$ & 28 & 52 & 21,9 & 84 & 31,3 & 20,2 & 9,7 & 0,97 & \multirow{4}{*}{ P. 2} \\
\hline & A3 & $10-34$ & 22 & 64 & 13,7 & 78 & 26,1 & 19,3 & 6,7 & 0,97 & \\
\hline & B1 & $34-79$ & 21 & 66 & 9,0 & 81 & 24,4 & 17,0 & 8,4 & 0,84 & \\
\hline & B21 & $79-166$ & 21 & 67 & 8,2 & 77 & 24,1 & 17,4 & 8,3 & 0,83 & \\
\hline \multirow{4}{*}{$\begin{array}{l}\text { ossolo Eutrófico média argilosa fase } \\
\text { inga hiperxerófila }\end{array}$} & A1 & $0-18$ & 6 & 16 & 5,8 & 33 & & & & & \multirow{4}{*}{ P.54 } \\
\hline & B1 & $18-50$ & 6 & 23 & 3,9 & 48 & 8,9 & 4,0 & 7,3 & 0,73 & \\
\hline & B21 & $50-90$ & 11 & 23 & 3,3 & 63 & 9,8 & 4,6 & 8,0 & 0,80 & \\
\hline & B22 & $90-118$ & 14 & 24 & 3,7 & 78 & 10,9 & 6,8 & 6,3 & 0,63 & \\
\hline \multirow{4}{*}{$\begin{array}{l}\text { dzólico textura média/argilosa fase } \\
\text { sta }\end{array}$} & Ap & $0-30$ & 18 & 20 & 24,9 & 10 & 22,9 & 13,3 & 9,6 & 0,96 & \multirow{4}{*}{ P.6 } \\
\hline & A12 & $30-48$ & 7 & 34 & 15,9 & 4 & 23,4 & 13,9 & 9,5 & 0,95 & \\
\hline & $\mathrm{A} 3$ & $48-112$ & 5 & 33 & 12,0 & 5 & 25,1 & 13,4 & 11,7 & 1,17 & \\
\hline & B21tx & $112-116$ & 19 & 47 & 5,0 & 28 & 28,9 & 19,0 & 9,9 & 0,99 & \\
\hline \multirow{4}{*}{$\begin{array}{l}\text { rófico textura arenosa/média } \\
\text { sta }\end{array}$} & A1 & $0-12$ & 25 & 6 & 4,5 & 20 & 9,4 & 5,0 & 7,2 & 0,72 & \multirow{4}{*}{ P.34 } \\
\hline & A3 & $12-33$ & 22 & 13 & 5,1 & 7 & 10,8 & 6,7 & 6,4 & 0,64 & \\
\hline & B1 & $33-58$ & 26 & 15 & 3,9 & 12 & 12,2 & 7,9 & 6,3 & 0,63 & \\
\hline & B22 & $58-118$ & 27 & 28 & 3,3 & 16 & & & & & \\
\hline \multirow{4}{*}{$\begin{array}{l}\text { dzólico Eutrófico To textura } \\
\text { édia/argilosa fase floresta }\end{array}$} & A & $0-30$ & 31 & 27 & 10,5 & 98 & 20,0 & 12,0 & 10,4 & 1,04 & \multirow{4}{*}{ P.4 } \\
\hline & $\mathrm{B} 21 \mathrm{t}$ & $30-45$ & 17 & 48 & 7,6 & 95 & 20,0 & 14,0 & 10,2 & 1,02 & \\
\hline & $\mathrm{B} 22 \mathrm{t}$ & 45-96 & 18 & 46 & 4,4 & 95 & 21,1 & 12,0 & 12,6 & 1,26 & \\
\hline & $\mathrm{B} 23 \mathrm{t}$ & 96-150 & 19 & 53 & 4,9 & 94 & & & & & \\
\hline
\end{tabular}




\begin{tabular}{|c|c|c|c|c|c|c|c|c|c|c|c|}
\hline \multirow[t]{2}{*}{ Solo } & \multirow[t]{2}{*}{ Horizonte } & \multirow{2}{*}{$\begin{array}{l}\text { Profundidade } \\
(\mathrm{cm})\end{array}$} & \multirow{2}{*}{$\begin{array}{c}\text { Silte } \\
\%\end{array}$} & \multirow{2}{*}{$\underset{\%}{\text { Argila }}$} & \multirow{2}{*}{$\begin{array}{c}\text { CTC } \\
\mathrm{meq} / 100 \mathrm{~g} \text { solo }\end{array}$} & \multirow{2}{*}{$\underset{\%}{\text { Volume }}$} & $1 / 3 \mathrm{~atm}$ & $15 \mathrm{~atm}$ & \multicolumn{2}{|c|}{$\mathrm{AD}$} & \multirow[t]{2}{*}{ Perfil } \\
\hline & & & & & & & \multicolumn{2}{|c|}{$\%$ peso } & $\%$ volun & $\mathrm{mm} / \mathrm{cm}$ & \\
\hline \multirow{5}{*}{$\begin{array}{l}\text { dzólico Eutrófico To textura média fase } \\
\text { sta }\end{array}$} & A1 & $0-10$ & 16 & 21 & 11,6 & 63 & 15,0 & 9,7 & 7,8 & 0,78 & \multirow{5}{*}{ P.29 } \\
\hline & A3 & $10-20$ & 17 & 24 & 8,8 & 55 & 13,5 & 8,6 & 7,2 & 0,72 & \\
\hline & B1 & $20-40$ & 12 & 31 & 8,3 & 61 & 14,8 & 9,3 & 7,8 & 0,78 & \\
\hline & B2 & $40-66$ & 14 & 32 & 8,4 & 73 & 16,8 & 10,4 & 8,7 & 0,87 & \\
\hline & B3 & $66-87$ & 14 & 34 & 7,4 & 76 & 16,9 & 10,7 & 8,2 & 0,82 & \\
\hline \multirow{3}{*}{$\begin{array}{l}\text { dsólico Eutrófico Ta textura argilosa fase } \\
\text { oresta caducufólia }\end{array}$} & A1 & $0-20$ & 36 & 44 & 19,6 & 88 & 24,7 & 15,5 & 14,9 & 1,49 & \multirow{3}{*}{ P.1 } \\
\hline & $\mathrm{B} 2 \mathrm{t}$ & $20-65$ & 26 & 64 & 19,5 & 100 & 24,8 & 17,2 & 12,3 & 1,23 & \\
\hline & B3t & $65-120$ & 25 & 64 & 20,0 & 88 & 24,8 & 17,4 & 13,0 & 1,30 & \\
\hline \multirow{4}{*}{$\begin{array}{l}\text { Roxa estruturada Similar Eutrófica } \\
\text { extura argilosa }\end{array}$} & Ap & $0-16$ & 19 & 23 & 7,9 & 40 & 27,3 & 13,9 & 13,4 & 1,34 & \multirow{4}{*}{ P.13 } \\
\hline & $\mathrm{B} 1$ & 16-34 & 17 & 49 & 7,3 & 38 & 31,9 & 23,4 & 8,5 & 0,85 & \\
\hline & B21 & 34-61 & 19 & 48 & 6,5 & 51 & 30,3 & 21,2 & 9,1 & 0,91 & \\
\hline & B22 & $61-150$ & 30 & 36 & 5,5 & 55 & 25,7 & 24,7 & 11,0 & 1,10 & \\
\hline \multirow{3}{*}{$\begin{array}{l}\text { ZEM AVERMELHADO textura } \\
\text { fase floresta caducifólia }\end{array}$} & A & $0-15$ & 30 & 58 & 40,4 & 100 & 42,5 & 33,5 & 13,1 & 1,31 & \\
\hline & $\mathrm{B} 2$ & $15-40$ & 31 & 64 & 41,7 & 100 & 32,8 & 24,9 & 11,2 & 1,12 & \\
\hline & B3 & $40-60$ & 39 & 50 & 36,3 & 100 & 29,6 & 20,7 & 13,1 & 1,31 & \\
\hline \multirow{5}{*}{$\begin{array}{l}\text { runo Não Cálcico textura argilosa fase } \\
\text { ga hipoxerófila }\end{array}$} & A & $0-16$ & 27 & 28 & 23,7 & 92 & 27,0 & 18,8 & 12,2 & 1,22 & \multirow{5}{*}{ P.51 } \\
\hline & B1 & $16-29$ & 21 & 45 & 29,0 & 99 & 32,9 & 23,9 & 14,0 & 1,40 & \\
\hline & B2 & $29-48$ & 25 & 44 & 32,3 & 98 & 34,8 & 25,1 & 15,3 & 1,53 & \\
\hline & B3 & $48-65$ & 32 & 29 & 30,2 & 100 & 30,7 & 23,2 & 10,8 & 1,08 & \\
\hline & $\mathrm{C}$ & $65-90$ & 31 & 8 & 20,6 & 100 & 20,5 & 14,4 & 9,2 & 0,92 & \\
\hline
\end{tabular}




\begin{tabular}{|c|c|c|c|c|c|c|c|c|c|c|c|}
\hline \multirow[t]{2}{*}{ Solo } & \multirow[t]{2}{*}{ Horizonte } & \multirow{2}{*}{$\begin{array}{l}\text { Profundidade } \\
(\mathrm{cm})\end{array}$} & \multirow{2}{*}{$\begin{array}{l}\text { Silte } \\
\%\end{array}$} & \multirow{2}{*}{$\underset{\%}{\text { Argila }}$} & \multirow{2}{*}{$\begin{array}{c}\text { CTC } \\
\text { meq/100g solo }\end{array}$} & \multirow{2}{*}{$\underset{\%}{\text { Volume }}$} & $1 / 3 \mathrm{~atm}$ & $15 \mathrm{~atm}$ & \multicolumn{2}{|c|}{$\mathrm{AD}$} & \multirow[t]{2}{*}{ Perfil } \\
\hline & & & & & & & \multicolumn{2}{|c|}{$\%$ peso } & $\%$ volum & $\mathrm{mm} / \mathrm{cm}$ & \\
\hline \multirow{5}{*}{$\begin{array}{l}\text { mbissolo Eutrófico textura argilosa fase } \\
\text { ga hipoxerófila substrato calcário }\end{array}$} & A11 & $0-15$ & 25 & 52 & 23,2 & 84 & 26,5 & 18,6 & 9,6 & 0,96 & \multirow{5}{*}{ P.1 } \\
\hline & A12 & $5-15$ & 25 & 55 & 19,7 & 77 & 22,7 & 15,7 & 8,9 & 0,89 & \\
\hline & B21 & $15-33$ & 26 & 56 & 15,7 & 61 & 21,8 & 13,9 & 10,8 & 1,08 & \\
\hline & B22 & $33-77$ & 23 & 58 & 18,2 & 67 & 22,3 & 15,1 & 10,4 & 1,04 & \\
\hline & B31 & $77-113$ & 34 & 46 & 15,7 & 70 & 22,5 & 14,4 & 11,7 & 1,17 & \\
\hline \multirow{4}{*}{ lo fase floresta caducufólia } & A & $0-20$ & 31 & 56 & 33,1 & 89 & 35,7 & 23,4 & 16,3 & 1,63 & \multirow{4}{*}{ P.42 } \\
\hline & $\mathrm{C} 1$ & $20-42$ & 8 & 89 & 44,8 & 80 & 45,6 & 33,8 & 16,4 & 1,64 & \\
\hline & $\mathrm{C} 2$ & $42-63$ & 13 & 78 & 65,6 & 91 & 39,2 & 29,8 & 12,7 & 1,27 & \\
\hline & $\mathrm{C} 3$ & $63-80$ & 31 & 61 & 59,4 & 96 & 37,0 & 26,7 & 14,5 & 1,45 & \\
\hline \multirow{4}{*}{$\begin{array}{l}\text { anossolo Solódico textura } \\
\text { a fase caatinga hiperxerófila }\end{array}$} & $\mathrm{A}$ & $0-20$ & 23 & 4 & 2,7 & 66 & 6,6 & 2,1 & 8,0 & 0,80 & \multirow{4}{*}{ P.27 } \\
\hline & $\mathrm{B} 2 \mathrm{t}$ & $20-35$ & 10 & 39 & 16,1 & 81 & 25,1 & 17,6 & 13,0 & 1,30 & \\
\hline & B3 & $35-90$ & 21 & 27 & 21,3 & 100 & 21,3 & 13,1 & 14,9 & 1,49 & \\
\hline & $\mathrm{C}$ & $90-120$ & 11 & 4 & 16,1 & 100 & 10,9 & 7,4 & 5,8 & 0,58 & \\
\hline \multirow{4}{*}{$\begin{array}{l}\text { onetz Solodizado textura média fase } \\
\text { sta com babaçu }\end{array}$} & A & $0-13$ & 45 & 9 & 6,3 & 79 & 12,1 & 4,7 & 10,3 & 1,03 & \multirow{4}{*}{ P. 28} \\
\hline & B1 & $13-40$ & 36 & 19 & 12,4 & 49 & 16,7 & 8,4 & 12,2 & 1,22 & \\
\hline & B2 & $40-100$ & 63 & 20 & 9,6 & 100 & 21,4 & 9,8 & 18,0 & 1,80 & \\
\hline & B3 & $100-125$ & 53 & 28 & 13,3 & 100 & 24,0 & 14,6 & 14,2 & 1,42 & \\
\hline \multirow{3}{*}{$\begin{array}{l}\text { ay pouco Húmico Distrófico textura } \\
\text { fase floresta de vázea }\end{array}$} & A & $0-20$ & 37 & 58 & 18,0 & 23 & 36,0 & 25,5 & 12,9 & 1,29 & \multirow{3}{*}{ P.50 } \\
\hline & $\mathrm{IICg}$ & $20-50$ & 32 & 57 & 15,9 & 6 & 30,7 & 21,8 & 12,6 & 1,26 & \\
\hline & IIICg & $50-110$ & 25 & 59 & 20,6 & 4 & 29,9 & 20,6 & 13,0 & 1,30 & \\
\hline
\end{tabular}




\begin{tabular}{|c|c|c|c|c|c|c|c|c|c|c|c|}
\hline \multirow[t]{2}{*}{ Solo } & \multirow[t]{2}{*}{ Horizonte } & \multirow{2}{*}{$\begin{array}{l}\text { Profundidade } \\
(\mathrm{cm})\end{array}$} & \multirow{2}{*}{$\begin{array}{l}\text { Silte } \\
\%\end{array}$} & \multirow{2}{*}{$\begin{array}{c}\text { Argila } \\
\%\end{array}$} & \multirow{2}{*}{$\begin{array}{c}\text { CTC } \\
\mathrm{meq} / 100 \mathrm{~g} \text { solo }\end{array}$} & \multirow{2}{*}{$\underset{\%}{\text { Volume }}$} & $1 / 3 \mathrm{~atm}$ & $15 \mathrm{~atm}$ & \multicolumn{2}{|c|}{$\mathrm{AD}$} & \multirow[t]{2}{*}{ Perfil } \\
\hline & & & & & & & \multicolumn{2}{|c|}{$\%$ peso } & $\%$ volun & $\mathrm{mm} / \mathrm{cm}$ & \\
\hline \multirow{5}{*}{$\begin{array}{c}\text { romórfica Distrófica Ta textura } \\
\text { sta de várzea }\end{array}$} & A & $0-5$ & 21 & 23 & 16,7 & 34 & 21,2 & 11,6 & 11,9 & 1,19 & \multirow{5}{*}{ P.59 } \\
\hline & B1p1 & $5-35$ & 19 & 28 & 13,3 & 22 & 18,2 & 10,2 & 10,8 & 1,08 & \\
\hline & B2p1 & $35-52$ & 20 & 33 & 21,8 & 11 & 20,5 & 13,3 & 9,7 & 0,97 & \\
\hline & B3p1 & $52-64$ & 25 & 47 & 31,5 & 13 & 26,9 & 18,4 & 11,4 & 1,14 & \\
\hline & $\mathrm{Cp} 1$ & $64-100$ & 30 & 55 & 41,4 & 16 & 28,7 & 20,8 & 10,1 & 1,01 & \\
\hline \multirow{4}{*}{$\begin{array}{l}\text { lo Aluvial Eutrófico textura siltosa fase } \\
\text { sta de várzea }\end{array}$} & A & $0-22$ & 63 & 34 & 18,3 & 51 & 36,0 & 19,8 & 19,5 & 1,95 & \multirow{4}{*}{ P.65 } \\
\hline & IIC1 & $22-48$ & 53 & 43 & 21,6 & 54 & 29,3 & 18,1 & 15,2 & 1,53 & \\
\hline & IIIC2 & $48-95$ & 58 & 34 & 20,8 & 43 & 26,3 & 14,1 & 17,3 & 1,73 & \\
\hline & IVC3 & $95-150$ & 63 & 30 & 20,8 & 57 & 28,4 & 14,9 & 18,5 & 1,85 & \\
\hline \multirow{5}{*}{$\begin{array}{l}\text { o Aluvial Eutrófico textura média, fase } \\
\text { sta de várzea }\end{array}$} & Ap & $0-12$ & 45 & 33 & 15,2 & 93 & 29,8 & 17,6 & 17,4 & 1,74 & \multirow{5}{*}{ P. 58} \\
\hline & A12 & 13119 & 40 & 37 & 14,1 & 85 & 24,6 & 16,8 & 10,6 & 1,06 & \\
\hline & IIC1 & $35-60$ & 37 & 32 & 10,0 & 82 & 21,2 & 14,7 & 9,4 & 0,09 & \\
\hline & IIIC2 & $60-90$ & 39 & 25 & 7,4 & 77 & 16,7 & 10,1 & 10,2 & 1,02 & \\
\hline & IVC3 & $90-150$ & 35 & 28 & 10,4 & 81 & 17,6 & 11,5 & 9,4 & 0,94 & \\
\hline \multirow{3}{*}{$\begin{array}{l}\text { lo Aluvial Eutrófico textura argilosa fase } \\
\text { inga hiperxerófila }\end{array}$} & A11 & $0-23$ & 25 & 41 & 30,6 & 100 & 28,4 & 18,0 & 14,3 & 1,43 & \multirow{3}{*}{ P.13 } \\
\hline & A12 & $23-70$ & 29 & 35 & 27,5 & 100 & 27,1 & 18,7 & 11,7 & 1,17 & \\
\hline & CXx & $70-120$ & 29 & 41 & 28,1 & 89 & 28,2 & 19,4 & 12,5 & 1,25 & \\
\hline \multirow{3}{*}{$\begin{array}{l}\text { egossolo Eutrófico textura arenosa fase } \\
\text { inga hiperxerófila }\end{array}$} & A11 & $0-20$ & 8 & 4 & 4,6 & 50 & 6,0 & 2,4 & 5,5 & 0,55 & \multirow{3}{*}{ P.34 } \\
\hline & A12 & $20-75$ & 12 & 5 & 3,5 & 69 & 5,4 & 2,4 & 4,7 & 0,47 & \\
\hline & CXx & $75-150$ & 11 & 3 & 1,6 & 78 & 3,4 & 1,3 & 3,7 & 0,37 & \\
\hline
\end{tabular}




\begin{tabular}{|c|c|c|c|c|c|c|c|c|c|c|c|}
\hline \multirow[t]{2}{*}{ Solo } & \multirow[t]{2}{*}{ Horizonte } & \multirow{2}{*}{$\begin{array}{c}\text { Profundidade } \\
(\mathrm{cm})\end{array}$} & \multirow{2}{*}{$\begin{array}{c}\text { Silte } \\
\%\end{array}$} & \multirow{2}{*}{$\underset{\%}{\text { Argila }}$} & \multirow{2}{*}{$\begin{array}{c}\text { CTC } \\
\text { meq/100g solo }\end{array}$} & \multirow{2}{*}{$\underset{\%}{\text { Volume }}$} & $1 / 3 \mathrm{~atm}$ & $15 \mathrm{~atm}$ & \multicolumn{2}{|c|}{$\mathrm{AD}$} & \multirow[t]{2}{*}{ Perfil } \\
\hline & & & & & & & \multicolumn{2}{|c|}{$\%$ peso } & $\%$ volun & $\mathrm{mm} / \mathrm{cm}$ & \\
\hline \multirow{4}{*}{$\begin{array}{l}\text { egossolo Eutrófico textura arenosa fase } \\
\text { inga hiperxerófila }\end{array}$} & A11 & $0-20$ & 18 & 3 & 5,0 & 70 & 7,4 & 2,2 & 8,2 & 0,82 & \multirow{4}{*}{ P.RN-5 } \\
\hline & A12 & $20-45$ & 19 & 5 & 4,8 & 58 & 7,9 & 2,7 & 7,7 & 0,77 & \\
\hline & $\mathrm{C} 1$ & $45-95$ & 17 & 6 & 3,4 & 61 & 6,6 & 2,5 & 6,8 & 0,68 & \\
\hline & $\mathrm{C} 2$ & $95-110$ & 16 & 3 & 3,7 & 77 & 5,5 & 1,8 & 6,5 & 0,65 & \\
\hline \multirow{4}{*}{ osas Distróficas } & A1 & $0-15$ & 14 & 6 & 6,2 & 6 & 9,2 & 4,9 & 6,7 & 0,67 & \multirow{4}{*}{ P.83 } \\
\hline & A3 & $15-40$ & 8 & 8 & 2,8 & 8 & 5,7 & 3,8 & 2,8 & 0,28 & \\
\hline & $\mathrm{C} 1$ & $40-82$ & 8 & 12 & 2,5 & 9 & 6,2 & 4,3 & 2,9 & 0,29 & \\
\hline & $\mathrm{C} 2$ & $82-128$ & 7 & 13 & 2,0 & 9 & 6,4 & 4,2 & 3,5 & 0,35 & \\
\hline \multirow{2}{*}{$\begin{array}{l}\text { lo Litólico Distrófico textura argilosa } \\
\text { o substrato siltito }\end{array}$} & A & $0-10$ & 50 & 41 & 7,8 & 11 & 27,7 & 17,3 & 14,1 & 1,41 & \\
\hline & $\mathrm{C}$ & $10-30$ & 52 & 43 & 7,6 & 8 & 29,1 & 17,7 & 15,6 & 1,56 & \\
\hline \multirow{2}{*}{$\begin{array}{l}\text { lo Litólico Eutrófico textura média fase } \\
\text { inga hiperxerófila substrato gnaisse }\end{array}$} & A11 & $0-15$ & 13 & 9 & 6,2 & 78 & 12,0 & 5,1 & 9,5 & 0,95 & \multirow{2}{*}{ P. } \\
\hline & A12 & $15-37$ & 14 & 10 & 6,1 & 78 & 12,5 & 5,0 & 10,5 & 1,05 & \\
\hline
\end{tabular}

Fonte: Cavalcanti (1979) 


\section{REFERÊNCIAS BIBLIOGRÁFICAS}

ANDRADE, C. L. T.; COELhO, E. F.; COUTO, L. e SILVA, E. L. Manejo de Irrigação. Parâmetros de solo-água para a engenharia de irrigação e ambiental. XXVII congresso Brasileiro de Engenharia Agrícola. p. 1-45. Poços de Caldas MG. 1998.

ARRUDA, F. B. A agricultura irrigada frente a administração de recursos hídricos no estado de São Paulo. Campinas - SP. IAC. 1994. Apresentado ao Comitê da Bacia Hidrográfica dos Rios Piracicaba, Capivarí e Jundiaí - mimeografo.

AUGuStO, S. G.; SEDIYAMA, G. C. MANTOVANI, E. C. Variação temporal da evapotranspiração de referência e os efeitos em projetos e manejo de sistemas de irrigação. In. Congresso Brasileiro de Engenharia Agrícola - CONBEA. II. 1996. Bauru SP e CDROM Jaboticabal SP. SBEA/ALIA/UNESP.

AZEVEDO, L. G. PORTO. R. L. L. Modelos de simulação e de rede de fluxo (extraído do capítulo 4 do livro Técnicas Quantitativas para o Gerenciamento de Recursos Hídricos, ABRH/EUFRGS). Outubro. 2002.

BASTOS, E. A. Distribuição de freqüência da evapotranspiração potencial de Teresina - PI através do modelo de Gumbel. Engenharia Agrícola. Campinas - SP. v. 14. P. 99-104. 1994.

BERNARDO, S. Manejo de Irrigação. Irrigação e Produtividade. XXVII congresso Brasileiro de Engenharia Agrícola. p. 117-132. Poços de Caldas - MG. 1998.

BERNARDO, S. Manual de irrigação. $6^{\text {a }}$ edição. Universidade Federal de Viçosa. Imprensa Universitária. Viçosa - MG. 657p. 1995. 
CARdoso H. E. A. MANTOVANI, E. C. COSTA, L. C. Manual do SISDA - Sistema de Suporte a Decisão Agrícola - versão 2.0. SRH/MMA - DEA/UFV. Ministério do Meio Ambiente, dos Recursos Hídricos e da Amazônia Legal Secretaria de Recursos Hídricos. 85p. 1997.

CIRINO, C. G. GUERRA, H. O. C. Utilização das relações energia/umidade na caracterização físico-hídrica dos solos. Pesquisa Agropecuária Brasileira. Brasília. v. 29. n. 12. p. 1973-1978. dez. 1994.

CLARK, D. CropWat for Windows: User Guide. Version 4.2. 43p. October. 1998.

DOORENBOS, J.; KASSAM, A. H. Yield response to water. Roma: FAO - Irrigation and Drainage. Paper 33. 193p. 1979.

DOORENBOS, J.; KASSAM, A. H. Efeito da água no rendimento das culturas. Tradução de H. R. Gheyi, A. A. de Souza , J. F. Medeiros. Campina Grande. UFPB. 306p. Estudos FAO: Irrigação e Drenagem, 33. 1974.

DOORENBOS, J.; PRUITT, W. O. Guidelines for predicting crop water requeriments. Roma: FAO - Irrigation and Drainage. Paper 24. 144p. 1977.

FERNANDES, E. J.; TURCO, J. E. P. e RODRIGUES, J. D. Balanço hídrico do solo em culturas de soja irrigada. Engenharia Agrícola. Sociedade Brasileira de Engenharia Agrícola-SBEA. v. 19. n. 1. p. 43-52. Set.1999.

FRIZZONE, J. A. Manejo de Irrigação. Função de Produção. XXVII congresso Brasileiro de Engenharia Agrícola. p. 86-116. Poços de Caldas - MG. 1998.

GARTUNO, H. Efficient water use: a multi-dimensional approach. In: GARTUNO, H.; CORTÉS, F. A. (editores Efficient water use. Montevideo. UNESCO-ROSTLAC. p. 17-24. 1994. 
GOLDBERG, D.; TEIXEIRA, A. S. Drip irrigation: principles, design and agricultural practices. Kfar Shmaryahu / Israel: Ed. Drip Irrigation Scientific Publications. 300p. 1976

GOMES, H. P. Engenharia de irrigação: hidráulica dos sistema pressurizados, aspersão e gotejamento. $3^{\underline{a}}$ edição. Universidade Federal da Paraíba. Campina Grande - PA. 412 p. 1999.

HARGREAVES, G. H.; SAMANI, Z. A. Economics considerations on deficit irrigation. Journal of the Irrigation and Drainage Engineering. New York. v. 110. n. 4. p. $343-235.1984$.

JENSEN, M. E. Consumptive use of water and irrigation water requirements. New York: ASCE. 215p. 1973.

KLAR, A. E. Irrigação: freqüência e quantidade de aplicação. São Paulo: Nobel. 156p. 1991.

KLAR, A. E. A água no sistema solo-planta-atmosfera. São Paulo. Nobel. 408 p. 1984.

LABADIE, J. W. Reservoir system optimization models. In: Decision support systems applied the water resources engineering. São Paulo. 1998.

LEME, E. J. A. otimização da irrigação da cana-de-açúcar (saccharum spp) via coeficientes de cultura, função de produção e programação dinâmica. Tese (doutorado) apresentada a EESC/USP. 399 p. Novembro. 1991

LIMA, J. E. F. W. FERREIRA, R. S. A. CHRISTOFIDIS, D. O estado das águas no Brasil/organização Marcos Aurélio Vasconcelos de Freitas. ANEEL, SIH; MMA. SRH; MME/Brasília - DF. Parte 3. p. 73-82. O uso da irrigação no Brasil. 1999.

LISBOA NETO, H. PORTO R. L. L. Sistema de suporte a decisão em engenharia de recursos hídricos desenvolvimento piloto para as bacias do rios Paraguaçu e 
itapicuru, no Estado da Bahia. Décimo Quarto Simpósio Brasileiro de Recursos Hídricos. Aracaju. ABRH. 2001.

MAROUELLI, W. A. Manejo da irrigação de hortaliças. Circular Técnica CNPH, 2 Brasília: CNPH/EMBRAPA. Jan. 1986.

MENDONÇA, A. S. Regionalização hidrológica. Hidrologia aplicada à gestão de pequenas bacias hidrográficas. Organizado por João Batista Dias de Paiva e Eloiza Maria Cauduro Dias de Paiva. Porto Alegre - R.S. Capítulo 7. P. 165-168. 2001.

MOTA, F. S. Meteorologia Agrícola. 7ª ed. São Paulo: Nobel. 376p. 1989.

PORTO, R. L. L. AZEVEDO, L. Técnicas quantitativas para o gerenciamento de recursos hídrico. Porto Alegre - RS. Cap.2. p.43-95: Sistemas de suporte a decisões de recursos hídricos. 1997

REICHARDT, K. A água em sistemas agrícolas. São Paulo - SP. 188 p. Editora Manole Ltda. 1990.

REICHARDT, K. Processos de transferência no sistema solo-planta-atmosfera. 4.ed. rev. amp. Campinas: Fundação Cargill. 445p. 1985.

RIGUETTO, A. M. Hidrologia e Recursos Hídricos. São Carlos - SP. 840 p. EESC/USP. Projeto REENGE. 1998.

ROBERTO, A. N. Modelos de rede de fluxo para alocação da água entre múltiplos usos em uma bacia hidrográfica. Dissertação (mestrado). Escola Politécnica da Universidade de São Paulo. Departamento de Engenharia Hidráulica e Sanitária. São Paulo. 2002.

ROBERTO, A. N. e PORTO, R. L. O sistema ModSimLS: um modelo de rede de fluxo para simulação de bacias hidrográficas. Décimo Quarto Simpósio Brasileiro de Recursos Hídricos. Aracaju. ABRH. 2001. 
ROBERTO, A. N. e PORTO, R. L. Alocação da Água entre Múltiplos Usos em uma Bacia Hidrográfica. Décimo Terceiro Simpósio Brasileiro de Recursos Hídricos. Belo Horizonte. ABRH. 1999.

SEDIYAMA, G. C. Evapotranspiração. In: Associação Brasileira de Educação Agrícola Superior. Engenharia de Irrigação: Necessidade de água para os cultivos. Brasília: ABEAS. Mod. 4. p. 3-66. 1987.

SERRUTO, A. R. C. Balanço hídrico com base ecológica da vertente do lago Titicaca. São Paulo.. 210p. Tese (doutorado). Escola Politécnica da Universidade de São Paulo. 1992

TELLES, D. A. Águas doces no Brasil. Água na agricultura e pecuária. Organização e coordenação ciêntífica Aldo da Cunha Rebouças, Benedito Braga, José Galizia Tundisi. p. 305-337. São Paulo. Escrituras Editora. 1999.

TELLES, D. A. Determinação das demandas de água para irrigação: evapotranspiração de referência no Estado de São Paulo. São Paulo, 2v. 501p. Tese (Doutorado). Escola Politécnica, Universidade de São Paulo. 1996.

TWENTY-SIXTH FAO REGIONAL CONFERENCE FOR LATIN AMERICA AND THE CARIBBEAN. Water as a resource for food production. Merida, Mexico. p. 10-14. April. 2000.

VALADÃO, L. T. Evapotranspiração e coeficientes de cultura do feijoeiro em dois níveis do lençol freático. Dissertação (mestrado). 112p. Faculdade de Ciências Agronômicas. UNESP. Botucatu. SP. 1995.

VILA NOVA, N. A., REICHARDT, K. Engenharia Hidrológica. Evaporação/evapotranspiração. Coleção ABRH de Recursos Hídricos. p. 145-197. Editora da UFRJ. 1989. 
WURBS, R. Reservoir-system simulation and optimization models. Journal of Water Resources Planning and Management. ASCE. v. 119. n. 4. p. 455-472. 1993.

YEH, W. W-G. Reservoir management and operations models: a state-of-the-art review. Water Resources Research. v.21. n.12. p.1797-1818. 1985. 


\section{BIBLIOGRAFIA COMPLETAR}

ALLEN, R. G.; PEREIRA. L. S.; RAES. D. and SMITH. M. Crop evapotranspiration guidelines for computing crop water requerements - FAO irrigation and drenage paper 56. Rome, 1998.

A INSERÇÃO REGIONAL DO PROJETO DE TRANSPOSIÇÃO DO RIO SÃO FRANCISCO PARA O NORDESTE SETENTRIONAL - A Integração das Águas com o Rio Tocantins. Ministério da Integração Nacional. Secretaria de InfraEstrutura Hídrica. Elaboração: VBA Consultores S/C Ltda. p. 12-17. Fortaleza. Julho. 2000

AZEVEDO, L. G. PORTO. R. L. L. LABADIE. J. W. MODSIM: modelo de rede de fluxo de bacias hidrográficas. 142p. 1999.

AZEVEDO, L. G. PORTO, R. L. L. FILHO. K. Z. Técnicas quantitativas para o gerenciamento de recursos hídrico. Cap.4, p.165-225: Modelos de simulação e de redes de fluxo. Porto Alegre - RS. 1997.

BARRET, J. W. H., SKOGERBOE, G. V. Crop functions and the allocation and use of irrigation water. Agric. Water Manege. Amsterdam. v. 3. p. 53-64. 1980.

BERTONI J. C. TUCCI, C. E. M. Precipitação. Hidrologia: ciência e aplicação. Organizado por Carlos E. M. Tucci. Porto Alegre-R.S. Editora da Universidade. ABRH. 2ª edição. Capítulo 5. p. 177-252. 1997.

DANTAS NETO, J. Modelos de decisão para otimização do padrão de cultivo, em áreas irrigadas, baseados nas funções de resposta das culturas à água. Tese (mestrado). UNESP. Faculdade de Ciências Agronômicas. Campus de Botucatu. 125p. 1994. 
FREITAS, A. V. SANTOS, A. H. M. O estado das águas no Brasil/organização Marcos Aurélio vasconcelos de Freitas ANEEL, SIH; MMA. SRH; MME/Brasília - DF. Parte 1. p. 13-16. Importância da água e da informação hidrológica. 1999.

HEXEM, R. W., HEADY, E. O. Water production functions for irrigated agriculture. Iowa: Iowa State University Press. 215p. 1978.

REICHARDT, K. A água na produção agrícola. São Paulo - SP. 119 p. McGraw-Hill do Brasil. 1978.

SAAD, J. C. C.; SCALOPPI, E. J. Análise dos principais métodos climáticos para estimativa da evapotranspiração. In: Congresso Nacional de Irrigação e Drenagem. 8. Anais. v.2. ABID. p. 999-1021. Florianópolis. 1988.

SAlATI, E.; LEMOS, H. M. E. Águas doces no Brasil. Água e o desenvolvimento sustentável. Organização e coordenação científica Aldo da Cunha Rebouças, Benedito Braga, José Galizia Tundisi. p. 39-64. São Paulo. Escrituras Editora. 1999. SIERRA, L. N., ISLA, D. B. Estimación de funciones de produção em la zona de Rio Verde, San Luis Potosi. Agrociencia. Chapingo. n. 20. p. 37-41. 1975.

STEGMAN, E. C. Irrigation scheduling: applied timing criteria. Adv. Iriga. New York. v. 2. p. 1-29. 1983.

TELLES, D. A. Evapotranspiração: a teoria e a prática. Trabalho apresentado na disciplina de Complementos de hidrologia na Escola Politécnica da Universidade de São Paulo. São Paulo, 1992.

TELLES, D. A. Elaboração de Projetos de Irrigação. Programa Nacional de Irrigação Fundação CTH. Coordenador Técnico. Capítulo 1. p. 1-85. Brasília. 1986. 
WALLACE, J. S. Increasing agricultural water use efficiency to meet future food production. Agriculture, Ecosystems and Environment. n. 82. p. 105-205. December 2000.

YARON, D. BRESLER, E. Economic analysis of on-farm irrigation using response functions of crop. Adv. Irrig. New York. v. 2. p.223-255. 1983.

YARON, D. Estimation and use of water production functions in crop. J. Irriga. Drain. Eng. New York. v. 97. p. 291-303. 1971.

ZAHED, K. F. Algumas metodologias para o dimensionamento e operação de reservatórios. São Paulo, 1984. 258p. Dissertação (Mestrado) - Escola Politécnica, Universidade de São Paulo. 